\title{
Untersuchungen zur Funktion des RanGAP1 Proteins
}

\author{
Dissertation \\ zur Erlangung des Doktorgrades \\ der Mathematisch-Naturwissenschaftlichen Fakultäten \\ der Georg-August-Universität zu Göttingen
}

vorgelegt von

Florian Kiendl

aus München

Göttingen 2007 
D7

Referent: Prof. Dr. Frauke Melchior

Korreferent: Prof. Dr. Ralf Ficner

Tag der mündlichen Prüfung: 03.05.2007 


\section{Inhaltsverzeichnis}

$\begin{array}{ll}\text { Abkürzungen } & 7\end{array}$

$\begin{array}{ll}\text { Allgemeine Abkürzungen } & 7\end{array}$

Physikalische Größen 9

$\begin{array}{ll}\text { Präfixe } & 10\end{array}$

Abkürzungen der Gene und ihrer Produkte $\quad 10$

Ein- und Dreibuchstabencode für Aminosäuren $\quad 11$

Übersetzungsvorschläge häufig verwendeter Begriffe 11

$\begin{array}{ll}\text { Zusammenfassung } & 12\end{array}$

$\begin{array}{ll}\text { Einleitung } & 13\end{array}$

Die Ras-Superfamilie 13

Die ARF-Familie 16

Die Rab-Familie 16

Die Ran-Familie $\quad 19$

Der Kern-Zytoplasma-Transport in Interphase 20

Ran in Mitose $\quad 22$

Besonderheiten des GTPase-aktivierenden Proteins RanGAP1 23

Sumoylierung als posttranslationale Modifikation 24

Das SUMO-Konsensus Motiv 26

Die SUMO-Maschinerie $\quad 26$

Molekulare und funktionelle Konsequenzen der Sumoylierung 28

Das SUMO-Bindemotiv 29

Ausgangssituation dieser Arbeit $\quad 30$

Identifizierung von Eferin als Bindepartner von RanGAP1 30

Eferin 31

Domänenstruktur 32

Homologie $\quad 32$

Mögliche Funktion in Interphase und Mitose 33

$\begin{array}{ll}\text { Aufgabenstellungen } & 34\end{array}$ 
$\begin{array}{ll}\text { Material und Methoden } & 35\end{array}$

$\begin{array}{ll}\text { Material } & 35\end{array}$

Technische Ausrüstung 35

$\begin{array}{ll}\text { Laborgeräte } & 35\end{array}$

$\begin{array}{ll}\text { Computer } & 37\end{array}$

$\begin{array}{ll}\text { Chemikalien und Verbrauchsmaterial } & 37\end{array}$

$\begin{array}{ll}\text { Medien, Puffer, Lösungen } & 37\end{array}$

$\begin{array}{ll}\text { Puffer } & 38\end{array}$

$\begin{array}{ll}\text { Lösungen } & 40\end{array}$

Komplexe Reagenzien und Reaktionssets $\quad 40$

$\begin{array}{ll}\text { Molekulargewichtsstandard } & 41\end{array}$

$\begin{array}{ll}\text { Längenstandards DNA } & 41\end{array}$

Westernblot-Material $\quad 41$

$\begin{array}{ll}\text { Röntgenfilme } & 41\end{array}$

$\begin{array}{ll}\text { Materialien zur Filtration und Dialyse } & 41\end{array}$

Chromatografische Matrices und fertig gepackte Chromatografiesäulen 42

Enzyme, Primer, Plasmide und rekombinante Proteine 42

$\begin{array}{ll}\text { Enzyme } & 42\end{array}$

DNA-Oligonukleotide für PCR und RNA-Oligonukleotide für RNAi 43

RNA-Oligonukleotide für RNA-Interferenz-Anwendungen 43

DNA-Oligonukleotide zur Amplifikation und Sequenzierung 43

Plasmide und gestellte Plasmidkonstrukte $\quad 44$

Rekombinante Proteine $\quad 45$

$\begin{array}{ll}\text { Bakterienstämme } & 46\end{array}$

Eukaryotische Zelllinien 46

$\begin{array}{ll}\text { Antikörper } & 47\end{array}$

$\begin{array}{ll}\text { Primäre Antikörper } & 47\end{array}$

$\begin{array}{ll}\text { Sekundäre Antikörper } & 47\end{array}$

$\begin{array}{ll}\text { Methoden } & 48\end{array}$

Molekularbiologische Methoden 48

$\begin{array}{ll}\text { Präparation von Plasmid-DNA } & 48\end{array}$

Nukleinsäure-Fällung für Sequenzierung 49

Bestimmung der Nukleinsäure-Konzentration 49

Schneiden von DNA mit Restriktionsendonukleasen 49 
Agarose-Gelelektrophorese $\quad 50$

DNA-Extraktion aus Agarose-Gelen $\quad 50$

Ligation von DNA-Fragmenten $\quad 51$

Polymerase-Kettenreaktion $\quad 51$

DNA-Sequenzierung nach der Didesoxy-Kettenabbruchmethode 52

Zellbiologische Methoden 53

Herstellung transformationskompetenter Bakterien $\quad 53$

Transformation kompetenter Bakterien $\quad 53$

Kultivierung humaner Zelllinien $\quad 54$

Einfrieren und Auftauen von Gewebekulturzellen 54

Zellzahlbestimmung von Gewebekulturzellen $\quad 55$

Transiente Transfektion von Gewebekulturzellen 55

Dendrimer-Transfektion $\quad 55$

Kalziumphosphat-Transfektion $\quad 56$

Liposom-Transfektion von Gewebekulturzellen mit Oligonukleotiden $\quad 56$

Zellzyklus-Analyse im Durchflusszytometer 57

Zellzyklus-Arretierung von Säugerzellen $\quad 57$

Immunologische und immunobiochemische Methoden 58

Immunoblot-Analyse $\quad 58$

Kopplung und Kreuzvernetzung von Antikörpern an ProteinG-Sepharose $\quad 59$

Immunpräzipitation von Proteinen $\quad 59$

$\begin{array}{ll}\text { Immunzytologie: Fixierung und Anfärbung } & 60\end{array}$

Fixierungsmethoden für Immunfluoreszenz $\quad 60$

Antikörper-Inkubation, Färbung, Eindeckelung und Bildaufnahme 61

Herstellung von Antiseren $\quad 61$

Affinitätsreinigung von Antikörpern $\quad 62$

Biochemische Methoden 63

$\begin{array}{ll}\text { Konzentrationsbestimmung von Proteinen } & 63\end{array}$

Diskontinuierliche Polyacrylamid-Gelelektrophorese 64

Coomassie-Färbung von Proteingelen $\quad 64$

Gewinnung von Proteinen $\quad 64$

Präparation von Gesamt-Zelllysaten $\quad 64$

Präparation von Digitonin-Zellextrakten 65

Natriumcarbonat-Extraktion zur Gewinnung löslicher Proteine 65 
Expression rekombinanter Proteine in E. coli 65

Native Affinitätsreinigung von Hexahistidin-Eferin 66

Native Affinitätsreinigung von Ran 67

Denaturierende Aufreinigung von humanem RanGAP1 67

Aufreinigung der TEV-Protease $\quad 69$

Differentielle Detergenzfraktionierung 70

$\begin{array}{ll}\text { Interaktionsstudien } & 70\end{array}$

$\begin{array}{ll}\text { Immobilisierung von Proteinen über } \mathrm{Ni}^{2+} & 70\end{array}$

Immobilisierung über Cyanogenbromid-aktivierte Sepharose 71

SUMO-Bindungsversuch (= SUMO binding assay) 71

$\begin{array}{ll}\text { Enzymatische Reaktionen } & 72\end{array}$

Radioaktive Beladung von Ran $\quad 72$

GTPase-Aktivitätsversuch (= GAP assay) 72

SUMO-Modifikationsversuch (= SUMOylation assay) 73

In vivo Sumoylierungsversuch (= in vivo SUMOylation assay) 73

In vitro Phosphorylierung $\quad 74$

In vitro Degradationsversuch $\quad 74$

$\begin{array}{ll}\text { Ergebnisse } & 75\end{array}$

$\begin{array}{ll}\text { Werkzeuge für in vitro und in vivo Studien } & 75\end{array}$

$\begin{array}{ll}\text { Klonierung unterschiedlicher Eferin-Expressionskonstrukte } & 75\end{array}$

$\begin{array}{ll}\text { Aufreinigung von rekombinantem His-Eferin für in vitro Experimente } & 78\end{array}$

Reinigung und Charakterisierung eines Antikörpers gegen Eferin $\quad 79$

$\begin{array}{ll}\text { Charakterisierung von Eferin } & 83\end{array}$

Eferin besitzt ein auffällig niedriges endogenes Expressionslevel 83

Endogenes Eferin lokalisiert abwechselnd an recyclisierende Endosomen, Centrosomen und die Teilungsfurche $\quad 84$

YFP-Eferin zeigt ein ähnliches Lokalisationsmuster wie endogenes Eferin $\quad 89$

Eferin ist mit Membranen assoziiert und löslich im Zytoplasma vertreten $\quad 93$

RanGAP1 ist mit endogenem und überexprimiertem Eferin copräzipitierbar 94

Aktivierung des spindle checkpoints führt zu Abbau von Eferin 98

Eferin wird in vitro rasch und quantitativ phosphoryliert 103

Aurora-A Kinase ist eine in vitro Kinase für Eferin 106

Phosphorylierung von Eferin könnte dessen Stabilität beeinflussen 107 
RNAi gegen Eferin beeinflusst den Zellzyklus 109

Mitotische RanGAP1-Lokalisation bleibt bei Eferin-knock down erhalten 112

Eferin besitzt zwei SUMO-Bindedomänen 117

Eferin bindet präferentiell an SUMO1 118

Eferin wird trotz E3-Ligasen in vitro nicht modifiziert 119

Keine Hinweise auf eine in vivo Sumoylierung von Eferin 122

Rekonstitution der Wechselwirkung von RanGAP1(*SUMO1) und Eferin ist in vitro bisher nicht möglich 124

$\begin{array}{ll}\text { RanGAP1 in Mitose } & 126\end{array}$

Aufgereinigte RanGAP1 Mutanten zeigen gegenüber Ubc9 gleiches

Bindungsverhalten

RanBP2-RanGAP1*SUMO1-Ubc9-Komplex bleibt nach mitotischer

Phosphorylierung stabil assoziiert

Rekombinante RanGAP1-Varianten zeigen im GTPase Aktivitätstest gleiche Aktivität

Aktivierende Eigenschaften bleiben bei RanGAP1-Phosphorylierung unbeeinflusst

Diskussion

Die Funktion der mitotischen RanGAP1 Phosphorylierung

Eferin interagiert mit RanGAP1

SUMO1 als mögliches Bindeglied zwischen RanGAP1 und Eferin

Eferin ist an recyclisierenden Endosomen, den Centrosomen sowie an der

Teilungsfurche zu finden

RNAi-Depletion von Eferin führt zur Verlängerung der G1/G0 und G2/M-Phase 140

Eferin hat keinen Einfluss auf die RanGAP1 Lokalisation

Spezifischer Verlust von Eferin in Meta- und Anaphase

Phosphorylierung als möglicher Regulationsmechanismus für Eferin

Modell zur Funktionsweise von Eferin

Ausblick 
Inhaltsverzeichnis

Anhang

158

Curriculum Vitae

160 


\section{Abkürzungen}

\section{Allgemeine Abkürzungen}

A

aa

Abb.

ADP

AG

AMP

APS

ATP

BCA

BSA

C

C- / c-

cDNA

$\mathrm{CMV}_{\mathrm{P}}$

cyc

ddNTP

DEAE

DMEM

DMSO

DNA

dNTP

DTT

E. coli

E1

E2

E3

EDTA

EGTA

FACS

FCS

FPLC
Adenin, in Zusammenhang mit DNA und RNA

Aminosäuren (engl.: amino acids)

Abbildung

Adenosin-5'-diphosphat

Arbeitsgruppe

Adenosin-5'-monophosphat

Ammoniumpersulfat

Adenosin-5'-triphosphat

engl.: bicinchoninic acid

Albumin aus Rinderserum (engl.: bovine serum albumin)

Cytosin, in Zusammenhang mit DNA und RNA

Carboxy- / carboxy-

komplementäre DNA (engl.: complementary DNA)

Cytomegalovirus-Promotor

cyclisierend (engl.: cycling)

2', 3'-Didesoxynukleosid-5'-triphosphat

Diethylaminoethyl-

engl.: Dulbecco's modified Eagles medium

Dimethylsulfoxid

Desoxyribonukleinsäure (engl.: desoxyribonucleic acid)

2'-Desoxynukleosid-5'-triphosphat

Dithiothreitol

Escherichia coli

Ubiquitin / SUMO aktivierendes Enzym

Ubiquitin / SUMO konjugierendes Enzym

Ubiquitin / SUMO Ligase

Ethylendiamintetracetat

Ethylenglykol-bis-( $\beta$-aminoethylether)-N,N'-tetracetat

engl.: fluorescence activated cell sorting

Fötales Kälberserum (engl.: fetal calf serum)

engl.: fast performance liquid chromatography 
G

GDP

GMP

GTP

$\mathrm{H}+\mathrm{L}$

HEPES

His-

IDA

IF

$\lg G$

IPTG

IU

$\mathrm{kD}$

LB

M

MCS

N- / n-

NCS

NEM

noc

NP40

$\mathrm{OH}$

$\mathrm{P}$

PAGE

PBS

PCR

PEFA

$\mathrm{pH}$

PMSF

PPi

RIPA

RNA

RNAi

RNAse
Guanin, in Zusammenhang mit DNA und RNA

Guanosin-5'-diphosphat

Guanosin-5'-monophosphat

Guanosin-5'-triphosphat

schwere und leichte Kette (engl.: heavy and light)

[4-(2-Hydroxyethyl)piperazino]-ethansulfonsäure

Hexahistidin, in Zusammenhang mit Fusionsproteinen

engl.: iminodiacetic acid

Immunfluoreszenz-Analyse

Immunglobulin G

Isopropyl- $\beta$-Thiogalaktopyranosid

internationale Einheiten (engl.: international units)

Kilodalton

Luria-Bertani

molar (Mol / I)

multiple Klonierungsstelle (engl.: multiple cloning site)

Amino- / amino-

Serum neugeborener Kälber (engl.: newborn calf serum)

$\mathrm{N}$-Ethylmaleimid

Nocodazol-arretiert

Nonylphenyl-polyethylenglykol

Hydroxy

Phosphat

Polyacrylamid-Gelelektrophorese

engl.: phosphate buffered saline

Polymerasekettenreaktion (engl.: polymerase chain reaction)

4-(2-Aminoethyl)-benzensulfonylfluorid·Hydrochlorid

negativer dekadischer Logarithmus der Protonenkonzentration

Phenylmethylsulfonylfluorid

Pyrophosphat

engl.: radioimmune precipitation assay

Ribonukleinsäure (engl.: ribonucleic acid)

interferrierende RNA (engl.: RNA interference)

Ribonuklease 


$\begin{array}{ll}\text { RPMI } & \text { engl.: Roswell Park Memorial Institute } \\ \text { SDS } & \text { Natriumlaurylsulfat (engl.: Sodiumdodecylsulfat) } \\ \text { T } & \text { Thymin, im Zusammenhang mit DNA und RNA } \\ \text { TAE } & \text { Tris / Acetat / EDTA } \\ \text { TE } & \text { Tris / EDTA } \\ \text { TEMED } & \text { N,N,N',N'-Tetramethylethylendiamin } \\ \text { TEV } & \text { engl.: tabacco etch virus } \\ \text { TLC } & \text { engl.: thin layer chromatography } \\ \text { Tris } & \text { Tris-(hydoxymethyl)-aminomethan } \\ \text { Triton X100 } & \text { 4-(1,1,3,3-Tetramethylbutyl)phenyl-polyethylenglykol } \\ \text { TSS } & \text { engl.: transformation sensitizing solution } \\ \text { Tween-20 } & \text { Polyoxyethylen(20)-sorbitan-monolaureat } \\ \text { U } & \text { Uracil, im Zusammenhang mit RNA } \\ \text { U/min } & \text { Umdrehungen pro Minute } \\ \text { UV } & \text { Ultraviolett } \\ \text { v/v } & \text { Volumen pro Volumen (engl.: volume per volume) } \\ \text { w/v } & \text { Gewicht pro Volumen (engl.: weight per volume) } \\ \text { WB } & \text { Westernblot-Analyse }\end{array}$

\section{Physikalische Größen}

$\begin{array}{ll}\text { A } & \text { Ampere } \\ \mathrm{Ci} & \text { Curie } \\ \mathrm{g} & \text { Erdbeschleunigung (im Kontext von Zentrifugation) } \\ \mathrm{g} & \text { Gramm } \\ \mathrm{h} & \text { Stunde } \\ \mathrm{I} & \text { Liter } \\ \mathrm{m} & \text { Meter } \\ \mathrm{min} & \text { Minute } \\ \text { OD } & \text { optische Dichte } \\ \mathrm{s} & \text { Sekunde } \\ \mathrm{V} & \text { Volt }\end{array}$




\section{Präfixe}

$\begin{array}{ll}\text { c- } & \text { Centi- } \\ \mathrm{k}- & \text { Kilo- } \\ \mathrm{m}- & \text { Milli- } \\ \mu- & \text { Mikro- } \\ \mathrm{n}- & \text { Nano- } \\ \mathrm{p}- & \text { Piko- }\end{array}$

\section{Abkürzungen der Gene und ihrer Produkte}

$\begin{array}{ll}\text { AAA } & \text { Tripel Alanin-Mutante } \\ \text { ARF } & \text { ADP-Ribosylierungsfaktor } \\ \text { ARF-BD } & \text { ARF-Bindedomäne } \\ \text { EEE } & \text { Tripel Glutamat-Mutante } \\ \text { GAP } & \text { engl.: GTPase activating protein } \\ \text { GAP-BD } & \text { GAP-Bindedomäne } \\ \text { GEF } & \text { engl.: guanine nucleotide exchange factor } \\ \text { GFP } & \text { grün fluoreszierendes Protein (engl.: green fluorescent protein) } \\ \text { GST } & \text { Glutathion-S-Transferase } \\ \text { H2B } & \text { Histon2B } \\ \text { KD } & \text { engl.: dead / damaged / defective kinase } \\ \text { Nuf } & \text { engl.: nuclear fallout } \\ \text { RBD } & \text { Rab11-Bindedomäne } \\ \text { WT } & \text { Wildtyp } \\ \text { YFP } & \text { gelb fluoreszierendes Protein (engl.: yellow fluorescent protein) } \\ \Delta C & \text { Deletion des C-Terminus / c-terminale Trunkierung } \\ \Delta F G & \text { Deletion der FG-Wiederholungen } \\ \Delta N & \text { Deletion des N-Terminus / n-terminale Trunkierung }\end{array}$




\section{Ein- und Dreibuchstabencode für Aminosäuren}

$\begin{array}{lll}\text { A } & \text { Ala } & \text { Alanin } \\ \text { D } & \text { Asp } & \text { Asparaginsäure } \\ \text { E } & \text { Glu } & \text { Glutamat } \\ \text { F } & \text { Phe } & \text { Phenylalanin } \\ \text { G } & \text { Gly } & \text { Glycin } \\ \text { H } & \text { His } & \text { Histidin } \\ \text { I } & \text { Hle } & \text { Isoleucin } \\ \text { K } & \text { Lys } & \text { Lysin } \\ \text { L } & \text { Leu } & \text { Leucin } \\ \text { M } & \text { Met } & \text { Methionin } \\ \text { P } & \text { Pro } & \text { Prolin } \\ \text { Q } & \text { Gln } & \text { Glutamin } \\ \text { R } & \text { Arg } & \text { Arginin } \\ \text { S } & \text { Ser } & \text { Serin } \\ \text { T } & \text { Thr } & \text { Threonin } \\ \text { V } & \text { Val } & \text { Valin } \\ \text { X } & - & \text { beliebig } \\ \Psi & - & \text { aliphatisch }\end{array}$

\section{Übersetzungsvorschläge häufig verwendeter Begriffe}

$\begin{array}{ll}\text { assay } & \text { Experiment / Untersuchung } \\ \text { beads } & \text { Matrix(material) } \\ \text { bridging factor } & \text { Überbrückungsfaktor } \\ \text { input } & \text { Gesamteintrag / Eingangsgröße } \\ \text { knock down } & \text { Depletion } \\ \text { pulldown } & \text { Präzipitationsexperiment } \\ \text { tag } & \text { Epitop / Markierung } \\ \text { target } & \text { Zielprotein / Substrat } \\ \text { coiled coil } & \text { gewundene Spirale }\end{array}$




\section{Zusammenfassung}

Das RanGTPase-aktivierende Protein RanGAP1 ist ein essentieller Bestandteil des RanGTPase-Zyklus. Dieser wird für den aktiven Transport von Makromolekülen zwischen Kern und umgebendem Zytoplasma genutzt und ermöglicht darüber hinaus wichtige Funktionen bei mitotischen Prozessen. Ein signifikanter Teil von RanGAP1 ist posttranslational mit SUMO1 modifiziert und dies führt zu einer stabilen Assoziation mit dem Protein RanBP2. Dadurch wird RanGAP1 in Interphase zum Bestandteil der Kernporenkomplexe, während in Mitose ein kleiner Teil von RanGAP1 mit RanBP2 als Komplex an Kinetochoren und der Spindel auftaucht. Untersuchungen zur Funktion des RanGAP1 Proteins standen im Mittelpunkt dieser Arbeit. Zunächst sollte ein putativer Bindepartner von RanGAP1, das Protein Eferin, näher charakterisiert werden. Eferin war zuvor in einer yeast two hybrid Studie als Bindepartner identifiziert worden. In der vorliegenden Arbeit konnte Eferin als Bindepartner von RanGAP1 in Säugerzellen bestätigt und darüber hinaus erstmals auch als SUMO1Bindeprotein beschrieben werden. Die weitere Charakterisierung zeigte, dass sich die Lokalisation von Eferin im Verlauf des Zellzyklus von den recyclisierenden Endosomen zu den Centrosomen und schließlich zur Teilungsfurche verlagert, während Eferin in Meta- und Anaphase abgebaut wird. Schließlich führte die Beobachtung einer in vitro Phosphorylierung von Eferin mit mitotischen Extrakten zur Identifizierung von Aurora-A als eine in vitro Kinase für Eferin. Aufgrund dieser Ergebnisse wird vorgeschlagen, dass Phosphorylierung Abbau und / oder Lokalisation von Eferin regulieren könnte.

Ein zweites Projekt betraf die Regulation von RanGAP1 durch zellzyklusabhängige Phosphorylierung. In Zusammenarbeit mit Dr. Swaminathan konnte gezeigt werden, dass Phosphorylierung von RanGAP1 in Mitose weder die Stabilität des RanBP2RanGAP1*SUMO1-Ubc9-Komplexes noch die aktivierenden Eigenschaften von RanGAP1 direkt beeinflusst. Die Ergebnisse dieses Projektes flossen in die Veröffentlichung Swaminathan, Kiendl et al. (2004) J Cell Biol ein. 


\section{Einleitung}

\section{Die Ras-Superfamilie}

Das als Onkogen klassifizierte GTP-bindende Protein Ras war das erste identifizierte Mitglied einer bis dahin unbekannten GTPase-Familie. Als solches wurde es zum Namensgeber aller Ras-ähnlichen GTPasen (= Ras-Superfamilie), welche untereinander hohe Struktur- (Abb. A) und Sequenzähnlichkeiten aufweisen [ $\left.{ }^{1}\right]$. Diese relativ kleinen GTPasen, mit einer Größe von 20 - 40 kD, steuern als molekulare Schalter essentielle Funktionen der Zelle. Ihnen ist eine hohe Affinität zu GTP und GDP gemein, die durch mehrere GTP/GDP-Bindemotivelemente (= G-Domäne) vermittelt wird $\left[{ }^{1-3}\right]$.

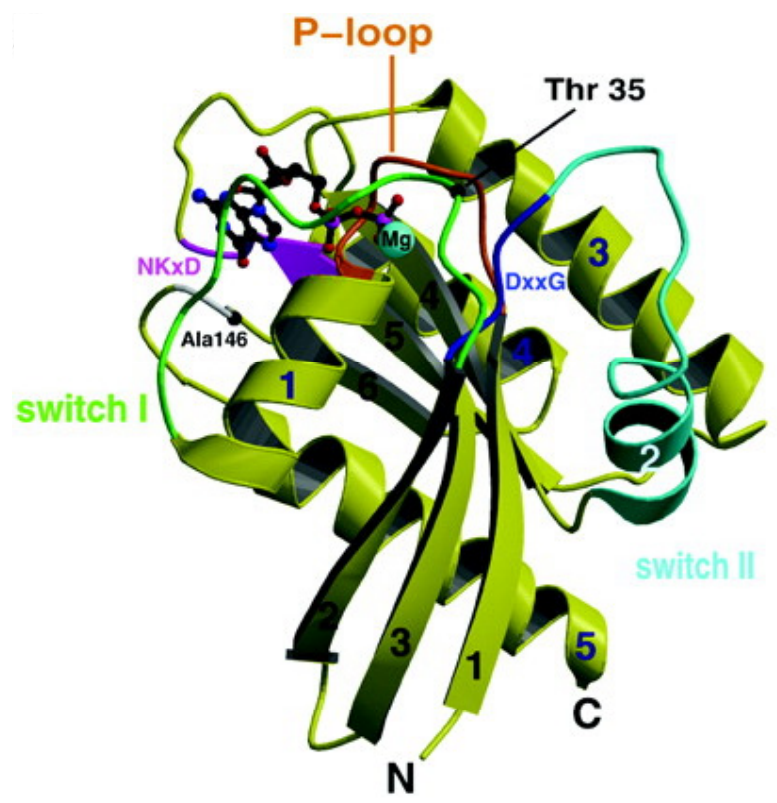

\section{Abbildung A: repräsentative Struktur der G-Domäne der Ras-Superfamilie}

Farbig hervorgehobene Zahlen beziffern die fünf Helices und sechs $\beta$-Faltblätter der G-Domäne; farblich abgesetzt sind die switch I - und switch II - Regionen; NKxD-Motiv und P-loop sind für die Nukleotidbindung, Ala146 und DxxG-Motiv für die Guaninnukleotid-Spezifität verantwortlich; Thr 35 ist an der Magnesiumbindung beteiligt; Guaninnukleotid und Magnesiumion sind im Kugel-Stab-Modell dargestellt; übernommen aus Vetter und Wittinghofer $\left[{ }^{3}\right]$.

Eine Beladung mit GTP bewirkt im Gegensatz zu einer GDP-beladenen Form eine geringe Konformationsänderung, die sich hauptsächlich in den switch I- und switch II - Regionen bemerkbar macht (Abb. B) [ $\left.{ }^{3}\right]$. 


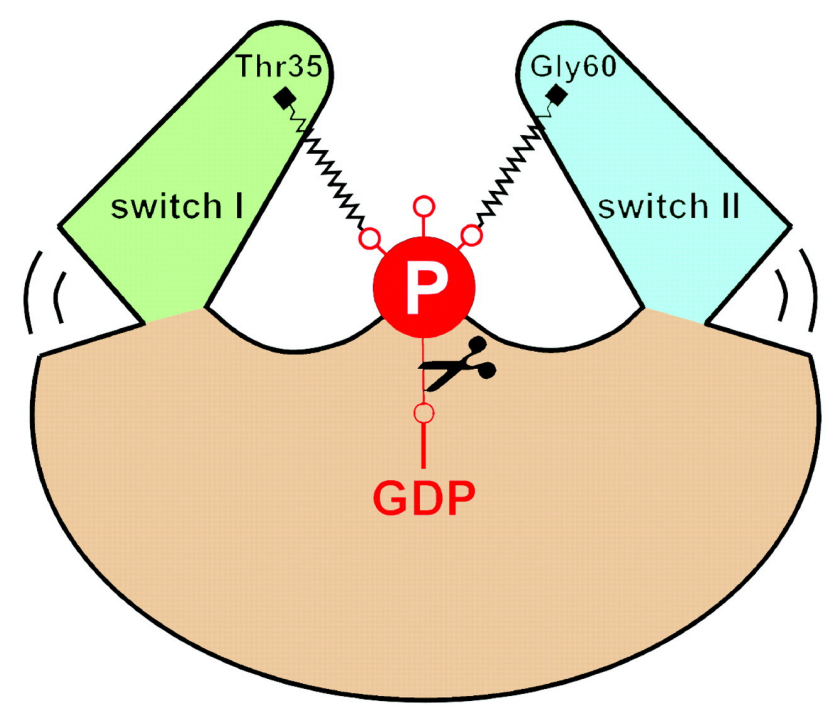

Abbildung B: schematische Darstellung des molekularen Schaltermechanismus der GTPasen Thr35 und Gly60 sind die invarianten Aminosäuren, welche die $\mathrm{Y}$-Phosphatgruppe (als großes $\mathrm{P}$ geschrieben) binden; GTP-Hydrolyse (in Form der Schere dargestellt) lässt die gespannten switch I und switch /l-Regionen in eine entspannte Konformation zurückschnellen; übernommen aus Vetter und Wittinghofer $\left[{ }^{3}\right]$.

Regulatoren und Effektoren der GTPasen sind in der Lage, diese beiden Konformationen zu unterscheiden und interagieren deshalb entweder nur mit der GTP- oder nur mit der GDP-gebundenen Form der GTPase [1,3]. Um nun zwischen der GTP- und der GDP-gebundenen Form hin und her wechseln zu können (= GTPase-Zyklus), sind für die GTPasen der Ras-Superfamilie zwei Hilfsfaktoren erforderlich. Aufgrund ihrer niedrigen intrinsischen GTPase-Aktivität benötigen all diese GTPasen zunächst ein GTPase-akktivierendes Protein (= GAP), welches die Konversion von gebundenem GTP zu GDP deutlich steigert [ $\left.{ }^{4}\right]$, während ein Guaninnukleotid-Austauschfaktor (= quanine nucleotide exchange factor $=\mathrm{GEF})$ den Austausch des gebunden GDP durch GTP bewerkstelligt [ $\left.{ }^{3}\right]$. Erst durch diese beiden Hilfsfaktoren können die GTPasen den GTPase-Zyklus vollziehen (Abb. C) und mit unterschiedlichen Bindepartnern interagieren. 


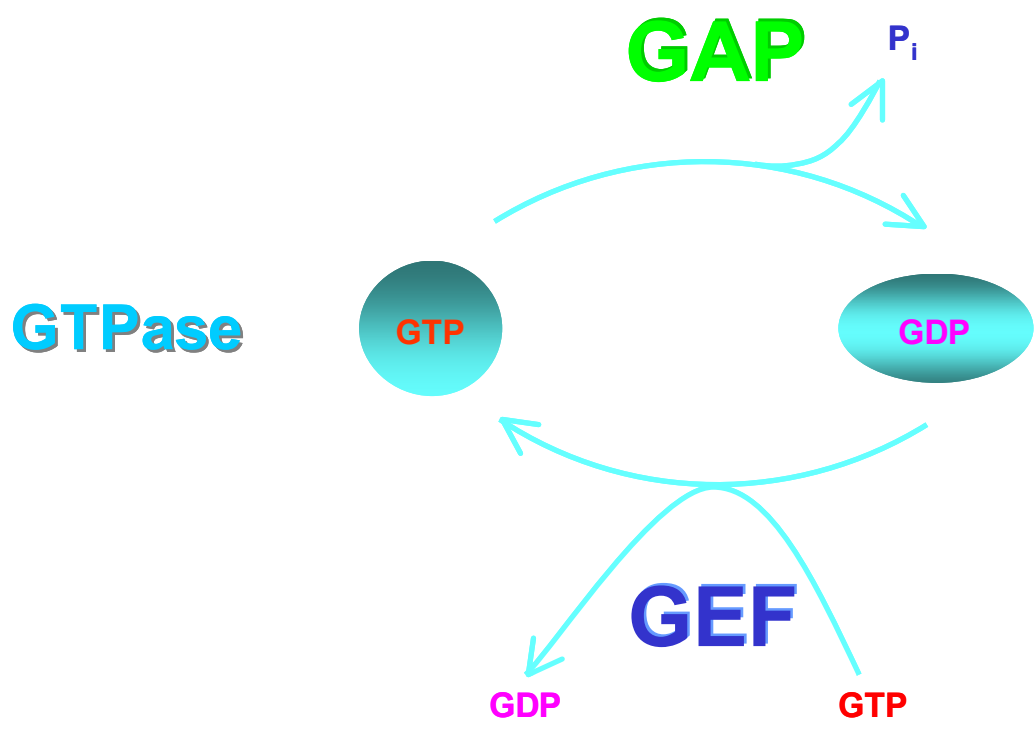

\section{Abbildung C: Modell des GTPase-Zyklus}

Der Guaninnukleotid-Status erlaubt die Unterscheidung der GTPase-Konformation; (GEF = guanine nucleotide exchange factor, GAP = GTPase activating protein).

Aufgrund von Ähnlichkeiten in der Sequenz lassen sich die Mitglieder der RasSuperfamilie in fünf Familien unterteilen. Im Einzelnen sind dies die Ras-, die Rho-, die Rab-, die ARF-, und die Ran-Familie [ $\left.{ }^{1,2}\right]$. Proteine der Ras- und der Rho-Familie steuern die Genexpression jeweils über eigene Signaltransduktionswege, darüber hinaus regulieren die Rho-GTPasen die Zytoskelett-Reorganisation. ARF-GTPasen sind für die Vesikelknospung verantwortlich, während die Rab-GTPasen die VesikelZielsteuerung übernehmen. Die Ran-Familie sorgt in Interphase für den KernZytoplasma-Transport und in Mitose für die Mikrotubuli-Organisation [2].

Wegen der Thematik dieser Arbeit wird im Weiteren nur auf die ARF-, Rab- und RanGTPasen eingegangen. 


\section{Die ARF-Familie}

Die ARF-GTPasen wurden ursprünglich als Cofaktoren für die Choleratoxinkatalysierte ADP-Ribosylierung eines G-Proteins $\left(G_{s} \alpha\right.$, verantwortlich für die Adenylatzyklase-Stimulation) identifiziert $\left.{ }^{5}\right]$. Seither steht das Kürzel ARF für ADP-Ribosylierungsfaktor, obwohl diese Proteine primär eine GTPase-Funktion besitzen. ARF-GTPasen wurden wegen Sequenzbesonderheiten in drei Klassen (Klasse I: Arf1, 2, 3; Klasse II: Arf4, 5; Klasse III:Arf6) eingeteilt [6]. Zu den GTPasen der ARF-Familie gehören des Weiteren Arl-, Arp- und Sar-GTPasen, die hier nur der Vollständigkeit halber genannt sind $\left[{ }^{7}\right]$. Einige Mitglieder der ARF-Familie werden, im Gegensatz zu allen übrigen GTPasen der Ras-Superfamilie, n-terminal an einem Glycin myristoyliert. Dem modifizierten N-Terminus ist es nach Konformationsänderung zur aktivierten ARF-GTP Form hin überhaupt erst möglich im Zusammenspiel mit den switch I - und II - Regionen an designierte Membranen und Effektoren zu binden $\left[{ }^{1,2}\right]$. Die beiden am besten untersuchten GTPasen dieser Familie sind Arf1 und Arf6. Arf1 wird Vesikelknospung am trans-Golgi-Netzwerk und an Endosomen durch Rekrutierung von Hüllproteinen, namentlich Clathrin und COPI (= coat protein complex I), zugeschrieben. Zusätzlich scheint Arf1 in Kooperation mit Mitgliedern der Rho-Familie Aktin-Polymerisation zu induzieren, was wiederum Vesikelknospung erleichtern könnte. Arf6 dagegen scheint an Prozessen wie Aktinund Membran-Remodellierung und Endosomen-Recycling beteiligt zu sein. Darüber hinaus wird Arf6 für die finalen Schritte bei der Zytokinese benötigt [ $\left.{ }^{7}\right]$.

\section{Die Rab-Familie}

Die Rab-GTPasen wurden zuerst als Ras-ähnliche Proteine im Gehirn

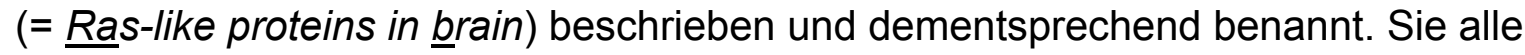
sind Regulatoren des Vesikeltransports zwischen Organellen sowie der Exo- und Endozytose. Dabei sind die Rabs (= RabGTPasen) an Prozessen wie Vesikelknospung, -bildung, -transport, bis hin zur Vesikelfusion beteiligt $\left.{ }^{1,8}\right]$. Die immense Vielfalt an bekannten Vesikeltransportwegen spiegelt sich in der bemerkenswert hohen Zahl von mehr als 60 bisher identifizierten Rab-GTPasen wider.

Sie üben meist spezialisierte Funktionen aus und können jeweils bestimmten intrazellulären Kompartimenten zugeordnet werden. 
Dabei muss aber betont werden, dass die RabGTPasen allein keinen Vesikeltransport bewerkstelligen können. Vielmehr bedarf es weiterer Proteinfamilien, allen voran die SNARE-Proteine (= soluble $\underline{N S F-\underline{a} t t a c h m e n t ~ p r o t e i n ~ r e c e p t o r) ~ f u ̈ r ~ d i e ~ A n-~}$ dockung und Fusion von Vesikeln $\left[{ }^{9}\right]$, aber auch der Motorproteine für die Vesikelbewegung. Eine Vielzahl weiterer Effektoren und Regulatoren hilft dabei alle nötigen Schritte aufeinander abzustimmen.

Ein allgemein gefasstes Modell zum Verständnis der Wirkungsweise der Rabs wird im Folgenden erläutert. Zunächst muss jedoch erklärt werden, wie die RabGTPasen ihre Funktion als periphere Membranproteine ausüben können.

Neu synthetisierte RabGTPasen müssen, um mit Membranen interagieren zu können, zunächst in einem Cystein-haltigen Motiv an ihrem C-Terminus mit ein bis zwei hydrophoben Geranylgeranylgruppen prenyliert werden $\left[{ }^{1}\right]$. Dies geschieht mit

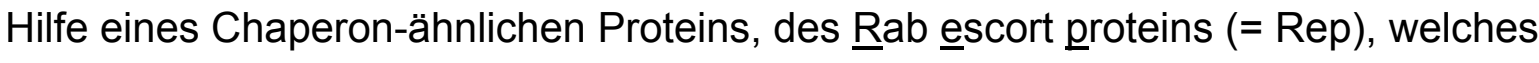
die frisch synthetisierte RabGTPase erkennt, bindet und schließlich einer Geranylgeranyltransferase zur Modifikation präsentiert (siehe Abb. D). Nach erfolgter Prenylierung hält das Rep die gebundene GTPase weiter in löslicher Form und liefert sie schließlich mit GDP beladen an der designierten Membran ab $\left[{ }^{10}\right]$. Hat eine Bindung an der Membran über die Prenylreste stattgefunden, erfolgt unmittelbar der Austausch von GDP zu GTP durch ein RabGEF.

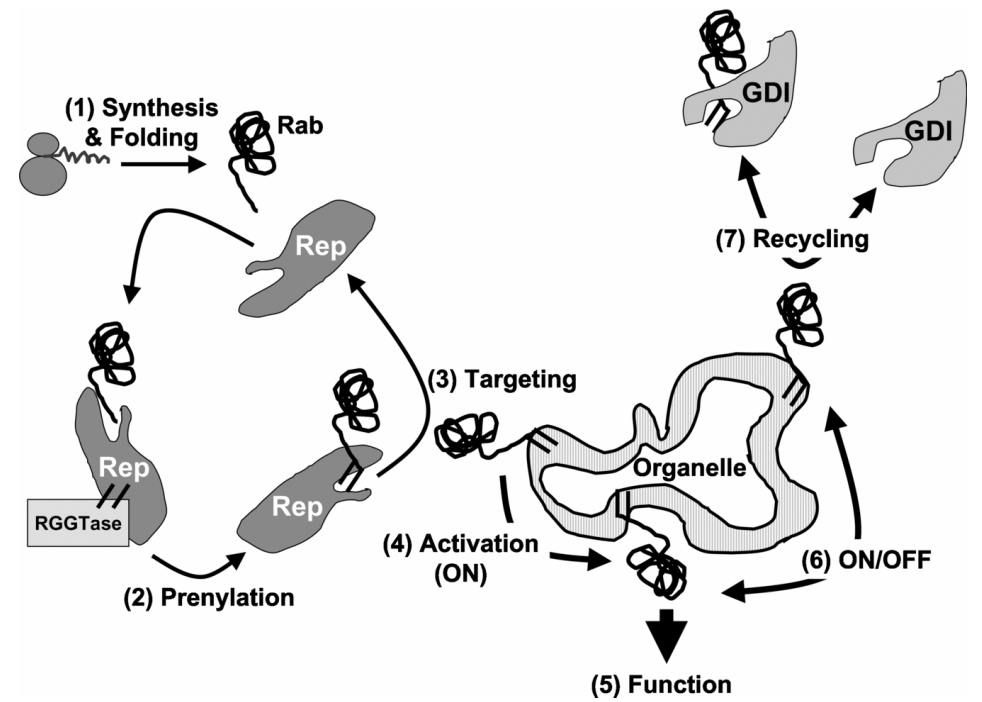

\section{Abbildung D: Entstehung und Recycling-Zyklus der RabGTPasen}

Schematischer Ablauf der Synthese und Faltung (1) der löslichen GTPase; ihrer Prenylierung (2) durch eine Geranylgeranyltransferase (= RGGTase), der Eskortierung (3) zur Zielmembran durch Rep (=Rab escort protein), der Aktivierung durch GTP (4), der Funktionsausübung (5) und Inaktivierung durch GTP-Hydrolyse (6) und ihre Entfernung aus der Membran mit anschließendem Recycling (7) durch GDI (= GDP dissociation inhibitor); übernommen aus Ali und Seabra $\left[{ }^{10}\right]$. 
Damit wird zum einen die Entfernung der RabGTPase aus der Membran durch ein Protein Namens RabGDI (= RabGDP dissociation inhibitor) verhindert, wie auch die Überführung in die aktivierte Form erreicht $\left[{ }^{10}\right]$. Ist die RabGTPase einmal aktiviert, bindet sie Effektormoleküle und steuert nachgeschaltete Prozesse wie z.B. Vesikellenkung. Nach Abschluss der Aktion erfolgt die Überführung in eine inaktive GDPForm. Dies wird von einem RabGAP katalysiert. Nun kann der RabGDI (siehe oben) die inaktivierte RabGTPase von der Membran entfernen und einer erneuten Runde des zielgerichteten Vesikeltransports zur Verfügung stellen. Dabei hat der GDI, ähnlich zum Rep, nicht nur die Funktion, die GDP beladene RabGTPase im Zytoplasma löslich vorzuhalten und bei Bedarf an der Membran anzuliefern, sondern sie von dort auch wieder zu entfernen $\left[{ }^{10}\right]$. Da der GDI eine hohe Affinität zu RabGDP aufweist, wird für die Anlieferung der GTPase an der Membran (wie in Abb. E dargestellt) ein zusätzlicher GDI-Entfernungsfaktor ( $=\underline{G} D I$ displacement f factor $=\mathrm{GDF})$ vorgeschlagen $\left[{ }^{11}\right]$.

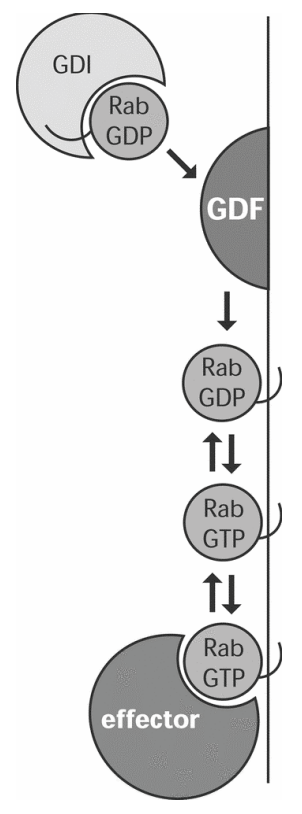

\section{Abbildung E: Modell zur Rekrutierung der RabGTPasen an Membranen}

Anlieferung der prenylierten GDP-beladenen RabGTPase durch GDI (= GDP dissociation inhibitor) an der Membran; GDF (= GDI displacement factor) bewirkt die Loslösung der GTPase aus dem GDI und erlaubt die Bindung an der Membran; RabGTPase kann nach Aktivierung durch ein GEF (= guanine nucleotide exchange factor) mit Effektoren in Wechselwirkung treten; übernommen aus Pfeffer $\left[{ }^{11}\right]$. 
Es bedarf noch weiterer Untersuchungen, um die Funktionsweise der RabGTPasen vollständig zu klären. Nach bisherigen Vorstellungen ist der Rab-abhängige Vesikeltransport einer genauen Feinabstimmung unterworfen, um die Integrität der einzelnen Organellen einer Zelle zu gewährleisten $\left[{ }^{9}\right]$.

\section{Die Ran-Familie}

Ran wurde ursprünglich als nukleäre, Ras-ähnliche (= Ras-like nuclear) GTPase entdeckt. Es ist das alleinige Mitglied der Ran-Familie und bleibt, im Gegensatz zu etlichen anderen GTPasen, posttranslational unmodifiziert. Als mengenmäßig häufigste GTPase der Ras-Superfamilie ist es für den Kern-Zytoplasma-Transport verantwortlich $\left[{ }^{1,12}\right]$. Ran reguliert diesen Import und Export über den RanGTPaseZyklus, für den es zwei Hilfsfaktoren benötigt (Abb. F). Die Hydrolyse des gebunden GTP zu GDP erfordert das aktivierende Protein RanGAP1 (= RanGTPase activating protein 1) $\left.{ }^{13-15}\right]$. Nach dieser Konversion muss das gebundene GDP durch GTP ersetzt werden. Dies geschieht mit Hilfe eines zweiten Proteins, des RanGEF, das im Ran-System RCC1 (= regulator of chromosome condensation 1 ) genannt wird $\left[{ }^{12}\right]$. Da sich RCC1, an DNA gebunden, vorwiegend im Zellkern befindet $\left[{ }^{16,17}\right]$, herrscht hier eine hohe Konzentration an RanGTP. RanGAP1 dagegen ist zum Teil löslich im Zytoplasma vertreten und zum Teil durch posttranslationale Modifikation mit SUMO an der zytoplasmatischen Kernporen-Komponente RanBP2 verankert [ $\left.{ }^{18,19}\right]$. Durch die strikte Beschränkung auf die zytoplasmatische Seite der Kernhülle ist RanGAP1 außerhalb des Zellkernes für Hydrolyse von RanGTP zu RanGDP verantwortlich. 


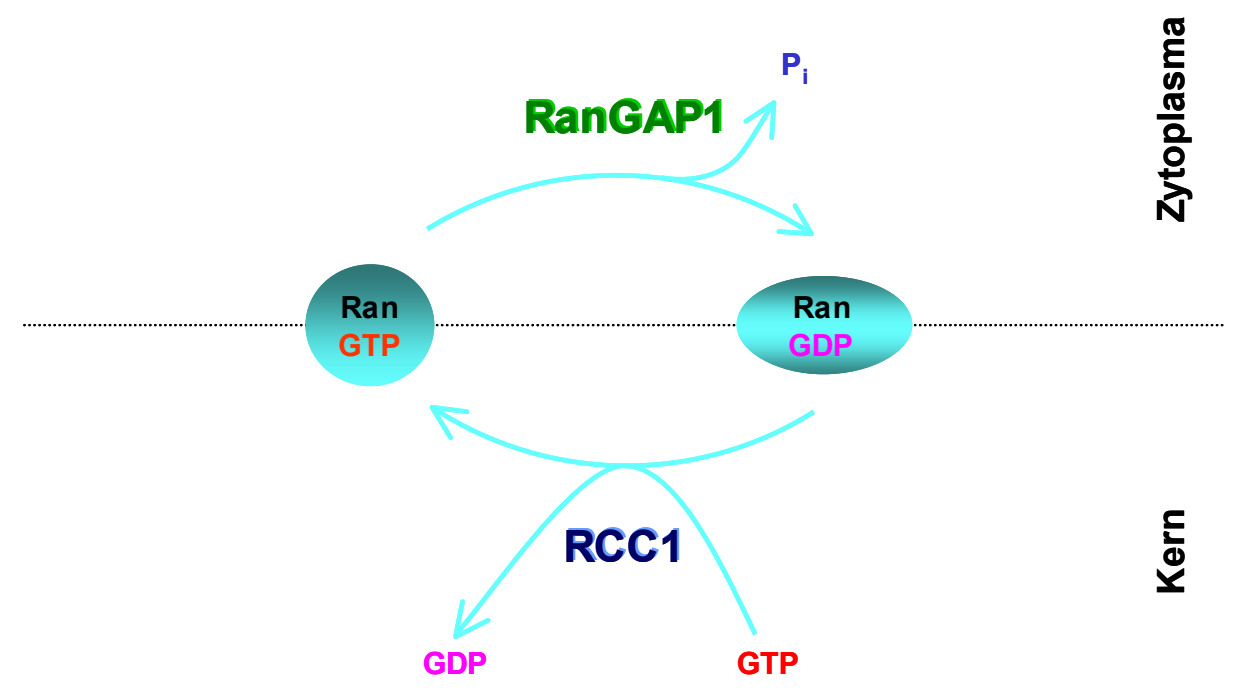

\section{Abbildung F: RanGTPase Zyklus}

Die unterbrochene Linie symbolisiert die räumliche Trennung von RanGAP1 und RCC1; RanGAP1 (= RanGTPase-aktivierendes Protein 1); RCC1 (= regulator of chromosome condensation 1).

Eine weitere Steigerung dieser Hydrolyse im Zytoplasma kommt durch das lösliche RanBP1 und die Kernporen-Komponente RanBP2 zustande [ $\left.{ }^{12}{ }^{20}\right]$. Beide vermögen RanGTP zu binden und steigern im Komplex mit RanGAP1 dessen aktivierende Eigenschaften. Die asymmetrische Lokalisation von RanGAP1 und RCC1 stellt also die treibende Kraft des Ran-abhängigen Kern-Zytoplasma-Transportes dar. Doch wie läuft dieser energiegetriebene aktive Transport genau ab?

\section{Der Kern-Zytoplasma-Transport in Interphase $\left[{ }^{12,20}\right]$}

Auf der zytoplasmatischen Seite binden Proteine aus der Familie der Importine das zu transportierende Frachtprotein (im Englischen cargo genannt) in Abwesenheit von Ran und transportieren es über Kernporenkomplexe in den Kern. Dort kommt es durch Bindung von RanGTP an die Importine zur Dissoziation des Importkomplexes unter Freisetzung des transportierten Proteins (siehe Abb. G). Die ihrerseits RanGTP-gebundenen Importine werden daraufhin in das Zytoplasma exportiert und dort durch Umsetzung des gebundenen GTP zu GDP für einen neuen Importzyklus freigesetzt. Export von Proteinen oder RNA aus dem Kern ins Zytoplasma ist dagegen nur in Anwesenheit von RanGTP möglich (Abb. G). Hierzu assembliert RanGTP mit dem Exportin und dem dazugehörigen cargo-Protein zum Exportkomplex. Auf den Export ins Zytoplasma folgt die Hydrolyse zu RanGDP, die den 
Zerfall des Komplexes und damit die Freisetzung aller beteiligten Komponenten bewirkt. Betrachtet man Import und Export zusammen, fällt auf, dass es in Bezug auf Ran keine ausgeglichene Bilanz gibt. Während dem Kern ein Ran Molekül durch Export entzogen wird, führt Import zu keinem simultanen Reimport eines RanMoleküls.

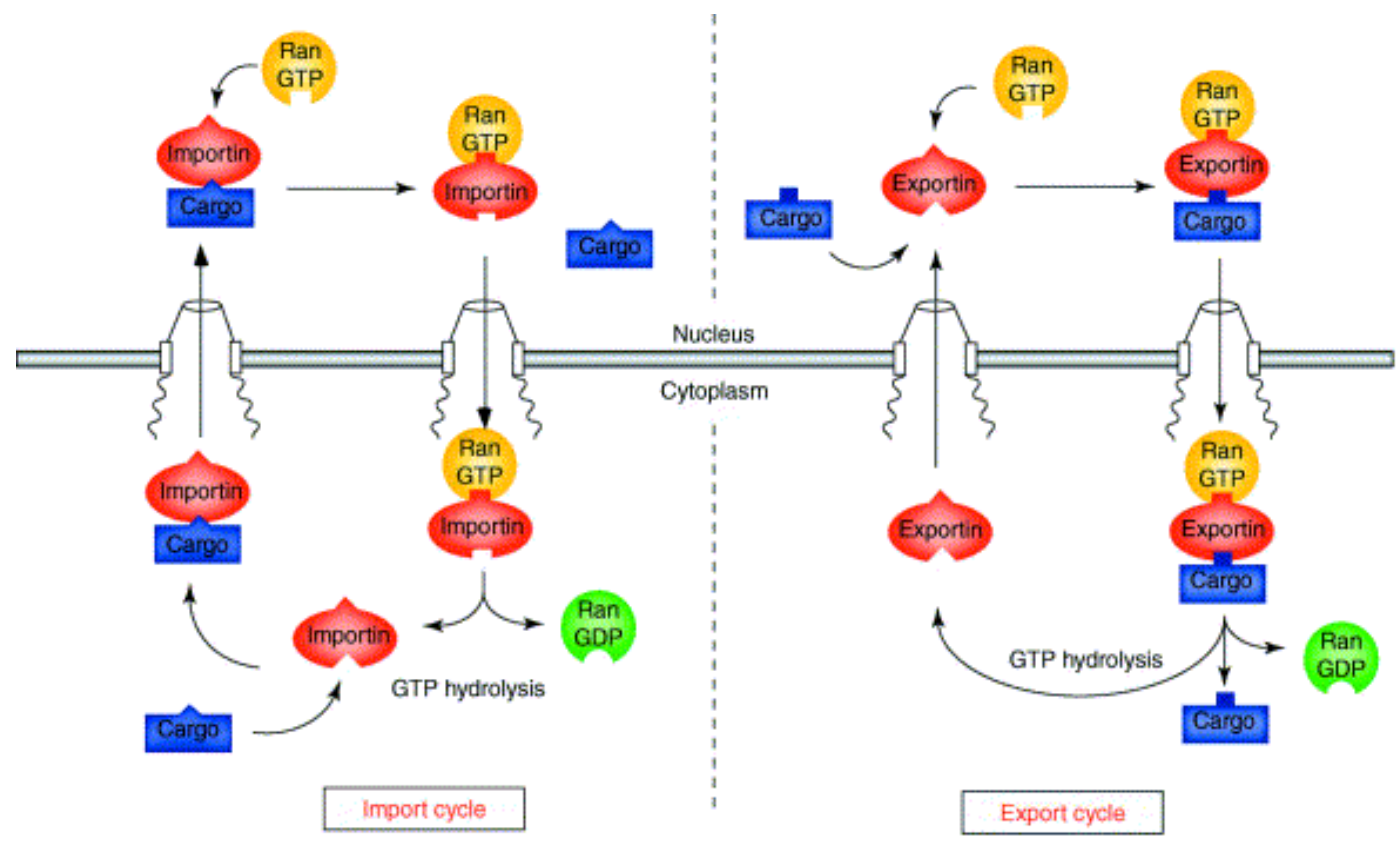

\section{Abbildung G: Kern-Zytoplasma-Transport}

Import- (linke Hälfte) und Export-Zyklus (rechte Hälfte); übernommen aus Kuersten et al $\left[^{20}\right]$.

Daher benötigt der Kern-Zytoplasma-Transport für den Reimport von Ran in den Kern einen eigenen Ran-Importeur. Dies ist das 10 kD große Protein NTF2 (= nuclear transport factor $\left.\underline{2}){ }^{21,22}\right]$. NTF2 bindet RanGDP im Zytoplasma und entlässt es nach erfolgtem Nukleotidaustausch als RanGTP im Kern.

Das Modell vom Kern-Zytoplasma-Transport wurde zum besseren Verständnis bisher vereinfacht dargestellt und soll an dieser Stelle ein wenig differenzierter betrachtet werden. Es muss zunächst ergänzt werden, dass für Import und Export viele verschiedene Rezeptoren nötig sind. Die Prototypen dieser Transportrezeptoren sind Importin $\beta$ und $\left.\mathrm{Crm} 1{ }^{23}\right]$. Bei den zu exportierenden cargos erkennt der Exportfaktor seine Fracht anhand eines Kernexportsignals (= nuclear export signal $=$ NES) in der cargo-Sequenz und transportiert es ins Zytoplasma. Beim Import dagegen werden nur manche der cargo-Proteine von Importin $\beta$ direkt erkannt und transportiert, während andere cargos für den Import zusätzlich das 
Adaptorprotein Importin a benötigen. Die Gemeinsamkeit letzterer cargo-Proteine

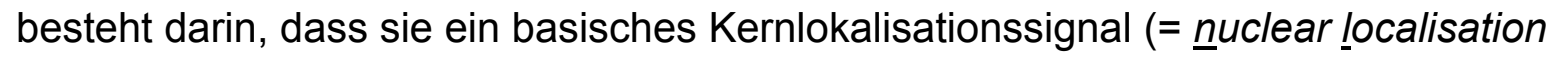
signal = NLS) tragen, welches von Importin $\alpha$ erkannt wird. Schließlich bindet Importin $\beta$ an Importin $\alpha$ und der Import findet statt.

Anschließend wird Importin a im Komplex mit RanGTP und dem Exportfaktor CAS zurück ins Zytoplasma transportiert, während bei Importin $\beta$ dafür RanGTP alleine ausreicht ${ }^{24,25}$. Nachfolgend müssen deshalb mittels NTF2 insgesamt zwei RanMoleküle in den Kern zurückgebracht werden. Für die Translokation der Exportine und Importine durch die Kernpore selbst wird kein Ran benötigt. In der Tat scheinen sich die Transportrezeptoren über schwache Interaktionen mit Phenylalanin-GlycinMotiv-Wiederholungen des Kernporenkomplexes, den FG-repeats, zwischen den beiden Kompartimenten frei bewegen zu können $\left[{ }^{26,27}\right]$. Die Direktionalität eines bestimmten Transportereignisses wird daher durch einen hohen RanGTP-Gehalt im Kern und durch die Hydrolyse von RanGTP zu RanGDP im Zytoplasma gesteuert.

\section{Ran in Mitose}

Wie bereits ausführlich geschildert, bewerkstelligt die GTPase Ran in Interphase den Kern-Zytoplasma-Transport. In Mitose allerdings entfällt diese Aufgabe aufgrund der Auflösung der Kernhülle, stattdessen werden ihr eine Fülle neuer Aufgaben zuteil. Als gesichert gilt die Beteiligung von Ran beim Aufbau der mitotischen Spindel [ $\left.{ }^{28-33}\right]$. Ein anschauliches Modell (siehe Abb. H) hierfür besagt, dass in unmittelbarer Nähe der kondensierten Chromosomen, aufgrund des chromatingebundenen RCC1, ein hoher Gehalt an RanGTP vorliegt $\left[{ }^{12,34,35}\right]$. Sogenannte Spindelassemblierungsfaktoren (= SAF) könnten für die Spindelbildung sorgen, werden aber von einem Komplex aus Importin a und Importin $\beta$ sequestriert und an ihrer Funktion gehindert. In direkter Nachbarschaft der Chromosomen jedoch führt ein Binden von RanGTP an die Importine zur Freisetzung der SAF und damit zur Ausbildung der Spindel. Daneben wird Ran eine Beteiligung an der Bildung der Kernmembran am Ende der Mitose zugeschrieben [ $\left.{ }^{36,37}\right]$. Anders als bei der Spindelassemblierung scheint es sich bei diesem Prozess jedoch nicht um eine Freisetzung sequestrierter Faktoren zu handeln. Der zugrunde liegende Mechanismus ist bisher unbekannt. Darüber hinaus wird Ran auch mit Regulation des spindle checkpoint in Verbindung gebracht $\left[{ }^{38}\right]$. 


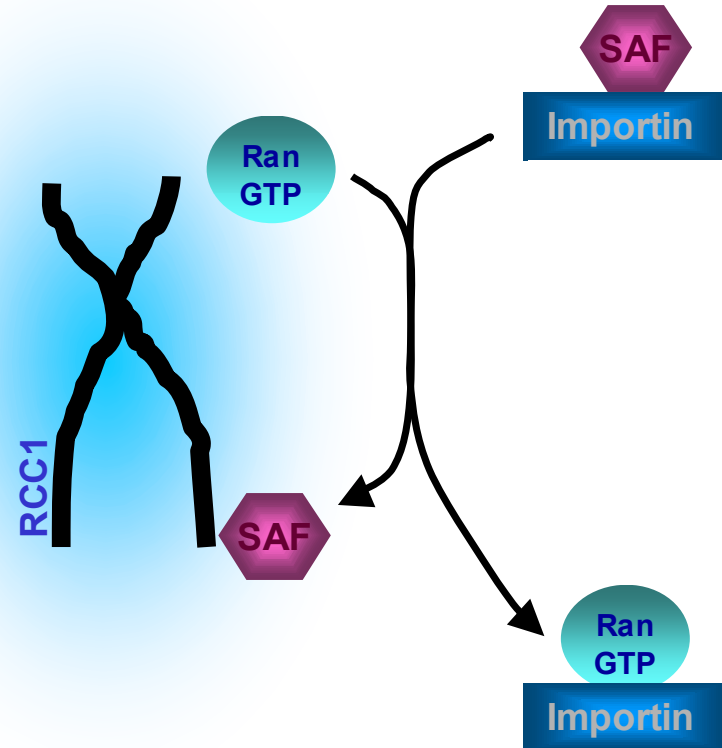

\begin{abstract}
Abbildung H: Modell zum chromatinabhängigen Spindelaufbau chromatingebundenes RCC1 (= regulator of chromosome condensation 1) bewirkt einen hohen RanGTP-Gehalt an den Chromosomen; RanGTP sequestriert in unmittelbarer Nachbarschaft zu den Chromosomen Importin und hat die Freisetzung von SAF (= Spindelassemblierungsfaktor) zur Folge; SAF löst die Bildung der mitotischen Spindel aus.
\end{abstract}

\title{
Besonderheiten des GTPase-aktivierenden Proteins RanGAP1 in Vertebraten
}

Das RanGTPase-aktivierende Protein RanGAP1 war bereits Gegenstand der Ausführungen. An dieser Stelle muss der Vollständigkeit halber aber noch auf Gemeinsamkeiten und Unterschiede einiger Homologe eingegangen werden. Vergleicht man RanGAP1 verschiedener Organismen miteinander (siehe Abb. M), stellt man zunächst fest, dass alle in einer auffällig konservierten Region, der katalytischen Domäne, übereinstimmen. Geht man weiter, so findet sich bei vertebratem RanGAP1 die Besonderheit einer c-terminalen Verlängerung und bei Pflanzen die einer entsprechenden n-terminalen Domäne $\left[{ }^{39}\right]$. In Hefe dagegen ist, außer der katalytischen Domäne und dem sauren Bereich, kein zusätzlicher Bereich anzutreffen. Während bei Pflanzen allein diese n-terminale Domäne zur Verankerung an Komponenten der Kernhülle genügt, bedarf es im c-terminalen Bereich von vertebratem RanGAP1 für eine Verankerung an der Kernpore zusätzlich der Modifikation mit SUMO [ [8, 19, 40$]$. Erst diese posttranslationale Veränderung erlaubt eine Interaktion zwischen 
RanGAP1 und der Kernporenkomponente RanBP2 [ ${ }^{18,19,40,41}$ ]. Zu welchem Zweck RanGAP1 in Pflanzen und Vertebraten an der Kernhülle bzw. Kernpore verankert wird, ist nicht klar. Im Folgenden soll die angeführte Modifikation mit SUMO besprochen werden.

\section{Sumoylierung als posttranslationale Modifikation}

Für die posttranslationale Modifikation von Proteinen steht eine breite Palette möglicher Veränderungen bereit, die eine Erweiterung ihrer Grundeigenschaften erlauben. Zu den prominentesten zählen Phosphorylierung, Acetylierung, Methylierung, die Anhängung von Zucker- oder Fettresten, die Verknüpfung mit kleinen Proteinen aus der Gruppe der Ubiquitin-ähnlichen Proteine oder die Verknüpfung mit Ubiquitin selbst.

Wird ein Protein mit dem Ubiquitin-ähnlichen Protein SUMO modifiziert, so spricht man von Sumoylierung. Der Name SUMO steht dabei stellvertretend für

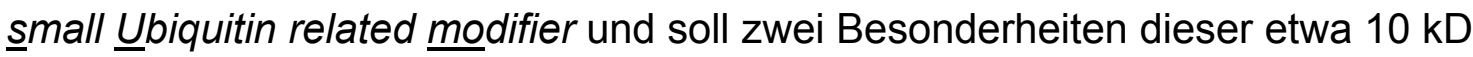
großen Proteine herausstellen: 1.) Der ursprünglich namensgebende Vertreter der SUMO-Familie, SUMO1, besitzt trotz einer Sequenzhomologie von nur $18 \%$ eine erstaunlich hohe Strukturähnlichkeit mit Ubiquitin (siehe Abb. I) [ $\left.{ }^{42,43}\right]$.

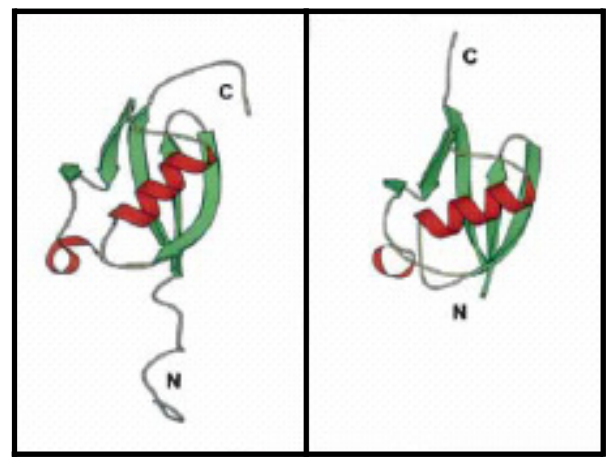

\section{SUMO1 Ubiquitin}

\section{Abbildung I: Struktur von SUMO1 und Ubiquitin}

Direkter Strukturvergleich zeigt die Ähnlichkeit zwischen SUMO1 und Ubiquitin auf; SUMO1 besitzt im Gegensatz zu Ubiquitin eine n-terminale Verlängerung; rot dargestellt sind $\alpha$-Helix, in grün $\beta$-Faltblattstruktur; übernommen von Frauke Melchior mit freundlicher Genehmigung von Peter Bayer $\left[{ }^{42}\right]$. 
2.) Vergleichbar zu Ubiquitinierung wird SUMO über eine Isopeptidbindung kovalent an die $\varepsilon$-Aminogruppe eines Akzeptorlysins im Zielprotein geknüpft $\left[{ }^{44}\right]$.

Die Grundvoraussetzungen für eine Sumoylierung sind dabei ein SUMO-Molekül, drei spezialisierte Enzyme, eine Energiequelle, das Substrat und schließlich, ganz analog zur Ubiquitinierung, die in Abb. J dargestellte Reaktionsabfolge.

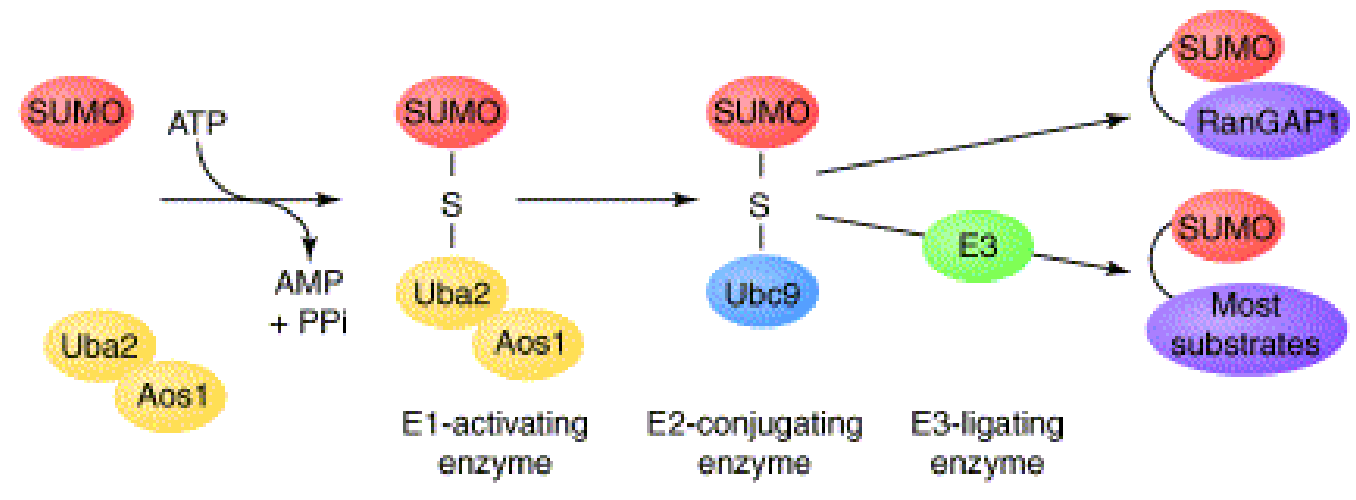

\section{Abbildung J: Sumoylierungskaskade}

Unter ATP-Verbrauch bindet das Heterodimer aus Aos1 und Uba2 als aktivierendes Enzym das SUMO-Molekül; Ubc9 übernimmt das SUMO-Molekül vom aktivierenden Enzym und konjugiert es mit oder ohne Hilfe einer E3-Ligase an das Zielprotein, übernommen aus Melchior et al. [ $\left.{ }^{45}\right]$.

In dieser bindet zunächst das aktivierende E1-Enzym Aos1 / Uba2 (auch SAE1 / SAE2 genannt) [ $\left.{ }^{46-49}\right]$ unter ATP-Verbrauch das SUMO-Molekül. Zwischenstufe dabei ist zunächst ein SUMO-Adenylat, welches schließlich über seine c-terminale Carboxygruppe mit dem Cystein des Aktiven Zentrums im E1Enzym eine Thioesterbindung bildet $\left[{ }^{50}\right]$. Nun tritt das konjugierende E2-Enzym Ubc9 auf den Plan und übernimmt den aktivierten SUMO-Rest vom E1-Enzym [ $\left.{ }^{48,51}\right]$. Die Übernahme vollzieht sich durch Ausbildung einer Thioesterbindung mit dem Cystein des Aktiven Zentrums im E2-Enzym. Während einige wenige Proteine (z.B. RanGAP1) direkt durch Ubc9 modifiziert werden [ $\left.{ }^{45}\right]$, benötigen die meisten eine weitere Klasse von Faktoren. Dies sind die verschiedenen E3-Enzyme. Diese E3Enzyme rekrutieren als eine Art Substraterkennungsfaktor das zu modifizierende Zielprotein und stärken den Kontakt zwischen E2-Enzym und Substrat. Dies hat eine deutliche Steigerung der Sumoylierung spezifischer Substrate zur Folge $\left[{ }^{45}\right]$. In Säugern stehen für die Modifikation eines Proteins mit SUMO vier Paraloge, SUMO1, SUMO2 / 3 sowie SUMO4 mit unterschiedlichen Eigenschaften zur Verfügung. In Hefe kennt man dagegen bisher nur ein SUMO-Gen, für Arabidopsis sind 
acht Gene bekannt $\left[{ }^{52}\right]$. Während sich SUMO2 und SUMO3 in drei Aminosäuren von einander unterscheiden, beträgt der Verwandtschaftsgrad dieser beiden Mitglieder zu SUMO1 nur 50\% [ $\left.{ }^{50}\right]$. Über das vierte Mitglied, SUMO4, ist bisher erst wenig bekannt $\left.{ }^{53-56}\right]$. Interessanter Weise ist, analog zur Ubiquitinierung, für die beiden Paraloge SUMO2 und SUMO3 die Bildung von SUMO-Ketten gezeigt worden $\left[{ }^{57}\right]$. Diese Kettenbildung ist möglich, da die Paraloge SUMO2, 3 und 4 ein SUMO-KonsensusMotiv, die Erkennungsstelle für Ubc9, tragen $\left[{ }^{58}\right]$.

\section{Das SUMO-Konsensus Motiv}

Eine Vielzahl von Verknüpfungsstellen sumoylierter Proteine weisen die KonsensusSequenz $\Psi$ KxE auf ( $\Psi$ steht für eine hydrophobe, $x$ für jede beliebige Aminosäure), welche von Ubc9 erkannt wird $\left[{ }^{59,60}\right]$. Doch nicht nur das Vorhandensein dieses Konsensus-Motivs ist ausreichend für eine Sumoylierung. Der Grund dafür wurde durch die Kristallstruktur des Komplexes aus RanGAP1 und Ubc9 deutlich $\left[{ }^{61}\right]$. Darin interagiert Ubc9 mit RanGAP1 nicht nur über dessen Akzeptorlysin $(=\mathrm{K})$ sondern auch mit dem benachbarten, aliphatischen $(=\Psi)$ Leucin und der sauren Aminosäure Glutamat (= E). Diese Art der Interaktion funktioniert natürlich nur, wenn das Erkennungsmotiv durch Einbettung in eine $\beta$-Faltblatt- oder eine loop-Struktur exponiert wird und in einer gestreckten Konformation vorliegt. Daneben gibt es aber Proteine, bei denen die Sumoylierung nicht im beschriebenen Erkennungsmotiv erfolgt. Zwei bekannte Beispiele sind PCNA [62] und E2-25K [ ${ }^{63}$, für die sich keine KonsensusSequenz definieren lässt.

\section{Die SUMO-Maschinerie}

Während es im SUMO-System vom E1- und E2-Enzym jeweils nur einen Vertreter

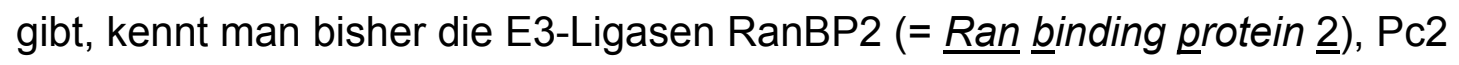
(= Polycomb protein 2$)$ und diverse PIAS-Proteine (= protein inhibitor of activated STAT), die neben einer Erhöhung der Sumoylierungsrate für die Erweiterung des Spektrums modifizierbarer Substrate sorgen $\left[{ }^{64-67}\right]$. Aufgrund der wachsenden Zahl sumoylierter Proteine wird angenommen, dass es mehr als drei E3-Ligase-Familien geben muss bzw. dass andere regulatorische Mechanismen auf der Ebene der Zielproteine und / oder der bekannten Enzyme greifen $\left[{ }^{45}\right]$. Doch wie die meisten 
Modifikationen, ist auch die Sumoylierungsreaktion der Umkehrbarkeit unterworfen (Abb. K). Zwar handelt es sich bei der ausgebildeten Isopeptidbindung um eine chemisch stabile, kovalente Verknüpfung, jedoch sind als Gegenpol zu den modifizierenden E1-, E2- und E3-Enzymen Isopeptidasen als demodifizierende Enzyme identifiziert worden $\left[{ }^{45}\right]$.

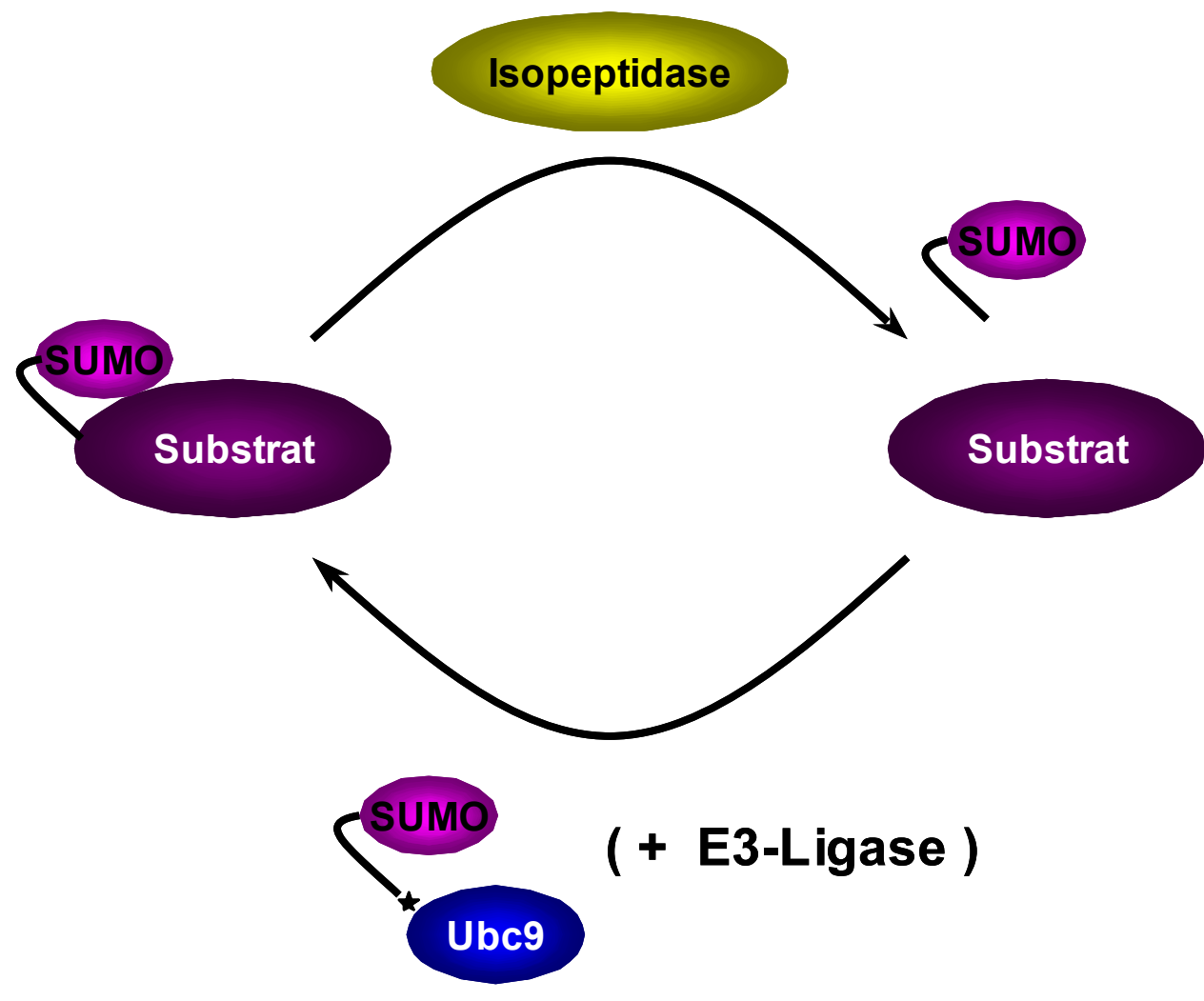

Abbildung K: Zyklus der Sumoylierung und Desumoylierung

Während das konjugierende Enzym Ubc9 (mit Hilfe einer E3-Ligase) den SUMO-Rest auf das Substrat überträgt, sind spezialisierte Isopeptidasen für SUMO-Dekonjugation, also die Umkehrung der Sumoylierungsreaktion, verantwortlich.

Diese hochaktiven Cystein-Proteasen sorgen für die rasche Einstellung eines Gleichgewichts aus modifizierten und demodifizierten Zielproteinen und weisen dabei eine Spezifität für SUMO (versus Ubiquitin) auf. Des Weiteren sind sie teilweise für die Reifung der SUMO-Vorläufer zu konjugierbaren SUMO-Molekülen verantwortlich (Abb. L) $\left.{ }^{45,50}\right]$. 


\section{SUMO $=\stackrel{\text { SUMO protease }}{\longrightarrow}$ SUMO}

\section{Abbildung L: SUMO-Reifung}

Isopeptidasen sind für die Reifung des SUMO-Vorläufers zum konjugierbaren SUMO-Molekül mit freiem Glycin-Glycin-Motiv im C-Terminus notwendig; übernommen aus Melchior et al. $\left.{ }^{45}\right]$.

Erwähnenswert ist, dass die genaueren Umstände der Auswahl eines bestimmten Mitgliedes der SUMO-Familie für eine bestimmte Sumoylierung oder die Substratspezifität der modifizierenden E3-Ligasen bzw. der demodifizierenden (SUMO-)Isopeptidasen noch genauerer Klärung bedürfen. Die Frage, die sich in diesem Zusammenhang auch stellt, ist die nach der Konsequenz der Sumoylierung.

\section{Molekulare und funktionelle Konsequenzen der Sumoylierung}

Sumoylierung hat nach bisherigem Kenntnisstand drei unterschiedliche molekulare Auswirkungen. So kann die Modifikation eines Proteins mit SUMO zur Maskierung eines Bindemotivs führen. Dieses Szenario wurde z.B. für E2-25K beobachtet, bei dem durch die Sumoylierung das Binden des E1-Enzyms für die Ubiquitinierung verhindert wird $\left.{ }^{63}\right]$. Die Konsequenz ist, dass das sumoylierte E2-25K an dem Akzeptorlysin nicht ubiquitiniert werden kann. Des Weiteren kann Sumoylierung für das betreffende Protein die Schaffung einer zusätzlichen Bindedomäne bedeuten. Diese Situation spiegelt sich beispielsweise bei RanGAP1 wider, welches erst nach Sumoylierung an die Kernporenkomponente RanBP2 rekrutiert wird [ $\left.{ }^{18,19,40,41}\right]$. Die Folge ist, dass RanGAP1, wie bereits früher beschrieben, der GTPase Ran bei der Umsetzung von GTP zu GDP vor Ort an der Kernpore helfen kann. Die dritte Möglichkeit ist die einer sumoylierungsabhängigen Konformationsänderung. Als Beispiel sei hier die Thymin-DNA-Glycosylase genannt $\left[{ }^{68}\right]$. Durch die Modifikation der Thymin-DNA-Glycosylase mit SUMO kommt es zu einer Konformationsänderung und in ihrer Folge zur Dissoziation der Thymin-DNA-Glycosylase von der DNA. Mit den genannten Beispielen ist nur ein Bruchteil aller beschriebenen funktionellen Konsequenzen abgedeckt, die molekularen Konsequenzen beschränken sich jedoch auf die drei dargelegten Situationen [ $[5,50,69,70]$. 
Zu betonen bleibt, dass Sumoylierung funktionell als Regulationsmechanismus anzusehen ist. Einerseits erfolgen Modifikation mit SUMO und Demodifikation sehr schnell, andererseits hat die Modifikation mit SUMO ähnliche molekulare Auswirkungen wie z.B. Phosphorylierung (Konformationsänderung, Schaffung einer Bindestelle). Darüber hinaus ist die Modifikation mit SUMO durch externe Stimuli (wie im Falle von Hitzeschock, osmotischem oder oxidativem Stress) [ $\left.{ }^{52,71,72}\right]$ oder durch Phosphorylierung modulierbar $\left[{ }^{73-75}\right]$. Abschließend muss für ein besseres Verständnis der oben beschriebenen molekularen Konsequenz einer SUMO-induzierten Konformationsänderung im Folgenden noch auf das SUMO-Bindemotiv eingegangen werden.

\section{Das SUMO-Bindemotiv}

Neben der stetig wachsenden Zahl sumoylierter Proteine rücken inzwischen vermehrt SUMO-bindende Proteine in den Fokus der Aufmerksamkeit. Ausgangspunkt dafür ist die Beobachtung, wonach auf Sumoylierung die Erkennung des modifizierten Proteins bzw. der entstandenen Domäne durch Bindeproteine folgt. Sequenzvergleiche verschiedener SUMO-bindender Proteine führten zu der Identifizierung eines SUMO-bindenden Aminosäuremotivs. Das für eine Erkennung von SUMO ursprünglich von Minty et al. $\left[{ }^{76}\right]$ vorgeschlagene SUMO-Bindemotiv wird im Wesentlichen durch die beiden Sequenzen [V/I]-x-[V/I]-[V/I] und [V/I]-[V/I]-x-[V/I/L] repräsentiert $\left[{ }^{77-79}\right]$.

Für eine Wechselwirkung zwischen SUMO und dem Bindeprotein kommen zum einen das gestreckte und hydrophobe SUMO-Bindemotiv und auf Seiten des SUMORestes die, zwischen $\alpha-H e l i x$ und $\beta$-Faltblatt eingebetteten hydrophoben und aromatischen Bereiche zum Tragen $\left[{ }^{80}\right]$. Nach wie vor unklar ist jedoch, wie Proteine mit einem SUMO-Bindemotiv einzelne SUMO-Isoformen unterscheiden können. Es bleibt abzuwarten, welche Schlüsse diesbezüglich aus zukünftigen Experimenten gezogen werden. 


\section{Ausgangssituation dieser Arbeit}

\section{Identifizierung von Eferin als Bindepartner von RanGAP1 im yeast two hybrid}

In einer yeast two hybrid-Interaktionsanalyse wurde mit der säugerspezifischen, c-terminalen Domäne von RanGAP1 (aus Mus musculus) nach möglichen Bindepartnern Ausschau gehalten (Abb. M). Die Hoffnung lag dabei auf der Identifikation neuer Zielproteine für die Sumoylierung durch Ubc9 und RanBP2 bzw. neuer Bindepartner zur Regulation des RanGTPase-Zyklus.
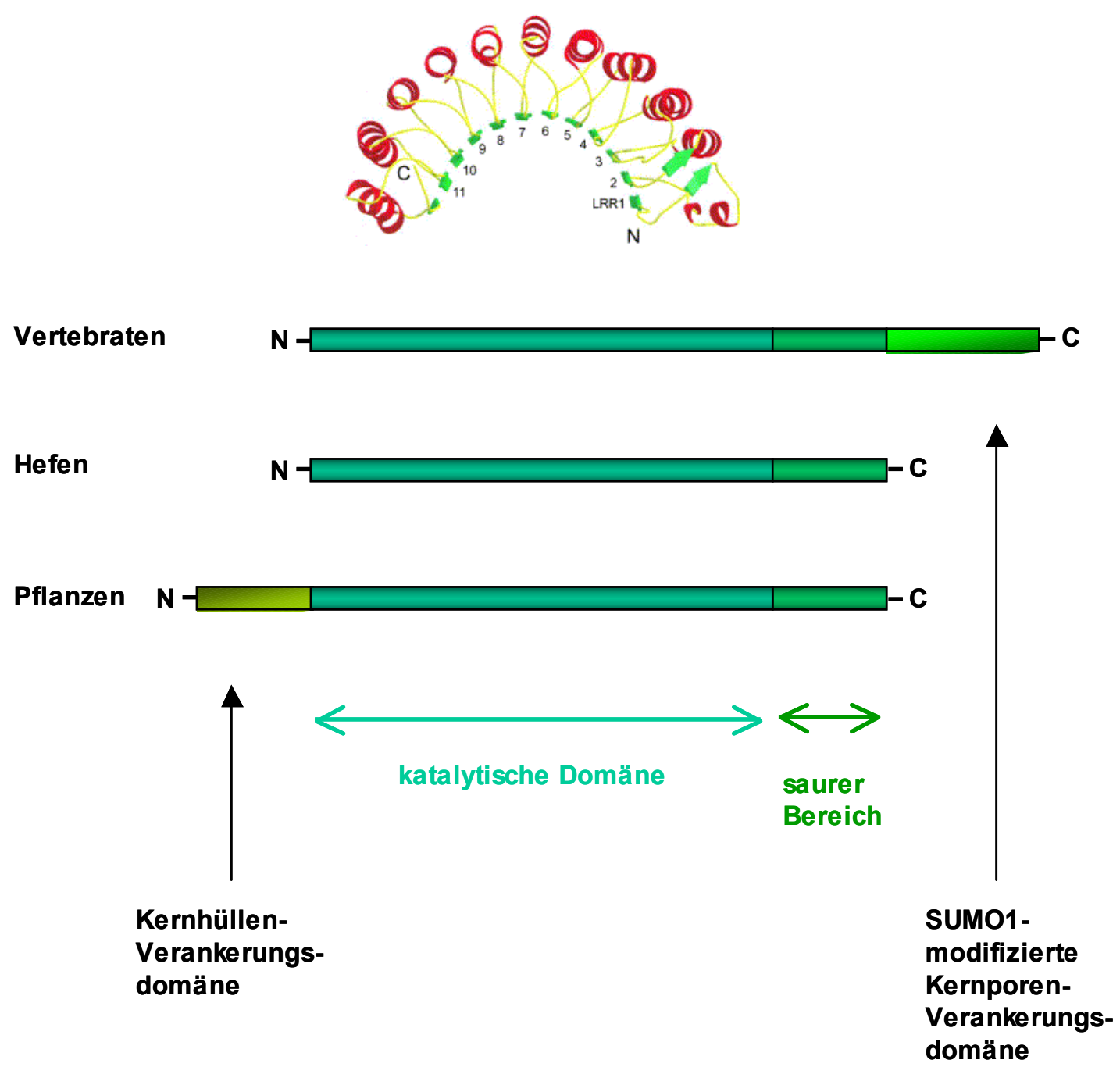

Abbildung M: Vergleich der Domänenorganisation des RanGAP ausgewählter Vertreter Alle Organismen weisen eine auffällige Konservierung der katalytischen Domäne und des daran anschließenden sauren Bereichs auf $\left[{ }^{39}\right]$; die Struktur der katalytischen Domäne des GAP aus Hillig et al. $\left[{ }^{81}\right]$; im Gegensatz zu Hefen weist das GAP in Pflanzen und Vertebraten eine eigene Verankerungsdomäne auf, die in Vertebraten zur Verankerung sumoyliert werden muss. 
In dieser Analyse wurde Ubc9 als bereits bekannter Bindepartner von RanGAP1 bestätigt und ein neuer, bislang spärlich beschriebener, Interaktionspartner mit Namen Eferin (als cDNA-Klon KIAA 0665 genannt $\left[{ }^{82}\right]$ ) gefunden. Die für diese Interaktion in RanGAP1 und Eferin nötigen Bindedomänen wurden von mir während der Diplomarbeit kartiert (siehe Abb. N; vergleiche Abb. O: grau unterlegte Domäne $=\mathrm{GAP}$ BD) $\left[{ }^{83}\right]$. Dabei zeigte sich, dass für die Wechselwirkung mit Eferin weder die Sumoylierung noch die Phosphorylierung von RanGAP1 an den bekannten Modifikationsstellen nötig ist.

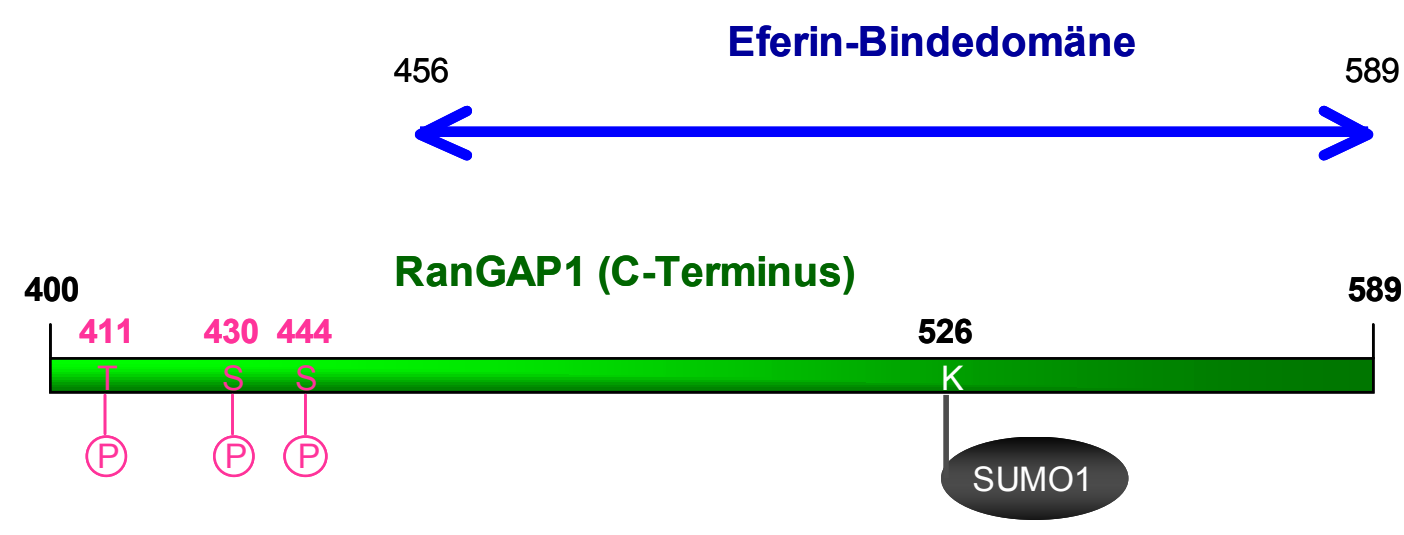

\section{Abbildung N: Interaktionsdomänen in RanGAP1}

Darstellung der minimalen Domäne von RanGAP1 (Mus musculus), die für die Interaktion mit Eferin und Ubc9 nötig ist $\left.{ }^{60}\right]$. Im C-Terminus von RanGAP1 sind die Positionen der posttranslationalen Modifikationen $\left[{ }^{84,85}\right]$ hervorgehoben ohne, dass diese für die jeweilige Interaktion von Nöten wären; modifizierte Abb. aus Kiendl $\left[{ }^{83}\right]$.

\section{Eferin}

Eferin steht als Akronym für EF-Hand containing Rab11 interacting protein. Damit wird der Fähigkeit Rechnung getragen mit Rab11 interagieren (und mittels EF-HandMotiv $\mathrm{Ca}^{2+}$ binden) zu können $\left[{ }^{86}\right]$. Weil neben Eferin mittlerweile fünf weitere, einander ähnliche Bindepartner von Rab11 identifiziert wurden, konnte daraus eine Familie Rab11-interagierender Proteine gebildet werden $\left[{ }^{86-89}\right]$. Grundeigenschaft dieser Familienmitglieder ist allein die Rab11-Bindedomäne (= Rab11 binding 
domain = RBD) $\left[{ }^{86}\right]$. Da Eferin das dritte Mitglied dieser Familie wurde, erhielt es den synonymen Namen Rab11-FIP3 (Rab11 family of interacting protein member \#3) und wurde wegen der nahen Verwandtschaft zu Rab11-FIP4 mit diesem einer eigenen Unterklasse zugeteilt ${ }^{89,90}$. Aufgrund der beschriebenen Wechselwirkung von Eferin und Rab11-FIP4 mit den GTPasen ARF 4, 5 und 6, wurde Eferin synonym Arfophilin1 und Rab11-FIP4 entsprechend Arfophilin2 genannt [ $\left.{ }^{91-93}\right]$.

\section{Domänenstruktur}

Innerhalb des C-Terminus von Eferin befinden sich sowohl Rab11-, ARF- als auch die RanGAP1-Bindedomäne [ ${ }^{83,86,92}$. Wie die Kartierungsergebnisse verdeutlichen (siehe Abb. O), überlappt die RanGAP1-Interaktionsdomäne (= GAP BD) nicht nur mit der ARF-Bindedomäne (= ARF BD), sondern auch mit der zweigeteilten coiled coil Domäne [ $\left.{ }^{89}, 92\right]$. Diese wird als Protein-Protein-Wechselwirkungsdomäne angesehen und zur Homo- und Heterodimerisierung genutzt $\left[{ }^{89}\right]$. Das EF-Hand-Motiv wurden bereits als $\mathrm{Ca}^{2+}$-Bindemotiv angesprochen. Daneben kann im Aminoterminus eine Prolin-reiche Domäne ausgemacht werden $\left[{ }^{87,90,92}\right.$ ], die eine sogenannte PESTSequenz enthält, welche ihrerseits mit Proteinabbau in Verbindung gebracht wird $\left[{ }^{94}\right]$.

\section{Homologie}

Als Homolog zu Eferin (und Rab11-FIP4) wurde in Drosophila melanogaster das Genprodukt Nuf (= nuclear fallout) ausgemacht $\left[{ }^{95}\right]$. Die Homologie zwischen Nuf und Eferin (und Rab11-FIP4) beschränkt sich im Wesentlichen auf den C-Terminus mit angenommenem coiled coil Bereich (Abb. O) [ $\left.{ }^{91}\right]$. Während früher Entwicklungsstadien bei Drosophila melanogaster trägt Nuf durch Umstrukturierung des AktinZytoskeletts und durch Wechselwirkung mit Rab11 letztlich entscheidend zur Bildung der Teilungsfurche bei [ ${ }^{96-98}$ ]. In diesem Zusammenhang ist eine Besonderheit von Nuf während der Mitose bemerkenswert. In Interphase befindet sich Nuf im Zytoplasma und reichert sich in Prophase an den Centrosomen an $\left[{ }^{99}\right]$. Da Nuf durch diese Lokalisation andere Proteine zur Teilungsfurche steuert, wurde bereits früh spekuliert, dass es dazu diene, Vesikel für die Bildung der Teilungsfurche auf die mitotischen Mikrotubuli zu laden $\left[{ }^{97}\right]$. 
nuclear fallout:

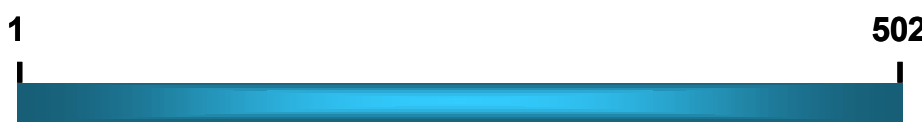

coiled coil

\section{Eferin:}

1

1549

756

Prolin-reiche Domäne $\quad$ EF EF

coiled coil

ARF BD

RBD

\section{GAP BD}

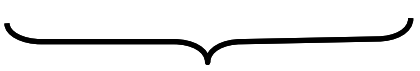

Eferin (c-term.)

Abbildung 0: Organisationsstruktur von nuclear fallout (= Nuf) und Eferin

Vorhergesagte oder beschriebene Domänen in Nuf und Eferin (EF = EF-Hand-Motiv; ARF-BD = ARFBindedomäne; RBD = Rab11-Bindedomäne; GAP-BD = RanGAP1-Bindedomäne); modifizierte Abb. aus Kiendl $\left.{ }^{83}\right]$.

\section{Mögliche Funktion in Interphase und Mitose}

Besonders gut untersucht ist die Interaktion von Eferin mit Rab11. Die GTPase Rab11 selbst gilt als Marker für recyclisierende Endosomen [ $\left.{ }^{100}\right]$, welche die Rückführung endozytierter Plasmamembran über Vesikeltransport in die Wege leitet. Da endosomale Vesikel als Membranreservoir für die Bildung der Teilungsfurche in Zytokinese dienen könnten [ $\left.{ }^{101}\right]$, wurde spekuliert, dass Eferin und Rab11 an diesem Prozess zur Bildung der Teilungsfurche beteiligt sind. Diese Hypothese wird auch dadurch gestützt, dass bei Drosophila Nuf und Rab11 in diesem Prozess involviert sind $\left[{ }^{96}\right]$. Für Eferin war bis zu Beginn dieser Arbeit lediglich eine Rab11-abhängige Lokalisation an den recyclisierenden Endosomen beschrieben [ ${ }^{87,90}$. Wie Vor- 
arbeiten von Dr. Andreas Gast zur Lokalisation von Eferin bislang zeigten, konnte Eferin nur in mitotischen Zellen und in diesen nur an den Centrosomen detektiert werden. Diese mitotische Lokalisation von Eferin überschnitt sich wiederum mit der berichteten centrosomalen Lokalisation von Nuf in Drosophila $\left[{ }^{99}\right]$.

\section{Aufgabenstellungen}

Ziel dieser Arbeit sollte zunächst sein, die im yeast two hybrid gefundene Interaktion zwischen RanGAP1 und Eferin in vivo (in Säugerzellen) zu bestätigen und die funktionelle Konsequenz dieser Interaktion zu untersuchen. Wie Ergebnisse der Kartierung der Interaktionsdomänen nahelegen (siehe Abb. N), sollte insbesondere überprüft werden, ob Ubc9 als möglicher Überbrückungsfaktor (= bridging factor) für die Interaktion zwischen RanGAP1 und Eferin fungiert. Des Weiteren sollte, da sich für Eferin in Mitose eine centrosomale Lokalisation gezeigt hatte, diese genauer untersucht und anschließend geklärt werden, wie eine mitotische Anreicherung von Eferin an Centrosomen zu Stande kommt. 


\section{Material und Methoden}

\section{Material}

\section{Technische Ausrüstung}

\section{Laborgeräte}

allgemeiner Laborbedarf

Schubert \& Weiss, München

Schütt Labortechnik, Göttingen

Einwegmaterial, Zentrifugen- und Zellkulturgefäße

Brand, Wertheim

B. Braun, Melsungen

Becton Dickinson, Heidelberg

Eppendorf, Hamburg

Greiner, Frickenhausen

Josef Peske, Aindling-Pichl

Nunc, Wiesbaden

Sarstedt, Nümbrecht

Zinsser Analytic, Frankfurt

Nunc, Wiesbaden

Corning, New York (USA)

Falcon, (USA)

Glaswaren

Schott, Mainz

Merck, Darmstadt

Roth, Karlsruhe

Hirschmann, Eberstadt

Pipetten

Gilson, Middleton (USA)

Eppendorf, Hamburg

Pipettierhilfe Pipettboy

Becton Dickinson, Heidelberg

Wasseraufbereitungsanlage Ultra Clear

Wasseraufbereiter Purelab Plus UV/UF

Digital-pH-Meter CG843

Waagen Delta Range PE 3600 und PC 4400

Feinwaage Extend

Tischautoklav Tuttnauer 3870 EL

$$
\text { SG, Barsbüttel }
$$

Seral, Ransbach-Baumbach

Schott, Mainz

Mettler-Toledo, Giessen

Sartorius, Göttingen

Systec, Wettenberg 
Beschallungsgerät Sonopuls HD2070

Bandelin, Berlin

Eismaschine

Ziegra, Isernhagen

Mischgerät Vortex Genie 2

Scientific, Bohemia (USA)

Wärmeblöcke

Zentralwerkstatt des MPI für Biochemie, Martinsried

Heizschüttelblock Thermomixer compact

Eppendorf, Hamburg

Gefrierschrank Premium no frost $\left(-20^{\circ} \mathrm{C}\right)$

Liebherr, Ochsenhausen

Tiefkühlschrank $-86^{\circ} \mathrm{C}$ Freezer $\left(-80^{\circ} \mathrm{C}\right)$

Forma Scientific, Marietta (USA)

Tiefkühlschrank HFU $86\left(-80^{\circ} \mathrm{C}\right)$

Heraeus, Hanau

Durchlichttisch

Schütt Laborbedarf, Göttingen

UV-Leuchttisch Herolab UVT 2020 (365 nm)

Herolab, Wiesloch

Photometer DU640

Beckman, München

Photometer BioPhotometer

Eppendorf, Hamburg

Netzgerät PowerPac200

Biorad, München

Netzgeräte EPS301 und EPS 300

GE Healthcare, München

Elektrophorese-Apparaturen Zentralwerkstatt des MPI für Biochemie, Martinsried

Biorad, München

Kühlzentrifuge J6MI

Beckman Coulter, München

Kühlzentrifuge Avanti J30I

Beckman Coulter, München

Kühlzentrifuge Allegra X-15R

Beckman Coulter, München

Ultrazentrifuge OptimaMax

Beckman Coulter, München

Rotoren JS 4.2, JA 30.50Ti, SX4750, TLA 100.3

Beckman Coulter, München

Tischzentrifuge Centrifuge 5415C

Eppendorf, Hamburg

Tischzentrifuge TOMY Capsulefuge

PolyLabo, Straßbourg (RF)

PCR Maschine Primus

MWG Biotech, Ebersberg

PCR Maschine GeneAmp PCR System 2400

Perkin Elmer, Norwalk (USA)

Bakterienbrutschrank Kelvitron t

Heraeus, Hanau

Schüttelinkubator Innova 4230

Sterilwerkbänke Hera safe

New Brunswick Scientific, Edison (USA)

Zellkulturinkubator Hera cell

Heraeus, Hanau

Zellkulturinkubator Incucell

Heraeus, Hanau

Rührsteuerung Variomag Biomodul 40B

MMM Medcenter, Planegg

Rührplatten Biosystem

$\mathrm{H}+\mathrm{P}$ Labortechnik, München

Probenkonzentrator SpeedVac Concentrator

H+P Labortechnik, München

Vakuumpumpe

Bachhofer, Reutlingen

Vacuubrand, Wertheim 
Chromatografiesystem Äkta Purifier

Fluoreszenzmikroskop Axioskop II

CCD-Kamera MicroMax

Dokumentationssystem LAS 3000

Dokumentationssystem Gel Jet Imager

Phospholmager BAS-2500

Zytometer FACS Calibur

Curix 60, Röntgenfilmentwickler

Scanner 4990 Photo

Scanner CanoScan LiDE25
GE Healthcare, München Carl Zeiss Microlmaging, Jena

Princeton Instruments, New Jersey (USA)

Fujifilm, Tokyo (Japan) Intas, Göttingen

Fujifilm, Tokyo (Japan)

Becton Dickinson, Heidelberg

Agfa, Köln

Epson, Meerbusch

Canon, Krefeld

\section{Computer}

Alle am Computer anfallenden Aufgaben wurde mit Hilfe von Maclntosh- oder Windows-Betriebssystem-basierenden Rechnern bewältigt. Die dazu verwendeten Auswertungsprogramme waren IPLab 3.5.5 (Becton Dickinson, Heidelberg), BioEdit 7.0.1 (Isis Pharmaceuticals, USA) sowie Motfit LT 3.0 (Verify Software House, USA).

\section{Chemikalien und Verbrauchsmaterial}

\section{Medien, Puffer, Lösungen}

Chemikalien wurden, sofern nicht anders vermerkt, in Analyse-Qualität von den Firmen Merck (Darmstadt), Sigma-Aldrich (Taufkirchen), Serva (Heidelberg) und Roth (Karlsruhe) bezogen. Zellkulturmedien und Medienzusätze stammten von Life Technologies (Karlsruhe), Invitrogen (Karlsruhe), Sigma-Aldrich (Taufkirchen), PAA (Cölbe) und Becton Dickinson (Heidelberg).

Solange nicht anders lautend, wurden alle Lösungen mit $\mathrm{H}_{2} \mathrm{O}$ als Lösungsmittel angesetzt und bei Raumtemperatur gelagert. Als $\mathrm{H}_{2} \mathrm{O}$ wird bei den angegebenen Rezepturen (über die Hausanlage) deionisiertes, nachfolgend durch eine Wasseraufbereitungsanlage filtriertes und nur für DNA-Anwendungen (PCR, Ligation, Aufnahme von DNA) zusätzlich autoklaviertes Wasser angesehen.

Dampfsterilisation wässriger Lösungen erfolgte im Autoklaven über 20 min bei $121^{\circ} \mathrm{C}$. Zur Einstellung des $\mathrm{pH}-$ Wertes diente $\mathrm{KOH}, \mathrm{NaOH}$, Essigsäure oder $\mathrm{HCl}$, 
wobei HEPES-Puffer stets mit $\mathrm{KOH}$, Tris-Puffer meist mit $\mathrm{HCl}$ eingestellt wurden. Abweichungen sind ansonsten jeweils vermerkt.

\section{Puffer}

TAE-Puffer:

$1 \mathrm{mM}$ EDTA, $40 \mathrm{mM}$ Tris-Acetat $\mathrm{pH}$ 7,7

TE-Puffer:

$1 \mathrm{mM}$ EDTA, $10 \mathrm{mM}$ Tris- $\mathrm{HCl} \mathrm{pH}$ 8,0 und autoklaviert

LB-Medium (flüssig):

$1,0 \%(w / v)$ Bactotrypton, $0,5 \%$ (w/v) Hefeextrakt (= selected yeast extract), $1,0 \%(\mathrm{w} / \mathrm{v}) \mathrm{NaCl}, \mathrm{pH} 7,0$ mit $\mathrm{NaOH}$ eingestellt und autoklaviert

LB-Selektionsmedium (fest): 1,0\% (w/v) Bactotrypton, 0,5\% (w/v) Hefeextrakt, $1,0 \%(\mathrm{w} / \mathrm{v}) \mathrm{NaCl}, \mathrm{pH} 7,0$ mit $\mathrm{NaOH}$ eingestellt, $1,5 \%(w / v)$ Agar-Agar (=Bacto-Agar); nach dem Autoklavieren Zugabe von 60 mg Kanamycin bzw. Chloramphenicol oder $100 \mu \mathrm{g}$ Ampicillin pro ml Medium, steriler Plattenguss, Lagerung bei $4^{\circ} \mathrm{C}$

PBS-Puffer: $140 \mathrm{mM} \mathrm{NaCl}, 2,7 \mathrm{mM} \mathrm{KCl}, 10 \mathrm{mM} \mathrm{Na}_{2} \mathrm{HPO}_{4}$, 1,8 $\mathrm{mM} \mathrm{KH}_{2} \mathrm{PO}_{4}, \mathrm{pH} 7,5$ eingestellt mit $\mathrm{NaOH}$

Transportpuffer: 110 mM Kaliumacetat, 2mM Magnesiumacetat, 1 mM EGTA, 20mM HEPES pH 7,3

Carbonatpuffer: $0,2 \mathrm{M} \mathrm{Na}_{2} \mathrm{CO}_{3}, \mathrm{pH} 8.9$ mit $\mathrm{HCl}$ eingestellt PBST: $0,2 \%(v / v)$ Tween-20 in PBS 
SDS-Probenpuffer:

\begin{tabular}{|c|c|c|c|}
\hline Endkonzentration & $\mathbf{1 x}$ & $\mathbf{2 x}$ & $\mathbf{4 x}$ \\
\hline Tris pH 6,8 & $50 \mathrm{mM}$ & $100 \mathrm{mM}$ & $200 \mathrm{mM}$ \\
\hline SDS (w/v) & $2 \%$ & $4 \%$ & $8 \%$ \\
\hline Bromphenolblau (w/v) & $0,1 \%$ & $0,2 \%$ & $0,4 \%$ \\
\hline Glycerol (v/v) & $10 \%$ & $20 \%$ & $40 \%$ \\
\hline DTT & $100 \mathrm{mM}$ & $200 \mathrm{mM}$ & $400 \mathrm{mM}$ \\
\hline
\end{tabular}

SDS-Polyacrylamid-Gele:

1. Zusammensetzung des Trenngels:

\begin{tabular}{|c|c|c|c|c|c|c|}
\hline Polyacrylamid-Gehalt & $5 \%$ & $6 \%$ & $8 \%$ & $10 \%$ & $15 \%$ & $20 \%$ \\
\hline $\mathrm{H}_{2} \mathrm{O}$ & $42,9 \mathrm{ml}$ & $40,7 \mathrm{ml}$ & $36,0 \mathrm{ml}$ & $31,3 \mathrm{ml}$ & $19,6 \mathrm{ml}$ & $7,9 \mathrm{ml}$ \\
\hline $2 \mathrm{M}$ Tris pH 8,8 & $14,0 \mathrm{ml}$ & $14,0 \mathrm{ml}$ & $14,0 \mathrm{ml}$ & $14,0 \mathrm{ml}$ & $14,0 \mathrm{ml}$ & $14,0 \mathrm{ml}$ \\
\hline $\begin{array}{c}\text { Acrylamid : Bis-Acrylamid } \\
(30: 0,8)\end{array}$ & $11,7 \mathrm{ml}$ & $14,0 \mathrm{ml}$ & $18,7 \mathrm{ml}$ & $23,3 \mathrm{ml}$ & $35,0 \mathrm{ml}$ & $46,7 \mathrm{ml}$ \\
\hline $20 \%(w / v)$ SDS & $350 \mu \mathrm{l}$ & $350 \mu \mathrm{l}$ & $350 \mu \mathrm{l}$ & $350 \mu \mathrm{l}$ & $350 \mu \mathrm{l}$ & $350 \mu \mathrm{l}$ \\
\hline $10 \%(w / v)$ APS & $700 \mu \mathrm{l}$ & $700 \mu \mathrm{l}$ & $700 \mu \mathrm{l}$ & $700 \mu \mathrm{l}$ & $700 \mu \mathrm{l}$ & $700 \mu \mathrm{l}$ \\
\hline TEMED $100 \%$ & $70 \mu \mathrm{l}$ & $70 \mu \mathrm{l}$ & $70 \mu \mathrm{l}$ & $70 \mu \mathrm{l}$ & $70 \mu \mathrm{l}$ & $70 \mu \mathrm{l}$ \\
\hline
\end{tabular}

2. Zusammensetzung des $4 \%$ igen Sammelgels: $0,1 \%(w / v)$ SDS, 0,1\% (w/v) APS, 0,1\% (v/v) TEMED, 4\% (w/v) Acrylamid, $0,1 \%(w / v)$ Bis-Acrylamid, $50 \mathrm{mM}$ Tris- $\mathrm{HCl} \mathrm{pH}$ 6,8 


\section{Lösungen}

Stocklösungen (bei $-80^{\circ} \mathrm{C}$ gelagert):

GDP: $\quad 50 \mathrm{mM}$ GDP, $50 \mathrm{mM}$ Magnesiumacetat, $50 \mathrm{mM}$ HEPES pH 7,4 GTP: $\quad 50 \mathrm{mM}$ GTP, $50 \mathrm{mM}$ Magnesiumacetat, $50 \mathrm{mM}$ HEPES pH 7,4

Stocklösungen (bei $-20^{\circ} \mathrm{C}$ gelagert):

APS:

$10 \%(w / v)$ in $\mathrm{H}_{2} \mathrm{O}$

ATP: $100 \mathrm{mM}$ in $100 \mathrm{mM}$ Magnesiumacetat, 20 mM HEPES pH 7,4

Taxol: $10 \mathrm{mM}$ in $100 \%(\mathrm{v} / \mathrm{v})$ DMSO

Nocodazol: $25 \mathrm{mM}$ in 100\% (v/v) DMSO

Thymidin: $200 \mathrm{mM}$ in sterilem PBS

Digitonin: $10 \%(w / v)$ Digitonin in $100 \%(v / v)$ DMSO

IPTG-Stocklösung: 1M IPTG in $\mathrm{H}_{2} \mathrm{O}$, sterilfiltriert

Ampicillin: $100 \mathrm{mg} / \mathrm{ml} \mathrm{H}_{2} \mathrm{O}$

Kanamycin: $60 \mathrm{mg} / \mathrm{ml} \mathrm{H}_{2} \mathrm{O}$

Chloramphenicol: $60 \mathrm{mg} / \mathrm{ml} \mathrm{H}_{2} \mathrm{O}$ Aprotinin: $1 \mathrm{mg} / \mathrm{ml} 20 \mathrm{mM}$ HEPES pH 7,4

Leupeptin: $1 \mathrm{mg} / \mathrm{ml}$ 100\% (v/v) DMSO Pepstatin A: $1 \mathrm{mg} / \mathrm{ml}$ 100\% (v/v) DMSO PEFA: $100 \mathrm{mM}$ in $\mathrm{H}_{2} \mathrm{O}$ PMSF: $100 \mathrm{mM}$ in $100 \%$ (v/v) Propan-2-ol MG132: $10 \mathrm{mM}$ in $100 \%(\mathrm{v} / \mathrm{v})$ DMSO

\section{Komplexe Reagenzien und Reaktionssets (= Kits)}

Sequenziermix BigDyeTerminator v1.1

Desoxynukleotid-Set (10 mM dNTP-Mix)

Polyfect, Transfektions-Reagenz

Oligofectamin, Transfektionsreagenz

Adjuvant TiterMax Gold

Freund's Adjuvant, incomplete

Eindeckmedium MobiGlow

Eindeckmedium Cytomation Fluorescent Mounting Medium
Applied Biosystems, Foster City (USA) MBI Fermentas, St.Leon-Rot Qiagen, Hilden Invitrogen, Karlsruhe Sigma-Aldrich, Taufkirchen Sigma-Aldrich, Taufkirchen MoBiTec, Göttingen

Dako, Hamburg 
BCA und Micro BCA Protein Assay Reagent Kit

Pierce, Rockford (USA)

HiSpeed Plasmid Midi Kit

Qiagen, Hilden

QIAquick PCR Purification Kit

Qiagen, Hilden

QIAquick Gel Extraction Kit

Qiagen, Hilden

Rotiphorese Gel 30

Roth, Karlsruhe

Chemolumineszenzsubstrat Super Signal West Femto

Pierce, Rockford (USA)

Chemolumineszenzsubstrat Super Signal West Pico

Chemolumineszenzsubstrat Immobilon Western

Pierce, Rockford (USA)

Millipore, Eschborn

Phosphatase Inhibitor Cocktail 2

Sigma-Aldrich, Taufkirchen

\section{Molekulargewichtsstandard (Protein-Größenstandard)}

BenchMark Protein Ladder

Life Technologies, Karlsruhe

Prestained Protein Marker

Bio-Rad, München

\section{Längenstandards DNA}

GeneRuler $1 \mathrm{~kb}$ Ladder Plus

MBI Fermentas, St. Leon-Rot

GeneRuler 100 bp Ladder Plus

MBI Fermentas, St. Leon-Rot

\section{Westernblot-Material}

Nitrocellulose-Transfermembran Protran

Whatman, Dassel

Filterpapier 3 MM Whatman

Whatman, Dassel

\section{Röntgenfilme}

Es wurden Röntgenfilme BioMax MS, BioMax MR der Firma Kodak (Stuttgart) und Hyperfilm ECL von GE Healthcare (München) eingesetzt.

\section{Materialien zur Filtration und Dialyse}

Zentrifugationsfiltereinheiten Centricon 5, 10 und 30

Millipore, Eschborn

Zentrifugationsfiltereinheiten Vivaspin 5, 10 und 30

Vivascience, Hannover

Sterilfilter $(0,22-0,45 \mu \mathrm{m})$

Pall, Dreieich 
Millipore, Eschborn

Renner, Dannstadt

Sterilfiltermembran

Dialyseschläuche Spectra-Por

Mehrweg-Chromatografiesäulen

Leersäulen Bio-spin, Poly-Prep und Econo-pac

Filtersäulen Costar

Filtersäulen Ultrafree MC
Sartorius, Göttingen

Millipore, Eschborn

Roth, Karlsruhe

Sigma-Aldrich, Taufkirchen

Biorad, München

Corning, New York (USA)

Millipore, Eschborn

\section{Chromatografische Matrices und fertig gepackte Chromatografiesäulen}

ProBond Nickel-Chelating Resin

DEAE-Sepharose fast flow

Q-Sepharose fast flow

Cyanogenbromid-aktivierte Sepharose 4B

UltraLink immobilized Protein G Sepharose

Protein G Agarose

HiLoad Superdex 200 HR 26/60

HiLoad Superdex 75 HR 10/30

NAP 5 Entsalzungssäulen

AutoSeq G-50

Dünnschichtchromatografie-Platten PEI Cellulose F
Invitrogen, Karlsruhe GE Healthcare, München Sigma-Aldrich, Taufkirchen Sigma-Aldrich, Taufkirchen Pierce, Rockford (USA) Roche, Mannheim GE Healthcare, München GE Healthcare, München GE Healthcare, München GE Healthcare, München Merck, Darmstadt

\section{Enzyme, Primer, Plasmide und rekombinante Proteine}

\section{Enzyme}

Enzyme sowie dazugehörige Reaktionspuffer wurden von den Firmen New England Biolabs (Schwalbach/Taunus), MBI Fermentas (St. Leon-Rot), Merck (Darmstadt), Promega (Mannheim), Qiagen (Hilden), Roche (Mannheim) und Stratagene (Heidelberg) bezogen. Sofern nicht anders angegeben, wurden die vom Hersteller angegebenen Reaktionsbedingungen gewählt. 


\section{DNA-Oligonukleotide für PCR und RNA-Oligonukleotide für RNAi}

Alle genannten DNA-Oligonukleotide wurden von Sigma-Aldrich (Taufkirchen), MWG-Biotech (Ebersberg) und Metabion (Martinsried) oder aus der Syntheseabteilung der Arbeitsgruppe Oesterhelt (MPI für Biochemie, Martinsried) bezogen. Nach Erhalt der Oligonukleotide wurden selbige katalogisiert, als Aliquote mit einer Konzentration von $10 \mathrm{pmol} / \mu \mathrm{l}$ eingestellt und wie die Originalstocks bei $-20^{\circ} \mathrm{C}$ bis zur weiteren Verwendung weggefroren.

RNA-Oligonukleotide wurden von Dharmacon (USA) bezogen und nach Hybridisierung als Aliquote mit einer Konzentration von $50 \mu \mathrm{M}$ bei $-20^{\circ} \mathrm{C}$ gelagert.

\section{RNA-Oligonukleotide für RNA-Interferenz-Anwendungen (= RNAi-Oligo)}

scrambled RNAi \#1.1:

scrambled RNAi \#1.2:

RNAi Oligo KIAA 5.1:

RNAi Oligo KIAA 5.2:

RNAi Oligo KIAA 6.1:

RNAi Oligo KIAA 6.2:
UAGCGACUAAACACAUCAAUU

AAUUGAUGUGUUUAGUCGCUA CUGGCCAUCAGGAUCUCCG CGGAGAUCCUGAUGGCCAG GAGCCUCUUCUCCACAGCC GGCUGUGGAGAAGAGGCUC

DNA-Oligonukleotide zur Fragment-Amplifikation und Plasmid-Sequenzierung \#030 SP6 Promotor GATTTAGGTGACACTATAG \#099 T3 Promotor ATTAACCCTCACTAAAGGGA \#112 T7 Promotor TAATACGACTCACTATAGGG \#244 KIAA 3' EcoR I CGGAATTCAGGCTGGACCTTCCTG \#304 KIAA Seq. aa573 GCTTCTGCTTCTCCTCC \#305 KIAA Seq. aa151 GCCACCGAGCGCGGGGCG \#313 KIAA Seq. aa518 GCCGGGTCTCTTCCAGGAC \#314 KIAA Seq. aa234 GGGGCAGAGCAGGTGAAGG \#343 KIAA Seq. aa84 CCCGGGCCGTCCGCCCC \#344 KIAA Seq. aa666 CCTGCTTCAGCCTGCGGACC \#608 T7 Terminator GCTAGTTATTGCTCAGCGG \#660 pE-gcyFP-N1 Seq. CACCATGGTGGCGACCGGTGG \#661 KIAA full 5' Xhol TCTCGAGGCATGGCGTCGGCCCCGCCGGCC 
\#662 KIAA $\triangle \mathrm{N} 5^{\prime}$ Xhol \#663 KIAA full length \#664 KIAADRabBD 3' \#665 KIAADGAPBD 3' \#667 KIAA pure GAP-BD \#683 KIAADARFBD 3' \#684 KIAA Xhol \#688 $\mathrm{CMV}_{\mathrm{P}}$ \#696 KIAA pETM-11 Nco I \#697 KIAA pETM-11 Xho I \#698 KIAA Seq. aa367 \#699 KIAA 5' BamHI \#767 Seq KIAA aa653 \#768 Seq. KIAA aa167
CCTCGAGGGATGCAGCAACTGGACGAGGAGAACAGT CAGAATTCGCTTGACCTCCAGGATGGACGG GAGAATTCGAGAGAAGGCTGTGGAGAAG CAGAATTCGTAGCCTGGTCTGCAGGTTCTCGA CAGAATTCGGCGGCCCCGCCGCTGCTCGGC

CAGAATTCGCTGGTGCCTCTCGTGACTCAG GCCTTCTCGAGGCATGGCGTCGGCCCCGCCGGCC ACGGTGGGAGGTCTATATAAGC CGATTTGCCTCTCGGGGCCATGGCGTCGGCC CACCTCGAGGTCGACGGTATCGATAAGCTTG CCCCTTCAGGTTGCAGCTCAGGGTGC CTAAGTACTTGGATCCCAGTGGGC CGCGCCCGGGAGAGCGAGCTGGAGCAGG CTCCAGCGCCAGCTCGCCCGCCGTG

\section{Plasmide und gestellte Plasmidkonstrukte}

Prokaryotische Expressionsvektoren

\begin{tabular}{|l|l|l|}
\hline Bezeichnung & Besonderheit & Herkunft \\
\hline pETM11 & $\begin{array}{l}\text { His-Epitop entfernbar durch } \\
\text { TEV-Proteaseverdau }\end{array}$ & $\begin{array}{l}\text { Markus Rudolph, Abteilung } \\
\text { Ficner, Universität Göttingen }\end{array}$ \\
\hline pBluescript II KS (+) & LacZ-Gen & Stratagene, Heidelberg \\
\hline pCR blunt II TOPO & Vektor für TOPO-Klonierung & Invitrogen, Karlsruhe \\
\hline
\end{tabular}

Eukaryotische Expressionsvektoren

\begin{tabular}{|l|l|l|}
\hline Bezeichnung & Besonderheit & Herkunft \\
\hline pEYFP-C1 & n-terminales YFP-Fusionsepitop & CLONTECH, Heidelberg \\
\hline pEYFP-N1 & c-terminales YFP-Fusionsepitop & CLONTECH, Heidelberg \\
\hline pACT2 & Gal4-Aktivierungsdomäne & CLONTECH, Heidelberg \\
\hline
\end{tabular}


gestellte prokaryotische Expressionsvektoren

\begin{tabular}{|l|l|l|}
\hline Bezeichnung & Besonderheit & Herkunft \\
\hline pET28a-Eferin & $\begin{array}{l}\text { His-Eferin aa 1 - 756 } \\
\text { (human) }\end{array}$ & $\begin{array}{l}\text { Andreas Gast } \\
\text { AG Melchior }\end{array}$ \\
\hline pET28a-Eferin $\Delta \mathrm{C}$ & $\begin{array}{l}\text { His-Eferin } \mathrm{C} \text { aa 1 - 434 } \\
\text { (human) }\end{array}$ & Frauke Melchior \\
\hline pET11d-Ran & Ran (human) & Frauke Melchior \\
\hline pET11d-RanGAP1-WT & $\begin{array}{l}\text { RanGAP (murin) } \\
\text { Wildtyp }\end{array}$ & $\begin{array}{l}\text { Sowmya Swaminathan, } \\
\text { AG Melchior }\end{array}$ \\
\hline pET11d-RanGAP1-AAA & $\begin{array}{l}\text { RanGAP (murin) } \\
\text { T411A/S430A/S444A }\end{array}$ & $\begin{array}{l}\text { Sowmya Swaminathan, } \\
\text { AG Melchior }\end{array}$ \\
\hline pET11d-RanGAP1-EEE & $\begin{array}{l}\text { RanGAP (murin) } \\
\text { T411E/S430E/S444E }\end{array}$ & $\begin{array}{l}\text { Sowmya Swaminathan, } \\
\text { AG Melchior }\end{array}$ \\
\hline pET23a-RanGAP1 & $\begin{array}{l}\text { RanGAP (human) } \\
\text { Wildtyp }\end{array}$ & $\begin{array}{l}\text { Annette Flotho, } \\
\text { AG Melchior }\end{array}$ \\
\hline
\end{tabular}

\section{Rekombinante Proteine}

Die meisten der gereinigte Proteine wurden von Kollegen der Arbeitsgruppe zur Verfügung gestellt. Weitere rekombinante Proteine wurden von mir nach bereits etablierten oder eigens entworfenen Methoden aufgereinigt.

\begin{tabular}{|l|l|}
\hline Protein & Aufreinigungsprotokoll / Herkunft \\
\hline His-Aos1 / Uba2 & Pichler et al. $\left[{ }^{67,102}\right]$ \\
\hline Ubc9 & Pichler et al. $\left[{ }^{67,}{ }^{102}\right]$ \\
\hline SUMO1 & Pichler et al. $\left[{ }^{67,},{ }^{102}\right]$ \\
\hline RanBP2 $\Delta F G$ & Pichler et al. $\left[{ }^{67}\right]$ \\
\hline PIAS $(1,3, \times \alpha \times \beta)$ & Marilyn Tirard \\
\hline RanGAP1 & siehe Methoden $\left[{ }^{18}\right]$ \\
\hline GST-p53 & Andreas Gast \\
\hline His-Eferin & siehe Methoden \\
\hline His-Eferin $\Delta$ C & siehe Methoden \\
\hline GST-Eferin $\Delta N$ & Andreas Gast \\
\hline His-TEV-Protease & siehe Methoden \\
\hline Ran & siehe Methoden $\left[{ }^{103}\right]$ \\
\hline Ubiquitin & Sigma-Aldrich, Taufkirchen \\
\hline
\end{tabular}




\section{Bakterienstämme}

Escherichia coli Stamm DH5a (Invitrogen): F- Ф80lacZC $\triangle$ (lacZYA-argF)U169 deoR recA1 endA1 hsdR17 (rK-mK+) supE44 $\lambda$ thi-1 gyrA96 relA1

Escherichia coli Stamm TOP10 (Invitrogen): F- mcrA $\Delta$ (mrr-hsdRMS-mcrBC) Ф80lacZ $\Delta$ M15 $\Delta$ lacX74 recA1 deoR araD139 $\Delta$ (ara-leu)7697 galU galK rpsL $\left(\mathrm{Str}^{\mathrm{R}}\right)$ endA1 nupG

Epicurian coli Stamm B BL21(DE3) (Stratagene): F- dcm ompT hsdS(rB-mB-) gal $\lambda \mathrm{DE} 3$

Epicurian coli Stamm BL21(DE3) CODONplus(Stratagene): argU, ileY, leuW, proL tRNA genes

Escherichia coli Stamm B (DE3) Rosetta (Novagen): F- ompT hsdS $\mathrm{B}_{\mathrm{B}}\left(\mathrm{r}_{\mathrm{B}^{-}} \mathrm{m}_{\mathrm{B}^{-}}\right)$gal dcmlacY1(DE3) pRARE $\left(\mathrm{Cm}^{\mathrm{R}}\right)$

\section{Eukaryotische Zelllinien (Linie, Eigenheit, Abstammung, Herkunft)}

\section{Menschlichen Ursprungs:}

K562, in Suspension wachsend, chronische, myeloide Leukämiezellen

Raji, in Suspension wachsend, Burkitt-Lymphomzellen

HL60, in Suspension wachsend, akute, myeloide Leukämiezellen

Jurkat, in Suspension wachsend, akute, lymphoblastische Leukämiezellen

HeLa, in Suspension wachsend, Cervix-Adenokarzinomzellen

HeLa, adhärent wachsend, Cervix-Adenokarzinomzellen

HEK293, adhärent wachsend, embryonale Nierenzellen

MCF7, adhärent wachsend, Brust-Adenokarzinomzellen

293T, adhärent wachsend, HEK293 mit dem T-Antigen des SV-40 Virus transformiert

\section{Weitere Säugerzellen:}

Cos7, adhärent wachsend, Nierenzellen von Cercopithecus aethiops

NIH3T3, adhärent wachsend, embryonale Fibroblasten von Mus musculus

Rat1, adhärent wachsend, Fibroblasten von Rattus norvegicus

NB, adhärent wachsend, Neuroblastomzellen von Mus musculus 


\section{Antikörper}

\section{Primäre Antikörper}

\begin{tabular}{|c|c|c|c|c|}
\hline Bezeichnung & erkanntes Antigen & Spezies & $\begin{array}{l}\text { eingesetzte } \\
\text { Verdünnung } \\
\text { a) WB, b) IF }\end{array}$ & $\begin{array}{l}\text { Herkunft / } \\
\text { Aufreinigung }\end{array}$ \\
\hline anti-GFP & GFP und YFP-Epitop & Kaninchen & a) $1: 5.000$ & Santa Cruz, Heidelberg \\
\hline $\begin{array}{l}\text { anti-p53 } \\
\text { (DO-1) }\end{array}$ & p53 (humanes) & Maus & a) $1: 1.000$ & Santa Cruz, Heidelberg \\
\hline anti-Ubc9 & Ubc9 (humanes) & Ziege & a) $1: 1.000$ & $\begin{array}{l}\text { Andrea Pichler, } \\
\text { AG Frauke Melchior }\end{array}$ \\
\hline anti-Eferin & $\begin{array}{l}\text { His-Eferin (aa } 1 \text { - 756; } \\
\text { humanes) }\end{array}$ & Kaninchen & $\begin{array}{l}\text { a) } 1: 1.000 \\
\text { b) } 1: 100\end{array}$ & $\begin{array}{l}\text { Andreas Gast, } \\
\text { AG Frauke Melchior }\end{array}$ \\
\hline anti-Eferin $\Delta \mathrm{C}$ & $\begin{array}{l}\text { His-Eferin } \Delta C \\
\text { (aa } 1-434 ; \text { humanes) }\end{array}$ & Ziege & $\begin{array}{l}\text { a) } 1: 1.000 \\
\text { b) } 1: 100\end{array}$ & $\begin{array}{l}\text { selbst, diese Arbeit } \\
\text { AG Frauke Melchior }\end{array}$ \\
\hline anti- $\beta$-Tubulin & $\beta$-Tubulin & Kaninchen & $\begin{array}{l}\text { a) } 1: 1.000 \\
\text { b) } 1: 100\end{array}$ & Santa Cruz, Heidelberg \\
\hline $\begin{array}{l}\text { anti-y-Tubulin } \\
\text { (GTU-88) }\end{array}$ & $\mathrm{y}$-Tubulin & Maus & $\begin{array}{l}\text { a) } 1: 5.000 \\
\text { b) } 1: 500\end{array}$ & $\begin{array}{l}\text { Sigma-Aldrich, } \\
\text { Taufkirchen }\end{array}$ \\
\hline $\begin{array}{l}\text { anti-Rab11 } \\
\text { (Klon 47) }\end{array}$ & Rab11 (aa 88 - 207) & Maus & a) $1: 1.000$ & $\begin{array}{l}\text { Becton Dickinson, } \\
\text { Heidelberg }\end{array}$ \\
\hline anti-BP2 & RanBP2 $\Delta F G$ & Ziege & a) $1: 500$ & $\begin{array}{l}\text { Jenny Vordemann, } \\
\text { AG Frauke Melchior }\end{array}$ \\
\hline anti-RanGAP & RanGAP1 (murines) & Ziege & $\begin{array}{l}\text { a) } 1: 6.000 \\
\text { b) } 1: 500\end{array}$ & $\begin{array}{l}\text { Annette Flotho, } \\
\text { AG Frauke Melchior }\end{array}$ \\
\hline
\end{tabular}

\section{Sekundäre Antikörper}

\begin{tabular}{|c|c|c|c|c|}
\hline Bezeichnung & gekoppelt mit & Spezies & $\begin{array}{l}\text { eingesetzte Verdünnung } \\
\text { a) WB, b) IF }\end{array}$ & Herkunft \\
\hline anti-mouse $\lg G,(\mathrm{H}+\mathrm{L})$ & Peroxidase & Ziege & a) $1: 10.000$ & $\begin{array}{l}\text { Dianova, } \\
\text { Hamburg }\end{array}$ \\
\hline anti-rabbit $\lg G,(\mathrm{H}+\mathrm{L})$ & Peroxidase & Ziege & a) $1: 10.000$ & $\begin{array}{l}\text { Dianova, } \\
\text { Hamburg }\end{array}$ \\
\hline anti-goat IgG, $(\mathrm{H}+\mathrm{L})$ & Peroxidase & Esel & a) $1: 10.000$ & $\begin{array}{l}\text { Dianova, } \\
\text { Hamburg }\end{array}$ \\
\hline anti-mouse $\lg G,(H+L)$ & Cу 3 & Esel & b) $1: 500$ & $\begin{array}{l}\text { Dianova, } \\
\text { Hamburg }\end{array}$ \\
\hline anti-rabbit lgG, $(\mathrm{H}+\mathrm{L})$ & Cу 3 & Esel & b) $1: 500$ & $\begin{array}{l}\text { Dianova, } \\
\text { Hamburg }\end{array}$ \\
\hline anti-goat IgG, $(\mathrm{H}+\mathrm{L})$ & Alexa Fluor 488 & Esel & b) $1: 500$ & $\begin{array}{l}\text { MoBiTec, } \\
\text { Göttingen }\end{array}$ \\
\hline anti-rabbit $\lg G,(\mathrm{H}+\mathrm{L})$ & Alexa Fluor 488 & Esel & b) $1: 500$ & $\begin{array}{l}\text { MoBiTec, } \\
\text { Göttingen }\end{array}$ \\
\hline anti-goat IgG, $(\mathrm{H}+\mathrm{L})$ & Alexa Fluor 594 & Esel & b) $1: 500$ & $\begin{array}{l}\text { MoBiTec, } \\
\text { Göttingen }\end{array}$ \\
\hline
\end{tabular}




\section{Methoden}

Alle angewandten Methoden wurden, sofern nicht eigens aufgeführt, nach gängigen Protokollen aus Current Protocols in Molecular Biology von F.M. Ausubel et al., Current Protocols in Protein Science von J.E. Coligan et al. und Current Protocols in Cell Biology von J.S. Bonifacino et al. (alle erschienen bei John Wiley \& Sons, New York) durchgeführt.

\section{Molekularbiologische Methoden}

\section{Präparation von Plasmid-DNA}

Das Protokoll zur Isolierung plasmidischer DNA basiert auf der von Birnboim und Doly [ ${ }^{104,105}$ ] entwickelten Methode, der alkalischen Lyse.

Zur Präparation kleiner Mengen Plasmid-DNA aus E. coli wurde 3 ml LB-Selektionsmedium mit einer einzelnen Bakterienkolonie von entsprechender LB-Selektionsplatte beimpft und über Nacht bei $37^{\circ} \mathrm{C}$ geschüttelt. Die Kultur wurde für 5 min bei $4500 \mathrm{~g}$ zentrifugiert, das Bakterien-Pellet in $300 \mu \mathrm{l} 4^{\circ} \mathrm{C}$ kaltem Puffer P1 (10 mM EDTA, $100 \mu \mathrm{g} / \mathrm{ml}$ RNase A, $50 \mathrm{mM}$ Tris- $\mathrm{HCl}$ pH 8,0) resuspendiert. Nach Zugabe von $300 \mu \mathrm{l}$ alkalischer Lösung P2 (200 mM NaOH, 1\% (w/v) SDS) wurde das Gemisch einige Male vorsichtig invertiert und 5 min bei Raumtemperatur inkubiert. Anschließend wurde $300 \mu$ l eisgekühlter Puffer P3 (3 M Kaliumacetat pH 5,5) zugegeben, der Ansatz durch vorsichtiges Invertieren gemischt und 10 min auf Eis gehalten. Die ausfallenden Proteine, das präzipitierende Kaliumdodecylsulfat und die unlösliche chromosomale Bakterien-DNA wurden durch Zentrifugation für 20 min bei $4^{\circ} \mathrm{C}$ und $15.000 \mathrm{~g}$ pelletiert und entfernt. Die lösliche Plasmid-DNA wurde mit dem 0,8-fachen Volumen reinem Propan-2-ol, über Entzug gebundenem Wassers, aus dem Überstand gefällt und durch Zentrifugation sedimentiert. Zur Entfernung von verbliebenem Propan-2-ol und Salzresten wurde die DNA mit $800 \mu$ l 70\% (v/v) Ethanol gewaschen und über 10 min bei $15.000 \mathrm{~g}$ zentrifugiert, der Überstand verworfen und das DNA-Pellet an der Luft getrocknet. Die aufgereinigte DNA wurde schließlich in $50 \mu \mathrm{H}_{2} \mathrm{O}$ oder TE-Puffer gelöst.

Zur Isolierung größerer Mengen reiner Plasmid-DNA wurde der HiSpeed Plasmid Midi-Kit von Qiagen eingesetzt. Alle erforderlichen Inkubations- und Zentrifugations- 
schritte wurden nach dem Protokoll der Firma Qiagen durchgeführt. Fällung mit Propan-2-ol und Ethanolwaschschritt erfolgten nach dem Herstellerprotokoll, nach Lufttrocknung wurde die DNA in sterilen $\mathrm{H}_{2} \mathrm{O}$ oder endotoxinfreiem TE-Puffer (Qiagen) zurückgelöst und konnte zur Transformation von Säugerzellen eingesetzt werden. Plasmid-DNA wurde stets bei $-20^{\circ} \mathrm{C}$ gelagert.

\section{Nukleinsäure-Fällung für Sequenzierung}

Eine wässrige DNA-Lösung wurde auf eine Endmolarität von 0,3 M Natriumacetat (pH 5,2) und 12,5 mM EDTA eingestellt und mit 5-fachem Volumen reinen Ethanol versetzt. Nach vorsichtigem Mischen inkubierte die Mixtur zur Präzipitation zunächst bei Raumtemperatur für 5 min. Die DNA wurde durch 15-minütige Zentrifugation bei $13.000 \mathrm{~g}$ pelletiert und mitausgefallenes Salz durch Behandlung mit 70\% (v/v) Ethanol aus dem DNA-Präzipitat entfernt. Die durch erneute Zentrifugation pelletierte Nukleinsäure wurde an der Luft oder unter Vakuum getrocknet und in einem geeigneten Volumen $\mathrm{H}_{2} \mathrm{O}$ oder Puffer aufgenommen.

\section{Bestimmung der Nukleinsäure-Konzentration}

DNA-Konzentrationen wässriger Lösungen wurden spektralphotometrisch bestimmt. Dafür wurde die Extinktion einer verdünnten DNA-Lösung im Photometer bei einer Wellenlänge von 260 und $280 \mathrm{~nm}$ gemessen. Eine Extinktion von 1 bei $260 \mathrm{~nm}$ entspricht einer Konzentration von $50 \mathrm{ng} / \mu \mathrm{l}$ doppelsträngiger DNA. Als Maß für die Reinheit der DNA-Lösung diente das Verhältnis der Extinktionen bei $260 \mathrm{~nm}$ und $280 \mathrm{~nm}$, es sollte für DNA bei etwa 1,8 liegen $(\mathrm{pH} 8,0)$. Wenn erforderlich wurden gemessene DNA-Konzentrationen durch Angleich in einem Agarose-Gel aufeinander abgestimmt.

\section{Schneiden von DNA mit Restriktionsendonukleasen}

Zum Nachweis palindromischer Restriktionsschnittstellen und um DNA für Klonierungszwecke zugänglich zu machen, war selbige einem Restriktionsverdau zu unterziehen. Dazu wurden pro $\mu \mathrm{g}$ zu schneidende Plasmid-DNA 1 bis 2,5 IU des Restriktionsenzyms und 1/10 Volumen an entsprechendem, enzymspezifischen 
10-fach Puffer zugegeben. Um unspezifische Spaltaktivität der Endonukleasen zu verhindern, wurde darauf geachtet, dass das Reaktionsvolumen mindestens das 10-fache der in Glycerol gelösten Enzyme betrug. Die Dauer der Restriktionsspaltung betrug mindestens $2 \mathrm{~h}$, bei der für das jeweilige Enzym optimalen Temperatur. Gleichzeitiges Schneiden der DNA mit unterschiedlichen Restriktionsenzymen erfolgte nach den Angaben des Herstellers oder wurde, falls dies nicht möglich war, seriell durchgeführt. Die Reaktion wurde durch Zugabe von 1/5 Volumen des 6-fach DNA-Auftragspuffer (Zusammensetzung siehe Agarose-Gelelektrophorese) beendet und die Vollständigkeit des Verdaus gelelektrophoretisch überprüft.

\section{Agarose-Gelelektrophorese}

Je nach Größe der zu trennenden DNA-Fragmente wurden 0,8- bis 2\%-ige (w/v) Agarose-Gele verwendet. Für hohe Trennschärfe großer Fragmente wurde eine niedrige Agarosekonzentration, für gute Trennschärfe kleiner Fragmente wurde eine hohe Konzentration gewählt. Das eingewogene Agarosepulver wurde in entsprechendem Volumen TAE-Puffer gelöst und aufgekocht. Die schlierenfreie Lösung wurde in die dafür vorgesehene Gelapparatur gegossen, ein Kamm zur Aussparung der Geltaschen eingesetzt und nach vollständiger Auspolymerisierung des Gels dieses mit TAE-Puffer überschichtet. Die mit 1/5 Volumen 6-fach DNA-Auftragspuffer (10 mM Tris- $\mathrm{HCl}$ pH 8,0, 50 mM EDTA, 1\% (w/v) SDS, 30\% (v/v) Glycerol, 0,1\% (w/v) Bromphenolblau, 0,1\% (w/v) Xylencyanol) versetzten Proben und ein Längenstandard wurden in die Geltaschen pipettiert und bei 5 V / cm Laufstrecke aufgetrennt, bis die untere Farbbande (ca. 300 bp) etwa 3/4 der Elektrophoresestrecke zurückgelegt hatte. Nach dem Gellauf wurden die Gele in einem Ethidiumbromid-Bad (20 $\mu$ l Ethidiumbromid auf ca. $200 \mathrm{ml}$ TAE-Puffer) für etwa 20 min gefärbt. Die DNA wurde durch das interkalierende Ethidiumbromid im UV-Licht sichtbar gemacht und digital aufgenommen.

\section{DNA-Extraktion aus Agarose-Gelen}

Die Isolierung von DNA-Fragmenten aus Agarose-Gelen wurde mit Hilfe des QIAquick Gelextraction Kit der Firma Qiagen nach Protokoll durchgeführt. Dazu wurde die entsprechende DNA-Bande auf dem UV-Durchlichttisch (365 nm) aus dem 
Gel herauspräpariert und das Gelstück in ein Eppendorf-Reaktionsgefäß gegeben. Anschließend wurde die Agarose durch Zugabe des entsprechenden Puffers und Erhitzung der Probe im Heizschüttelblock auf $50^{\circ} \mathrm{C}$ aufgeschmolzen, um die DNA in Lösung zu bringen. Dieses Gemisch wurde über eine DNA-bindende Matrix gegeben, mehrfach gewaschen, mit TE-Puffer oder $\mathrm{H}_{2} \mathrm{O}$ von der Säule eluiert und direkt weiterverwendet (z.B. Ligation) oder bei $-20^{\circ} \mathrm{C}$ aufbewahrt.

\section{Ligation von DNA-Fragmenten}

Zur Verknüpfung eines DNA-Fragments mit einem Plasmidvektor über kohäsive DNA-Enden wurden 50 bis 100 ng Plasmid-DNA (Vektor) und ein zwei- bis vierfacher molarer Überschuss des DNA-Fragments (= insert) mit dem entsprechenden Volumen 10-fach Ligasepuffer, 2,5 - 5 IU T4-DNA-Ligase und $\mathrm{H}_{2} \mathrm{O}$ zu dem erforderlichen Endvolumen vereinigt. Der Reaktionsansatz wurde bei $16^{\circ} \mathrm{C}$ über Nacht inkubiert. Zur Transformation chemisch kompetenter Bakterien wurden 1/4 - 1/20 des Ligationsansatzes verwendet.

\section{Polymerase-Kettenreaktion $\left[{ }^{106}\right]$}

Die Polymerase-Kettenreaktion (im Weiteren als PCR bezeichnet) wurde als das Verfahren zur exponentiellen Vermehrung von DNA-Bereichen definierter Länge und Sequenz eingesetzt. Man macht sich dabei die Eigenschaft von hitzestabilen Polymerasen zunutze, die einen Einzelstrang zu einem Doppelstrang ergänzen können, wenn ihnen ein kurzer doppelsträngiger Bereich mit freien $3^{\prime}-\mathrm{OH}$-Ende zur Verfügung steht. Beide eingesetzten Oligonukleotide mit freiem 3'-OH-Ende (= Primer) werden für die Reaktion im Überschuss zugesetzt und binden in den flankierenden Bereichen der zu amplifizierenden Sequenz. Wegen der Schwierigkeiten bei der Amplifikation GC-reicher Sequenzen wurde für die Klonierung von Eferin die für ihre akkurate und hohe Syntheserate bekannte Phusion-Polymerase (New England Biolabs) eingesetzt. 
Typische Zusammensetzung eines PCR-Reaktionsansatz:

15 - 50 ng Ausgangs-DNA

$10 \mathrm{nMol}$ dNTP

25 pMol 3'- Primer

25 pMol 5'-Primer

$1,5 \mu \mathrm{ll}$ DMSO (100\%)

$0,5 \mu$ l DNA-Polymerase Phusion

$10 \mu \mathrm{l}$ 5x Phusion-Polymerase GC Reaktionspuffer

in $\mathrm{H}_{2} \mathrm{O}$ bei einem Endvolumen von $50 \mu \mathrm{l}$

Nach einem initialen Denaturierungsschritt bei $98^{\circ} \mathrm{C}$ durchlief die zu vermehrende Probe in mehreren Zyklen eine Reaktionsabfolge bestehend aus Denaturierung bei $98^{\circ} \mathrm{C}$, Primer-Anlagerung (= Hybridisierung) bei 55 bis $68^{\circ} \mathrm{C}$ und Elongation der DNA bei $72^{\circ} \mathrm{C}$.

Anschließend wurde der Reaktionsansatz auf $4^{\circ} \mathrm{C}$ abgekühlt, die jeweiligen PCR-

Produkte direkt mit dem PCR Aufreinigungs-Kit (Qiagen) oder nach Agarose-

Gelelektrophorese mit dem Gelextraktions-Kit (Qiagen) nach dem entsprechenden Produktprotokoll aufgereinigt.

\section{DNA-Sequenzierung nach der Didesoxy-Kettenabbruchmethode $\left[{ }^{107}\right]$}

Die nichtradioaktive Sequenzierungsreaktion wurde mit dem Big Dye Terminator Cycle Sequencing ReadyReaction-Mix der Firma Applied Biosystems durchgeführt. Dieses Reagenz enthält neben Puffer eine Taq-Polymerase, mit vier verschiedenfarbigen Fluorophoren markierte ddNTPs und einen dNTP-Mix. Die Produkte der PCR werden für die Sequenzierung dadurch detektierbar, dass die farbig markierten ddNTPs bei Einbau stets zu einem Kettenabbruch führen und so Fragmente unterschiedlicher Länge und Endmarkierung entstehen.

Ein zur Sequenzierung verwendeter Standardreaktionsansatz von $10 \mu$ enthielt $10 \mathrm{pMol}$ Primer, 0,5 $\mu \mathrm{g}$ Matrizen-DNA, $5 \mu \mathrm{l}$ Big Dye Mix und die entsprechende Menge $\mathrm{H}_{2} \mathrm{O}$.

Nach einer dreiminütigen Inkubation bei $96^{\circ} \mathrm{C}$ durchlief der Reaktionsansatz 40 Zyklen, jeweils bestehend aus Denaturierungsphase von $30 \mathrm{~s}$ bei $96^{\circ} \mathrm{C}$, Hybridisierungsphase von $15 \mathrm{~s}$ bei $50^{\circ} \mathrm{C}$ und Synthesephase von 4 min bei $60^{\circ} \mathrm{C}$. 
Bis zur weiteren Verarbeitung wurde der Ansatz auf $4^{\circ} \mathrm{C}$ gekühlt.

Nach der Polymerase-Kettenreaktion folgte eine Aufreinigung der Probe über eine zentrifugierbare Gelfiltrationssäule (AutoSeq G50, GE Healthcare) laut Herstellerangaben, durch die unverbrauchte dNTPs, ddNTPs, der Puffer sowie die Polymerase entfernt wurden. Alternativ wurde die amplifizierte DNA, wie unter NukleinsäureFällung beschrieben, präzipitiert.

Die Auftrennung und Detektion der Reaktionsprodukte wurde vom Service der Abteilung Oesterhelt (MPI für Biochemie, Martinsried) bzw. Abteilung Pieler (Universität Göttingen) übernommen.

\section{Zellbiologische Methoden}

\section{Herstellung transformationskompetenter Bakterien}

Um transformierbare Bakterien zu gewinnen, wurden $500 \mu \mathrm{l}$ einer stationären Kultur von E. coli DH5a mit 50 ml LB-Medium verdünnt und in einem Schüttelinkubator bis zu einer $\mathrm{OD}_{600}$ von 0,5 bis 0,8 kultiviert. Die Bakterien wurden dann bei $4^{\circ} \mathrm{C}$ und $2.000 \mathrm{~g}$ abzentrifugiert und das Bakterienpellet in $2 \mathrm{ml}$ eiskalter TSS-Lösung (10\% (w/v) Polyethylenglykol 6000, 5\% (v/v) DMSO, 50 mM MgCl2 in LB-Medium) resuspendiert. Die Bakteriensuspension wurde 10 min auf Eis inkubiert und anschließend mit $500 \mu$ 87\% (v/v) Glycerol vorsichtig gemischt. Die Suspension wurde zu je $100 \mu \mathrm{l}$ aliquotiert, in flüssigem Stickstoff schockgefroren und bei $-80^{\circ} \mathrm{C}$ aufbewahrt.

\section{Transformation kompetenter Bakterien}

Ein Aliquot gefrorener transformationskompetenter Bakterien (DH5a für DNAAmplifikation; BL21(DE3), BL21(DE3)CODONplus oder Rosetta (DE3) für Proteinexpression) wurden auf Eis aufgetaut. Dann wurde etwa $1 \mathrm{ng}$ Plasmid-DNA zur Bakteriensuspension gegeben und 20 min auf Eis inkubiert. Das Bakterien-DNAGemisch wurde für $45 \mathrm{~s}$ bei $42^{\circ} \mathrm{C}$ inkubiert (Hitzeschock führt zur DNA-Aufnahme) und danach sofort für 2 - 3 min auf Eis gestellt. Sodann wurde LB-Medium hinzugegeben und die Bakterien für 45 min bei $37^{\circ} \mathrm{C}$ unter Schütteln inkubiert. Für die Ausplattierung der Bakterien auf LB-Selektionsplatten wurde die Bakterienkultur $10 \mathrm{~s}$ bei $15.000 \mathrm{~g}$ abzentrifugiert und der Überstand größtenteils abgenommen. In dem 
verbliebenen $50 \mu$ l Medium wurden die Bakterien resuspendiert und das gesamte Volumen auf einer zuvor angewärmten Selektionsplatte mit sterilen Glaskügelchen (Durchmesser: $5 \mathrm{~mm}$ ) ausgerollt. Anschließend wurde die Platte bei $37^{\circ} \mathrm{C}$ für 14 $18 \mathrm{~h}$ bis zum Erscheinen von Bakterienkolonien inkubiert.

Zum Ansetzen einer LB-Flüssigkultur wurde eine Einzelkolonie von entsprechender Selektionsplatte in LB-Selektionsmedium angeimpft und im Brutschüttler bei $37^{\circ} \mathrm{C}$ über Nacht inkubiert.

\section{Kultivierung humaner Zelllinien}

Adhärente Säugerzelllinien wurden in DME-Medium (= DMEM) mit 4500 mg / I Glucose, $1 \mathrm{mM}$ Natriumpyruvat, 10\% FCS, $100 \mathrm{lU} / \mathrm{ml}$ Penicillin und 100 mg / ml Streptomycin bei $37^{\circ} \mathrm{C}, 5 \% \mathrm{CO}_{2}$ und $100 \%$ Luftfeuchtigkeit in Zellkulturschalen variabler Größe kultiviert. Die Zellen wurden alle zwei bis drei Tage vor Erreichen der Konfluenz passagiert. Dazu wurden die Zellen zunächst mit PBS gespült, von der Zellkulturschale (Durchmesser $10 \mathrm{~cm}$ ) mit $1 \mathrm{ml} 10 \times$ Trypsin / EDTA abgelöst und in einer Verdünnung von 1:3 bis 1:10 auf neuen Kulturschalen angesetzt. HeLaSuspensionszellen wurden in Joklik's-Medium mit 10\% NCS, 100 IU / ml Penicillin und $100 \mu \mathrm{g} / \mathrm{ml}$ Streptomycin bei $37^{\circ} \mathrm{C}$ in Spinner-Flaschen unter konstantem Rühren (100 U/min) kultiviert. Alle übrigen Säuger-Suspensionszellen wurden statt in Joklik's-, in RPMI 1640-Medium mit 10\% hitzeinaktiviertem FCS, 100 IU / ml Penicillin und $100 \mu \mathrm{g} / \mathrm{ml}$ Streptomycin in Kulturflaschen kultiviert, dabei mindestens einmal täglich durch sanftes Schütteln vollständig in Suspension gebracht. Die Zelldichte der Suspensionskulturen wurde durch tägliches Verdünnen mit frischem Medium zwischen $2,5 \times 10^{5}$ und $10^{6}$ Zellen pro ml gehalten.

\section{Einfrieren und Auftauen von Gewebekulturzellen}

Säugerzellen wurden zum Zweck der Lagerung stets aus einer logarithmisch wachsenden Population eingefroren. Dazu wurden diese, falls erforderlich, zunächst mit Trypsin abgelöst, um dann bei $200 \mathrm{~g}$ für 5 min pelletiert zu werden. Dann wurden die Zellen in frischem Kulturmedium resuspendiert und die Zellsuspension auf eine Gesamtkonzentration von 5 - 10\% (v/v) DMSO gebracht. Je $1 \mathrm{ml}$ der Suspension wurde in ein Einfrierröhrchen abgefüllt, in reinem Propan-2-ol langsam auf $-80^{\circ} \mathrm{C}$ ab- 
gekühlt und zur dauerhaften Lagerung in flüssigen Stickstoff überführt. Das rasche Auftauen der Zellen erfolgte bei $37^{\circ} \mathrm{C}$ im Wasserbad. Dabei wurde $1 \mathrm{ml}$ aufgetaute Zellsuspension mit $15 \mathrm{ml}$ Standardmedium verdünnt, in eine $15 \mathrm{~cm}$ Zellkulturschale überführt und kultiviert.

\section{Zellzahlbestimmung von Gewebekulturzellen}

Zellzahlen wurden über drei alternative Methoden bestimmt. Zum einen wurde ihr Wert durch Auszählung in einer Neubauer-Zählkammer ermittelt. Des weiteren diente bei Ansätzen im Großmaßstab das Nassgewicht (für 5 min bei $200 \mathrm{~g}$ ) pelletierter Zellen als Wert zur Bestimmung der Zellzahl. Hier entsprach ein Gewicht von 500 mg einer Zellzahl von $10^{8}$ Zellen.

War bei adhärenten Zellen nur eine Annäherung nötig, wurde ausgehend von der Plattengrundfläche eine Abschätzung mit einem Wert von 1,25 x $10^{5}$ Zellen $/ \mathrm{cm}^{2}$ (bei völliger Konfluenz) vorgenommen.

\section{Transiente Transfektion von Gewebekulturzellen}

\section{Dendrimer-Transfektion}

Für die Transfektion adhärenter HeLa-Zellen wurde der Polyfect Transfection Reagent-Kit der Firma Qiagen verwendet. Wie im Herstellerprotokoll angegeben, wurden die Zellen bei einer Konfluenz von 30 - 50\% transfiziert. Um eine geringere Expression zu erreichen, wurde die zu transfizierende DNA $(0,2-0,4 \mu \mathrm{g})$ zusammen mit einem pACT-Leerplasmid $(1,1-1,3 \mu \mathrm{g})$ kotransfiziert. Damit wurde die vom Hersteller gefordert Gesamtmenge von je 1,5 $\mu$ g Plasmid-DNA je Vertiefung einer 6-wellPlatte erfüllt. Im Detail wurde $15 \mu \mathrm{l}$ DNA-Gemisch in $73 \mu \mathrm{l}$ serum- und antibiotikumfreiem DMEM-Medium mit $12 \mu$ Polyfect versetzt. Jeder Ansatz wurde zur Komplexbildung zwischen DNA und Dendrimeren durch Verwirbelung für $10 \mathrm{~s}$ gründlich gemischt und 10 min bei Raumtemperatur inkubiert. Nach Zugabe von $600 \mu \mathrm{l}$ antibiotikum- und serumhaltigen DMEM-Medium wurde durch auf- und abpipettieren jeder Ansatz ein weiteres Mal gemischt. Jeder Transfektionsansatz wurde sofort in die bereits mit je 1,5 ml antibiotikum- und serumhaltigem DMEM-Medium versorgten Vertiefungen überführt, gleichmäßig verteilt und für 20 - 48 h auf den Zellen belassen. 


\section{Kalziumphosphat-Transfektion}

Je Kulturschale (Durchmesser $15 \mathrm{~cm}$ ) wurden $30 \mu \mathrm{g}$ Plasmid-DNA mit $150 \mu \mathrm{l}$ einer zweimolaren $\mathrm{CaCl}_{2}$-Lösung versetzt und mit sterilem $\mathrm{H}_{2} \mathrm{O}$ auf $1,5 \mathrm{ml}$ gebracht. Dieses Gemisch wurde langsam zu 1,5 ml eines sterilen HEPES-Transfektionspuffers (250 mM NaCl, 1,5 mM Na $2 \mathrm{HPO}_{4}, 50 \mathrm{mM}$ HEPES pH 6,95) unter sanftem Schwenken zugetropft. Zur Bildung der $\mathrm{Ca}_{3}\left[\mathrm{PO}_{4}\right]_{2}$-DNA-Präzipitate wurde der Ansatz für 30 min bei Raumtemperatur stehen gelassen, dann auf die mit DMEM-Medium versorgten Zellen pipettiert. Nach 6 - $8 \mathrm{~h}$ wurde das Medium gewechselt und die Zellen bis zur Ernte weiterkultiviert.

\section{Liposom-Transfektion von Gewebekulturzellen mit Oligonukleotiden (= RNAi)}

Für die Transfektionsreaktion wurden zunächst die komplementären RNAOligonukleotide für eine Minute bei $90^{\circ} \mathrm{C}$, dann für $1 \mathrm{~h}$ bei $37^{\circ} \mathrm{C}$ in Annealing-Puffer (100 mM Natriumacetat, 2 mM Magnesiumacetat, 50 mM HEPES pH 7,3) hybridisiert. Die hybridisierten Oligonukleotide wurden als Aliquote mit einer Konzentration von $50 \mu \mathrm{M}$ bis zu ihrem Einsatz bei $-20^{\circ} \mathrm{C}$ weggefroren.

Adhärente HeLa-Zellen wurden bei einer Konfluenz von 30 - 50\% mit dem Oligofectamin Reagenz der Firma Invitrogen transfiziert. Alle Transfektionsansätze wurden nach Optimierung der Bedingungen stets nach dem unten dargestellten Schema durchgeführt. Dabei wurden Mix A und Mix B parallel pipettiert und für 10 min bei Raumtemperatur inkubiert.

\begin{tabular}{|l|l|l|l|l|l|l|l|}
\cline { 2 - 8 } \multicolumn{2}{c|}{} & Ansatz 1 & Ansatz 2 & Ansatz 3 & Ansatz 4 & Ansatz 5 & Ansatz 6 \\
\hline Mix A & $\begin{array}{l}\text { Oligonukleotid } \\
5 \text { (anti-Eferin) }\end{array}$ & $5 \mu \mathrm{l}$ & - & $2,5 \mu \mathrm{l}$ & - & - & - \\
\cline { 2 - 9 } & $\begin{array}{l}\text { Oligonukleotid } \\
6 \text { (anti-Eferin) }\end{array}$ & - & $5 \mu \mathrm{l}$ & $2,5 \mu \mathrm{l}$ & - & - & - \\
\cline { 2 - 9 } & $\begin{array}{l}\text { Oligonukleotid } \\
\text { scrambled }\end{array}$ & - & - & - & $5 \mu \mathrm{l}$ & - & - \\
\cline { 2 - 9 } & optiMEM & $365 \mu \mathrm{l}$ & $365 \mu \mathrm{l}$ & $365 \mu \mathrm{l}$ & $365 \mu \mathrm{l}$ & $370 \mu \mathrm{l}$ & - \\
\hline Mix B & Oligofectamin & $8 \mu \mathrm{l}$ & $8 \mu \mathrm{l}$ & $8 \mu \mathrm{l}$ & $8 \mu \mathrm{l}$ & $8 \mu \mathrm{l}$ & - \\
\cline { 2 - 9 } & optiMEM & $22 \mu \mathrm{l}$ & $22 \mu \mathrm{l}$ & $22 \mu \mathrm{l}$ & $22 \mu \mathrm{l}$ & $22 \mu \mathrm{l}$ & - \\
\hline
\end{tabular}


Zwischenzeitlich wurden die zu transfizierenden Zellen mit 1,6 ml serum- und antibiotikafreiem DMEM-Medium versorgt. Dann wurden Mix A und Mix B miteinander vermischt und für weitere 30 min bei Raumtemperatur inkubiert. Schließlich wurde jedes Gemisch auf die Zellen pipettiert, diese im Inkubator für 24 - 96 h kultiviert. Oligonukleotidkonzentrationen betrugen bei allen transfizierten Zellen final $125 \mathrm{nM}$

\section{Zellzyklus-Analyse im Durchflusszytometer (= FACS-Analyse)}

Sollten adhärente Zellen einer FACS-Analyse (FACS = fluorescence activated cell sorting) unterzogen werden, so wurden diese zunächst trypsiniert und einmal mit PBS gewaschen. 1/3 des Ansatzes wurde für Westernblot-Analyse abgezweigt, die restlichen 2/3 nochmals mit PBS gewaschen und zur Propidiumiodid-Färbung herangezogen. Dafür wurden die Zellen nach Pelletierung bei $200 \mathrm{~g}$ über $5 \mathrm{~min}$ bei $4^{\circ} \mathrm{C}$ in frischer 1\% (w/v) Formaldehyd-PBS-Lösung resuspendiert und für 20 min auf Eis fixiert. Nachdem die Zellen erneut pelletiert worden waren, mussten sie zweifach in PBS gewaschen werden. Im letzten Schritt wurden die pelletierten Zellen in Propidiumiodid-Färbelösung (20 $\mu \mathrm{g} / \mathrm{ml}$ Propidiumiodid, $200 \mu \mathrm{g} / \mathrm{ml}$ RNAse A, $0,1 \%$ (v/v) Triton X100, in PBS) resuspendiert. Nach Inkubation der Zellen für 15 min auf Eis wurden selbige direkt oder nach Lagerung bei $4^{\circ} \mathrm{C}$ über Nacht im Durchflusszytometer gemessen. Die FACS-Analyse wurde wie in Flow Cytometry von M. G. Ormerod (3. Auflage erschienen bei Oxford University Press) beschrieben, durchgeführt. Proben für Westernblot-Analyse wurden in SDS-Probenpuffer aufgenommen und vor der SDS-PAGE 5 min lang bei $95^{\circ} \mathrm{C}$ aufgekocht.

\section{Zellzyklus-Arretierung von Säugerzellen}

Zur Arretierung von Säugerzellen in definierten Phasen des Zellzyklus wurden selbige in den dafür nötigen Endkonzentrationen, bei Taxol mit $5 \mu \mathrm{M}$, bei Nocodazol mit $250 \mathrm{nM}$ und bei Thymidin mit 2 mM, für eine Dauer von $18 \mathrm{~h}$ behandelt. Hierbei wurden die Inhibitoren dem Nährmedium zugesetzt. Dabei bewirkt die Behandlung mit Taxol oder Nocodazol eine Arretierung in Prometa- und Metaphase, während Thymidin die Zellen bereits am G1/S-Übergang arretiert. 


\section{Immunologische und immunobiochemische Methoden}

\section{Immunoblot-Analyse (= Westernblot-Analyse)}

Die über SDS-PAGE aufgetrennten Proteine wurden über Elektrotransfer auf eine Nitrocellulose-Membran übertragen (= blotting). Auf die Anode der blotting-Apparatur wurde mit Transferpuffer (25 mM Tris, 193 mM Glycin, 0,036\% (w/v) SDS, 20\% (v/v) Methanol) getränktes Whatman 3MM-Papier in drei Lagen, die Membran (engl.: blot), das Trenngel, und drei weitere getränkte Lagen Whatman 3MM-Papier geschichtet und der Kathodendeckel leitend damit verbunden. Der Transfer erfolgte bei konstanten 20 Volt und maximaler Amperezahl. Damit betrug die Transfer-Leistung etwa 16 Watt pro Blot. Zur Sichtbarmachung der transferierten Proteine wurde die Membran nach erfolgtem Transfer einige Minuten in Ponceau-Färbelösung (0,5\% (w/v) Ponceau S, 1\% (v/v) Essigsäure) inkubiert, mit 1\% (v/v) Essigsäure gewaschen, dokumentiert und die Markerbanden durch Nachzeichnen dauerhaft sichtbar gemacht.

Zur anschließenden spezifischen Proteindetektion wurde die Membran in PBSTMilch (= PBST mit 5\% (w/v) Magermilchpulver) zunächst für mindestens 60 min bei Raumtemperatur abgesättigt und so gegen unspezifisches Binden der Antikörper geblockt. Anschließend wurde die Membran mindestens $1 \mathrm{~h}$ bei Raumtemperatur in einer geeigneten Verdünnung des ersten Antikörpers in PBST-Milch inkubiert, dann dreimal für je 10 min in PBST gewaschen. Es folgte die Inkubation mit einem, gegen den ersten Antikörper gerichteten, peroxidasegekoppelten Zweitantikörper (in PBSTMilch) für $60 \mathrm{~min}$. Daraufhin wurde die Membran zweimal $15 \mathrm{~min}$ mit PBST gewaschen. Die Sichtbarmachung der spezifischen Proteinbanden erfolgte über Chemolumineszenz. Dazu wurde die Blotmembran in Chemolumineszenzsubstrat inkubiert. Dies führt zur Umsetzung des enthaltenen Luminols (durch die PeroxidaseAktivität des Zweitantikörpers) unter Photonenemission, welche zur Belichtung eines Röntgenfilms genutzt wurde. Alternativ wurde die Chemolumineszenz in dem Dokumentationsgerät LAS 3000 digital aufgenommen.

In Fällen, in denen die Membran zur Detektion eines weiteren Poteins verwendet werden sollte, wurde die bereits auf der Membran haftende Peroxidaseaktivität durch Inkubation für 45 min bei Raumtemperatur mit $1 \mathrm{mM} \mathrm{NaN}_{3}$ (in PBST-Milch) inaktiviert. 


\section{Kopplung und Kreuzvernetzung von Antikörpern an ProteinG-Sepharose}

Zunächst wurde die gewünschte Antikörper-Lösung bei $13.000 \mathrm{~g}$ für 3 min bei Raumtemperatur von möglichen Präzipitaten befreit, dann $50 \mu$ in PBS äquilibrierte Ultralink ProteinG-Sepharose (entsprachen $25 \mu \mathrm{l}$ Sepharose-Matrix) zu $100 \mu \mathrm{g}$ dieses Antikörpers zugegeben. Der Ansatz wurde mit PBS im Volumen aufgefüllt und $1 \mathrm{~h}$ bei Raumtemperatur auf dem Drehrad inkubiert, danach zweimal im 10-fachen Volumen 0,2 $\mathrm{M} \mathrm{Na}_{2} \mathrm{~B}_{4} \mathrm{O}_{7}(\mathrm{pH} \mathrm{9,0)}$ gewaschen. Die Sepharose wurde in 10-fachem Volumen Natriumboratpuffer resuspendiert, mit $20 \mathrm{mM}$ Dimethylpimelimidat (= DMP) versetzt, 30 min bei Raumtemperatur auf dem Drehrad inkubiert, bevor sie einmal mit 0,2 M Ethanolamin pH 8,0 gewaschen wurde. Um die Reaktion der Kreuzvernetzung abzustoppen, wurden die Sepharose für $2 \mathrm{~h}$ bei Raumtemperatur in 0,2 $\mathrm{M}$ Ethanolamin $(\mathrm{pH} 8,0)$ auf Drehrad rotiert, einmal mit PBS gewaschen und ungebundene Antikörpermoleküle mit 0,1 M Glycin ( $\mathrm{pH} 3,0)$ abgelöst. Die Antikörper-Sepharose wurde mit PBS gründlich nachgewaschen und bei $4^{\circ} \mathrm{C}$ bis zur weiteren Verwendung gelagert.

\section{Immunpräzipitation von Proteinen}

Präzipitationen mit spezifischen Antikörpern wurden durchgeführt, um ein bestimmtes Protein aus Zellextrakten aufzureinigen, oder assoziierte Proteine zu identifizieren. Alle Schritte wurden bei $4^{\circ} \mathrm{C}$ unter Verwendung gekühlter Lösungen ausgeführt. Der an ProteinG-Sepharose gebundene und kreuzvernetzte spezifische Antikörper wurde nach zweimaligem Waschen im entsprechenden Puffer als Suspension zur Bildung der Antigen-Antikörper-Komplexe 1 - $3 \mathrm{~h}$ mit dem Proteinextrakt inkubiert. Nach erneutem dreimaligem Waschen mit Puffer wurden die Sepharose in 2x SDS-Probenpuffer aufgenommen und nach 5-minütigem Kochen mittels SDS-PAGE und Westernblot analysiert. War eine Vorreinigung des Extraktes zwecks Beseitigung unspezifischer Bindungen an das Sepharose-Material nötig, wurde dieser, vor der eigentlichen Inkubation mit dem gekoppelten Antikörper, mit der gleichen Menge antikörperfreier Sepharose-Matrix für 45 min vorinkubiert. Nach diesem Schritt konnte die Sepharose-Matrix abgetrennt und der vorgereinigte Extrakt zur Immunpräzipitation eingesetzt werden.

Neben der hier beschrieben Vorgehensweise zur Immunpräzipitation wurde eine weitere Variante genutzt. Die Veränderungen dabei waren dahingehend, dass statt 
ProteinG-Sepharose der Firma Pierce die von Roche vertriebene ProteinG-Agarose verwendet und die eingesetzten Antikörper nicht kreuzvernetzt wurden. Bezüglich der Reihenfolge änderte sich im Inkubationsschema Folgendes: Extrakte wurden für 90 min zunächst nur mit dem Antikörper inkubiert, zur Entfernung unerwünschter Präzipitate für 10 min bei $15.000 \mathrm{~g}$ zwischenzentrifugiert, danach die Agarose-Matrix zugeben und der gesamte Ansatz für weitere 90 min inkubiert. Alle weiteren Schritten blieben unverändert.

\section{Immunzytologie: Fixierung und Anfärbung}

Für die Immunzytologie wurden adhärente HeLa-Zellen auf sterilen Deckgläschen in 6-well-Platten ausgesät und bis zu einer Konfluenz von $40 \%$ kultiviert. Alle für Fixierung und Anfärbung der Zellen nötigen Inkubations- und Waschschritte erfolgten in 6-well-Platten. Dabei wurden die Deckgläschen, ohne vorheriges Absaugen der jeweiligen (Nähr- bzw.) Inkubationslösung, in die entsprechende Vertiefung einer 6-well-Platte mit der Lösung des nächsten Inkubationsschrittes überführt. Zur Vermeidung von Autofluoreszenz in der Immunzytologie wurde allen PBS-basierenden Lösungen $1 \mathrm{mM} \mathrm{MgCl} 2$ zugesetzt.

\section{Fixierungsmethoden für Immunfluoreszenz}

\section{Methanol-Aceton-Fixierung}

Zunächst wurden die zu fixierenden Zellen auf den Deckgläschen in einem $-20^{\circ} \mathrm{C}$ kalten, Methanol-Aceton-Gemisch (jeweils 100\% (v/v) im Verhältnis von 1:1) für 10 min bei $-20^{\circ} \mathrm{C}$ fixiert. Nach der Fixierung wurden die Zellen luftgetrocknet, dann bei $4^{\circ} \mathrm{C}$ trocken gelagert oder direkt weiter verarbeitet.

Methanolfixierung

Zur Fixierung der Zellen wurden diese in $-20^{\circ} \mathrm{C}$ kaltem,100\% (v/v) Methanol für $10 \mathrm{~min}$ bei $-20^{\circ} \mathrm{C}$ inkubiert. Anschließend wurden die Zellen zweimal mit $4^{\circ} \mathrm{C}$ kaltem PBS gewaschen und direkt weiter verarbeitet. 
Formaldehyd-Fixierung mit Präpermeabilisierung

Als erstes wurden die Zellen auf den Deckgläschen für 5 min mit 0,005\% (w/v)

Digitonin in PBS auf Eis präpermeabilisiert. Die Fixierung erfolgte mit 4\%

Formaldehyd in PBS für zunächst 5 min auf Eis, dann für 10 min bei

Raumtemperatur. Es folgte ein Waschschritt mit PBS bevor die fixierten Zellen der weiteren Verarbeitung zur Verfügung standen bzw. bei $4^{\circ} \mathrm{C}$ gelagert werden konnten.

\section{Antikörper-Inkubation, Färbung, Eindeckelung und Bildaufnahme}

Zuvor fixierte Zellen wurden zunächst in vorgelegtem PBS gewaschen, anschließend mit BSA-Blocklösung (= PBS mit 2\% (w/v) BSA) für 10 - 15 min bei Raumtemperatur inkubiert. Die Inkubation mit dem ersten Antikörper, verdünnt in BSA-Blocklösung, erfolgte für mindestens 45 min bei Raumtemperatur. Die Zellen wurden erst mit PBST, dann mit PBS gewaschen und mit dem farbstoffmarkierten sekundären Antikörper und Hoechst-Farbstoff (beide verdünnt in BSA-Blocklösung) bei Raumtemperatur im Dunklen für mindestens 45 min inkubiert. Abschließend wurden die Deckgläschen mit PBST, mit PBS und kurz mit $\mathrm{H}_{2} \mathrm{O}$ gewaschen. Nachdem restliches $\mathrm{H}_{2} \mathrm{O}$ auf den Deckgläschen mit saugfähigen Einwegtüchern vom Rand her so gut wie

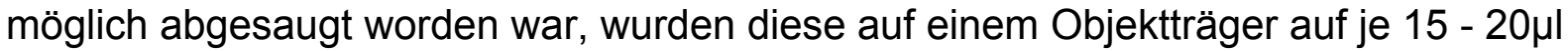
Eindeckmedium (MoBiTec bzw. Dako) invers aufgebracht. Die Polymerisation erfolgte über Nacht bei Raumtemperatur und die Objektträger wurden anschließend bis zur Auswertung am Axioskop II - Fluoreszenzmikroskop bei $4^{\circ} \mathrm{C}$ in Dunkelheit gelagert. Falls erforderlich wurden Reste von Eindeckmedium und PBS-Kristalle mit einer $\mathrm{H}_{2} \mathrm{O}$-Spülung und anschließender Propan-2-ol-Behandlung entfernt. Zur Auswertung am Fluoreszenzmikroskop kamen apochromatische Ölimmersionsobjektive (Firma Zeiss) mit einem Vergrößerungsfaktor von 10, 40, 63 und 100 zum Einsatz. Alle Bildaufnahmen wurden mit dem 63er Objektiv gemacht (numerische Apertur 1,4).

\section{Herstellung von Antiseren}

Zur Gewinnung des gewünschten Antigens wurden die jeweiligen Proteine rekombinant in E. coli exprimiert und über beschriebene Aufreinigungsmethoden bis zur höchstmöglichen Homogenität selbst gereinigt. Das gereinigte Protein $(1 \mathrm{mg} / \mathrm{ml})$ 
wurde für die erste Injektion im Verhältnis 1:1 mit TiterMax Gold über eine Doppelkanüle intensiv emulgiert. Zur Immunisierung wurde $500 \mu \mathrm{g}$ Protein von Angestellten der tierexperimentellen Einrichtung der Max-Planck-Institutes (Martinsried) subkutan einer Ziege injiziert. Auf die Erstimmunisierung folgten nach 6 Wochen jeweils im Abstand von 4 Wochen weitere, sogenannte Boost-Injektionen. TiterMax Gold wurde dabei durch Freund's Adjuvant incomplete ersetzt. Blut wurde jeweils 10 - 14 Tage nach Injektion abgenommen und der Erfolg der Immunisierung anhand der Steigerung der Sensitivität gegenüber dem Antigen im Westernblot überprüft. War die Sensitivität ausreichend, wurde das immunisierte Tier durch die Angestellten der tierexperimentellen Einrichtung ausgeblutet. Zur Gerinnung wurde das gewonnene Blut in unserer Abteilung ausgiebig mit einem Glasstab gerührt, $2 \mathrm{~h}$ unter wiederholtem Rühren bei Raumtemperatur belassen, anschließend über Nacht bei $4^{\circ} \mathrm{C}$ inkubiert. Nach nochmaligem Aufrühren wurde das geronnene Blut zur Abtrennung des Serums mit seinen festen Bestandteilen für 30 min bei $4^{\circ} \mathrm{C}$ mit $5.000 \mathrm{~g}$ abzentrifugiert. Das gewonnene Serum wurde bei $-20^{\circ} \mathrm{C}$ gelagert oder direkt zur Antikörperaufreinigung verwendet.

\section{Affinitätsreinigung von Antikörpern}

Zur Affinitätsreinigung des spezifischen Antikörpers wurden nach Angabe des Herstellers zunächst 5 mg des gereinigten und ausgiebig gegen Carbonatpuffer dialysierten Antigens über Nacht kovalent an Cyanogenbromid-aktivierte Sepharose 4B gekoppelt. Der Erfolg der Kopplung wurde über die Abnahme der $\mathrm{OD}_{280}$ (vor und nach der Reaktion) genommener Proben bestätigt. Alternativ geschah dies über eine in ihrer Intensität nachlassende Ponceau-Färbung der auf Nitrocellulose-Membran getropften Proben oder über das Verschwinden der Antigenbande eines Coomassiegefärbten Polyacrylamid-Gels. Die Kopplungsreaktion wurde durch Inkubation mit 0,2 M Ethanolamin für $1 \mathrm{~h}$ bei Raumtemperatur gestoppt, die Matrix mehrmals mit Carbonatpuffer gewaschen. Zwischenzeitlich wurde das antikörperhaltige Serum nach Zentrifugation (5.000 g, $\left.30 \mathrm{~min}, 4^{\circ} \mathrm{C}\right)$ 1:2 mit PBS verdünnt und schließlich über Nacht mit dem immobilisierten Antigen auf einem Drehrad bei $4^{\circ} \mathrm{C}$ inkubiert. Die Sepharose wurde fünfmal mit $0,5 \mathrm{M} \mathrm{NaCl}$ in PBS gewaschen und in eine Säule überführt. Die Elution des Antikörpers erfolgte mit 0,5 M NaCl in 0,2 M Essigsäure (pH 2,7). Das Eluat wurde in 0,5 ml Fraktionen aufgefangen und durch Zugabe von 
$1 \mathrm{M}$ Tris pH 9,0 (je $100 \mu$ l pro Fraktion) neutralisiert. Durch Aufspotten kleiner Mengen der aufgefangenen Fraktionen auf Nitrocellulose-Membran und anschließende Ponceau-Färbung wurden selbige auf ihren Proteingehalt hin getestet. Die antikörperhaltigen Fraktionen wurden vereinigt, gegen PBS dialysiert und über Zentrifugationsfiltereinheiten eingeengt. Nach Bestimmung der Konzentration über die $\mathrm{OD}_{280}\left(\mathrm{OD}_{280}=1\right.$ entspricht einer Konzentration von 0,8 $\mathrm{mg}$ Antiköper / ml) wurde die Antikörperlösung vor der Lagerung bei $-20^{\circ} \mathrm{C}$ im Verhältnis 1:1 mit $87 \%$ (v/v) Glycerol versetzt und gründlich gemischt. Die Qualität der gereinigten Antikörper wurde mit einer Titration gegen das spezifische Antigen und Totalzellextrakt von HeLa-Zellen im Immunoblot anhand seiner Detektionseigenschaften getestet.

\section{Biochemische Methoden}

Da bei den angewandten Methoden die eingesetzten Proteine vor Abbau und unerwünschter Demodifikation bzw. Modifikation zu schützen waren, wurden die jeweils erforderliche Protektoren in den nötigen Endkonzentrationen (1 mM DTT, PEFA, PMSF, EDTA und EGTA; $10 \mathrm{mM} \mathrm{NEM} \mathrm{und} \mathrm{lodoacetamid;} 1$ $\mu \mathrm{g} / \mathrm{ml}$ Leupeptin, Pepstatin und Aprotinin; 4 MM MG132; 3 mM Glutathion) eingesetzt.

\section{Konzentrationsbestimmung von Proteinen}

Die Bestimmung von Proteinkonzentrationen erfolgte nach drei alternativen Methoden. Zum einen wurde die Messung der Extinktion der betreffenden Proteinlösung bei einer Wellenlänge von $280 \mathrm{~nm}$ herangezogen. Die Berechnung der Konzentration des aufgereinigten Proteins erfolgte dann mit Hilfe des zugehörigen molaren Extinktionskoeffizienten, welcher für jedes Protein eigens über das Programm unter www.expasy.ch/tools/protparam.html ermittelt wurde. Da bei aufgereinigten Proteinen Abbauprodukte die Messung bei $280 \mathrm{~nm}$ verfälschen können, wurde die Konzentration auch mittels SDS-PAGE und anschließender Coomassie-Färbung des Gels abgeschätzt. Als Standard diente BSA, das in definierten Mengen mit auf das Gel aufgetragen wurde. Optional wurde die Bestimmung der Proteinkonzentration mit Hilfe des BCA Protein Assay Reagent Kit und des 
Micro BCA Protein Assay Reagent Kit der Firma Pierce nach den Angaben des Herstellers vorgenommen.

\section{Diskontinuierliche Polyacrylamid-Gelelektrophorese (= SDS-PAGE) [ ${ }^{108}$ ]}

Bei der diskontinuierlichen Gelelektrophorese werden Proteine zunächst in einem niederprozentigen Sammelgel fokussiert und anschließend in einem höherprozentigen Trenngel nach dem jeweiligen Molekulargewicht aufgetrennt. Eingesetzt wurden homogene Trenngele und 5 - 20\%ige Gradientengele. Das Trenngel war jeweils mit einem etwa $1 \mathrm{~cm}$ hohen 4\%igen Sammelgel überschichtet. Nach Polymerisation wurde das Gel in eine Vertikal-Elektrophoresekammer eingespannt und das Reservoir mit SDS-Elektrophoresepuffer (25 mM Tris, 192 mM Glycin, $0,05 \%(w / v)$ SDS) gefüllt. Vor dem Auftragen wurden die zu ladenden Proteine oder Proteinlösungen in dem entsprechenden Volumen $1 \times 1,2$ x oder 4 x SDS-Probenpuffer aufgenommen und 5 min bei $96^{\circ} \mathrm{C}$ gekocht. Die Elektrophorese erfolgte bei konstanten 10mA / Gel im Sammelbereich und 20 mA / Gel im Trennbereich bei jeweils maximaler Voltzahl. Damit betrug die Trenn-Leistung pro Gel etwa 3 bzw. 6 Watt.

\section{Coomassie-Färbung von Proteingelen}

Proteingele wurden zum Färben der aufgetrennten Proteine nach 20 - 60-minütiger Behandlung mit Fixierlösung (10\% (v/v) Essigsäure, 40\% (v/v) Ethanol) für mindestens $1 \mathrm{~h}$ oder über Nacht in Coomassie-Färbelösung (10\% (v/v) Essigsäure, 0,005\% (w/v) Coomassie Brilliant Blue R250) inkubiert, anschließend kurz mit $\mathrm{H}_{2} \mathrm{O}$ gespült und digital dokumentiert.

\section{Gewinnung von Proteinen}

\section{Präparation von Gesamt-Zelllysaten}

Zur Westernblot Analyse wurden stets frische, mit PBS gewaschene Pellets von trypsinierten adhärenten HeLa-Zellen oder gewaschene Suspensions-HeLa-Zellen in heißem 2 x SDS Probenpuffer aufgenommen. Alternativ wurden adhärente Zellen nach zweimaligem Waschen mit PBS direkt auf der Schale mit $95^{\circ} \mathrm{C}$ heißem $2 x$ SDS- 
Probenpuffer versetzt und selbige nach dem Abschaben in ein Eppendorfgefäß überführt. Nach 10 min Kochen wurden die Proben einer Ultraschall-Behandlung unterzogen und auf einem Gel aufgetragen. Die derart gewonnen Gesamt-Zelllysate enthielten etwa $2,5 \times 10^{4}$ Zellen / $\mu$ l.

\section{Präparation von Digitonin-Zellextrakten zur Gewinnung löslicher Proteine}

HeLa-Zellen wurden in PBS gewaschen, bei $200 \mathrm{~g}$ pelletiert, das Zellpellet gewogen und in doppeltem Volumen ( $\mathrm{ml} / \mathrm{mg}$ ) Transport- bzw. PBS-Puffer resuspendiert. Je $5 \times 10^{6}$ Zellen wurden nach Zugabe von je $1 \mu \mathrm{l}$ der Digitonin-Stocklösung für $5 \mathrm{~min}$ auf Eis inkubiert und der Permeabilisierungserfolg mit Trypanblau im Durchlichtmikroskop kontrolliert. Die permeabilisierten Zellen wurden für $10 \mathrm{~min}$ bei $5.000 \mathrm{~g}$ bei $4^{\circ} \mathrm{C}$ zentrifugiert, der Überstand daraus weitere $60 \mathrm{~min}$ lang bei $100.000 \mathrm{~g}$ und $4^{\circ} \mathrm{C}$ nachzentrifugiert. Der letzte Überstand wurde als Digitonin-Extrakt aliquotiert und für die Lagerung bei $-80^{\circ} \mathrm{C}$ in flüssigem Stickstoff weggefroren oder direkt weiterverwendet.

\section{Natriumcarbonat-Extraktion zur Gewinnung löslicher Proteine}

HeLa-Zellen wurden in PBS gewaschen und bei $200 \mathrm{~g}$ pelletiert. Dieses Zellpellet wurde gewogen und durch Zugabe des dreifachen Volumens ( $\mathrm{ml}$ Puffer / $\mathrm{g}$ Zellpellet) $125 \mathrm{mM}$ Natriumcarbonat auf Eis aufgeschlossen. Die aufgebrochenen Zellen wurden durch Zugabe des 5 -fachen Volumens Aufschlusspuffer $(300 \mathrm{mM} \mathrm{NaCl}$, $2 \%(\mathrm{v} / \mathrm{v}) \mathrm{NP} 40,1 \%(\mathrm{w} / \mathrm{v})$ Natriumdeoxycholat, $100 \mathrm{mM}$ Tris- $\mathrm{HCl}, \mathrm{pH} 8,0)$ und des 0,7-fachen Volumens $1 \mathrm{M} \mathrm{HCl}$ vorsichtig umgepuffert $(\mathrm{pH} 7,5)$ und für $10 \mathrm{~min}$ bei $5.000 \mathrm{~g}$ bei $4^{\circ} \mathrm{C}$ zentrifugiert. Der Überstand wurde $1 \mathrm{~h}$ lang bei $100.000 \mathrm{~g}$ und $4^{\circ} \mathrm{C}$ nachzentrifugiert und als Natriumcarbonat-Extrakt direkt zur Immunpräzipitation weiterverwendet. Alle bei der anschließenden Immunpräzipitation erforderlichen Waschschritte wurden mit IP-Puffer (150 mM NaCl, 0,5\% (w/v) Natriumdeoxycholat, $1 \%(\mathrm{v} / \mathrm{v}) \mathrm{NP} 40,50 \mathrm{mM}$ Tris-HCl, pH 8,0) durchgeführt.

\section{Expression rekombinanter Proteine in E. coli}

Zur Expression rekombinanter Proteine wurden die entsprechenden PlasmidKonstrukte in den E. coli Stamm BL21(DE3), BL21(DE3) CODON plus oder Rosetta 
(DE3) transformiert (siehe Übersichtstabelle). Eine Einzelkolonie der Transformation wurde am nächsten Tag von Selektionsplatte in 200 - 500 ml LB-Selektionsmedium überimpft und in Schikanekolben bei $150-200 \mathrm{U} / \mathrm{min}$ und $37^{\circ} \mathrm{C}$ über Nacht geschüttelt. Am nächsten Tag wurde das Bakterienpellet (30 min, $4.000 \mathrm{~g}$ ) dieser Vorkultur zum Animpfen von 2 Litern LB-Selektionsmedium verwendet. In der exponentiellen Wachstumsphase wurde bei einer $\mathrm{OD}_{600}$ von 0,6 - 0,8 mit IPTG die Proteinexpression induziert. Nach Induktion wurden die Zellen für die entsprechende Zeit bei der erforderlichen Temperatur kultiviert (siehe Übersichtstabelle), erneut abzentrifugiert (30 min, $4.000 \mathrm{~g}$ ), einmal im entsprechenden Lysispuffer (siehe Proteinaufreinigungen) gewaschen, direkt weiter aufgearbeitet oder bei $-80^{\circ} \mathrm{C}$ gelagert.

\begin{tabular}{|l|l|l|l|l|}
\hline $\begin{array}{l}\text { Plasmid bzw. } \\
\text { exprimiertes Protein }\end{array}$ & $\begin{array}{l}\text { Bakterien- } \\
\text { stamm }\end{array}$ & IPTG & Temperatur & Dauer \\
\hline $\begin{array}{l}\text { pET28a-Eferin und - } \\
\text { Eferin } \Delta \mathrm{C}\end{array}$ & $\begin{array}{l}\text { BL21(DE3) } \\
\text { CODON plus }\end{array}$ & $1 \mathrm{mM}$ & $27^{\circ} \mathrm{C}$ & $6 \mathrm{~h}$ \\
\hline pETM11-Eferin & Rosetta (DE3) & $1,25 \mathrm{mM}$ & $25^{\circ} \mathrm{C}$ & $6 \mathrm{~h}$ \\
\hline $\begin{array}{l}\text { pET11d- bzw. } \\
\text { pET23a-RanGAP1 }\end{array}$ & $\begin{array}{l}\text { BL21(DE3) bzw. } \\
\text { Rosetta (DE3) }\end{array}$ & $1 \mathrm{mM}$ & $37^{\circ} \mathrm{C}$ & $2 \mathrm{~h}$ \\
\hline pET11d-Ran & BL21(DE3) & $0,6 \mathrm{mM}$ & $37^{\circ} \mathrm{C}$ & $2 \mathrm{~h}$ \\
\hline His-TEV-Protease $^{2}$ & BL21(DE3) & $0,5 \mathrm{mM}$ & $23^{\circ} \mathrm{C}$ & $4 \mathrm{~h}$ \\
\hline
\end{tabular}

\section{Native Affinitätsreinigung von Hexahistidin-Eferin (= His-Eferin) und His- Eferin $\Delta C$}

Das Bakterienpellet der Proteinexpression (als pET28a- oder pETM11-Konstrukt) wurde in $50 \mathrm{ml}$ kaltem Lysispuffer ( $500 \mathrm{mM} \mathrm{NaCl}, 10 \mathrm{mM}$ Imidazol, $100 \mathrm{mM}$ HEPES $\mathrm{pH}$ 8,0) mit $1 \mathrm{mg}$ Lysozym / $\mathrm{ml}$ resuspendiert und für 45 min auf Eis inkubiert. Zur Abtrennung der bakteriellen Zelltrümmer wurden die aufgebrochenen Zellen $30 \mathrm{~min}$ bei $100.000 \mathrm{~g}$ zentrifugiert. Der Zentrifugationsüberstand wurde mit 10 - $15 \mathrm{ml}$ IDAAgarose-Matrix (ProBond Nickel-Chelating Resin von Invitrogen) versetzt und $1 \mathrm{~h}$ bei

\footnotetext{
${ }^{1}$ bei der RanGAP-Expression erfolgte die Induktion unmittelbar nach der Kultivierung über Nacht

${ }^{2}$ zur Expression der His-TEV-Protease wurde ein bereits transformierter Bakterienstamm gestellt (siehe Aufreinigung der TEV-Protease)
} 
$4^{\circ} \mathrm{C}$ auf einem Drehrad inkubiert. Die Agarose-Matrix mit daran immobilisiertem Protein wurde zunächst einmal mit 50 ml Lysispuffer, dann mit jeweils $100 \mathrm{ml}$ kaltem Waschpuffer 1 (1 M NaCl, 20 mM Imidazol, 100 mM HEPES pH 8,0) und Waschpuffer 2 (150 mM NaCl, 20 mM Imidazol, 50 mM HEPES pH 7,4) gewaschen und die Proteine anschließend mit Elutionspuffer (150 mM NaCl, 300 mM Imidazol, 50 mM HEPES pH 7,4) durch darin enthaltenes Imidazol eluiert. Das Eluat wurde für höhere Reinheit einer Nachreinigung (in Laufpuffer: 150 mM NaCl, 1 mM EDTA, 20 mM HEPES pH 7,4) durch Gelfiltration über eine HiLoad Superdex 200 HR 26/60-Säule unterzogen, schließlich eingeengt und in flüssigem Stickstoff für die Lagerung bei $-80^{\circ} \mathrm{C}$ schockgefroren.

\section{Native Affinitätsreinigung von Ran $\left[{ }^{103}\right]$}

Zunächst wurde das Pellet der bakteriellen Proteinexpression einem Gefrier-AuftauZyklus unterworfen, bevor es in $100 \mathrm{ml}$ Ran-Lysispuffer $(75 \mathrm{mM} \mathrm{NaCl}, 1 \mathrm{mM} \mathrm{MgCl}$, 50 mM Tris- $\mathrm{HCl}$ pH 8,0) mit $1 \mathrm{mg} / \mathrm{ml}$ Lysozym resuspendiert wurde. Inkubation für eine Stunde auf Eis ließ die Zellen aufbrechen, so dass im anschließenden Schritt durch Zentrifugation bei $100.000 \mathrm{~g}$ über $30 \mathrm{~min}$ bei $4^{\circ} \mathrm{C}$ ein klarer Überstand mit darin gelöstem rekombinanten Ran gewonnen wurde. Nach Inkubation mit 40 ml äquilibrierter DEAE-Sepharose blieb Ran im Durchbruch löslich, während alle anderen Proteine unter den gegebenen Bedingungen an das Säulenmaterial (DEAESepharose) banden. Der darauffolgende Waschschritte mit 20 ml Ran-Lysispuffer wurde mit dem Durchbruch vereinigt und zur Ausfällung von Ran mit 33,1\% (w/v) Ammoniumsulfat versetzt. Die Zugabe von Ammoniumsulfat erfolgte dabei schrittweise und die Fällung bei $4^{\circ} \mathrm{C}$ nahm mindestens $1 \mathrm{~h}$ in Anspruch. Das präzipitierte Ran-Protein wurde nach Pelletierung bei $100.000 \mathrm{~g}$ für 20 min und $4^{\circ} \mathrm{C}$ in $600 \mu \mathrm{l}$ GDP-haltigem Transportpuffer (250 $\mu$ M GDP) gelöst und nach erneuter Zentrifugation bei 100.000 g für höhere Reinheit über HiLoad Superdex 75 HR 10/30-Säule mit Transportpuffer als Laufmittel aufgereinigt. Ran-haltige Fraktionen wurden vereinigt und als Aliquote in flüssigem Stickstoff für die Lagerung bei $-80^{\circ} \mathrm{C}$ schockgefroren.

\section{Denaturierende Aufreinigung von humanem RanGAP1 $\left[{ }^{18}\right]$}

Das Bakterienpellet mit Proteinexpression von RanGAP1 wurde in $60 \mathrm{ml}$ kaltem RanGAP1-Lysispuffer (100 mM NaCl, 1 mM EDTA, 50 mM Tris- $\mathrm{HCl}$ pH 8,0) mit 1 mg 
Lysozym / ml Puffer resuspendiert und $1 \mathrm{~h}$ auf Eis inkubiert. Die lysierten Zellen wurden zur Abtrennung der löslich Bestandteile $1 \mathrm{~h}$ bei $100.000 \mathrm{~g}$ zentrifugiert. Der Überstand wurde verworfen und das Pellet mit dem in inclusion bodies enthaltenem RanGAP1 in $50 \mathrm{ml} 4^{\circ} \mathrm{C}$ kaltem Waschpuffer 1 (1\% (v/v) Triton X100, $50 \mathrm{mM}$ Tris-HCl $\mathrm{pH} 8,0$ ) in einem Glashomogenisator homogenisiert. Einem 20-minütigen Zentrifugationsschritt des Homogenats bei $4^{\circ} \mathrm{C}$ folgte der bereits beschriebene Waschschritt im Homogenisator, bevor das nach wie vor unlösliche RanGAP1 erneut bei $100.000 \mathrm{~g}$ über 20 min pelletiert wurde. Nun folgte Homogenisierung in $50 \mathrm{ml}$ kaltem Harnstoff-Waschpuffer (2 M Harnstoff, $50 \mathrm{mM}$ Tris-HCl pH 7,4) und eine Pelletierung bei $\left.100.000 \mathrm{~g} \mathrm{(20} \mathrm{min} \mathrm{bei} 4^{\circ} \mathrm{C}\right)$. Abschließend wurde das Pellet in $30 \mathrm{ml}$ Harnstoffpuffer (8 M Harnstoff, $50 \mathrm{mM}$ Tris-HCl pH 7,4) bei Raumtemperatur solubilisiert und unlöslich Bestandteile bei $100.000 \mathrm{~g}$ (20 min bei Raumtemperatur) abgetrennt. Um den Harnstoff aus der Lösung zu entfernen und um dem durch die denaturierenden Bedingungen entfalteten RanGAP1 eine Rückfaltung zu ermöglichen, wurde die Proteinprobe in Dialyseschläuche (Ausschlussgröße 12 - 14 kD) umgefüllt. Es folgte zunächst die Dialyse für $2 \mathrm{~h}$ bei Raumtemperatur, danach eine über-Nacht-Dialyse mit frischem, $4^{\circ} \mathrm{C}$ kaltem Dialysepuffer ( $150 \mathrm{mM} \mathrm{NaCl}, 50 \mathrm{mM}$ Tris- $\mathrm{HCl} \mathrm{pH} \mathrm{7,4,} \mathrm{je} 2 \mathrm{l}$ ). Nach extensiver Dialyse galt es präzipitierte Bestandteile durch Pelletierung abzutrennen $\left(100.000 \mathrm{~g}, 45 \mathrm{~min}, 4^{\circ} \mathrm{C}\right)$. Lösliches RanGAP1 wurde durch Zugabe von $15 \mathrm{ml}$ äquilibrierter Q-Sepharose aus der Proteinlösung entfernt. Die Sepharose mit gebundenem RanGAP1 wurden über eine Frittensäule zurückgehalten und das Säulenmaterial mit $300 \mathrm{ml}$ Waschpuffer $2(300 \mathrm{mM} \mathrm{NaCl}, 30 \mathrm{mM}$ Tris-HCl pH 7,5) gewaschen. Das in seiner Nettoladung negativ geladene RanGAP1 wurde durch Zugabe von $25 \mathrm{ml}$ Hochsalzpuffer $(1 \mathrm{M} \mathrm{NaCl}, 50 \mathrm{mM}$ Tris-HCl pH 7,5) von der Anionensäule (Q-Sepharose) eluiert. Durch Auftropfen von je $2 \mu \mathrm{l}$ der gesammelten $5 \mathrm{ml}-$ Fraktionen auf Nitrocellulose, mit anschließender Ponceau-Färbung, konnten die RanGAP1-haltigen Fraktionen identifiziert und vereinigt werden. Die vereinigten Eluate wurden für die Nachreinigung mit Hilfe von Zentrifugationsfiltereinheiten eingeengt und über Membranfilter klarfiltriert. Schließlich wurde dieses Filtrat über eine HiLoad Superdex 200 HR 26/60-Säule mit Transportpuffer als Laufmittel aufgetrennt. Fraktionen mit korrekt gefaltetem, katalytisch aktivem RanGAP1 erschienen als scharfer Scheitelwert mit einem angedeuteten Molekulargewicht von $150 \mathrm{kD}$, wurden vereinigt und schließlich in flüssigem $\mathrm{N}_{2}$ für die Lagerung bei $-80^{\circ} \mathrm{C}$ schockgefroren. 


\section{Aufreinigung der TEV-Protease}

Prinzipiell wäre eine Aufreinigung der His-TEV-Protease über gängige $\mathrm{Ni}^{2+}$-Affinitätschromatografie-Protokolle möglich gewesen. Da jedoch eine Protease hoher Aktivität und hoher Reinheit erwünscht war, wurde ein eigenes Aufreinigungsprotokoll ausgearbeitet. In diesem wurde als Oxidanzfänger Glutathion zugesetzt, insgesamt gründlicher und stringenter gewaschen, der Proteaseinhibitor Pepstatin stets in hoher Konzentration beigemischt und dem Dialysepuffer zur Inhibition metallabhängiger Proteasen EDTA zugesetzt. Für die Aufreinigung der TEV-Protease wurden expressionsplasmidtragende Bakterien als Glycerolstock von Marc Arnold (Arbeitsgruppe Ralph Kehlenbach, Universität Göttingen) gestellt. Diese wurden zunächst auf Selektionsplatten (Kanamycin / Chloramphenicol) ausgestrichen, dann zum Ansetzen einer Flüssigkultur verwendet. Das Bakterienpellet der Proteinexpression (geerntet $4 \mathrm{~h}$ nach Induktion mit 0,5 mM IPTG bei $23^{\circ} \mathrm{C}$ ) wurde in $200 \mathrm{ml}$ TEV-Lysispuffer (150 mM NaCl, 20\% (v/v) Glycerol, 0,03\% (v/v) NP40, 1 mM PMSF, $150 \mu \mathrm{M}$ Pepstatin A, 3 mM Glutathion, 10 mM Imidazol, 20 mM HEPES pH 7,5) durch Sonifikation aufgeschlossen, gefolgt von Zentrifugation für 15 min bei $15.000 \mathrm{~g}$ und $4^{\circ} \mathrm{C}$. Der lösliche Überstand wurde mit $10 \mathrm{ml}$ äquilibrierter $\mathrm{Ni}^{2+}$-IDA-Agarose (ProBond, Invitrogen) versetzt und für $1 \mathrm{~h}$ bei $4^{\circ} \mathrm{C}$ auf dem Drehrad inkubiert, bevor Agarose-Matrix und daran gebundenes Protein über eine Frittensäule zurückgehalten wurden. Es folgten Waschschritte mit jeweils einem Säulenvolumen (entspricht zehnfachem Matrix-Volumen) der TEV-Waschpuffer 1 - 3 (Waschpuffer 1: $100 \mathrm{mM} \mathrm{Na}_{2} \mathrm{CO}_{3}, 150 \mathrm{mM} \mathrm{NaCl}, 20 \%$ (v/v) Glycerol, 0,03\% (v/v) NP40, 1 mM PMSF, 1,5 $\mu$ M Pepstatin A, 3 mM Glutathion, 10 mM Imidazol; Waschpuffer 2: $1 \mathrm{M} \mathrm{NaCl}$, 20\% (v/v) Glycerol, 0,03\% (v/v) NP40, 1 mM PMSF, 1,5 $\mu$ M Pepstatin A, 3 mM Glutathion, 10 mM Imidazol, 20 mM HEPES pH 7,4; Waschpuffer 3: 150 mM NaCl, 20\% (v/v) Glycerol, 0,03\% (v/v) NP40, 1 mM PMSF, 1,5 $\mu$ M Pepstatin A, 3 mM Glutathion, 10 mM Imidazol, 20 mM HEPES pH 7,4) und schließlich Elution mit 50 ml TEV-Elutionspuffer (150 mM NaCl, 20\% (v/v) Glycerol, 0,03\% (v/v) NP40, 1 mM PMSF, 1,5 $\mu$ M Pepstatin A, 3 mM Glutathion, 150 mM Imidazol, 20 mM HEPES $\mathrm{pH} 7,4)$. Eluierte Fraktionen wurden bei $4^{\circ} \mathrm{C}$ gesammelt, die proteinhaltigen Fraktionen vereint und für $8 \mathrm{~h}$ in einem Dialyseschlauch mit einer Ausschlussgröße von 12 - 14 kD gegen 2 I TEV-Dialysepuffer (50\% (v/v) Glycerol, 150 mM NaCl, 5 mM DTT, 1 mM PMSF, 135 MM Pepstatin A, 1 mM EDTA, 20 mM HEPES pH7,5) dialysiert. Die dialysierte Protease wurde in Bezug auf Reinheit, Ausbeute und 
Aktivität überprüft, aliquotiert und in flüssigem Stickstoff für Lagerung bei $-80^{\circ} \mathrm{C}$ schockgefroren.

\section{Differentielle Detergenzfraktionierung $\left.{ }^{109}\right]$}

Um Hinweise für die Kompartimentzugehörigkeit eines bestimmten Proteins zu erlangen wurden adhärente HeLa-Zellen einer sequenziellen Fraktionierung mit verschiedenen Detergenzien unterzogen. Zu diesem Zweck wurden die Zellen wie in Chiang et al. beschrieben [ $\left.{ }^{109}\right]$ mit je $35 \mu \mathrm{l} / \mathrm{cm}^{2}$ Grundfläche des entsprechenden Puffers unter sanftem Schwenken für die angegebenen Zeiten auf Eis inkubiert. Nach jedem Inkubationsschritt wurden die Zellen mit demselben Puffer nachgespült, dann folgte die nächste Extraktion. Im letzten Extraktionsschritt wurden die verbleibenden Zellbestandteile mit dem entsprechenden Puffer versetzt und durch Abschaben geerntet, während die vorangegangenen Extrakte bei $4^{\circ} \mathrm{C}$ und $15.000 \mathrm{~g}$ über 5 min klarzentrifugiert wurden. Die klaren Überstände und der Extrakt des letzten Schrittes wurden über Nacht mit dem vierfachen Volumen eiskalten Acetons $\left(-20^{\circ} \mathrm{C}, 100 \% \mathrm{v} / \mathrm{v}\right)$ bei $-20^{\circ} \mathrm{C}$ gefällt. Die Pelletierung der präzipitierten Proteine erfolgte bei $3.000 \mathrm{~g}$ für $15 \mathrm{~min}$. Nach der Trocknung der Pellets wurden diese mit $1 \times$ SDS-Probenpuffer zurückgelöst, bei $95^{\circ} \mathrm{C}$ für 5 min aufgekocht und sonifiziert.

\section{Interaktionsstudien}

Für Interaktionsstudien von Kandidatproteinen wurden zwei sehr ähnliche Vorgehensweisen gewählt. Dabei wurde nach dem Prinzip vorgegangen, einen Proteinpartner an einer Matrix (im Weiteren als beads bezeichnet) zu immobilisieren und den (oder weitere) Bindepartner in löslicher Form zur Verfügung zu stellen.

\section{Immobilisierung von Proteinen über $\mathrm{Ni}^{2+}$}

Bei der Immobilisierung über $\mathrm{Ni}^{2+}$ wird stets das Protein immobilisiert, welches in der Lage ist, mit dem Nickelion der IDA-Agarose-Matrix $\left(=\mathrm{Ni}^{2+}\right.$-beads) einen Chelatkomplex zu bilden. Dies wird über ein His-Epitop (= His-tag), eine artifizielle Sechseroder Achterfolge von Histidinen, fusioniert am Amino- oder Carboxyterminus des zu bindenden Proteins, erreicht. Üblicherweise wurde ein zwei bis dreifacher molarer Überschuss des zu präzipitierenden Proteins, als Zellextrakt oder aufgereinigt als 
rekombinantes Protein, zu den mit dem immobilisierten Protein besetzten beads (meist $1 \mu \mathrm{g}$ Protein / $\mu$ l beads) zugegeben und für eine Stunde bei $4^{\circ} \mathrm{C}$ auf dem Drehrad inkubiert. Die Proben wurden, sofern kein Waschschritt nötig war, mit heißem 2 x SDS-Probenpuffer von den beads eluiert und für weitere Analysen auf Gel aufgetragen.

\section{Immobilisierung von Proteinen über Cyanogenbromid-aktivierte Sepharose}

Für einen Ansatz mit kovalent gebundenem Protein wurde selbiges, wie bereits unter Affinitätsreinigung von Antikörpern ausführlicher beschrieben, zunächst an Cyanogenbromid-aktivierte Sepharose kreuzvernetzt. Nach der kovalenten Bindung konnte dieses bead-Material im entsprechenden Puffer äquilibriert und mit Zellextrakten oder aufgereinigten rekombinanten Proteinen für $1-2 \mathrm{~h}$ bei $4^{\circ} \mathrm{C}$ auf dem Drehrad inkubiert werden. Das zu präzipitierende Protein wurde hierbei entweder äquimolar oder im dreifachen molaren Überschuss eingesetzt. Nach der Inkubation folgte dem Waschschritt die Elution der Probe mit heißem 2 x SDS-Probenpuffer. Bei schwachen Interaktionen wurde vor der Elution auf einen Waschschritt verzichtet.

\section{SUMO-Bindungsversuch (= SUMO binding assay)}

SUMO1, SUMO2 (jeweils rekombinant) bzw. Ovalbumin wurden mit einer Endkonzentration von jeweils $0,1 \mu \mathrm{g} / \mu \mathrm{l}$ an Cyanogenbromid-aktivierter Sepharose gekoppelt und zusammen mit inaktivierter (ungekoppelter) Cyanogenbromidaktivierter Sepharose als immobilisierte Matrix vorgelegt. Zur Absättigung unspezifischer Bindestelle wurden die Matrices für $1 \mathrm{~h}$ bei $4^{\circ} \mathrm{C}$ auf dem Drehrad in SUMOBindungspuffer (2 mg / ml Ovalbumin, 0,05\% (v/v) Tween-20 in Transportpuffer) vorinkubiert. Es folgte Zugabe der Kandidatenproteine (His-Eferin und His-Eferin $\Delta \mathrm{C}$ ) verdünnt im SUMO-Bindungspuffer mit einer Konzentration von je 0,33 $\mu \mathrm{g} / \mu \mathrm{l}$ und Inkubation für $4 \mathrm{~h}$ bei $4^{\circ} \mathrm{C}$ auf dem Drehrad. Dem Waschen der Matrices mit 0,05\% (v/v) Tween-20 in Transportpuffer folgte Elution mit 1x SDS-Ladepuffer, bevor die Proben nach SDS-PAGE über Coomassie-Färbung ausgewertet wurden. 


\section{Enzymatische Reaktionen}

\section{Radioaktive Beladung von Ran $\left[^{110}\right]$}

100 ng rekombinantes Ran wurden in Ran Ladepuffer (2,5 mM DTT, 10 mM EDTA, $25 \mu \mathrm{M}$ GTP, 2 mM ATP, 50mM HEPES pH 7,3) unter Zugabe von $20 \mu \mathrm{C} \alpha^{32} \mathrm{P}-\mathrm{GTP}$ 30 min lang bei $30^{\circ} \mathrm{C}$ inkubiert. Durch Zugabe von $\mathrm{MgCl}_{2}$ unter Einstellung einer Endkonzentration von $10 \mathrm{mM}$ erfolgte die eigentliche Beladung mit radioaktiv markiertem GTP. Um das beladene Ran von ungebundenen Nukleotiden abzutrennen, wurde das gesamte Gemisch auf eine äquilibrierte Nap5-Entsalzungssäule gegeben, zunächst mit $300 \mu \mathrm{l}$ Ran Wasch- und Elutionspuffer $(0,1 \mathrm{mg} / \mathrm{ml} \mathrm{BSA,} 5 \mathrm{mM} \mathrm{MgCl}$, 2 mM DTT, 50 mM HEPES pH 7,3) gewaschen und mit 1 ml desselben Puffers von der Säule eluiert. Die zu je $100 \mu$ l gesammelten Eluate wurden auf ihre Ran-Haltigkeit und Radioaktivität hin untersucht, bei Vorliegen beider Eigenschaften vereinigt und als Aliquote mit flüssigem Stickstoff für eine Lagerung bei $-80^{\circ} \mathrm{C}$ eingefroren. Das mit radioaktivem GTP beladene Ran wurde vor jeder Versuchsreihe auf seine enzymatische Aktivität hin untersucht, indem es mit und ohne dem GTPase aktivierenden Enzym RanGAP1 inkubiert und beide Umsetzungsreaktionen von GTP zu GDP im zeitlichen Verlauf miteinander verglichen wurden (siehe GAP assay).

\section{GTPase-Aktivitätsversuch (= GAP assay) $\left[{ }^{18}\right]$}

Im Vorfeld des Versuches war es nötig, Dünnschichtchromatografie-Platten (= thin layer chromatography = TLC) für eine Auftrennung vorzubereiten. Dazu wurden auf einer einheitlichen Startlinie für alle gewünschten Zeitpunkte Markierungen gemacht. Auf jeden Startpunkt (= Markierung auf der Startlinie) wurde als carrier je $1 \mu$ l eines 5 mM GTP/GDP-Mix getropft und anschließend diese TLC-Platten vollständig getrocknet. Üblicherweise wurde für den GAP assay eine Reaktion zur Darstellung der Autokonversion (von RanGTP zu RanGDP) und eine Reaktion zur Darstellung der RanGAP1-katalysierten Umsetzung angesetzt. Dazu wurde ein Ansatz mit 0,5 ng RanGAP1 und einer ohne RanGAP1 in je12 $\mu$ l GAP assay Puffer $(0,2$ mg / ml Ovalbumin, 0,05\% (v/v) Tween-20 in Transportpuffer) vorgelegt und die Reaktion durch Zugabe von $8 \mu$ radioaktiven Ran-GTP gestartet. Zu den gewünschten Zeitpunkten wurde je $1 \mu \mathrm{l}$ dieses Mix auf die festgelegten Startpunkte getropft und nach vollständiger Trocknung in einer Chromatografie-Kammer mit TLC-Laufpuffer 
(0,5 M LiCl, 1,0 M Ameisensäure) aufgetrennt. Zur Quantifizierung von GTP und GDP wurde die getrocknete TLC-Platte auf einer Phospholmager Screen-Folie für 1 - 3 h fixiert. Die Auswertung der GDP und GTP-Laufformen erfolgte am PhosphoImager-Gerät der Arbeitsgruppe Jentsch am MPI für Biochemie (Martinsried). Dabei hatte GDP gegenüber GTP stets die geringere Retensionszeit. Die Ergebnisse der Umsetzungsreaktion wurden anschließend rechnerisch ausgewertet und graphisch dargestellt.

\section{SUMO-Modifikationsversuch (= SUMOylation assay) $\left[{ }^{67}\right]$}

Für diesen Versuch wurden alle notwendigen Enzyme zur Verknüpfung von SUMO mit dem zu modifizierende Protein als rekombinante Proteine verwendet. Die Reaktion bewirkte eine ATP-abhängige Verknüpfung von SUMO mit dem Zielprotein und setzte sich aus SUMO 1 (80 ng), Aos1/Uba2 (100 ng), Ubc9 (200 ng), 0,05\% (v/v) Tween-20 und 0,2 mg / ml Ovalbumin zusammen. Nach Zugabe des zu modifizierenden Zielproteins (200 ng), wurde die Reaktion für 30 min in Anwesenheit von $1 \mathrm{mM}$ ATP bei $30^{\circ} \mathrm{C}$ inkubiert. Im Anschluss daran wurde der Erfolg der Modifikation im Westernblot oder als Coomassie-gefärbtes Gel überprüft, bevor die restliche Probe weiteren biochemischen Anwendungen zur Verfügung stand. Als Variante wurde dem ursprünglichen Ansatz aufgereinigtes E3-Enzym zugesetzt. Nach Zugabe von 100 ng rekombinanten Zielproteins wurde die Reaktion für $1 \mathrm{~h}$ 30 min einer Temperatur von $30^{\circ} \mathrm{C}$ ausgesetzt und durch Zugabe von 2x SDSProbenpuffer unter Kochen bei $96^{\circ} \mathrm{C}$ für 5 min zum Abbruch gebracht.

\section{In vivo Sumoylierungsversuch (= in vivo SUMOylation assay) $\left[{ }^{111,112}\right]$}

In diesem Versuchsaufbau kam eine stabile His-SUMO1 Zelllinie zum Einsatz, bei der ein mögliches Zielprotein auf endogenem Level oder auf Basis einer Überexpression (nach Transfektion mit dem entsprechenden Konstrukt) bezüglich der Modifikation mit His-SUMO1 untersucht werden sollte. Zur Ernte der angesetzten Zellen wurden selbige erst mit PBS gespült, dann in einer GuanidiniumhydrochloridLösung (6 M Guanidiniumhydrochlorid, 6,8 mM NaH $\mathrm{mO}_{4}, 93,2 \mathrm{mM} \mathrm{Na}_{2} \mathrm{HPO}_{4}, 10 \mathrm{mM}$ Tris- $\mathrm{HCl}$ pH 8,0) vollständig solubilisiert. Nach Sonifikation des Solubilisates werden mögliche Präzipitate durch 15-minütige Zentrifugation bei $4.000 \mathrm{~g}$ bei Raumtemperatur entfernt und der Überstand mit $\mathrm{Ni}^{2+}$-Agarose versetzt. Nach Zugabe von 
Imidazol zu einer finalen Konzentration von $5 \mathrm{mM}$ wird das Gemisch über Nacht bei Raumtemperatur auf dem Drehrad inkubiert. Es folgen stringente Waschschritte unter weiterhin denaturierenden Bedingungen mit der 6 M Guanidiumchlorid-Lösung und den in Rodriguez et al. beschriebenen Waschpuffern $\left[{ }^{112}\right]$. Schließlich wurden die modifizierten Proteine von der $\mathrm{Ni}^{2+}$-Agarose mit Imidazol und SDS-Probenpuffer eluiert und untersucht.

\section{In vitro Phosphorylierung}

Bei der in vitro Phosphorylierung wurden Digitonin-Zellextrakte unarretierter oder Nocodazol-arretierter Zellen mit jeweils 200 ng rekombinantem Eferin mit 1 mM ATP, $0,1 \%(v / v)$ Tween-20 und $0,2 \mu \mathrm{g} / \mu \mathrm{l}$ Ovalbumin bei $30^{\circ} \mathrm{C}$ für $30 \mathrm{~min}$ inkubiert, nach Zugabe von $2 x$ SDS-Probenpuffer bei $95^{\circ} \mathrm{C}$ für 5 min aufgekocht und nach SDSPAGE auf Modifikation hin untersucht.

\section{In vitro Degradationsversuch $\left[{ }^{113}\right]$}

Für den Degradationsversuch wurden Digitonin-Zellextrakte unarretierter oder Nocodazol-arretierter Zellen mit jeweils 400 pg rekombinantem Eferins, mit 1 mM ATP, $0,1 \%(v / v)$ Tween-20 und $0,2 \mu \mathrm{g} / \mu \mathrm{l}$ Ovalbumin bei $30^{\circ} \mathrm{C}$ für 30 min inkubiert. Des Weiteren wurde $4 \mu \mathrm{M}$ des Proteasom-Inhibitors MG132, als energieregenerierendes System $5 \mathrm{mM}$ Creatinphosphat mit $10 \mathrm{lU} / \mathrm{ml}$ Creatinphosphokinase, Phosphatase Inhibitor Cocktail 2 in einer Verdünnung von $1: 100$ und Ubiquitin in einer Endkonzentration von 1,25 mg / ml zugesetzt. Nach Zugabe von 2x SDSProbenpuffer wurde das Gemisch bei $95^{\circ} \mathrm{C}$ für 5 min aufgekocht und nach SDSPAGE auf Modifikation und Degradation hin untersucht. 


\section{Ergebnisse}

\section{Werkzeuge für in vitro und in vivo Studien}

Ziel dieser Arbeit war die biochemische und zellbiologische Charakterisierung des putativen RanGAP1-Interagierers Eferin. Dafür musste zunächst eine Reihe von Konstrukten erzeugt werden, die zur Expression von Eferin bzw. Eferin-Fragmenten in Bakterien- und Säugerzellen dienen sollten. Tabelle 1 fasst die generierten Konstrukte zusammen.

\section{Klonierung unterschiedlicher Eferin-Expressionskonstrukte}

Ausgangspunkt für die Klonierungsvorhaben war zum einen die von Dr. Andreas Gast beobachtete centrosomale Lokalisation von Eferin in Mitose, zum anderen die Identifikation von Eferin als möglicher Bindepartner von RanGAP1 in yeast two hybrid Versuchen sowie Veröffentlichungen zu weiteren Bindepartnern von Eferin. Zur Bestätigung der in der (indirekten) Immunfluoreszenz-Analyse beobachteten mitotischen Lokalisation von Eferin an den Centrosomen wurde deshalb zunächst ein fluoreszierendes YFP-Eferin-Fusionskonstrukt kloniert. Da die Bindedomänen (dargestellt in Abb. 1) der bekannten Interaktionspartner von Eferin bereits beschrieben waren [ ${ }^{83,86,92}$, stellte sich im Folgenden die Frage, welcher Domäne in Eferin die Vermittlung der centrosomalen Lokalisation zugeschrieben werden könnte. Zu diesem Zweck wurde Eferin sequentiell um die betreffenden Domänen verkürzt. Daneben wurde ein ausschließlich die RanGAP1-Bindedomäne-tragendes Konstrukt von Eferin neben einer Variante mit Deletion des Aminoterminus erzeugt. Schon die Klonierung dieser Fragmente an sich stellte eine besondere Herausforderung dar. Die DNA-Sequenz von Eferin ist auffallend GC-reich, weshalb bei der Klonierung nur eine Bausteinstrategie zum gewünschten Erfolg führte. Dabei wurden durch gezielte PCR-Amplifikation der Eferin-Sequenz kleinere Fragmente (= Bausteine) erzeugt und durch anschließende Ligation dieser unterschiedlichen Bausteine daraus die gewünschten Eferin-Konstrukte zusammengebaut. 

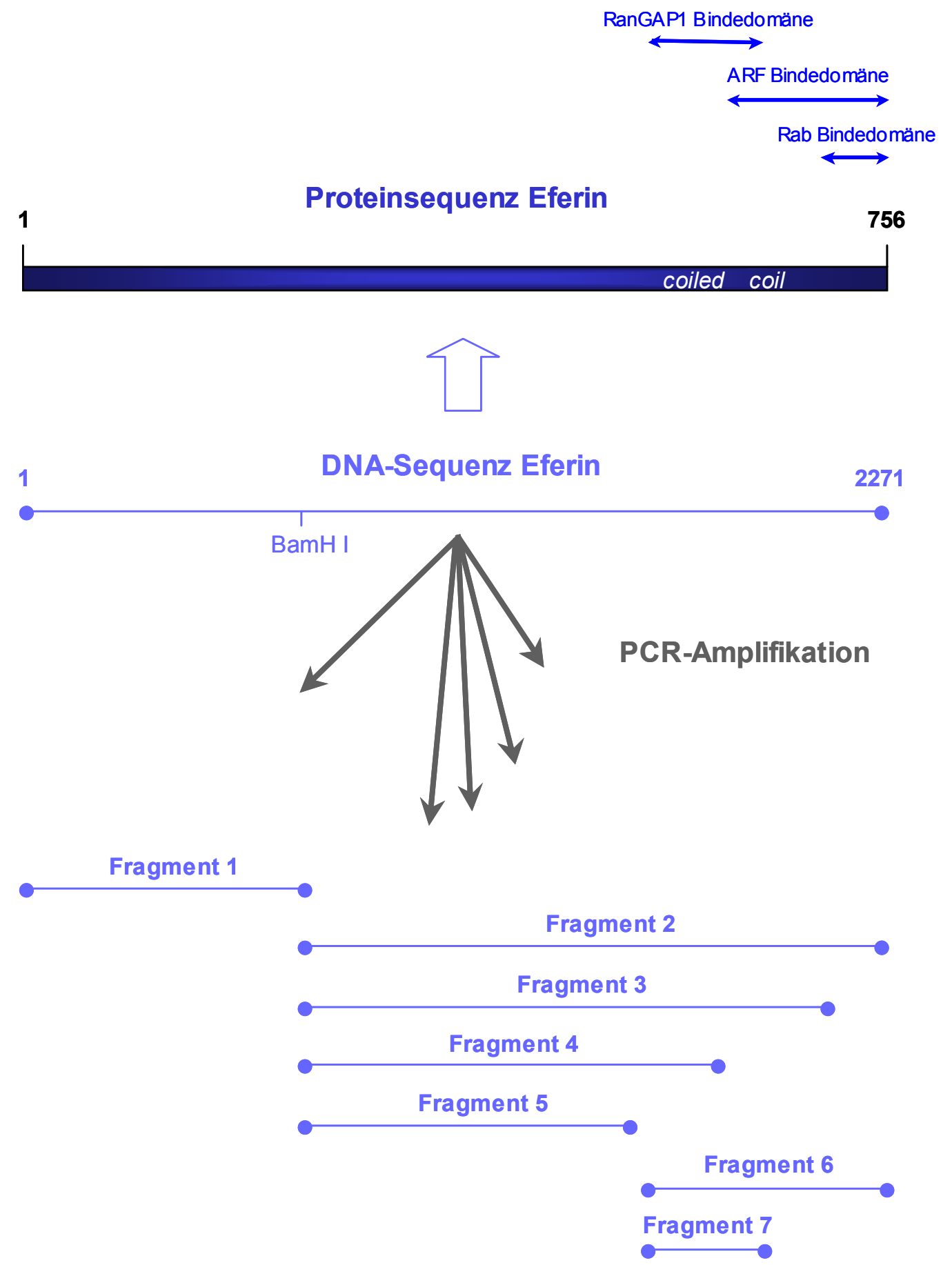

\section{Abbildung 1: Klonierungsstrategie der Eferin-Konstrukte}

Die mittels gezielter PCR amplifizierten Fragmente der Eferin-Sequenz wurden über Ligation zu unterschiedlichen neuen Konstrukten zusammengebaut; siehe Tabelle 1.

Da für die Transfektion von Säugerzellen zudem Überexpressionskonstrukte ohne zusätzliche Epitopmarkierung erwünscht waren, wurden selbige durch Umklonierung generiert. Dabei wurde die codierende Sequenz von Eferin, einschließlich des terminalen Stoppcodons, durch Restriktionsverdau aus den vorhandenen bakteriellen Expressionsplasmiden pET28a-Eferin und pET28a-Eferin $\Delta C$ ausgeschnitten. Diese 
beiden Fragmente wurden anschließend über die vor dem YFP-Epitop gelegenen, multiplen Restriktionsschnittstellen jeweils in einen pEYFP-N1-Vektor einligiert. Da die einklonierten Fragmente stets ein terminales Stoppcodon mitbrachten, kam es nicht zu Fusion mit dem c-terminalen YFP-Epitop.

\begin{tabular}{|c|c|c|c|c|c|c|}
\hline $\begin{array}{l}\text { Bezeichnung } \\
\text { des Konstruktes }\end{array}$ & $\begin{array}{l}\text { Ausgangs- } \\
\text { vektor }\end{array}$ & $\begin{array}{l}\text { eingesetzte } \\
\text { Primer }^{3}\end{array}$ & $\begin{array}{l}\text { verwendete } \\
\text { Fragmente bzw. } \\
\text { insert }\end{array}$ & $\begin{array}{l}\text { Ziel- } \\
\text { Vektor }\end{array}$ & $\begin{array}{l}\text { Ligation über } \\
\text { Restriktions- } \\
\text { schnittstellen }\end{array}$ & $\begin{array}{l}\text { Länge des } \\
\text { Eferin- } \\
\text { inserts (aa) }\end{array}$ \\
\hline $\begin{array}{l}\text { pEYPF-N1- } \\
\text { Eferin (Eferin- } \\
\text { YFP) }\end{array}$ & pET28a-Eferin & \begin{tabular}{|l|}
$\#$ 661, \# 698 \\
$\#$ 663, \# 699
\end{tabular} & $1+2$ & $\begin{array}{l}\text { pEYPF- } \\
\text { N1 }\end{array}$ & $\begin{array}{l}\text { Xho I / BamH I } \\
\text { BamH I / EcoR I }\end{array}$ & $1-756$ \\
\hline $\begin{array}{l}\text { pEYPF-C1- } \\
\text { Eferin (YFP- } \\
\text { Eferin) }\end{array}$ & $\begin{array}{l}\text { pEYPF-N1- } \\
\text { Eferin }\end{array}$ & $\begin{array}{l}\text { Umklonierung } \\
\text { statt PCR- } \\
\text { Amplifikation }\end{array}$ & $\begin{array}{l}\text { Eferin (Xho I / EcoR } \\
\text { I geschnitten) }\end{array}$ & $\begin{array}{l}\text { pEYPF- } \\
\text { C1 }\end{array}$ & Xho I / EcoR I & $1-756$ \\
\hline $\begin{array}{l}\text { pEYPF-N1- } \\
\text { Eferin } \Delta \text { Rab11- } \\
\text { BD }\end{array}$ & pET28a-Eferin & $\begin{array}{l}\text { \# 661, \# } 698 \\
\# \text { 664, \# } 699\end{array}$ & $1+3$ & $\begin{array}{l}\text { pEYPF- } \\
\text { N1 }\end{array}$ & $\begin{array}{l}\text { Xho I / BamH I } \\
\text { BamH I / EcoR I }\end{array}$ & $1-705$ \\
\hline $\begin{array}{l}\text { pEYPF-C1- } \\
\text { Eferin } \Delta \text { Rab11- } \\
\text { BD }\end{array}$ & $\begin{array}{l}\text { pEYPF-N1- } \\
\text { Eferin } \Delta \text { Rab11- } \\
\text { BD }\end{array}$ & $\begin{array}{l}\text { Umklonierung } \\
\text { statt PCR- } \\
\text { Amplifikation }\end{array}$ & $\begin{array}{l}\text { Eferin } \Delta \text { Rab11-BD } \\
\text { (Xho I / EcoR I } \\
\text { geschnitten) }\end{array}$ & $\begin{array}{l}\text { pEYPF- } \\
\text { C1 }\end{array}$ & Xho I / EcoR I & $1-705$ \\
\hline $\begin{array}{l}\text { pEYPF-N1- } \\
\text { Eferin } \Delta \text { ARF-BD }\end{array}$ & pET28a-Eferin & $\begin{array}{l}\# \text { \#661, \# } 698 \\
\# \text { 683, \# } 699\end{array}$ & $1+4$ & $\begin{array}{l}\text { pEYPF- } \\
\text { N1 }\end{array}$ & $\begin{array}{l}\text { Xho I / BamH I } \\
\text { BamH I / EcoR I }\end{array}$ & $1-610$ \\
\hline $\begin{array}{l}\text { pEYPF-C1- } \\
\text { Eferin } \triangle A R F-B D\end{array}$ & $\begin{array}{l}\text { pEYPF-N1- } \\
\text { Eferin } \triangle \text { ARF-BD }\end{array}$ & $\begin{array}{l}\text { Umklonierung } \\
\text { statt PCR- } \\
\text { Amplifikation }\end{array}$ & $\begin{array}{l}\text { Eferin } \triangle \mathrm{ARF}-\mathrm{BD} \\
\text { (Xho I / EcoR I } \\
\text { geschnitten) }\end{array}$ & $\begin{array}{l}\text { pEYPF- } \\
\text { C1 }\end{array}$ & Xho I / EcoR I & $1-610$ \\
\hline $\begin{array}{l}\text { pEYPF-N1- } \\
\text { Eferin } \triangle \text { RanGAP- } \\
\text { BD }\end{array}$ & pET28a-Eferin & \begin{tabular}{|l|}
$\#$ 661, \# 698 \\
$\#$ 665, \# 699
\end{tabular} & $1+5$ & $\begin{array}{l}\text { pEYPF- } \\
\text { N1 }\end{array}$ & $\begin{array}{l}\text { Xho I / BamH I } \\
\text { BamH I / EcoR I }\end{array}$ & \begin{tabular}{|l|}
$1-548$ \\
\end{tabular} \\
\hline $\begin{array}{l}\text { pEYPF-C1- } \\
\text { Eferin } \triangle \text { RanGAP- } \\
\text { BD }\end{array}$ & $\begin{array}{l}\text { pEYPF-N1- } \\
\text { Eferin } \triangle \text { RanGAP- } \\
\text { BD }\end{array}$ & $\begin{array}{l}\text { Umklonierung } \\
\text { statt PCR- } \\
\text { Amplifikation }\end{array}$ & $\begin{array}{l}\text { Eferin } \triangle \text { RanGAP-BD } \\
\text { (Xho I / EcoR I } \\
\text { geschnitten) }\end{array}$ & $\begin{array}{l}\text { pEYPF- } \\
\text { C1 }\end{array}$ & Xho I / EcoR I & $1-548$ \\
\hline $\begin{array}{l}\text { pEYPF-N1- } \\
\text { Eferin } \Delta N\end{array}$ & pET28a-Eferin & \# 662, \# 663 & 6 & $\begin{array}{l}\text { pEYPF- } \\
\text { N1 }\end{array}$ & Xho I / EcoR I & \begin{tabular}{|l|}
$549-756$ \\
\end{tabular} \\
\hline $\begin{array}{l}\text { pEYPF-C1- } \\
\text { Eferin } \Delta N\end{array}$ & $\begin{array}{l}\text { pEYPF-N1- } \\
\text { Eferin } \Delta \mathrm{N}\end{array}$ & $\begin{array}{l}\text { Umklonierung } \\
\text { statt PCR- } \\
\text { Amplifikation }\end{array}$ & $\begin{array}{l}\text { Eferin } \Delta \mathrm{N} \text { (Xho I / } \\
\text { EcoR I geschnitten) }\end{array}$ & $\begin{array}{l}\text { pEYPF- } \\
\text { C1 }\end{array}$ & Xho I / EcoR I & $549-756$ \\
\hline $\begin{array}{l}\text { pEYPF-N1- } \\
\text { Eferin } \\
\text { RanGAP1-BD }\end{array}$ & pET28a-Eferin & \# 662, \# 667 & 7 & $\begin{array}{l}\text { pEYPF- } \\
\text { N1 }\end{array}$ & Xho I / EcoR I & $549-645$ \\
\hline $\begin{array}{l}\text { pEYPF-C1- } \\
\text { Eferin } \\
\text { RanGAP1-BD }\end{array}$ & $\begin{array}{l}\text { pEYPF-N1- } \\
\text { Eferin RanGAP- } \\
\text { BD }\end{array}$ & $\begin{array}{l}\text { Umklonierung } \\
\text { statt PCR- } \\
\text { Amplifikation }\end{array}$ & $\begin{array}{l}\text { Eferin RanGAP-BD } \\
\text { (Xho I / EcoR I } \\
\text { geschnitten) }\end{array}$ & \begin{tabular}{|l} 
pEYPF- \\
C1
\end{tabular} & Xho I / EcoR I & $549-645$ \\
\hline $\mathrm{CMV}_{\mathrm{P}-\text {-Eferin } \Delta \mathrm{C}}$ & $\begin{array}{l}\text { pET28a- } \\
\text { Eferin } \Delta \mathrm{C}\end{array}$ & $\begin{array}{l}\text { Umklonierung } \\
\text { statt PCR- } \\
\text { Amplifikation }\end{array}$ & $\begin{array}{l}\text { Eferin } \Delta \mathrm{C} \text { (EcoR I / } \\
\text { Xho I geschnitten) }\end{array}$ & $\begin{array}{l}\text { pEYPF- } \\
\text { N1 }\end{array}$ & EcoR I / Sal I & $1-434$ \\
\hline $\mathrm{CMV}_{\mathrm{P}}$-Eferin & pET28a-Eferin & $\begin{array}{l}\text { Umklonierung } \\
\text { statt PCR- } \\
\text { Amplifikation }\end{array}$ & $\begin{array}{l}\text { Eferin (EcoR I / Xho } \\
\text { I geschnitten) }\end{array}$ & $\begin{array}{l}\text { pEYPF- } \\
\text { N1 }\end{array}$ & EcoR I / Sal I & $1-756$ \\
\hline pETM11-Eferin & pET28a-Eferin & $\begin{array}{l}\text { \# 696, \# } 698 \\
\# \text { 697, \# } 699\end{array}$ & $1+2$ & pETM11 & $\begin{array}{l}\text { Nco I / BamH I } \\
\text { BamH I / Xho I }\end{array}$ & $1-756$ \\
\hline
\end{tabular}

Tabelle 1

${ }^{3}$ Sequenzen in Material und Methoden 


\section{Aufreinigung von rekombinantem His-Eferin für in vitro Experimente}

Für biochemische Untersuchungen sowie Generierung und Affinitätsreinigung von Antikörpern stand bisher ein His-Eferin-Konstrukt im pET28a-Vektor zur Verfügung. Dieses Konstrukt besitzt zwischen dem His-Epitop (= His-tag) und der EferinSequenz eine Schnittstelle für die Thrombin-Protease. Daher bietet dieser Vektor die Möglichkeit, His-Eferin, nach Aufreinigung unter nicht-denaturierenden Bedingungen, zu einem epitopfreien (= tag-freien), nativen Eferin zu schneiden. Dieses sollte dann, ohne das eventuell störende Epitop, beispielsweise dazu verwendet werden, um in Zellextrakten nach neuen Bindepartnern zu suchen.

Daher wurde His-Eferin (als pET28a-Expressionsprotein) zunächst über $\mathrm{Ni}^{2+}$ Affinitätschromatografie aufgereinigt (Abb. 2, obere Hälfte). Wie sich zeigte, führte jedoch die Entfernung des His-tags mittels Thrombin-Protease zu einem vollständigen Verdau des gesamten Proteins (ohne Abb.). Zudem besaß His-Eferin, wie die vollständige Sequenzierung des pET28a-Eferin-Plasmids zeigte, zwischen dem His-tag und der eigentlichen Eferin-Sequenz elf zusätzliche Aminosäuren. pET28aEferin wurde deshalb zu einem His-tag-tragenden pETM11-Eferin mit einer unmittelbar vor der Eferin-Sequenz gelegenen TEV-Proteaseschnittstelle (= TEV cleavage site) umkloniert. Leider führte auch die Abspaltung dieses His-tags unter Zuhilfenahme der selbstaufgereinigten TEV-Protease (siehe Material und Methoden) zum Abbau des aufgereinigten Eferin-Proteins (ohne Abb.).

Da aufgereinigtes His-Eferin allein stets stabil war, wurde im Weiteren nur noch ungeschnittenes His-Eferin verwendet (Abb. 2). 


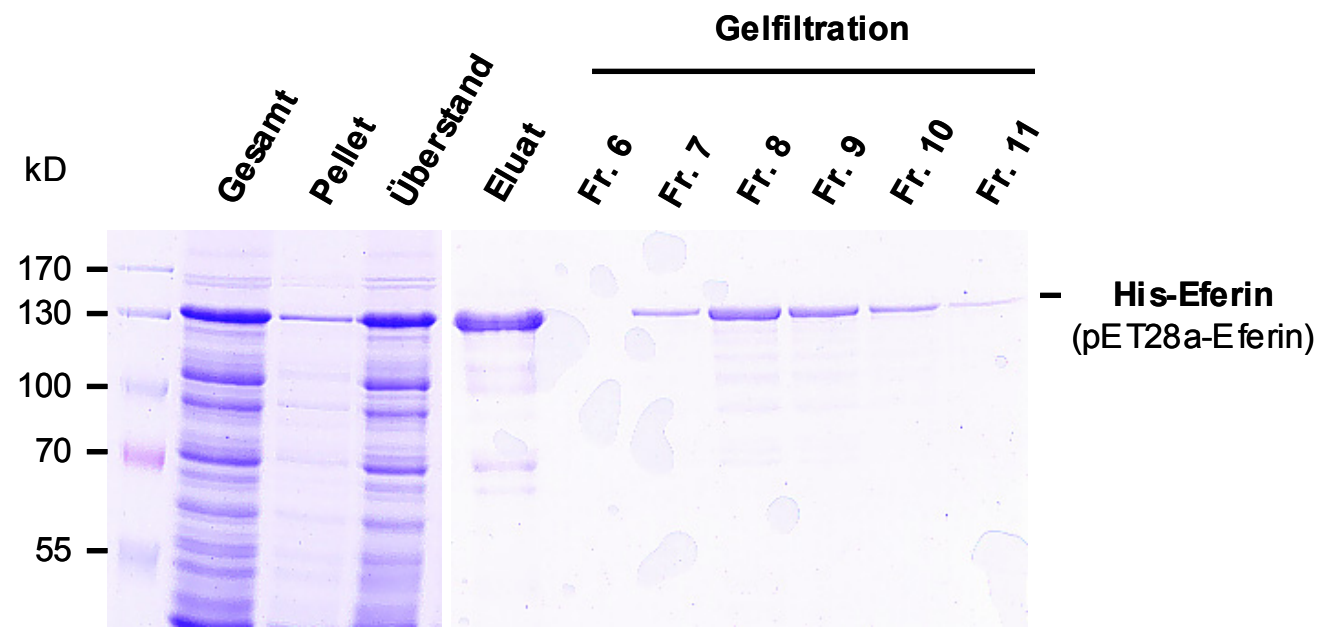

Gelfiltration

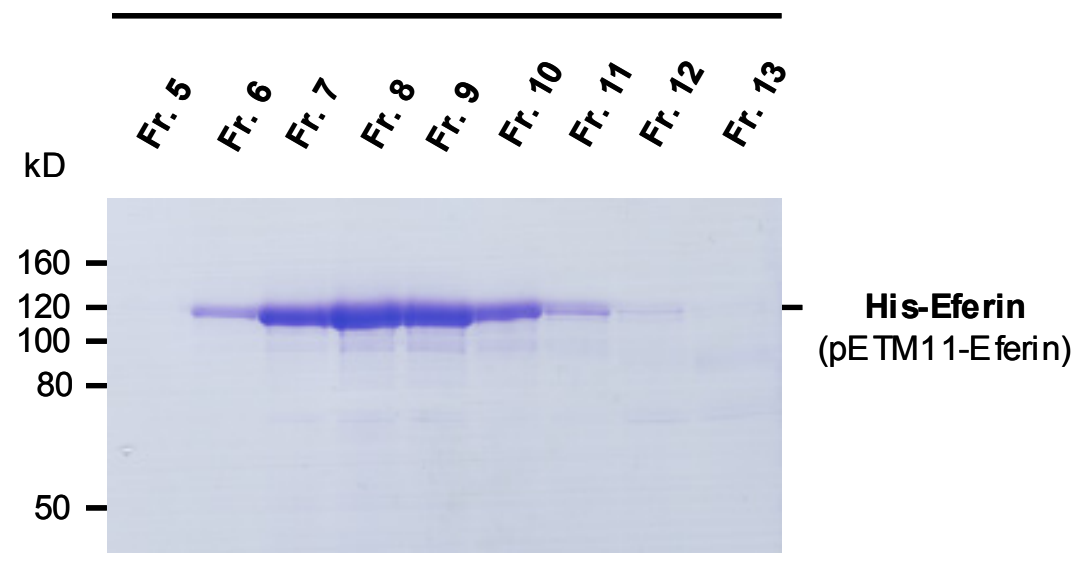

\section{Abbildung 2: Aufreinigung von His-Eferin}

Zunächst wurde eine Aufreinigung von His-Eferin ( $\mathrm{pET} 28 \mathrm{a}$-Eferin) über $\mathrm{Ni}^{2+}$-Affinitätschromatografie durchgeführt, darauf folgte die Nachreinigung mittels Gelfiltrationschromatografie. Wie in der linken Hälfte zu sehen, war der Großteil des exprimierten Proteins nach Aufschluss löslich im Überstand vertreten. In der rechten Hälfte sind zunächst das Eluat der $\mathrm{Ni}^{2+}$-Affinitätschromatografie und daran anschließend die His-Eferin-haltigen Fraktionen (außer Fraktion Nr. 6) der Gelfiltration abgebildet. In der unteren Hälfte ist die Aufreinigung von His-Eferin (pETM11-Eferin) nach gleicher Vorgehensweise gezeigt. Die Nachreinigungen durch Gelfiltration zeigen deutlich ein stabiles His-Eferin (wenig Abbauprodukte) ohne verbleibende Verunreinigungen des Eluats.

\section{Herstellung, Affinitätsreinigung und Charakterisierung eines}

\section{Antikörpers gegen Eferin}

Zu Beginn dieser Arbeit existierte in unserem Labor bereits ein (von Dr. Andreas Gast) gegen Eferin aufgereinigter Kaninchen-Antikörper, welcher in Mitose Centrosomen dekorierte. Zur Immunisierung des Kaninchens und bei der anschließenden Affinitätsreinigung des genannten Antikörpers war Eferin voller 
Länge verwendet worden, welches eine vorhergesagte coiled coil Domäne besitzt. Um auszuschließen, dass die Anfärbung der Centrosomen auf Kreuzreaktivität mit anderen centrosomalen coiled coil Proteinen zurückzuführen war, wurde in dieser Arbeit ein weiterer Antikörper hergestellt, bei dem auf die coiled coil Domäne des zur Immunisierung verwendeten Antigens verzichtet wurde (siehe Tabelle 1: pET28a-Eferin $\Delta C$ ).

Nach Aufreinigung von His-Eferin $\Delta \mathrm{C}$ über $\mathrm{Ni}^{2+}$-Affinitätschromatografie und Gelfiltration wurde das saubere Protein einer Versuchsziege nach Homogenisierung mit einem Adjuvans zur Immunisierung gespritzt ${ }^{4}$. Nach Erreichung der gewünschten Immunreaktion wurde das immunisierte Tier zur Ernte des Antikörpers ausgeblutet. Die weitere Aufreinigung des Antikörpers fand über Affinitätsreinigung gegen das immobilisierte Antigen statt (siehe Material und Methoden). Hierbei wurden aus $50 \mathrm{ml}$ Serum 3,4 mg affinitätsgereinigter Antikörper gewonnen, welcher in einer Konzentration von $1,4 \mathrm{mg} / \mathrm{ml}$ vorlag.

Danach erfolgte die Charakterisierung des aufgereinigten Antikörpers. Hierfür wurde die in der Westernblot-Analyse zur Detektion von rekombinantem Eferin erforderliche Antikörperverdünnung ermittelt (1: $1.000-2.000$, siehe Material und Methoden) und schließlich der aufgereinigte Antikörper mit dem bisherigen Eferin-Antikörper aus Kaninchen verglichen. Zu diesem Zweck wurden verschiedene Expressionsvarianten von rekombinantem Eferin benutzt. Dabei handelte es sich um Eferin voller Länge und um zwei verkürzte Varianten von Eferin: Eferin ohne coiled coil Domäne (= HisEferin $\Delta \mathrm{C}$ ) und die coiled coil Domäne allein (= GST-Eferin $\Delta \mathrm{N})$. Wie erwartet, reagierte der Kaninchen-Antiköper mit allen rekombinanten Varianten, während der Ziegen-Antikörper nur mit dem Eferin voller Länge und dem um die coiled coil Domäne verkürzten Eferin-Konstrukt reagierte (Abb. 3).

\footnotetext{
${ }^{4}$ Immunisierung und Ausbluten der Ziege wurde von der tierexperimentellen Einrichtung des MaxPlanck-Institutes (Martinsried) durchgeführt.
} 


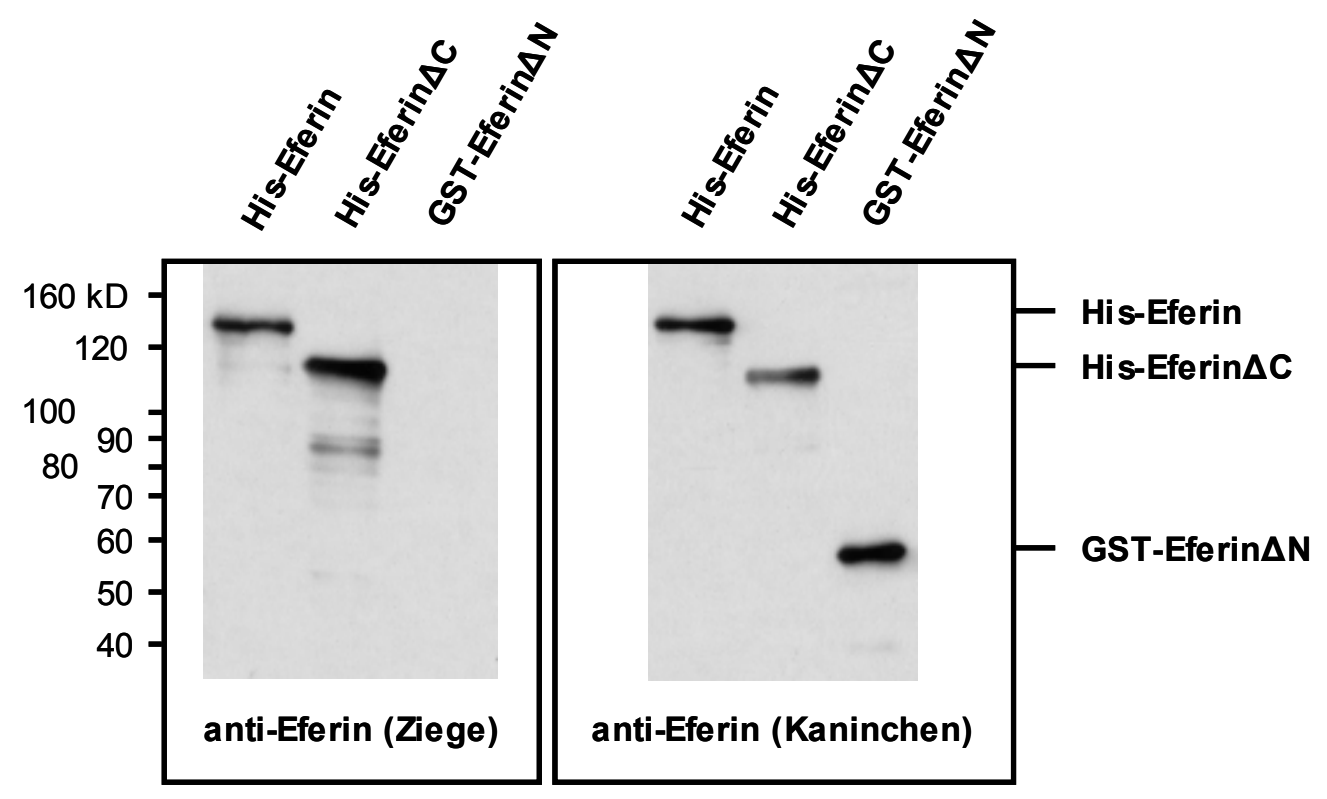

\section{Abbildung 3: Charakterisierung des Ziegen-Antikörpers gegen Eferin}

Zur Überprüfung der Spezifität des Ziegen-Antikörpers gegen den N-Terminus von Eferin wurden etwa die gleichen Mengen (je 0,5 $\mu$ g) rekombinanten Proteins von His-Eferin, His-Eferin $\Delta C$ und GSTEferin $\Delta N$ im Westernblot analysiert. Dazu wurde der bereits existierende Kaninchen-Antikörper mit dem affinitätsgereinigten Antikörper aus Ziege verglichen. Während der Kaninchen-Antikörper Eferin über die gesamte Länge erkannte, detektierte der Antikörper aus Ziege Eferin nur anhand des NTerminus (ohne Erkennung der coiled coil Region, welche durch GST-Eferin $\Delta \mathrm{N}$ repräsentiert wird).

Die Charakterisierung des neuen Antikörpers gegen Eferin sollte im Folgenden auf die Immunfluoreszenz-Analyse ausgeweitet werden. Zu diesem Zweck wurden HeLa-Zellen nach Transfektion mit RNAi-Oligonukleotiden zunächst fixiert, mit jeweils einem der beiden Antikörper (in einer Verdünnung von $1: 100$ ) inkubiert und anschließend analysiert. Hierbei konnte klar gezeigt werden, dass beide Antikörper eine centrosomale Anfärbung bewirken. Dies war im Falle des Ziegen-Antikörpers spezifisch für endogenes Eferin, während der Kaninchen-Antikörper trotz Depletion des endogenen Eferins weiterhin eine centrosomale Lokalisation in Meta- und Anaphase anzeigte (Abb. 4). Damit wurde deutlich, dass der Kaninchen-Antikörper neben seiner Spezifität für Eferin eine Kreuzreaktivität gegen Komponenten des Centrosoms besitzt. 


\section{anti-Eferin (Kaninchen)}

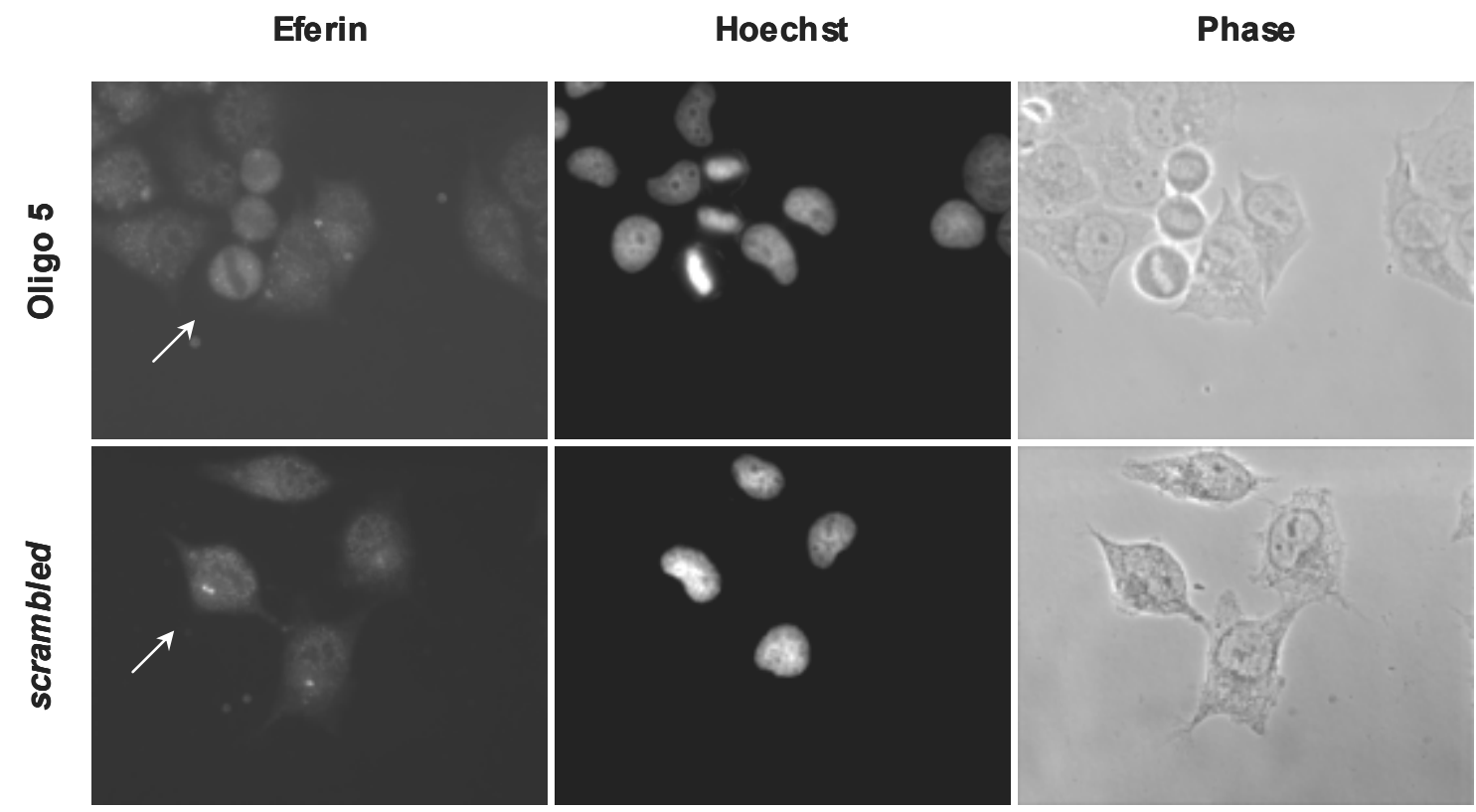

anti-Eferin (Ziege)

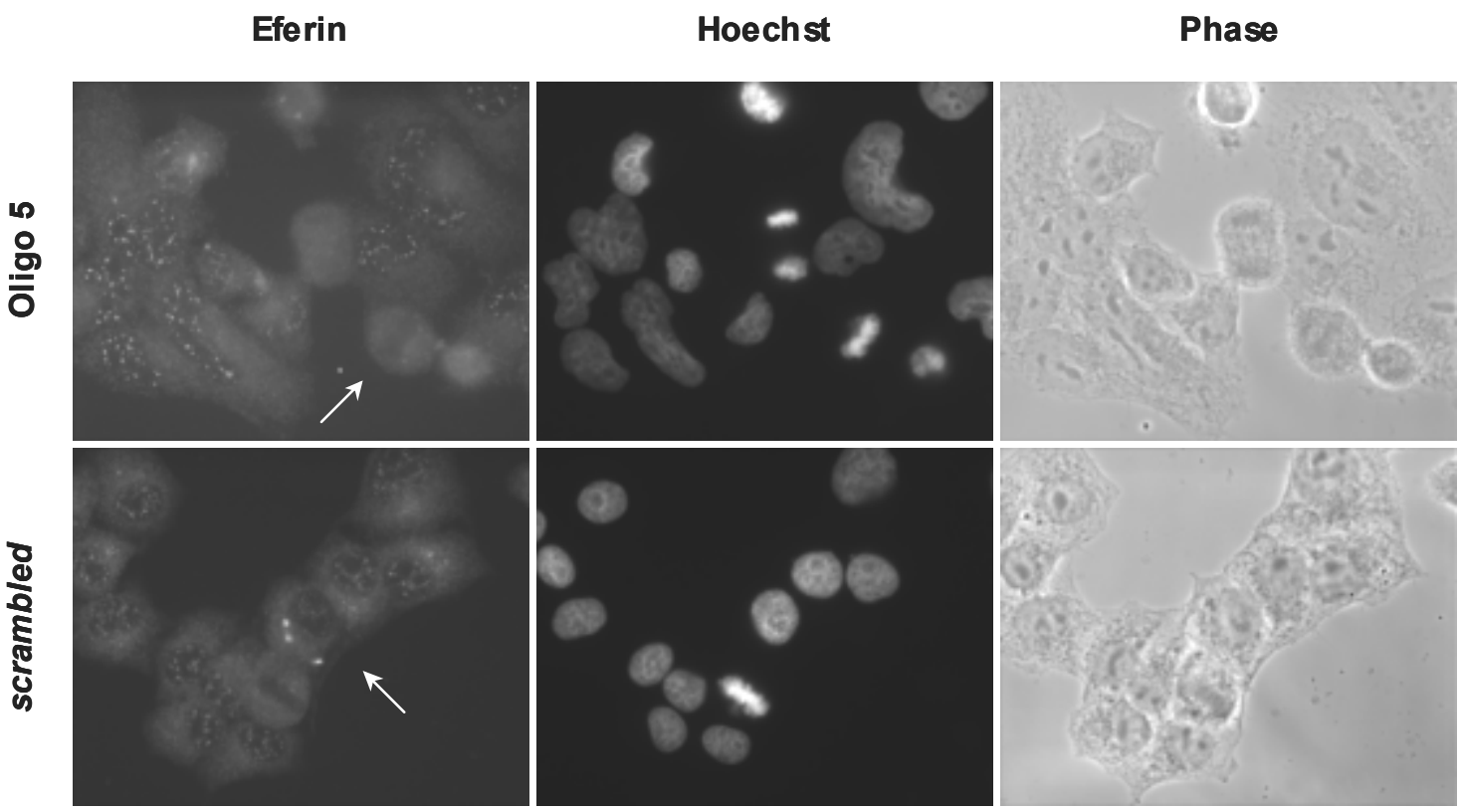

\section{Abbildung 4: RNAi gegen Eferin offenbart Kreuzreaktivität des Kaninchen-Antikörpers}

Die Depletion von Eferin in HeLa-Zellen wurde mittels RNAi-Methode durchgeführt (vergleiche Abb. 33). $48 \mathrm{~h}$ nach den hierfür durchgeführten Transfektionen wurden die behandelten Zellen in einem Gemisch aus Methanol und Aceton fixiert. Nach Lufttrocknung der Deckgläschen folgte die Anfärbung mit dem Kaninchen- oder Ziegen-Antikörper gegen Eferin. Einem Waschschritt folgte die Inkubation mit dem entsprechenden fluorophormarkierten Zweitantikörper (anti-Ziege Alexa 488 bzw. anti- 
Kaninchen Alexa 488) sowie die Anfärbung der DNA mittels Hoechst. Wie in der oberen Hälfte zu sehen, zeigt der Kaninchen-Antikörper trotz Eferin-Depletion nach wie vor eine centrosomale Lokalisation von Eferin in Metaphase an. Dies wird auf Kreuzreaktivität des Kaninchen-Antikörpers zurückgeführt. Der in der unteren Hälfte gezeigte Eferin-Antikörper aus Ziege zeigte bei mitotischen Zellen dagegen keine Kreuzreaktivität mit centrosomalen Proteinen.

\section{Charakterisierung von Eferin}

\section{Eferin besitzt ein auffällig niedriges endogenes Expressionslevel}

Nun sollte überprüft werden, ob der neu aufgereinigte Ziegen-Antikörper neben rekombinantem Eferin auch endogenes Protein erkennt. Daneben galt es, das endogene Level an Eferin pro Zelle abzuschätzen. Zu diesem Zweck wurde rekombinantes Eferin bekannter Konzentration in Gesamtzellextrakte bekannter Zellzahl gemischt und auf diese Weise eine Verdünnungsreihe hergestellt. Wie sich zeigte, erkannte der affinitätsgereinigte Antikörper sehr geringe Mengen rekombinanten Proteins (Abb. 5). Daneben konnte eine Abschätzung des endogenen Levels vorgenommen werden. Da das berechnete Molekulargewicht von Eferin 82 kD (und für RanGAP1 65 kD bzw. bei RanGAP1*SUMO1 75 kD) beträgt, jede Spur $5 \times 10^{4}$ Zellen repräsentierte und das endogene Signal von Eferin einem Signal von etwa $25 \mathrm{pg}$ (und bei RanGAP1 dem von etwa 1,5 ng) rekombinanten Proteins entsprach, konnte berechnet werden, dass pro Zelle gerade einmal 4.000 Kopien von Eferin vorhanden waren, während es bei RanGAP1 etwa 300.000 Kopien pro Zelle waren. 
His-Eferin
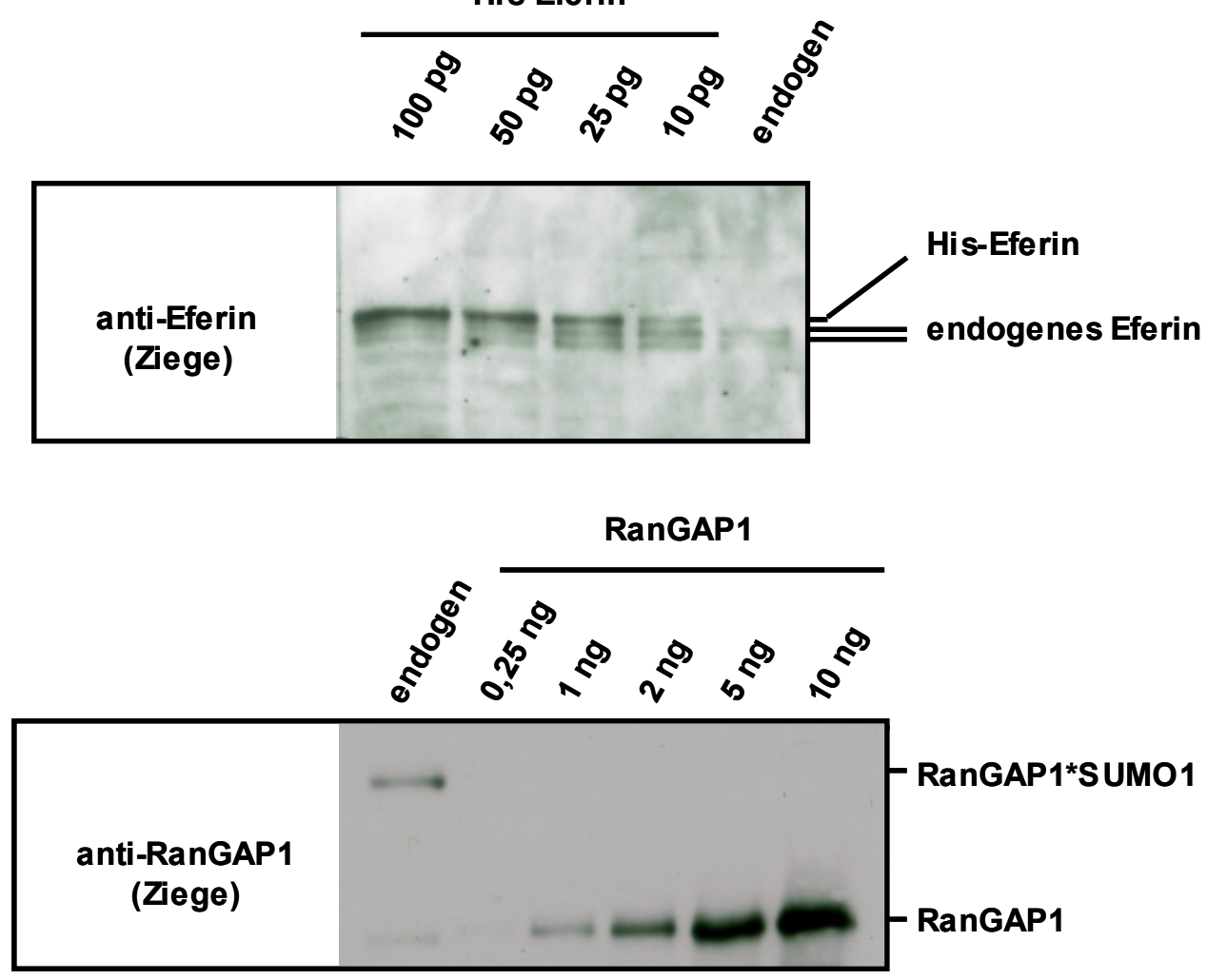

\section{Abbildung 5: Bestimmung der endogenen Menge von Eferin und RanGAP1}

Zur Bestimmung der Proteinmenge pro Zelle wurden die angegebenen Mengen rekombinanten Eferins (bzw. RanGAP1) in Zellextrakten verdünnt und aufgetragen. In jeder Spur befand sich das Äquivalent von $5 \times 10^{4}$ Zellen. Aus dem Vergleich der Signalstärken von rekombinantem zu endogenem Eferin (bzw. RanGAP1) konnte die Kopienzahl mit Hilfe des dazugehörigen Molekulargewichts berechnet werden. Für Eferin wurden so etwa 4.000 und für RanGAP1 etwa 300.000 Moleküle pro Zelle berechnet. Eferin wurde hier erstmals in seiner endogenen Form (in zwei Varianten = Dublette) detektiert.

\section{Endogenes Eferin lokalisiert abwechselnd an recyclisierende Endosomen, Centrosomen und die Teilungsfurche}

Als die Lokalisation von Eferin in humanen Zellinien erstmals von Dr. Andreas Gast mittels Antikörpern aus Kaninchen bestimmt wurde, konnte gezeigt werden, dass sich Eferin in der Mitose an den Centrosomen anreichert. Bei genauerer Analyse fiel auf (Abb. 6), dass Eferin als deutlich erkennbares Signal an reifenden Centrosomen auftauchte, während es in Interphase nicht detektierbar, also keinem bestimmten Organell zuzuschreiben war. Erstaunlicherweise ging dieses centrosomale Signal in Meta- und Anaphase stark zurück, tauchte aber in Telophase wieder deutlich sichtbar auf (Abb. 6). Da in dieser Arbeit bereits gezeigt wurde (siehe Abschnitt 
Antikörpercharakterisierung), dass der gegen Eferin gerichtete Kaninchen-Antikörper in Meta- und Anaphase eine Kreuzreaktivität mit centrosomalen Proteinen aufweist, sollte mit dem gegen die n-terminale Hälfte von Eferin gerichteten Ziegen-Antikörper die Lokalisation von Eferin nochmals untersucht werden.

Bei genauerer Untersuchung der mitosespezifischen Lokalisation von Eferin stellte sich für den Ziegen-Antikörper heraus, dass Eferin entgegen der bisherigen Beobachtung in Meta- und Anaphase nicht weiter an den Centrosomen zu detektieren war, während für die Übrigen in Frage kommenden Zellzyklus-Phasen Übereinstimmung herrschte (Abb. 7). Damit wurde für endogenes Eferin eine centrosomale Lokalisation nachgewiesen, welche sich ausschließlich auf Pro- und Telophase beschränkte. Darüber hinaus konnte in der Zytokinese, mit Hilfe des Ziegen-Antikörpers, erstmals eine Anreicherung an der Teilungsfurche (Abb. 7 unterste Bilderreihe, Einzelpfeile) und bei Arretierung von Zellen mit Thymidin in G1/S-Phase eine Anreicherung an den recyclisierenden Endosomen gezeigt werden (Abb. 8). 


\section{Eferin}
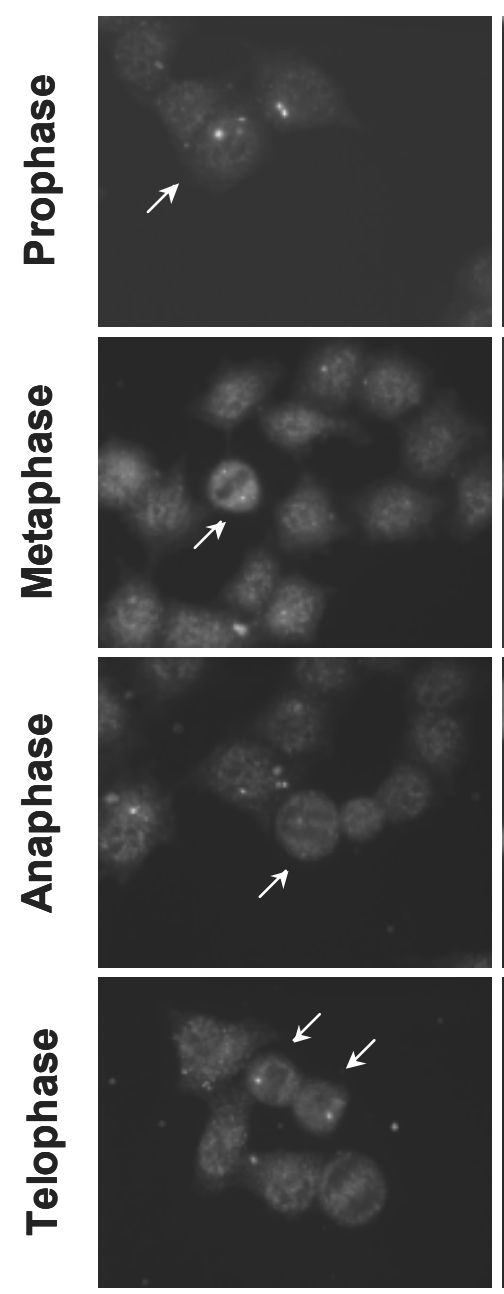

Hoechst
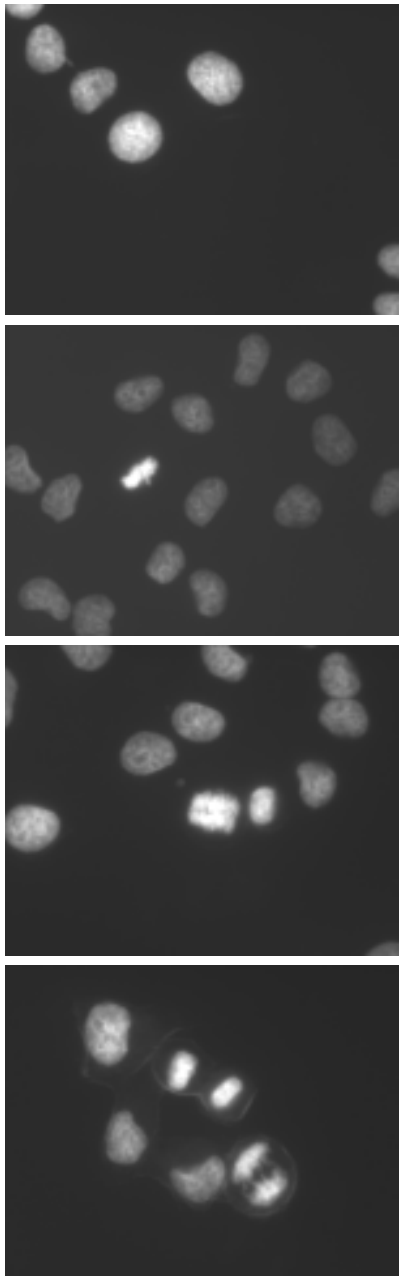

\section{Phase}
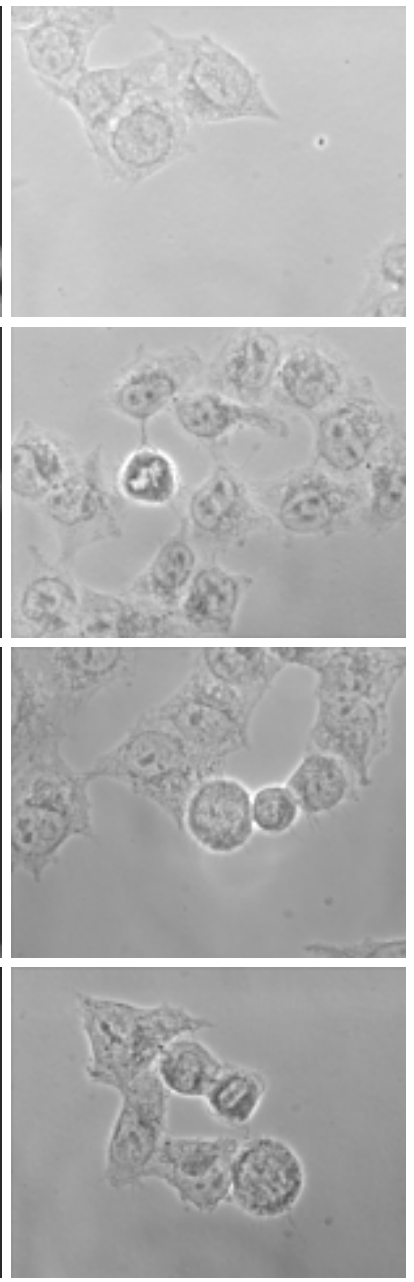

\section{Abbildung 6: Bestimmung der mitotische Lokalisation von Eferin mittels Kaninchen-Antikörper}

HeLa-Zellen wurden auf Deckgläschen in einem Methanol-Aceton-Gemisch fixiert. Nach Lufttrocknung der Zellen folgte eine Inkubation mit dem Kaninchen-Antikörper gegen Eferin sowie die Inkubation des Zweitantikörpers (anti-Kaninchen Alexa 488) und Anfärbung der DNA mittels Hoechst-Farbstoff. Die Dokumentation der Lokalisation von Eferin wurde am Fluoreszenzmikroskop durchgeführt. Hierbei zeigte sich in mitotischen Phasen eine centrosomale Lokalisation, während in Zellen der Interphase keinerlei Anreicherung nachzuweisen war. 


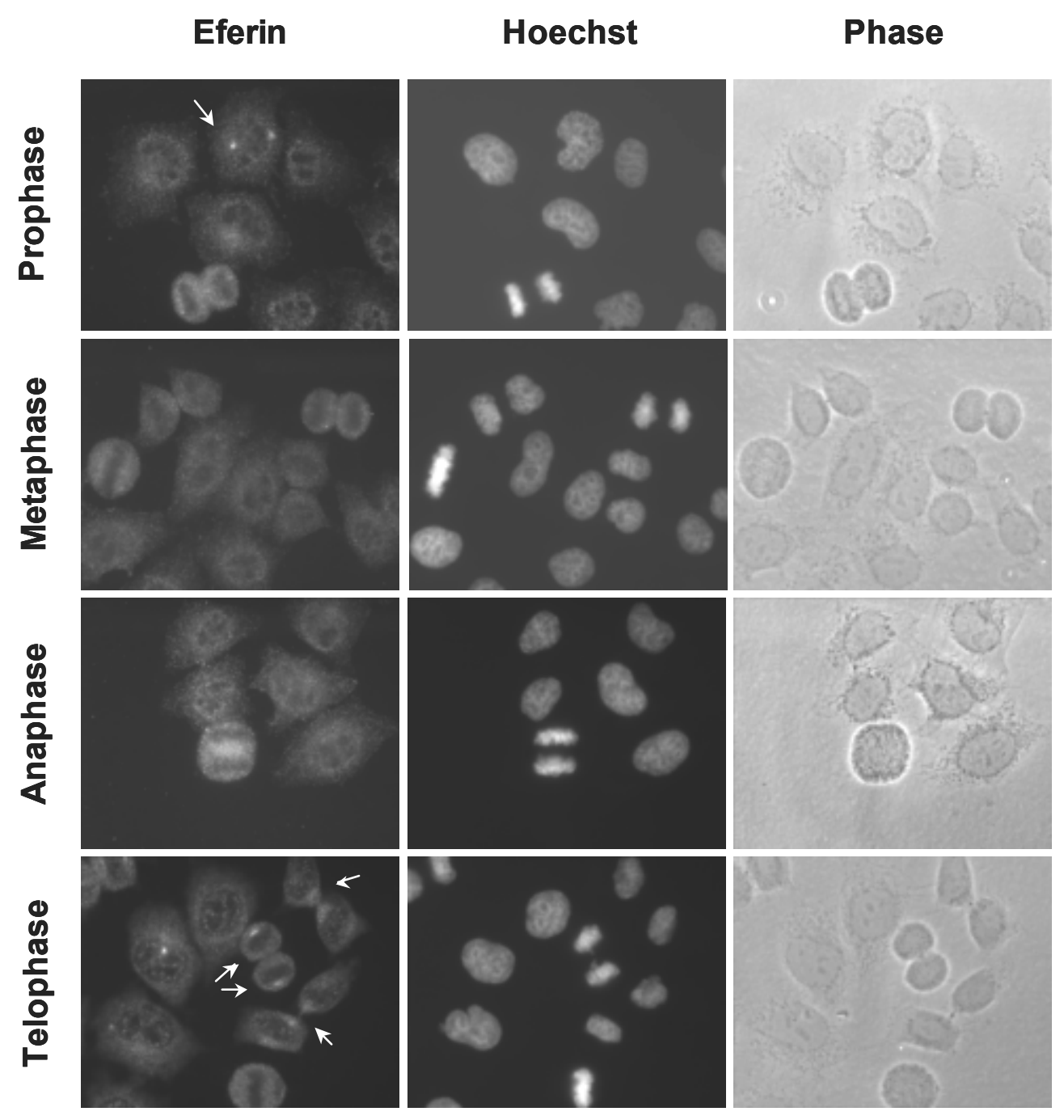

\section{Abbildung 7: Bestimmung der Lokalisation von Eferin mittels Ziegen-Antikörper}

HeLa-Zellen wurden auf Deckgläschen in einem Gemisch aus Methanol und Aceton fixiert. Nach Inkubation mit dem Ziegen-Antikörper gegen Eferin folgte die Inkubation des Zweitantikörpers (antiZiege Alexa 488) sowie die Anfärbung der DNA (Hoechst). Wie die Aufnahmen zur Lokalisation von Eferin wiedergeben, konnte eine centrosomale Lokalisation in Pro- und Telophase sowie eine Anreicherung an der Teilungsfurche in Zytokinese (unterste Bilderreihe, Zellenpaare nach Teilung neben der Zelle in Telophase) beobachtet werden. 


\section{Hoechst}

\section{Eferin}

y-Tubulin
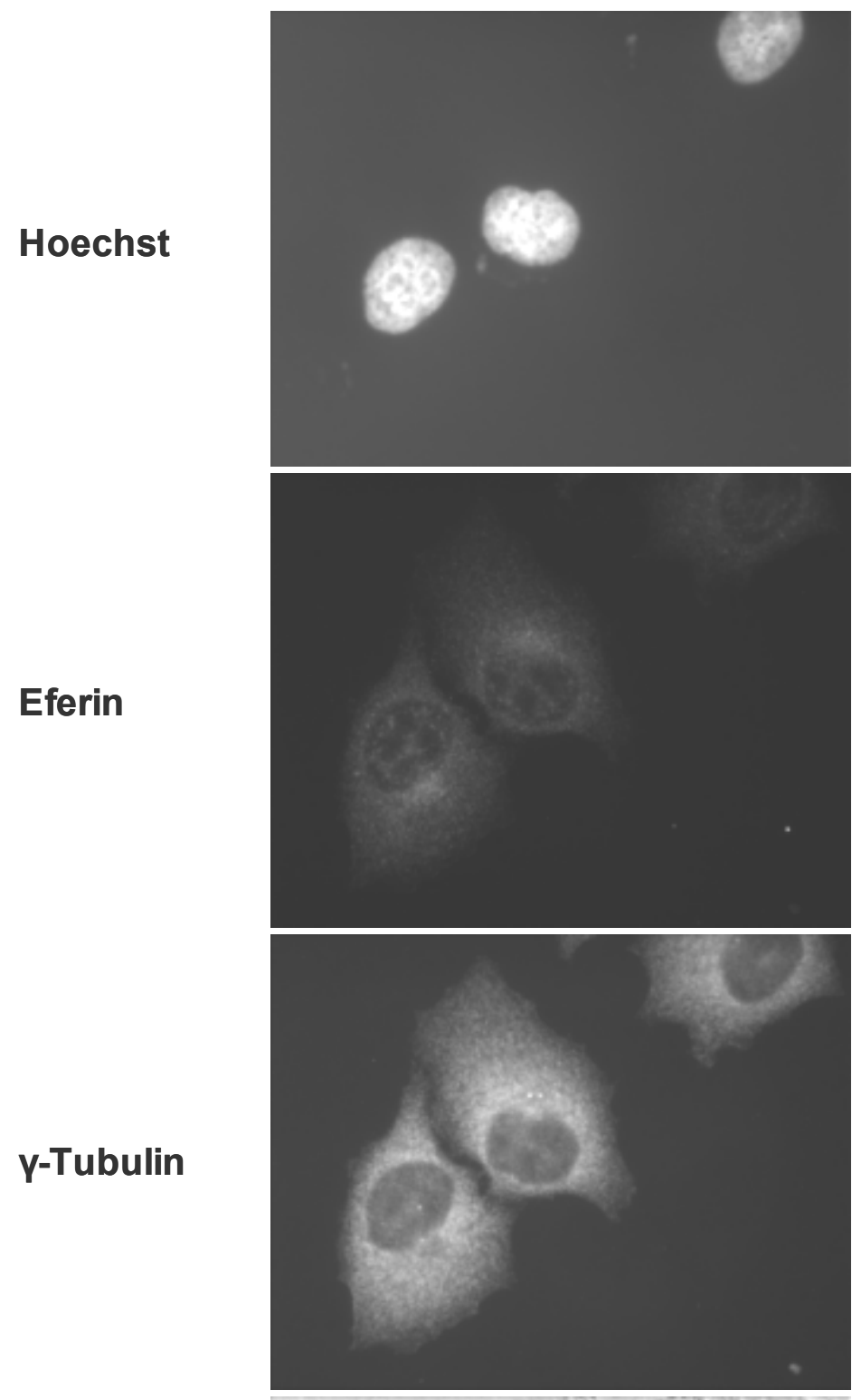

Phase

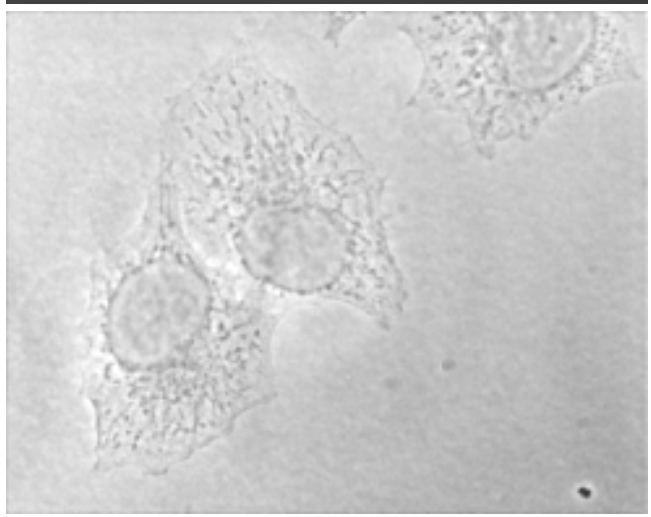

\section{Abbildung 8: Sichtbarmachung der endosomalen Lokalisation von Eferin}

Mit Thymidin für $20 \mathrm{~h}$ arretierte HeLa-Zellen wurden in einem Gemisch aus Methanol und Aceton fixiert. Nach Lufttrocknung der Deckgläschen folgte die Doppelanfärbung mit dem Ziegen-Antikörper gegen Eferin und einem gegen $y$-Tubulin gerichteten Maus-Antikörper. Einem Waschschritt schloss sich die Inkubation mit fluorophorgekoppelten Zweitantikörpern (anti-Ziege Alexa 488 und anti-Maus 
Cy 3) sowie die Anfärbung der DNA mittels Hoechst an. Wie zu sehen ist, haben sich die Centrosomen zu diesem Zeitpunkt (G1/S-Übergang) bereits verdoppelt (getrenntes Punktmuster bei $\mathrm{Y}$-Tubulin-Färbung) und Eferin ist in deren Umgebung wolkig angereichert. Aufgrund technischer Schwierigkeiten war die Detektion des bekannten Endosomen-Markerproteins Rab11 (recyclisierende Endosomen) und damit die eindeutige Zuordnung von Eferin zu diesem Kompartiment durch Colokalisation nicht möglich. Es wird aufgrund des Lokalisationsmusters jedoch angenommen, dass Eferin zu diesem Zeitpunkt, wie bereits mehrfach beschrieben, dem Kompartiment der recyclisierenden Endosomen angehört [86, 87, 91, 101, 114-116], welches am Ende der Mitose zur Bildung der Teilungsfurche benötigt wird.

\section{YFP-Eferin zeigt ein ähnliches Lokalisationsmuster wie endogenes}

\section{Eferin}

Zur Bestätigung der in der indirekten Immunfluoreszenz-Analyse durch Dr. Andreas Gast erstmals in Mitose beobachteten centrosomalen Lokalisation von Eferin wurde ein fluoreszierendes YFP-Eferin-Fusionskonstrukt kloniert (siehe Tabelle 1) und anschließend in HeLa-Zellen transfiziert. Dabei stellte sich heraus, dass Überexpression von YFP-Eferin zu massiver Aggregatbildung und zum Absterben der Zellen führte. Zellen, die nach Titration der zu transfizierenden DNA dagegen ein moderates Expressionslevel zeigten, bestätigten die mittels Antikörper gefundene zellzyklusabhängige Lokalisation endogenen Eferins. Neben Pro- und Telophase wurde nun aber auch in Meta- und Anaphase ein starkes Signal am Centrosom beobachtet (Abb. 9). Wie in der Zwischenzeit auch von anderen Arbeitsgruppen beschrieben [101,115, 116], konnte neben der centrosomalen Lokalisation in Mitose zusätzlich eine Lokalisation an der Teilungsfurche in Zytokinese beobachtet werden (Abb. 9, unterste Bilderreihe). Prinzipiell gibt die Expression von YFP-Eferin die mit den Ziegen-Antikörpern beobachteten Lokalisationen wieder. Da endogenes Eferin jedoch nur in geringsten Mengen in der Zellen vorhanden ist (Abb. 5), müssen einzelne YFP-Eferin Lokalisationen als Überexpressionsartefakte in Betracht gezogen werden. 


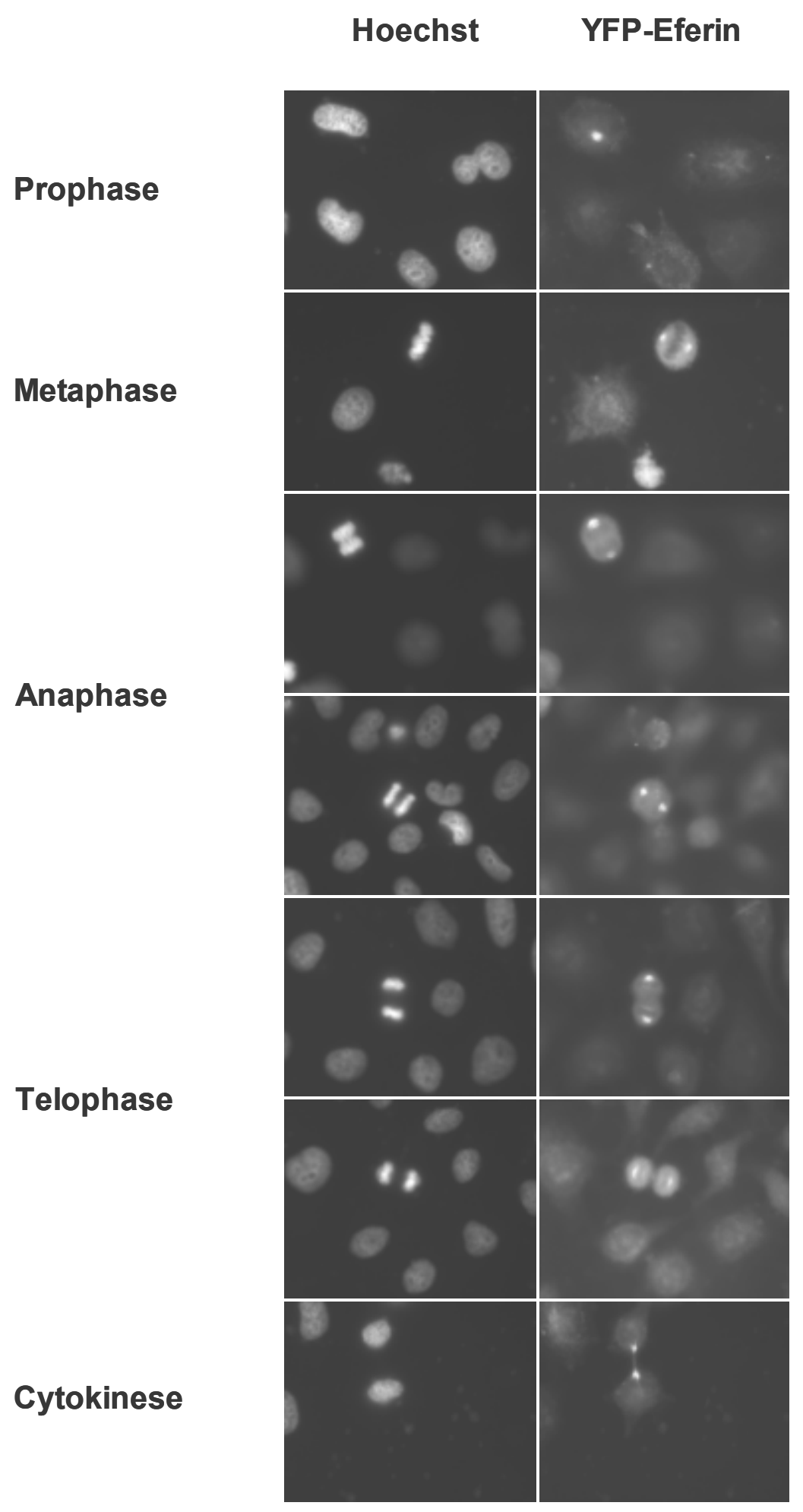

\section{Abbildung 9: Lokalisationsstudie mit pEYFP-Eferin}

Für $48 \mathrm{~h}$ mit pEYFP-C1-Eferin transfizierte HeLa-Zellen wurden zur Fixierung für $10 \mathrm{~min}$ bei $-20^{\circ} \mathrm{C}$ in $100 \%(\mathrm{v} / \mathrm{v})$ Methanol inkubiert und mittels Fluoreszenzmikroskopie analysiert. Zur Sichtbarmachung der DNA wurden die Zellen mit Hoechst-Farbstoff eingefärbt. Eine centrosomale Lokalisation von YFP-Eferin war in allen Phasen der Mitose festzustellen. In der Zytokinese fand eine Relokalisation von YFP-Eferin zur Teilungsfurche statt. 
Um zu überprüfen inwieweit die verschiedenen Domänen von Eferin zur korrekten Lokalisation beitragen, wurden Deletionsmutanten (jeweils als $\mathrm{n}$ - und c-terminale YFP-Fusion) auf ihre Lokalisation sowie phänotypische Auffälligkeit hin untersucht. Wie sich schnell zeigte, neigten selbst die verkürzten YFP-Konstrukte zur Aggregatbildung, wenn auch in abgeschwächter Form (ohne Abb.). Darüber hinaus ging die centrosomale Lokalisation bei jeglicher Veränderung der Sequenz verloren. Auch war, wie zwischenzeitlich von [ $\left.{ }^{101,116}\right]$ beschrieben, weder eine Anreicherung an der Teilungsfurche noch irgendeine Anreicherung anderer Art auszumachen. Bei Untersuchung der Expressionslevel stellte sich zudem heraus, dass jedes der exprimierten Eferin-Konstrukte (trotz verringerter Menge der Konstrukt-DNA bei Transfektion) zwar zunächst stabil war (Abb. 10), dann aber rasch und quantitativ abgebaut wurde (Abb. 11).

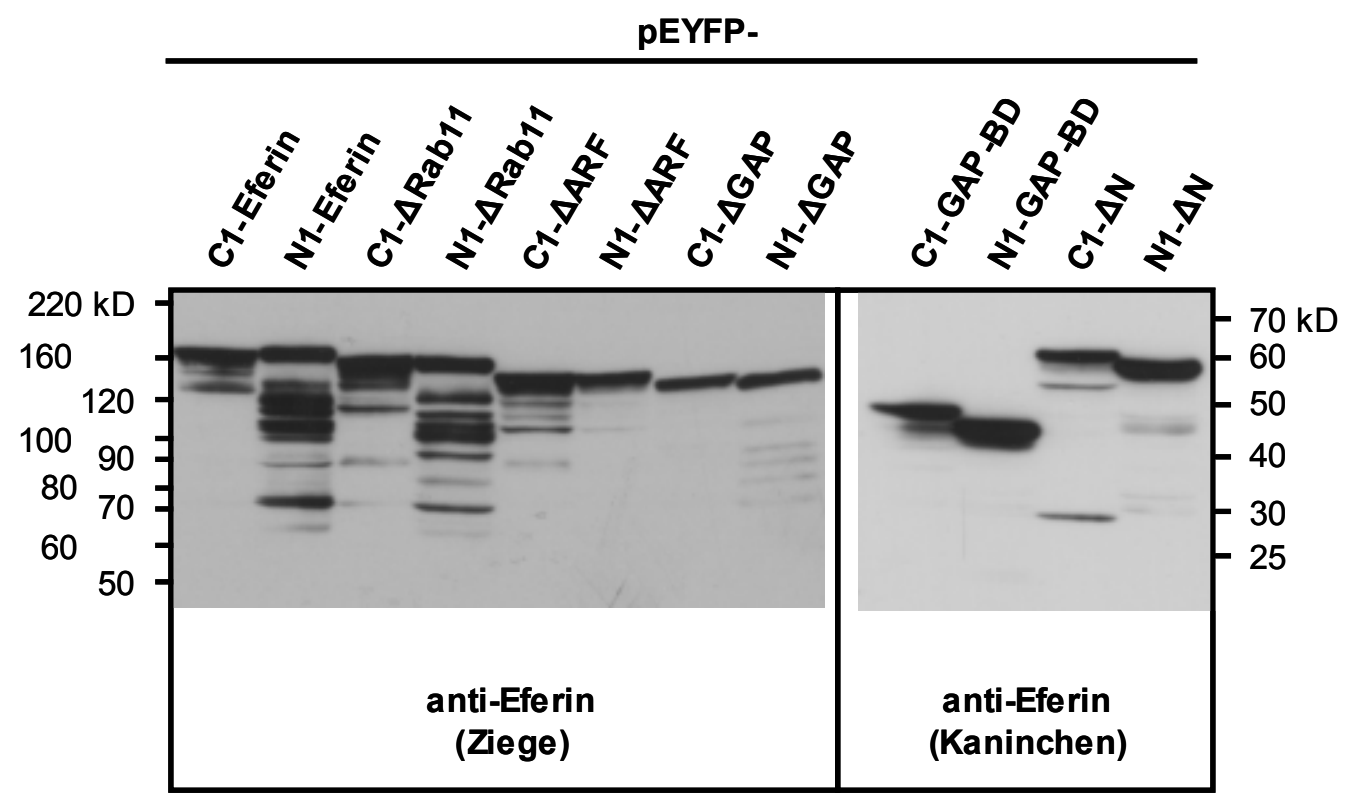

Abbildung 10: Untersuchung der Expression verschiedener pEYFP-Eferin-Konstrukte HeLa-Zellen wurden jeweils mit den angegebenen pEYFP-Konstrukten transfiziert und $20 \mathrm{~h}$ später für die Westernblot-Analyse mit Probenpuffer geerntet. Zur Detektion der unterschiedlichen Eferin Konstrukte wurden Antikörper aus Ziege und Kaninchen eingesetzt.

Dieser Befund deutet darauf, dass Eferin möglicherweise eine intrinsische Instabilität aufweist oder für eine korrekte Funktion raschen Abbau erfährt. In Hinblick darauf wurde auf weitere Untersuchungen mit Hilfe der pEYFP-Konstrukte verzichtet, da nicht ausgeschlossen werden konnte, dass bei einer beobachteten Anreicherung 
(z.B. an den Centrosomen oder der Teilungsfurche) lediglich Abbauprodukte detektiert würden.

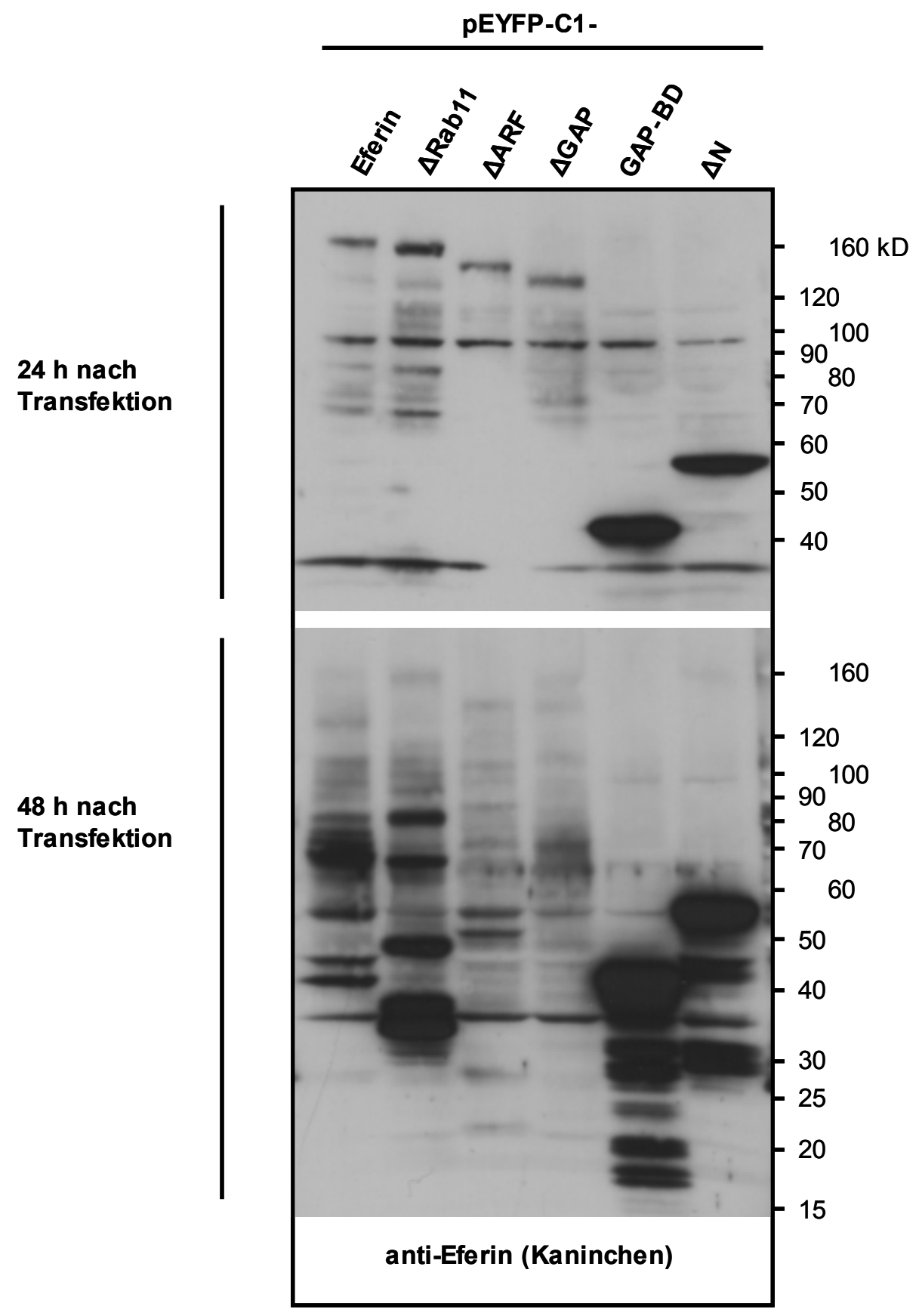

\section{Abbildung 11: Untersuchung der Degradation exprimierter pEYFP-Eferin-Konstrukte}

HeLa-Zellen wurden jeweils mit den angegebenen pEYFP-Konstrukten transfiziert und $24 \mathrm{~h}$ bzw. $48 \mathrm{~h}$ nach Transfektion für die Westernblot-Analyse geerntet. Zur Detektion der unterschiedlichen Eferin Konstrukte wurden Antikörper aus Kaninchen verwendet. Bereits $24 \mathrm{~h}$ nach Transfektion waren neben den exprimierten Konstrukten deutlich Degradationsprodukte zu erkennen, welche $48 \mathrm{~h}$ nach Transfektion den überwiegenden Anteil an detektierbaren Eferin-Konstrukten ausmachten. 


\section{Eferin ist mit Membranen assozilert und löslich im Zytoplasma vertreten}

Eferin wird von etlichen Arbeitsgruppen bis zum heutigen Tag als endosomales Protein, welches an der Zytokinese beteiligt ist, beschrieben [ $\left.{ }^{86,87,90,91,101,114-116}\right]$. Wie bereits in dieser Arbeit gezeigt, konnte Eferin in der Immunfluoreszenz-Analyse tatsächlich an endosomalen Strukturen detektiert werden. Da Eferin in unserer Arbeitsgruppe ursprünglich aber als Interagierer von RanGAP1 im yeast two hybrid identifiziert worden war, stellte sich uns die Frage, ob Eferin neben dieser membranassoziierten, endosomalen Form möglicherweise in einer weiteren Kompartimentassoziation existiert. Zu diesem Zweck wurde eine Fraktionierung durchgeführt, bei der versucht wurde, Eferin unter sequenziellem Einsatz verschiedener Detergenzien aus spezialisierten Organisationsstrukturen zu befreien und in einen löslichen Zustand zu überführen [ ${ }^{109,117}$ ]. Diese Methode erlaubt in einem gewissen Rahmen die Zuordnung eines Proteins zu Organellen, Kompartimenten oder Zellstrukturen $\left[{ }^{117,118}\right]$. Kurz gesagt wurden die Zellen der Reihe nach mit Digitonin-haltigem (zytoplasmatische Proteine / lösliche Zytoskelettproteine), Triton X100-haltigem (Membran-assoziierte Proteine), Deoxycholat- und NP40-haltigem (Kernmembranproteine / lösliche nukleäre Proteine) und SDS-haltigem Puffer (Proteine der Kernmatrix / Detergenz-resistente Zytoskelettproteine) extrahiert und die erhaltenen Fraktionen im Westernblot analysiert. Als Kontrollen wurden hierbei RanGAP1 (löslich / Membran-assoziiert / Zytoskelett-assoziiert), Rab11 (Membran-assoziiert) und Histon2B (DNA-assoziiert) mitgeführt. Nach Durchführung dieser Fraktionierungsmethode zeigte sich, dass Eferin zum Teil löslich im Zytoplasma vorliegt und in etwa gleichem Umfang mit Membranen (z.B. in Form von Vesikeln wie Endosomen) assoziiert ist (Abb. 12). Dieses Ergebnis lässt spekulieren, dass Eferin (als beschriebener Rab11 Interagierer) durch Rab11 an Membranen rekrutiert werden könnte. 


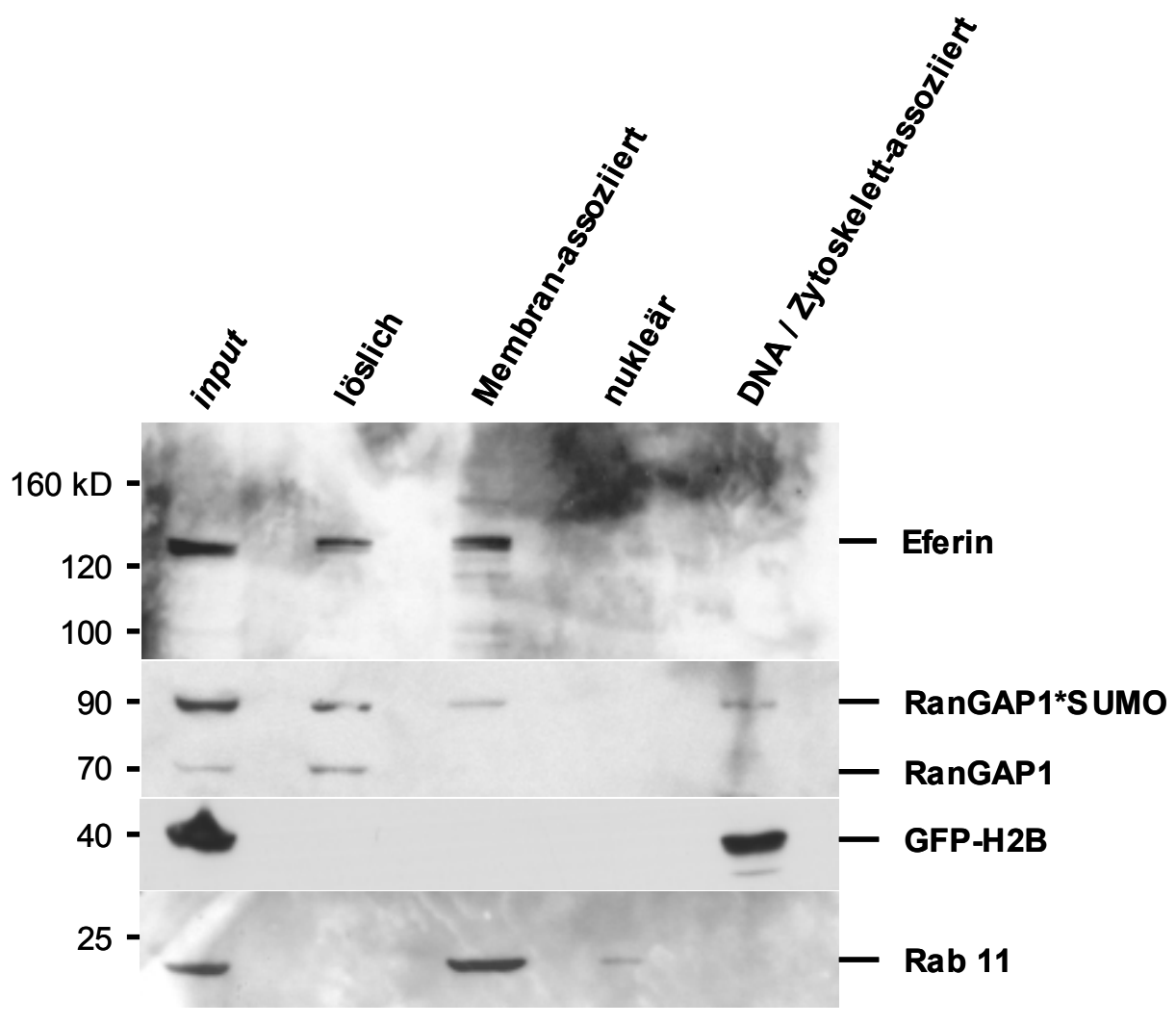

\section{Abbildung 12: Bestimmung der Kompartimentzugehörigkeit von Eferin}

Wie unter Material und Methoden beschrieben, wurden HeLa-Zellen bzw. GFP-Histon2B-HeLa-Zellen (zur Verfügung gestellt von Dr. Ludger Hengst, MPI für Biochemie, Martinsried) in den entsprechenden Puffern auf Eis inkubiert. Dadurch konnten unterschiedliche Extrakte gewonnen und die analysierten Proteine diesen zugeordnet werden. Zur Detektion der einzelnen Proteine kamen Antikörper gegen Eferin (Ziege), RanGAP1 (Ziege), GFP (Kaninchen) und Rab11 (Maus) zum Einsatz. Das DNA-assoziierte Histon2B (hier als GFP-H2B) wurde als Kontrolle mitgeführt. Während der Großteil des unmodifizierten bzw. sumoylierten RanGAP1 löslich im Zytoplasma vertreten war, war Membran- (z.B. als Bestandteil des Kernporenkomplexes in der Kernhülle) und Zytoskelettassoziiertes (möglicherweise die mitotische Spindel oder Kinetochore) RanGAP1 stets sumoyliert. Die GTPase Rab11, beschrieben als Marker für recyclisierende Endosomen, erschien als Membranassoziiertes Protein. Eferin zeigte sich als zytoplasmatisches und Membran-assoziiertes Protein.

\section{RanGAP1 ist mit endogenem und überexprimiertem Eferin copräzipitierbar}

Eferin war in unserem Labor im yeast two hybrid als Bindepartner von RanGAP1 identifiziert worden, ein Nachweis dieser Interaktion in Säugerzellen stand aber noch aus. Daher sollte in einer Immunpräzipitation mit löslichem Eferin aus Zellextrakten versucht werden, RanGAP1 zu copräzipitieren, um die im yeast two hybrid gemachte 
Beobachtung zu bestätigen $\left[{ }^{83}\right]$. Vor dem Hintergrund eines extrem niedrigen endogenen Expressionslevels wurden zwei Ansätze verfolgt. Zunächst wurde eine sehr große Menge an Zellen verwendet, um genügend Eferin mittels Immunpräzipitation anzureichern. Dieser Ansatz erlaubte erstmals den bis dahin schwierigen Nachweis einer in vivo Interaktion zwischen Eferin und RanGAP1. Wie in Abb. 13 zu sehen ist, führte nur die spezifische Immunpräzipitation von Eferin zu einer gleichzeitigen Copräzipitation von RanGAP1 und der deutlichen Anreicherung des beschriebenen Eferin-Interagierers Rab11. Dieser Versuch war aber nicht nur der erste Nachweis für die Interaktion von endogenem Eferin mit endogenem RanGAP1, sondern auch der erste Nachweis der Wechselwirkung von endogenem Eferin mit endogenem Rab11.

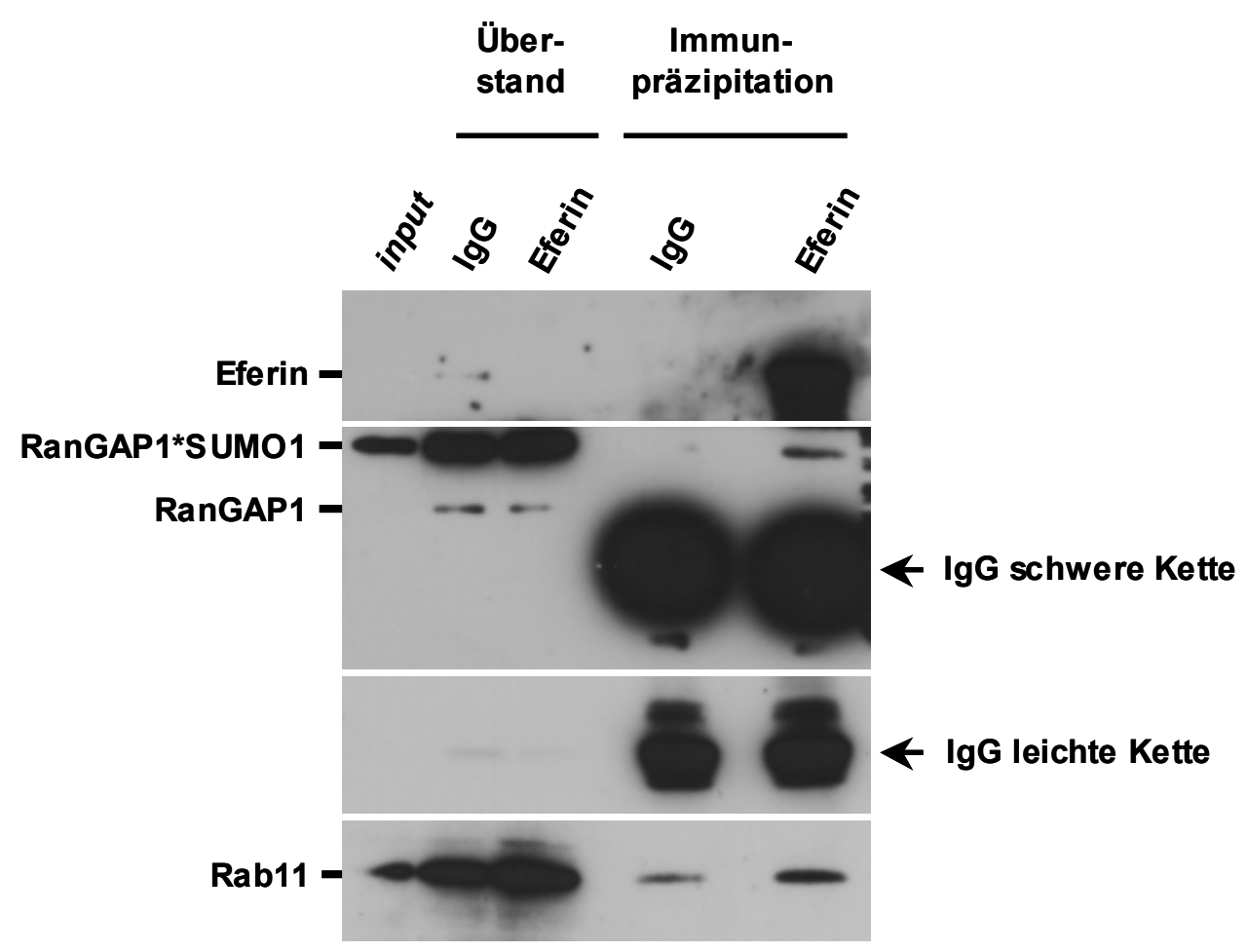

\section{Abbildung 13: Coimmunpräzipitation von RanGAP1 (und Rab11) mit Eferin}

Etwa $7 \times 10^{8}$ HeLa-Zellen wurden zur Solubilisierung peripherer Membranproteine zunächst in $125 \mathrm{mM}$ Natriumcarbonat aufgeschlossen und wie in Material und Methoden beschrieben umgepuffert. Danach wurde daraus durch Zentrifugation bei $100.000 \mathrm{~g}$ für $1 \mathrm{~h}$ bei $4^{\circ} \mathrm{C}$ der Zellextrakt für Immunpräzipitation gewonnen. Dieser wurde mit $15 \mu \mathrm{g}$ Antikörper gegen Eferin (aus Ziege) oder der gleichen Menge unspezifischen IgG-Antikörpers (Ziege) versetzt. Nach Inkubation bei $4^{\circ} \mathrm{C}$ für $2 \mathrm{~h}$ wurden beide Ansätze vor Zugabe der ProteinG-Agarose bei $15.000 \mathrm{~g}$ für $10 \mathrm{~min}$ zur Entfernung störender Präzipitate zentrifugiert. Nach einer weiteren Inkubation von $1 \mathrm{~h} 30 \mathrm{~min}$ bei $4^{\circ} \mathrm{C}$ folgten schließlich Wasch- und Elutionsschritt. Zur Detektion der einzelnen Proteine kamen Antikörper gegen 
Eferin (Ziege), RanGAP1 (Ziege) und Rab11 (Maus) zum Einsatz. Wie die Abbildung zeigt, konnte RanGAP1durch spezifische Präzipitation endogenen Eferins copräzipitiert und Rab11 stark angereichert werden. Die detektierten leichten und schweren Ketten der Immunglobuline zeigen dabei Mengengleichheit an. Da die Spuren des input und der beiden Immunpräzipitationsüberstände sichtbare Signalunterschiede aufweisen, muss an dieser Stelle eine Erklärung zu einem häufig vorgefundenen Phänomen abgegeben werden. Da alle Spuren die gleichen Zelläquivalente repräsentieren, scheint die Immunpräzipitation unter diesen Aufschlussbedingungen zu einer Entfernung detektionsstörender Faktoren zu führen. Dies schlägt sich z.B. in einer plötzlichen Detektierbarkeit von Eferin im IgG-Überstand gegenüber dem input wieder.

Beim zweiten Ansatz sollte eine erhöhte Menge an Eferin erreicht werden, indem Säugerzellen mit einem ungetagten Eferin-Konstrukt transfiziert wurden. Die Hoffnung bestand darin, dass diese Überexpression das relative RanGAP1-EferinVerhältnis angleichen würde. Als weitere Kontrolle diente das trunkierte EferinKonstrukt, welches um die putative RanGAP1-Bindedomäne verkürzt war. Nach Aufschluss der transfizierten Zellen wurde die Immunpräzipitation angesetzt. Dabei zeigte sich für beide Ansätze, dass neben der Präzipitation des jeweiligen EferinKonstruktes auch RanGAP1 und Ubc9 copräzipitierbar waren (Abb. 14). Auffällig war dabei, dass die Überexpression von Eferin nicht zu einer vermehrten Copräzipitation von RanGAP1 führte. Zudem hätte das trunkierte Eferin aufgrund der fehlenden RanGAP1-Bindedomäne keine Copräzipitation von RanGAP1 und Ubc9 zeigen sollen, sodass der gemachte Befund nur eine Erklärung zulässt: Präzipitiertes endogenes Eferin, welches neben dem überexprimierten, trunkierten Eferin(-Konstrukt) zu detektieren war, hatte die copräzipitierten Bindepartner in die Probe verschleppt. Zusätzlich scheint entweder eine Modifikation oder ein unbekannter bridging factor die limitierende Komponente dieser Interaktionen zu sein. 


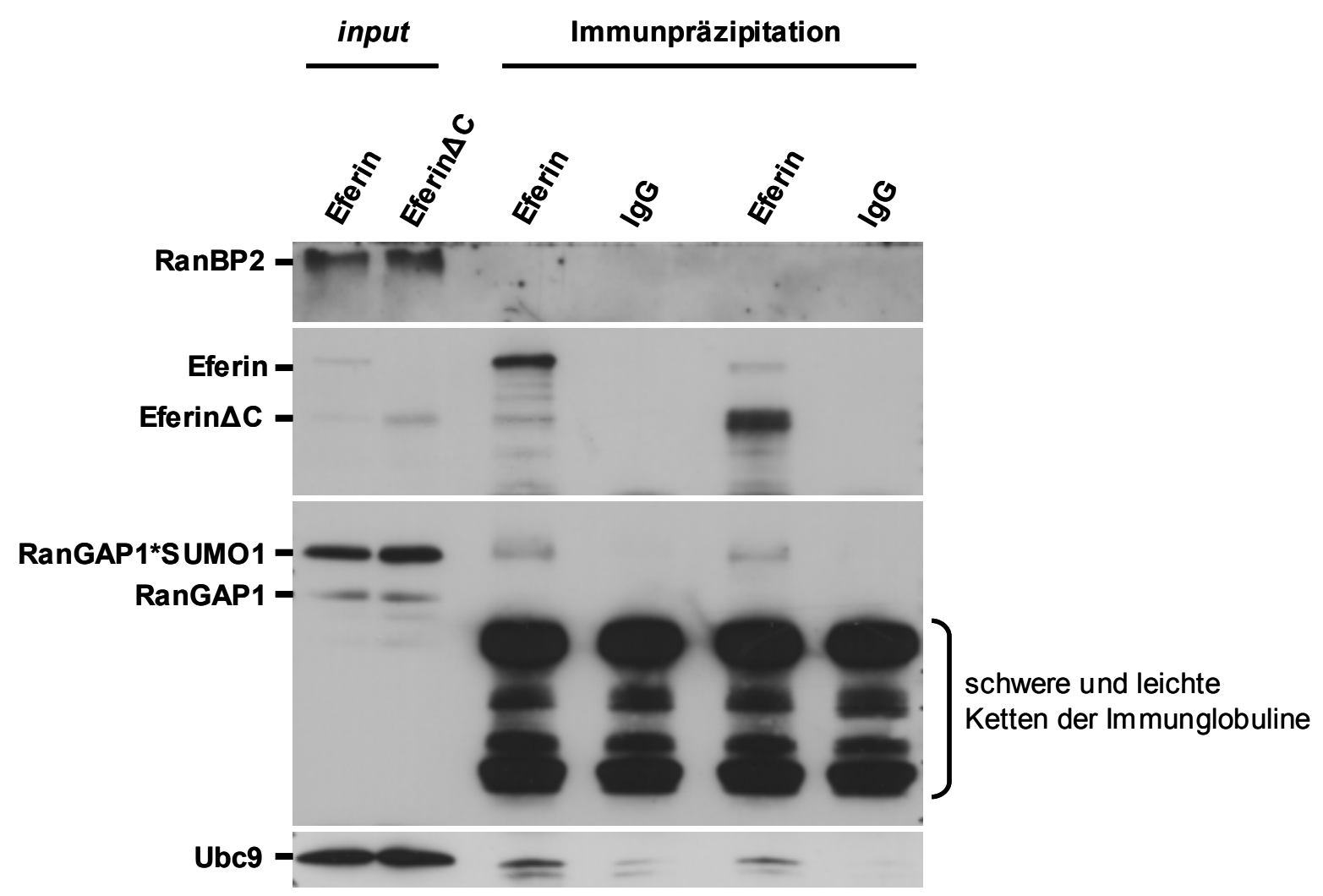

\section{Abbildung 14: Copräzipitation von RanGAP1 und Ubc9 mit überexprimiertem Eferin}

HeLa-Zellen wurden zunächst nach der Calciumphosphat-Methode mit tagfreiem Eferin ( $C M V_{P}$-Eferin) oder Eferin $\Delta \mathrm{C}\left(\mathrm{CMV}_{\mathrm{P}}\right.$-Eferin $\left.\Delta \mathrm{C}\right)$ transfiziert und $48 \mathrm{~h}$ später geerntet. Je 1,5 $\times 10^{8}$ HeLa-Zellen wurden wie bereits beschrieben für die Immunpräzipitation zur Natriumcarbonat-Extraktion eingesetzt. Je 50 mg Antikörper gegen Eferin (aus Ziege) bzw. die gleiche Menge unspezifischen IgG-Antikörpers (Ziege) wurden den Extrakten zugesetzt. Nach Inkubation bei $4^{\circ} \mathrm{C}$ für $2 \mathrm{~h}$ wurden alle Ansätze vor Zugabe der ProteinG-Agarose erneut zentrifugiert. Nach einer weiteren Inkubation von $1 \mathrm{~h} 30$ min bei $4^{\circ} \mathrm{C}$ folgten schließlich Wasch- und Elutionsschritt. Zur Detektion der einzelnen Proteine kamen Antikörper gegen Eferin (Ziege), RanGAP1 (Ziege), RanBP2 (Ziege) und Ubc9 (Ziege) zum Einsatz. Wie in der Abbildung zu sehen, konnte durch Präzipitation überexprimierten Eferins wider Erwarten in beiden Ansätzen RanGAP1 und Ubc9 copräzipitiert werden. Dies wird damit erklärt, dass stets das endogene Eferin anstatt des überexprimierten Eferins (Eferin bzw. Eferin $\Delta C$ ) RanGAP1 und Ubc9 copräzipitierte. Gleichzeitig zeigt dieser Versuch, dass RanBP2 an dieser Copräzipitation nicht beteiligt ist. 


\title{
Aktivierung des spindle checkpoints führt zu vollständigem Abbau von Eferin
}

Die Beobachtung, dass Eferin bei einer Immunfluoreszenz-Analyse erst in Mitose detektierbar wurde, führte zu Arretierungsversuchen mit Nocodazol, die darauf abzielten, eine Anreicherung von Eferin für Immunpräzipitations-Experimente zu erlauben. Erstaunlicherweise zeigte der Arrest stattdessen, dass Eferin in Nocodazol-arretierten Zellextrakten nicht mehr detektierbar war (Abb.15). Daher wurde vermutet, dass Eferin bei Nocodazol-Arrest abgebaut wird.

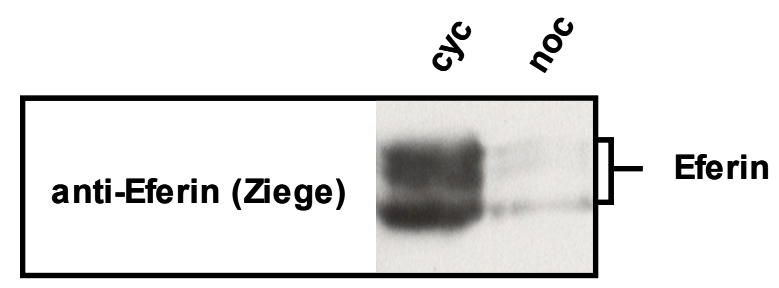

\begin{abstract}
Abbildung 15: Nocodazol-Arrest führt zu Verlust von Eferin
HeLa-Zellen wurden für $24 \mathrm{~h}$ mit Nocodazol (= noc) arretiert oder unbehandelt (= cyc) gelassen. Nach Ernte der Zellen wurden diese einer Digitonin-Extraktion unterzogen. Wie die Abbildung verdeutlicht, führte die Nocodazol-Behandlung zu einem fast vollständigem Verlust der Detektierbarkeit (mittels Antikörper aus Ziege) von Eferin.
\end{abstract}

Um ausschließen zu können, der Abbau von Eferin sei möglicherweise ein Artefakt der Nocodazol-Behandlung, wurde ein Arrest mit Taxol vorgenommen. Im Gegensatz zu Nocodazol bewirkt Taxol die Stabilisierung der Mikrotubuli, führt aber wie Nocodazol durch Aktivierung des spindle checkpoints zur Arretierung der behandelten Zellen in Prometa- und Metaphase. Bei Behandlung der Zellen mit Taxol zeigte sich in der Westernblot-Analyse, wie schon bei Nocodazol-Behandlung, der vollständige Rückgang des Eferin-Signals (Abb. 16). Dagegen führte eine Arretierung der Zellen mit Thymidin (G1/S-Arrest), gegenüber unbehandelten Zellen, zu keiner Veränderung des Expressionslevels von Eferin (Abb. 16). In einer FACSAnalyse konnte dabei der Erfolg des Zellzyklus-Arrestes für die Thymidin- und Nocodazol-behandelten Zellen belegt werden (Abb. 17). 


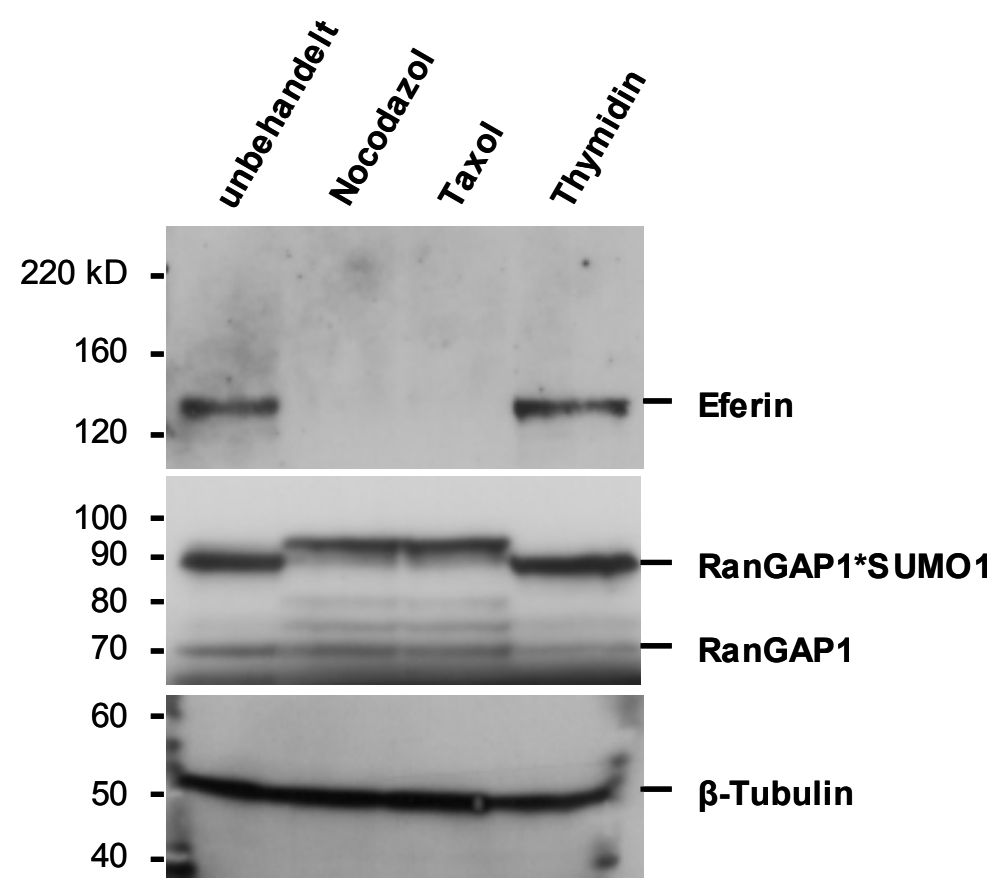

\section{Abbildung 16: Bestimmung der Eferin-Menge nach Zellzyklus-Arretierung}

Mit Nocodazol-, Taxol- oder Thymidin-behandelte und unbehandelte HeLa-Zellen wurden $24 \mathrm{~h}$ nach Arretierungsbeginn direkt in SDS-Probenpuffer aufgeschlossen. Zur Detektion der einzelnen Proteine kamen Antikörper gegen Eferin (Ziege), RanGAP1 (Ziege) und $\beta$-Tubulin (Kaninchen) zum Einsatz. Wie die Abbildung verdeutlicht, führte die Behandlung mit Nocodazol und Taxol zu einem vollständigen Abbau von Eferin. Thymidin-behandelte Zellen waren in Bezug auf die Eferin-Expression dagegen nicht von unbehandelten Zellen zu unterscheiden. Zur Bestätigung der Vollständigkeit des Arrestes wurde RanGAP1 herangezogen, das im Falle von Nocodazol- und Taxol-Behandlung die mitotische Phosphorylierungsform zeigte. Das detektierte $\beta$-Tubulin diente bei diesem Versuch als Ladekontrolle. Ein Teil dieser unbehandelten oder arretierten Zellen wurde vor dem Aufschluss für eine FACS-Analyse abgezweigt (siehe Abb. 17). 

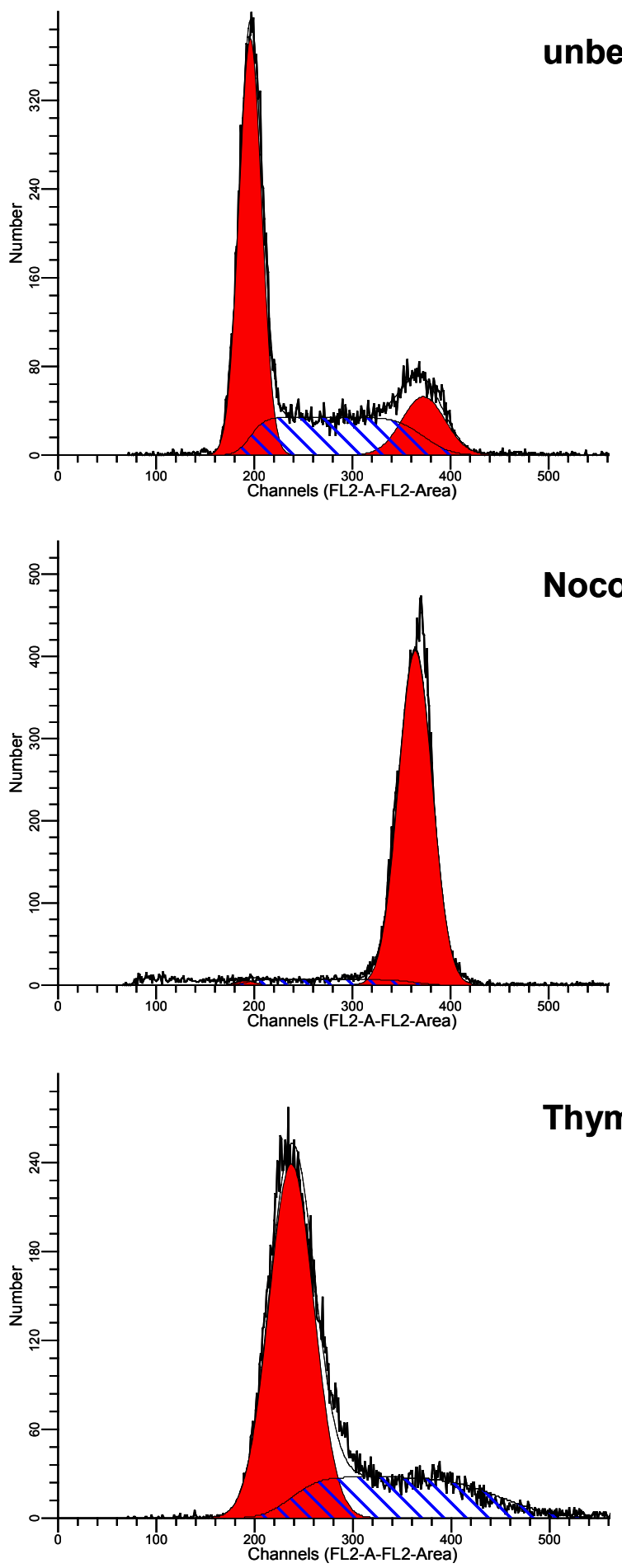

\section{Abbildung 17: Bestätigung des Erfolges der Arretierungsmaßnahmen mittels FACS-Analyse}

Mit Nocodazol- oder Thymidin-behandelte und unbehandelte HeLa-Zellen wurden $24 \mathrm{~h}$ nach Arretierungsbeginn zunächst durch Trypsinierung und Pelletierung geerntet, bevor sie mit Formaldehyd fixiert wurden. Nach Anfärbung mit Propidiumiodid erfolgte die Messung im FACS-Gerät. Wie die Abbildungen zeigen, führten die jeweiligen Behandlungen zu den erwarteten FACS-Profilen: Anreicherung von G1-Zellen bei Thymidin-Arrest und Anhäufung von Zellen mit doppeltem DNAGehalt bei Nocodazol-Behandlung. Auch die unbehandelten Zellen zeigten das erwartete FACS-Profil: 
klassische Verteilung von G1-, S-, G2-Zellen (G1 entspricht roter Fläche bei etwa 200, G2 ist durch rote Fläche bei etwa 400 repräsentiert, S-Phase-Zellen sind durch blau schraffierte Fläche dargestellt). Da die hier angewandte Ernte- und Fixierungsmethode bei den Taxol-arretierten Zellen zu einer starken Verklumpung führte, war eine Bestimmung des DNA-Gehaltes bei diesen Zellen nicht möglich.

In einem weiteren Versuch sollte nun geklärt werden, ob die durch Aktivierung des spindle checkpoint herbeigeführte Abnahme von Eferin mit einem Abbau durch das Proteasom zu erklären sei. Dazu wurden HeLa-Zellen in Anwesenheit des zellwandpermeablen Proteasom-Inhibitors MG132 mit Nocodazol arretiert. Wie sich zeigte, konnte damit tatsächlich der Abbau von Eferin verhindert werden (Abb. 18). Da jedoch MG132 als Proteasom-Inhibitor das korrekte Voranschreiten des Zellzyklus durch Blockierung des Abbaus wichtiger Regulatoren behindert, wurde angenommen, der verhinderte Abbau von Eferin sei durch Nichterreichen der Mitose (ähnlich zu einem Thymidin-Arrest) zu Stande gekommen. Tatsächlich konnte anhand des Phosphorylierungsstatus von endogenem RanGAP1 $\left[{ }^{85}\right]$ belegt werden, dass sich die betreffenden Zellen nicht in Mitose befanden (Abb. 18, untere Hälfte). 


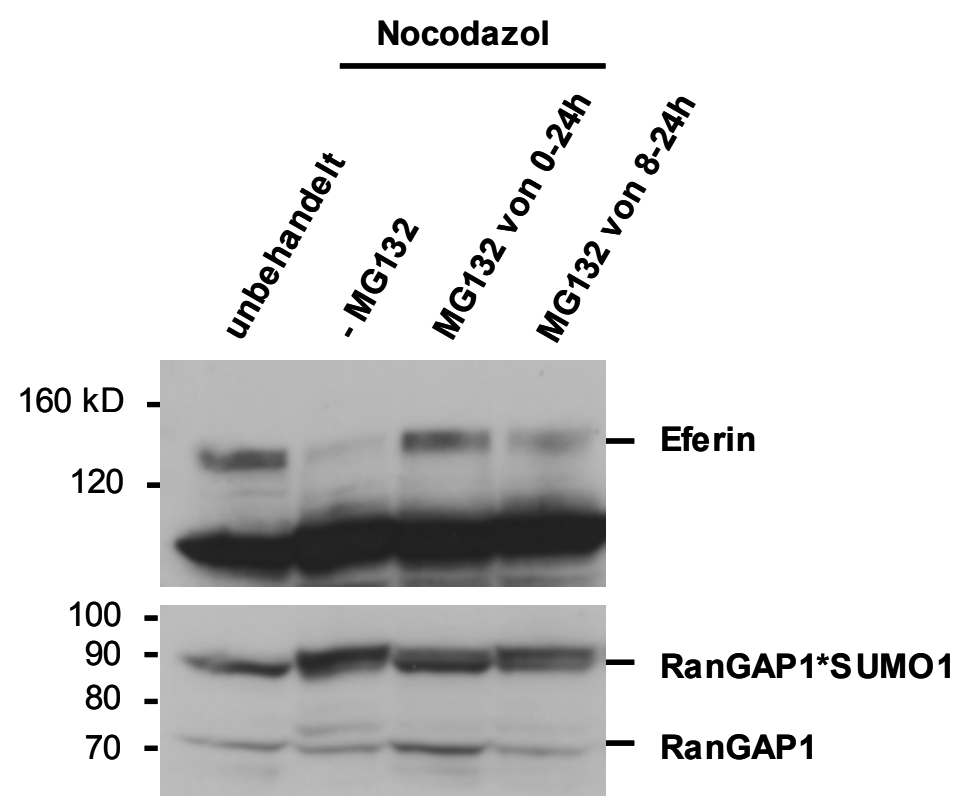

Abbildung 18: MG132 stört den Eintritt in die Mitose und verhindert Eferin-Degradation HeLa-Zellen wurden für $24 \mathrm{~h}$ mit Nocodazol arretiert oder unbehandelt gelassen. Die Nocodazolbehandelten Zellen wurden wiederum in drei parallelen Ansätzen mit dem Proteasom-Inhibitor MG132 versetzt oder unbehandelt gelassen. Dabei erfolgte die MG132-Zugabe unmittelbar oder um $8 \mathrm{~h}$ versetzt zur Nocodazol-Behandlung. Nach Ernte der Zellen konnte die Auswirkung der Behandlungen untersucht werden. Zur Detektion der einzelnen Proteine kamen Antikörper gegen Eferin (Ziege) und RanGAP1 (Ziege) zum Einsatz. Dabei zeigte sich (untere Hälfte), dass die Nocodazol-arretierten Zellen ohne MG132 gegenüber den unbehandelten Zellen vorwiegend die phosphorylierten Formen von RanGAP1 aufwiesen. Bei der gleichzeitigen Gabe von Nocodazol und MG132 kam es zu einer deutlichen Reduzierung der RanGAP1-Phosphorylierungen. Dabei führte die zeitlich versetzte Behandlung mit MG132 jedoch zu einer abgemilderten Reduzierung der RanGAP1-Phosphoform. Da RanGAP1-Phosphorylierung zu Beginn der Mitose erfolgt, lässt sich schlussfolgern, dass ein verhinderter Eintritt in die Mitose den Abbau von Eferin stört. Dieses Experiment lässt jedoch offen, ob Eferin in Mitose über das Proteasom oder ganz allgemein über Proteasen abgebaut wird.

Weil ein Verschwinden des Signals von Eferin aus Nocodazol- bzw. Taxolbehandelten Zellen noch mit Sequestrierung von Eferin in einem unlöslichen, möglicherweise SDS-stabilen Komplex zu erklären wäre, galt es diese Möglichkeit auszuschließen. Dazu wurden unbehandelte Zellen neben Nocodazol-arretierten Zellen einer Extraktion in Harnstoffpuffer unterzogen. Auch hier zeigte sich, dass Eferin nicht einfach in unlöslichen Komplexen sequestriert wird, sondern vielmehr tatsächlichen Abbau erfährt (Abb. 19).

Zusammenfassend zeigen die Experimente, dass Eferin in mitotisch arretierten Zellen degradiert wird. Ob es sich dabei um einen proteasomvermittelten Abbau handelt, bedarf weiterer Klärung. 


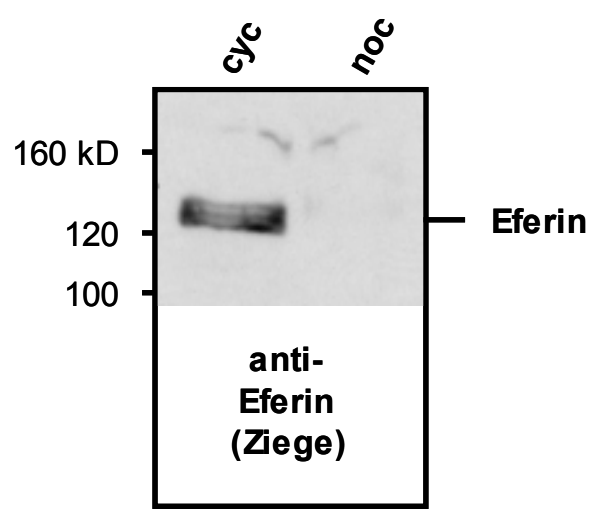

\begin{abstract}
Abbildung 19: Harnstoffextraktion bestätigt Degradation von Eferin nach Nocodazol-Arrest Unbehandelte oder mit Nocodazol-arretierte HeLa-Zellen wurden nach der Ernte zur Solubilisierung aller Proteine in Harnstoff-Extraktionspuffer (8 M Harnstoff, $0,2 \mathrm{M}$ Tris- $\mathrm{HCl} \mathrm{pH} 6,8$ ) resuspendiert und mit SDS-Probenpuffer verdünnt. Wie die Abbildung verdeutlicht, führte die Nocodazol-Behandlung zu einem tatsächlichen Abbau von Eferin.
\end{abstract}

\title{
Eferin wird in vitro mit Nocodazol-Extrakten rasch und quantitativ phosphoryliert
}

Da Eferin in Nocodazol-behandelten Zellen vollständig abgebaut wird, war die Fragestellung, ob dies mit rekombinantem Eferin und Nocodazol-Extrakten in vitro zu reproduzieren sei. Zu diesem Zweck wurden unterschiedliche Zellextrakte zusammen mit rekombinantem Protein in Anwesenheit von ATP bei $30^{\circ} \mathrm{C}$ inkubiert (Abb. 20). Wie sich zeigte, war dieses in vitro System nicht dazu geeignet, den bisher beobachteten Abbau zu rekonstituieren; stattdessen erfuhr das rekombinante Eferin in Nocodazol-Extrakten aber stets eine rasche und quantitative ATP-abhängige Modifikation (Abb. 21). 


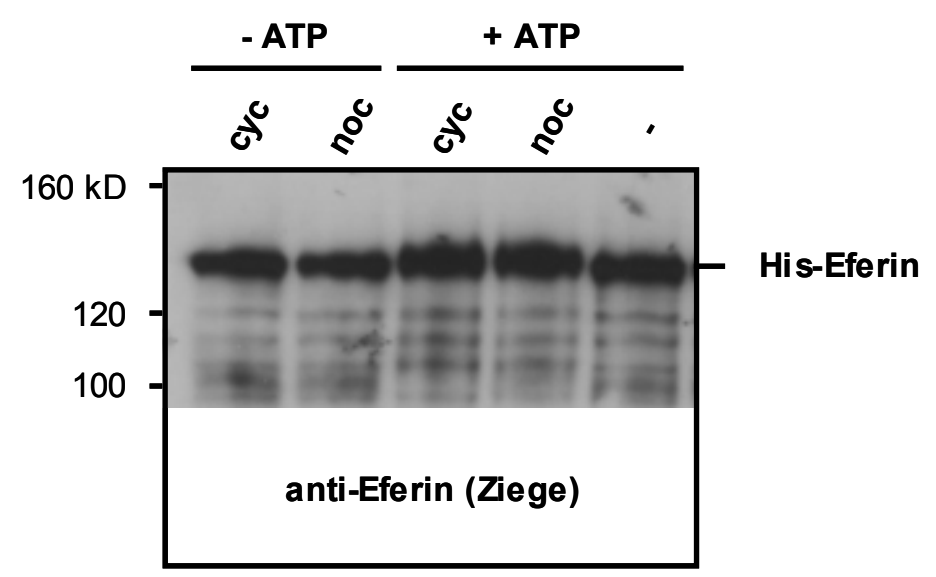

\section{Abbildung 20: Eferin erfährt in Zellextrakten eine ATP-abhängige Modifikation}

$200 \mathrm{ng}$ rekombinantes His-Eferin wurden für $2 \mathrm{~h}$ bei $30^{\circ} \mathrm{C}$ mit oder ohne ATP-Zugabe in den angegebenen Digitonin-Zellextrakten inkubiert. Die Zellextrakte unarretierter $(=\mathrm{cyc})$ oder Nocodazolarretierter HeLa-Zellen (= noc) waren zuvor durch Dialyse gegen den Aufschlusspuffer von endogenem ATP befreit worden. Nur in Anwesenheit von ATP und Zellextrakt erfuhr Eferin eine Modifikation, die zu einer Veränderung seiner elektrophoretischen Mobilität führte.

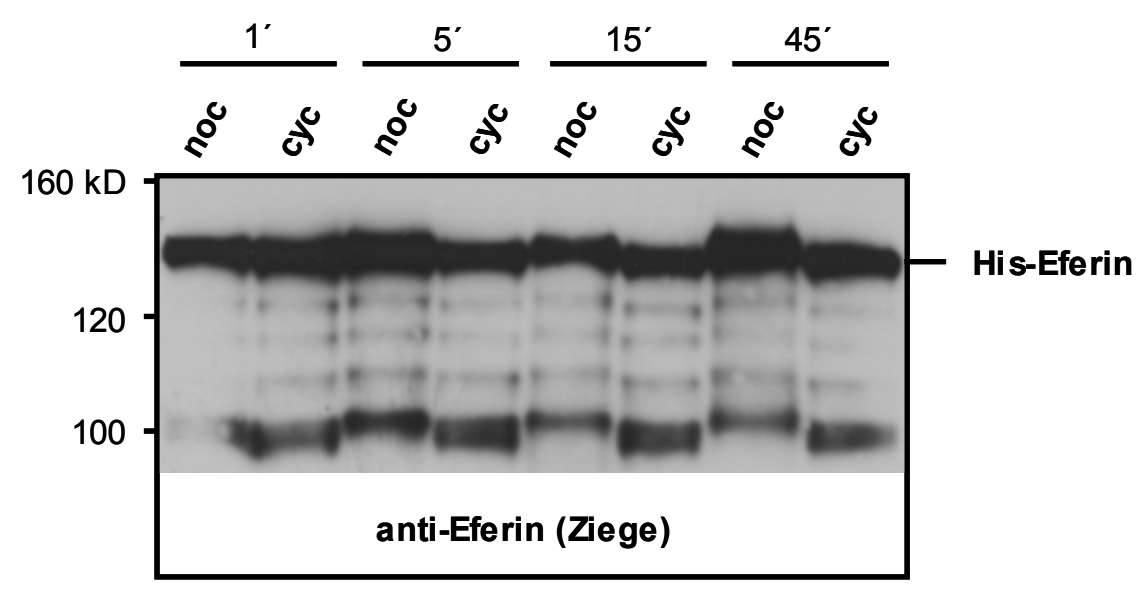

\section{Abbildung 21: ATP-abhängige Modifikation von Eferin erfolgt rasch und quantitativ}

$200 \mathrm{ng}$ rekombinantes His-Eferin wurden bei $30^{\circ} \mathrm{C}$ mit ATP in den angegebenen Zellextrakten für die angegebene Dauer inkubiert. Nur in Anwesenheit von ATP und Zellextrakt Nocodazol-arretierter Zellen erfuhr Eferin eine rasche und quantitative Modifikation, die bereits nach fünf Minuten vollzogen war. Diese Abbildung gibt deshalb auch eine Erklärungsmöglichkeit für das vorangegangene Experiment (Abb. 20). In diesem konnte auch mit dem Extrakt unarretierter Zellen eine Modifikation beobachtet werden. Da aber bei unarretierten Zellen etwa 5 - 10\% mitotische Zellen vorhanden sind (normal wachsende Zellpopulation), die den Nocodazol-arretierten Zellen entsprechen, konnten diese aufgrund der beobachteten Effizienz der Phosphorylierung innerhalb von $2 \mathrm{~h}$ die Modifikation durchführen, zu welcher die übrigen Interphase-Zellen des Extraktes nicht in der Lage sind. 
Diese machte sich in der SDS-Gelelektrophorese sowohl für Eferin als auch für die trunkierte Eferin-Mutante in einem geringen Größenzuwachs bemerkbar, so dass sich die Modifikationsstellen nicht eingrenzen ließen (ohne Abb.).

Um zu zeigen, dass es sich bei dieser Modifikation um eine Phosphorylierung handelt, wurde eine Markierung von Eferin mit radioaktivem $\mathrm{y}^{32} \mathrm{P}$-ATP vorgenommen. Tatsächlich konnte auf diesem Wege gezeigt werden, dass Eferin in dieser in vitro Situation in Anwesenheit von Nocodazol-Extrakt phosphoryliert wird (Abb. 22).

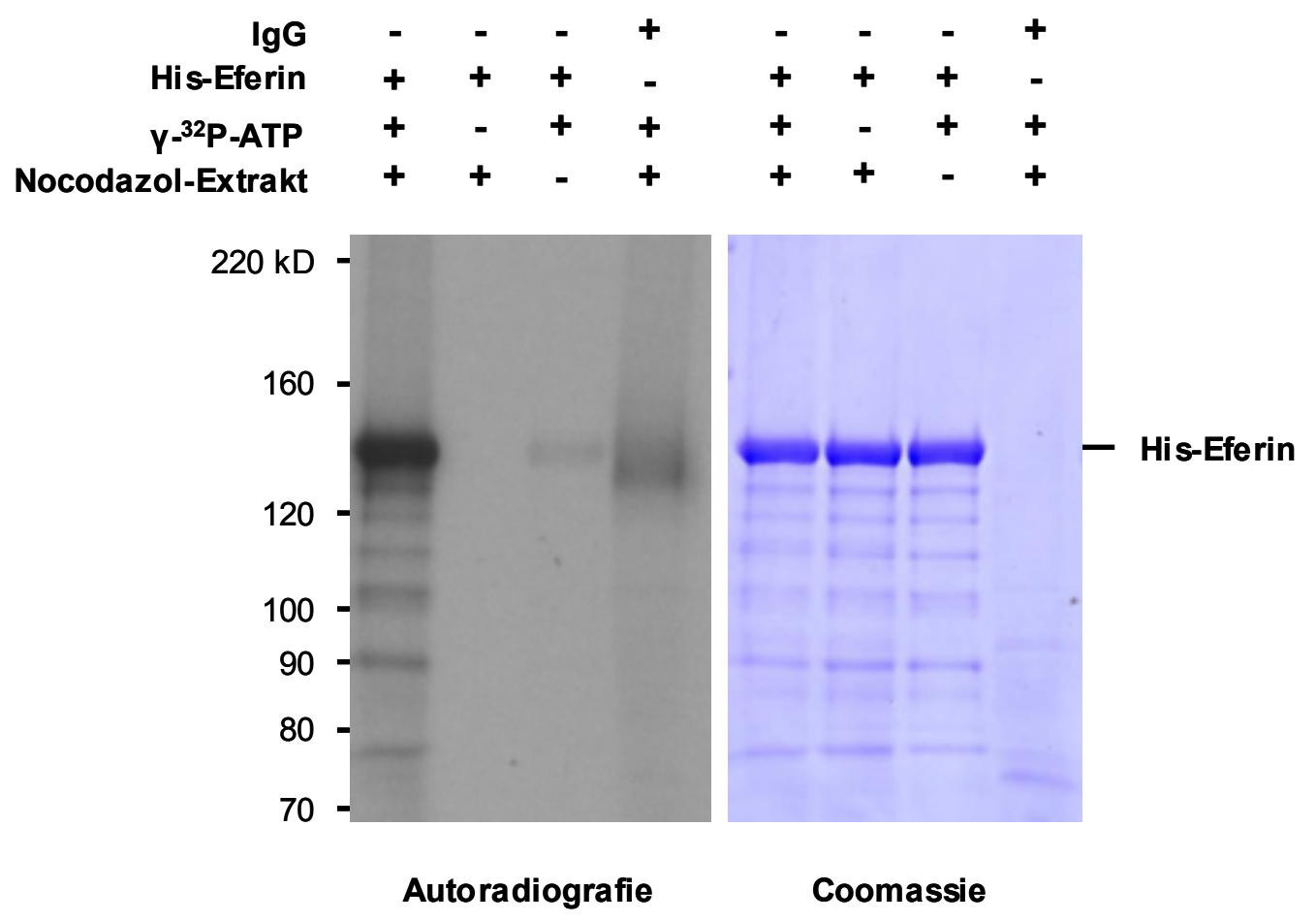

\footnotetext{
Abbildung 22: Bestätigung der ATP-abhängigen Modifikation von Eferin als Phosphorylierung Rekombinantes Eferin wurde mittels Eferin-Antikörper (Ziege) an ProteinG-Agarose immobilisiert. Im Kontrollansatz wurden unspezifische IgG-Antikörper aus Ziege ohne rekombinantes Eferin an ProteinG-Agarose immobilisiert. Beide Matrices wurden wie angegeben mit oder ohne $20 \mu \mathrm{Ci}$ [Y-32P] ATP (entspricht $10 \mathrm{nM}$ ) in An- oder Abwesenheit von Extrakten Nocodazol-arretierter Zellen für 45 min bei $30^{\circ} \mathrm{C}$ inkubiert. Nach einem Waschschritt mit 0,1\% (v/v) Tween-20 in PBS-Puffer folgten die gelelektrophoretische Auftrennung, Autoradiografie und Coomassie-Anfärbung der Proteinbanden. In der Coomassie-Anfärbung ist in den ersten drei Spuren die Mengengleichheit des eingesetzten Eferins zu sehen. Eine quantitative Phosphorylierung ist hier wegen der niedrigen Gesamtmenge an ATP gegen-über einem Überschuss an Eferin nicht auszumachen. In der ersten Spur der Autoradiografie ist jedoch die Phosphorylierung von Eferin deutlich zu sehen. Die in den beiden letzten Spuren zu detektierenden Signale repräsentieren das Hintergrundrauschen des Versuchsansatzes.
} 


\section{Aurora-A Kinase ist eine in vitro Kinase für Eferin}

Aufgrund der beobachteten Phosphorylierung von Eferin in Nocodazol-Extrakten stellte sich die Frage nach der dafür erforderlichen Kinase. Eine Besonderheit der Aurora-A Kinase machte diese zu einem möglichen Kandidaten für die Modifizierung von Eferin: Aurora-A lokalisiert wie Eferin in Mitose an die Centrosomen und wird dort selbst aktiviert [ $\left.{ }^{119,120}\right]$.

Zur Klärung dieser Möglichkeit wurde eine Kollaboration mit Thomas Kufer aus der Arbeitsgruppe von Erich Nigg aufgenommen, der ein Aurora-A Kinase-System etabliert hatte, welches in vitro eine Phosphorylierung möglicher Kandidaten-Proteine zulassen sollte. In der Tat gelang es Thomas Kufer mit zur Verfügung gestelltem HisEferin zu zeigen, dass eine Phosphorylierung durch die Aurora-A Kinase stattfindet (Abb. 23).

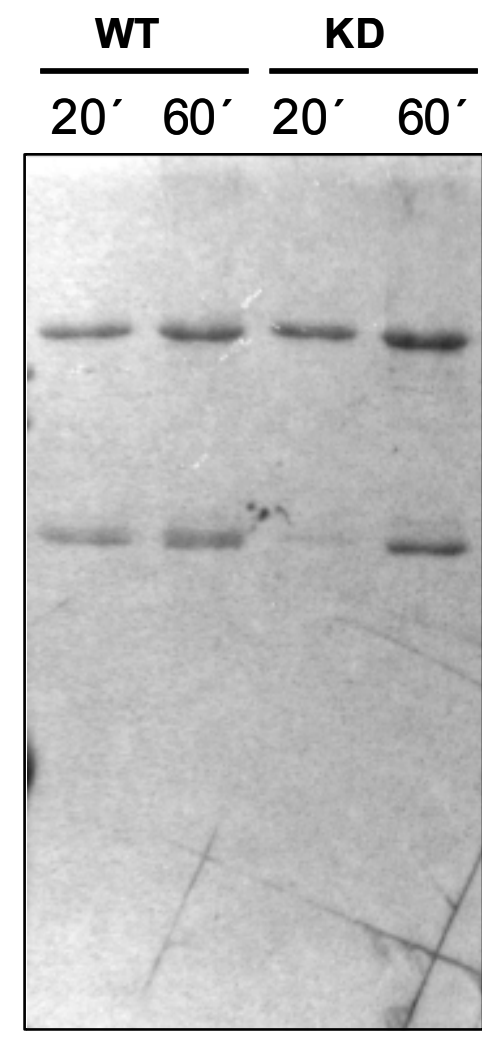

Coomassie

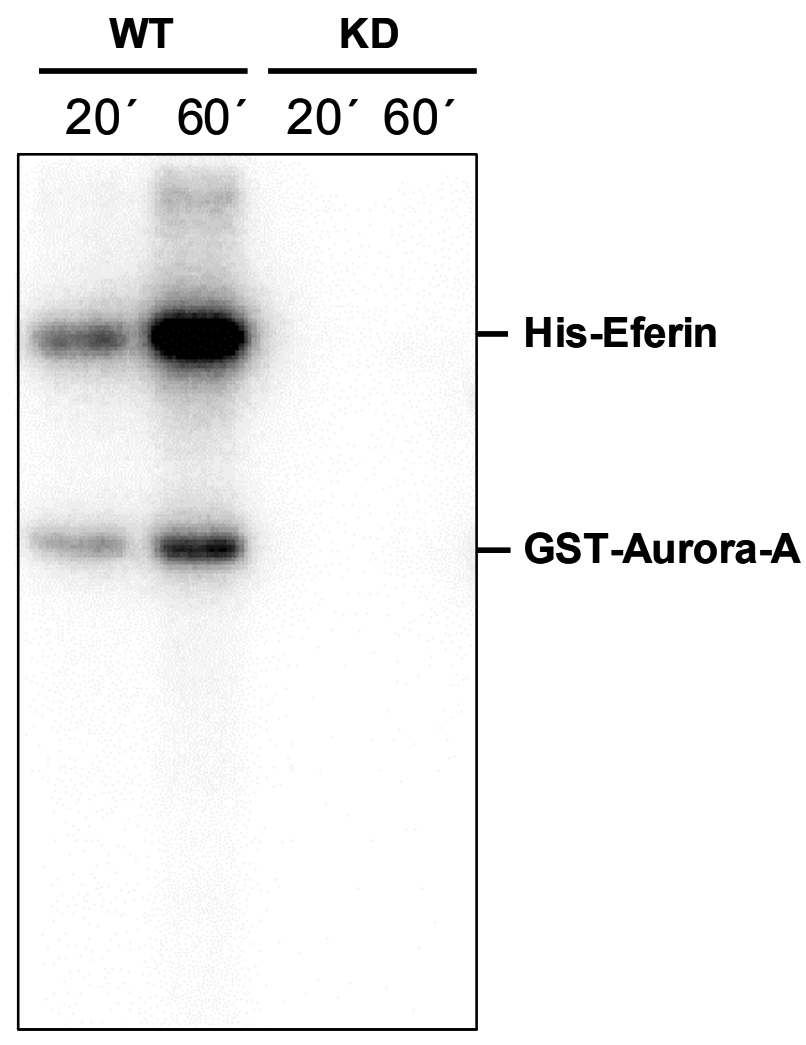

Autoradiografie

\section{Abbildung 23: Aurora-A als in vitro Kinase für Eferin}

Rekombinantes His-Eferin wurde in Anwesenheit von [Y-32P] ATP und rekombinanter Aurora-A Kinase (=WT) bzw. Aurora-A Kinase mit defekter Kinase-Domäne (= KD) für die angegebene Dauer inkubiert. Während die Coomassie-Anfärbung zeigt, dass rekombinantes Eferin in allen Ansätzen vorhanden war, beweist die Autoradiografie dass nur die intakte Aurora-A Kinase Eferin in vitro phosphoryliert [Abbildung Thomas A. Kufer, Abteilung Erich Nigg, MPI für Biochemie (Martinsried)]. 
Dieses Ergebnis lässt, zusammen mit den bisher gemachten Versuchen, den Schluss zu, dass in Mitose tatsächlich eine Phosphorylierung von Eferin erfolgt, die möglicherweise über die Aurora-A Kinase vermittelt wird.

\section{Phosphorylierung von Eferin könnte dessen Stabilität beeinflussen}

Nun war es von Interesse zu überprüfen, ob eine Phosphorylierung den Abbau von Eferin in irgendeiner Weise beeinflussen könnte. Denkbar war vor allem eine Ubiquitin-abhängige Degradation, weshalb den in vitro Phosphorylierungsansätzen Inhibitoren für den proteasomalen Abbau beigemengt wurden. Da sich in diesen Ansätzen mit Zellextrakten kein quantitativer Abbau zeigen ließ (Abb. 24), sollte untersucht werden, ob die Verknüpfung von Eferin mit Ubiquitin-Ketten nachzuweisen sein würde.

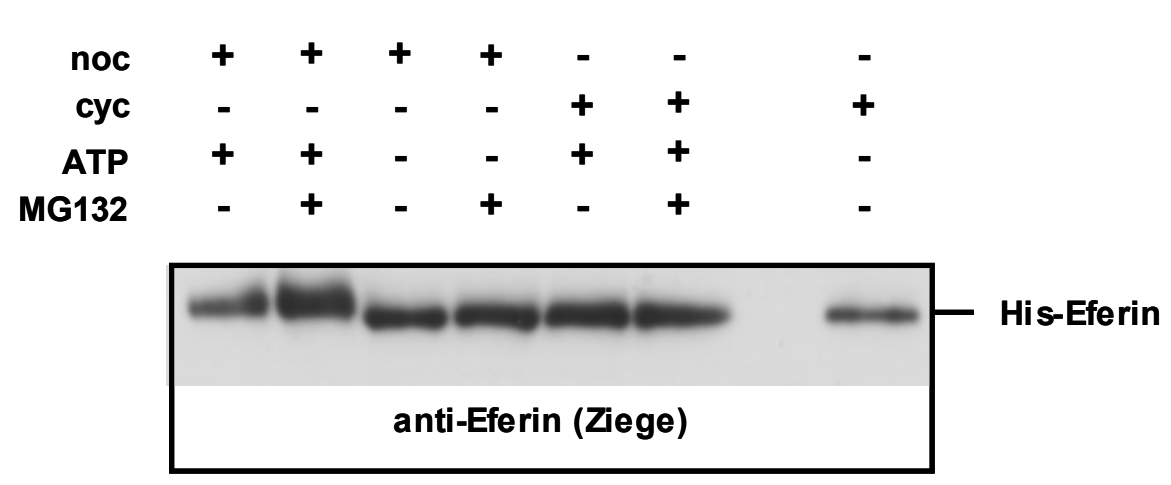

\section{Abbildung 24: in vitro Phosphorylierungs- und Degradationsversuch mit His-Eferin} Je $20 \mathrm{ng}$ rekombinantes His-Eferin wurden mit den angegebenen Zusätzen für $1 \mathrm{~h}$ bei $30^{\circ} \mathrm{C}$ inkubiert, dann einer Westernblot-Analyse unterzogen. Es zeigte sich dass Eferin zwar im Extrakt Nocodazolarretierter Zellen eine Phosphorylierung erfuhr, aber in keinem der Ansätze Abbau von Eferin zu erkennen war.

Um auszuschließen, endogenes Ubiquitin könne der limitierende Faktor dieser Reaktion sein, wurde ein weiterer Versuch angesetzt. In diesem wurde Eferin mittels spezifischer Antikörper zunächst an ProteinG-Agarose immobilisiert, bevor Ubiquitin, zusammen mit einem energieregenerierenden System zu dem ansonsten unveränderten, für die Phosphorylierung nötigen, Reaktionsgemisch beigesteuert wurde. 
Nach Beendigung der Reaktion wurde Eferin im Westernblot, nach Waschen der Immunpräzipitate, ohne mögliche Ubiquitin-Leiter-maskierende Faktoren analysiert. Zusammenfassend lässt sich sagen, dass unter den gegebenen Bedingungen trotz Phosphorylierung weder eine Ubiquitinierung noch ein Abbau von Eferin zu erreichen war (Abb. 25).

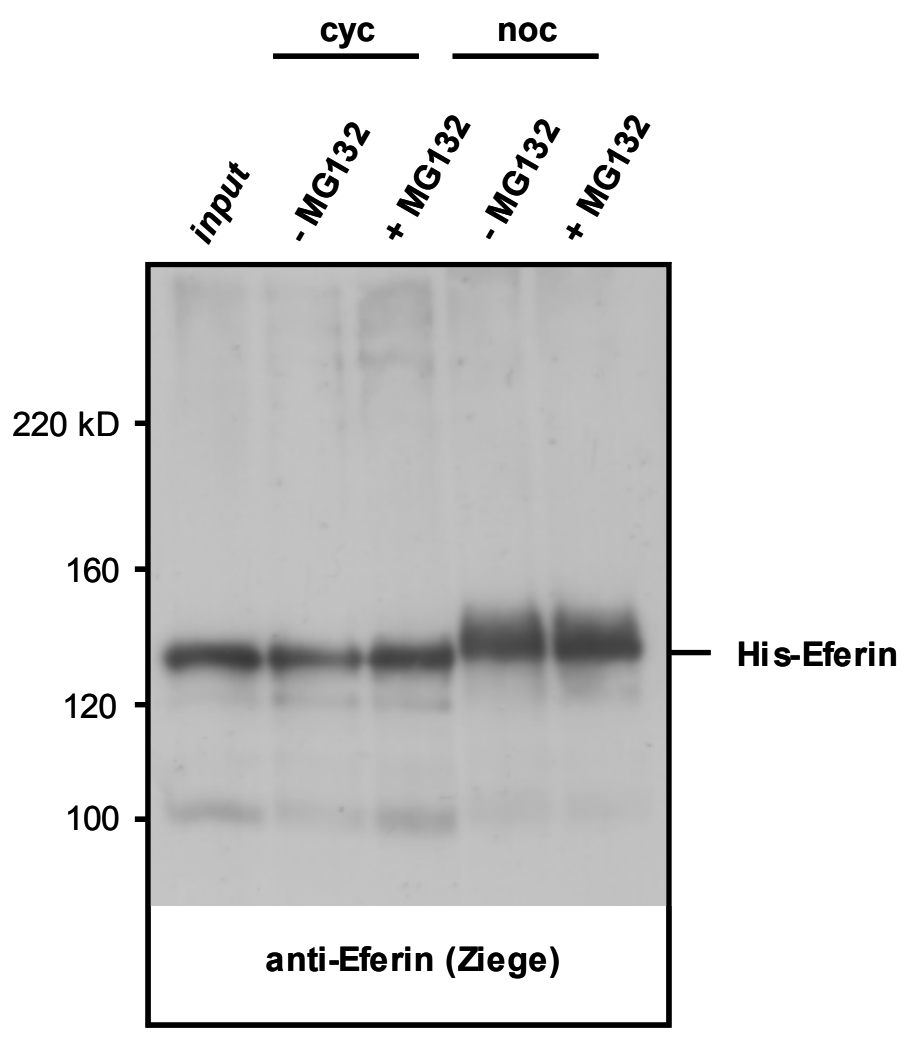

\section{Abbildung 25: Degradationsversuch mit Ubiquitin-Zugabe unter energieregenerierenden Bedingungen}

Rekombinantes His-Eferin wurde mit Hilfe von Ziegen-Antikörpern (gegen Eferin) in einer Konzentration von etwa $5 \mu \mathrm{g} / \mu \mathrm{l}$ an ProteinG-Agarose gekoppelt. Das immobilisierte Eferin wurde mit den angegebenen Komponenten und ATP für $3 \mathrm{~h}$ auf dem Drehrad bei Raumtemperatur inkubiert. Alle Ansätze enthielten, neben den genannten Komponenten und Extrakten, Ubiquitin sowie ein energieregenerierendes System, bestehend aus Creatinphosphat und Creatinphosphokinase. Der Versuch lieferte zwar die phosphorylierte Form von Eferin bei den Ansätzen mit Nocodazol-Extrakten, jedoch war weder Abbau noch eine ubiquitinierte Form von Eferin zu erkennen.

So bleibt unklar, ob die in Mitose vermutete Phosphorylierung von Eferin die Stabilität beeinflussen kann. 


\title{
RNAi gegen Eferin beeinflusst den Zellzyklus
}

Unter der Annahme, dass Eferin in Säugerzellen in einem wohl balancierten Level nötig ist, um in bestimmten Phasen der Mitose und Zytokinese spezifische und überlebenswichtige Funktionen auszuüben, wurde Eferin mittels RNAi-Technik aus den Zellen entfernt (= knock down). Zunächst wurde die Menge der einzusetzenden Oligonukleotide und die erforderliche Behandlungsdauer für den knock down ermittelt. Dabei stellte sich heraus, dass ein sehr guter knock down Erfolg bereits nach $24 \mathrm{~h}$ zu erzielen war, ohne dass die behandelten Zellen eine morphologische Veränderung aufwiesen (Abb. 26).

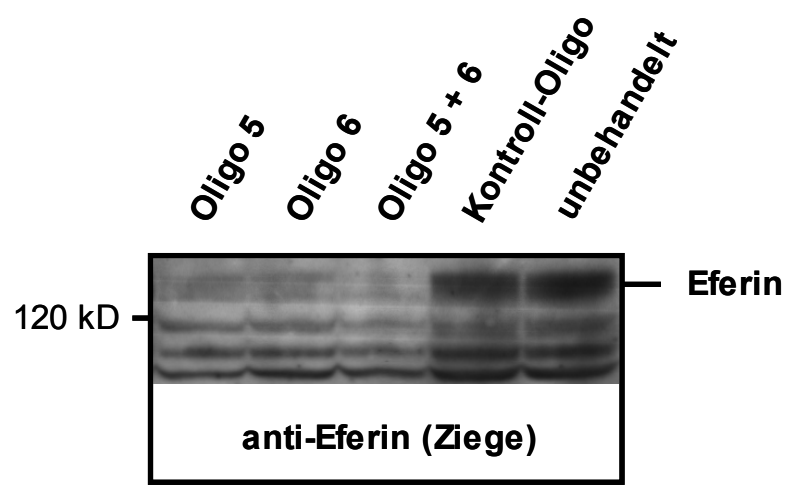

\begin{abstract}
Abbildung 26: RNAi-Technik führt bereits nach $24 \mathrm{~h}$ zur Depletion von Eferin In einem Experiment wurde der Grad der Depletion von Eferin mittels RNAi-Technik nach $24 \mathrm{~h}$ untersucht. Dazu wurden HeLa-Zellen mit unterschiedlichen Oligonukleotiden transfiziert und $24 \mathrm{~h}$ später für die Analyse geerntet. Es konnte gezeigt werden, dass mit beiden Oligonukleotiden bereits nach dieser kurzen Inkubationsdauer vollständige Depletion von Eferin zu erreichen war.
\end{abstract}

Um mögliche Effekte einer Depletion von Eferin auf den Zellzyklus zu analysieren, wurde das Experiment auf eine Inkubation von $48 \mathrm{~h}$ ausgedehnt und schließlich, neben einer Untersuchung der Populationsverteilung mittels FACS (Abb. 29), eine Westernblot-Analyse vorgenommen (Abb. 27). Bei einer Transfektion über $96 \mathrm{~h}$ ohne Retransfektion zeigte sich im Falle des Oligos 5 ein nahezu vollständiger knock down, während der Depletionserfolg mit Oligo 6 oder in Kombination der beiden Oligos stets schlechter ausfiel (Abb. 28). Dieser Befund korreliert mit den Ergebnissen der FACS-Analyse (Abb. 29). 


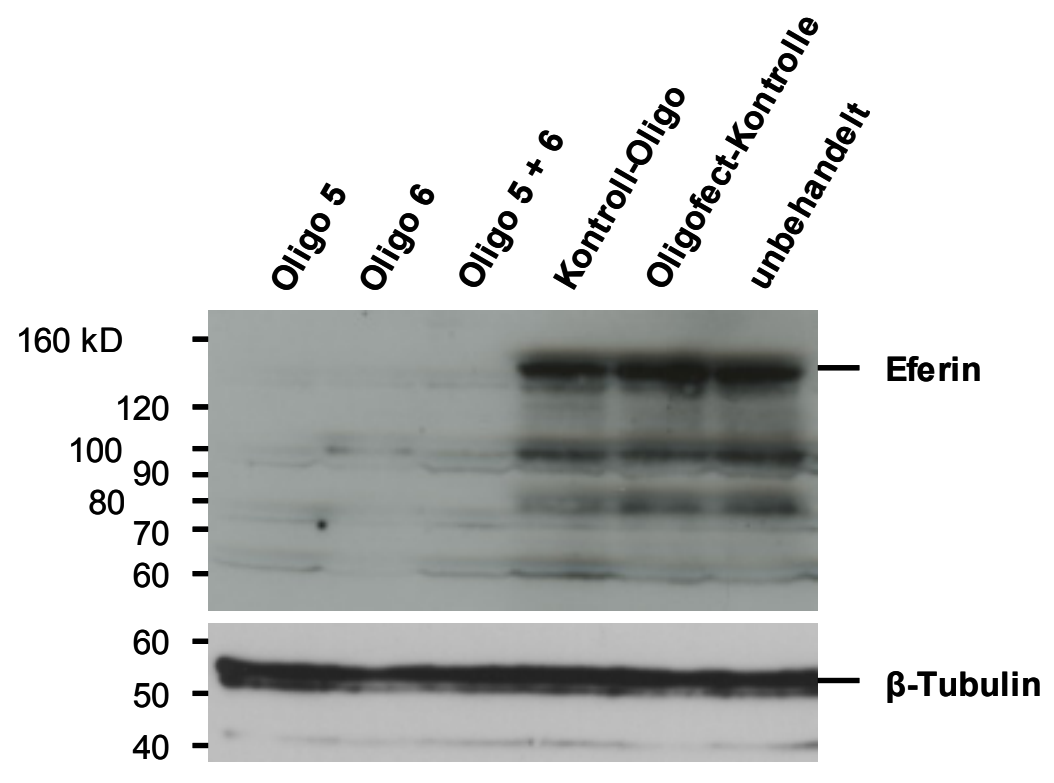

\section{Abbildung 27: RNAi-Retransfektion erlaubt vollständige Depletion von Eferin}

Für die Analyse mittels Durchflusszytometer wurden HeLa-Zellen $24 \mathrm{~h}$ nach der Ersttransfektion nochmals mit den angegebenen Oligonukleotiden retransfiziert und nach weiteren $24 \mathrm{~h}$ ein Teil davon für die Westernblot-Analyse geerntet. Zur Detektion der einzelnen Proteine kamen Antikörper gegen Eferin (Ziege) und $\beta$-Tubulin (Kaninchen) zum Einsatz. Wie die Abbildung verdeutlicht, war der Depletionserfolg $48 \mathrm{~h}$ nach Oligo-Transfektion vollständig.

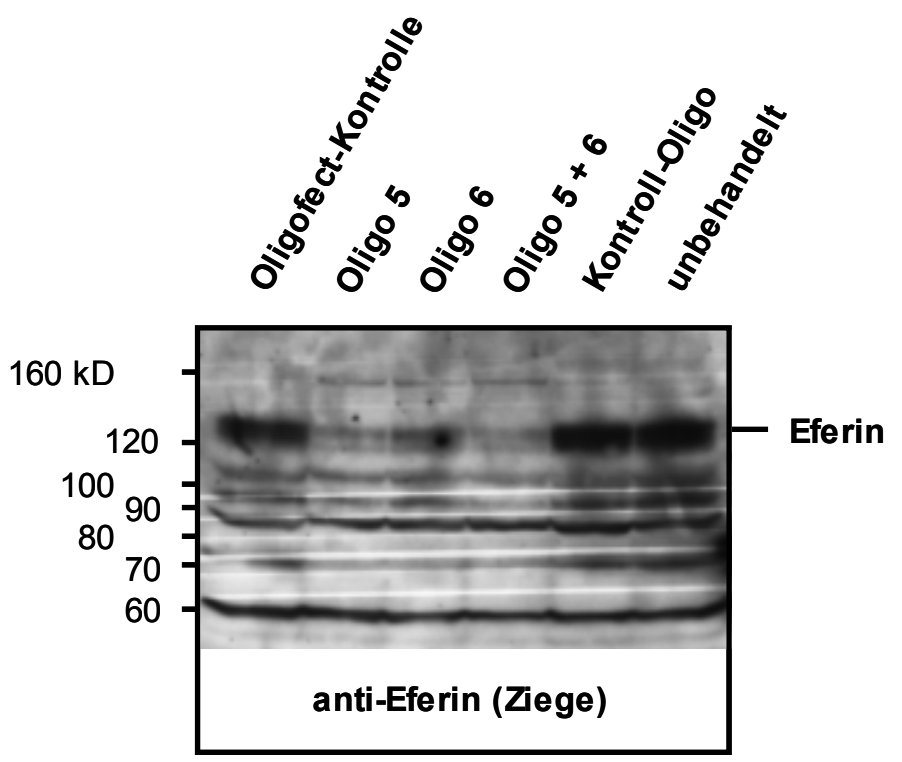

Abbildung 28: Unterschiedliche Depletionsstärke bei Anwendung der RNAi-Methode für Eferin HeLa-Zellen wurden mit den angegebenen Oligonukleotiden zur Depletion endogenen Eferins transfiziert und $96 \mathrm{~h}$ später geerntet. Wie sich zeigte, stellte sich dabei mit Oligo 5 der beste Depletionserfolg ein. 

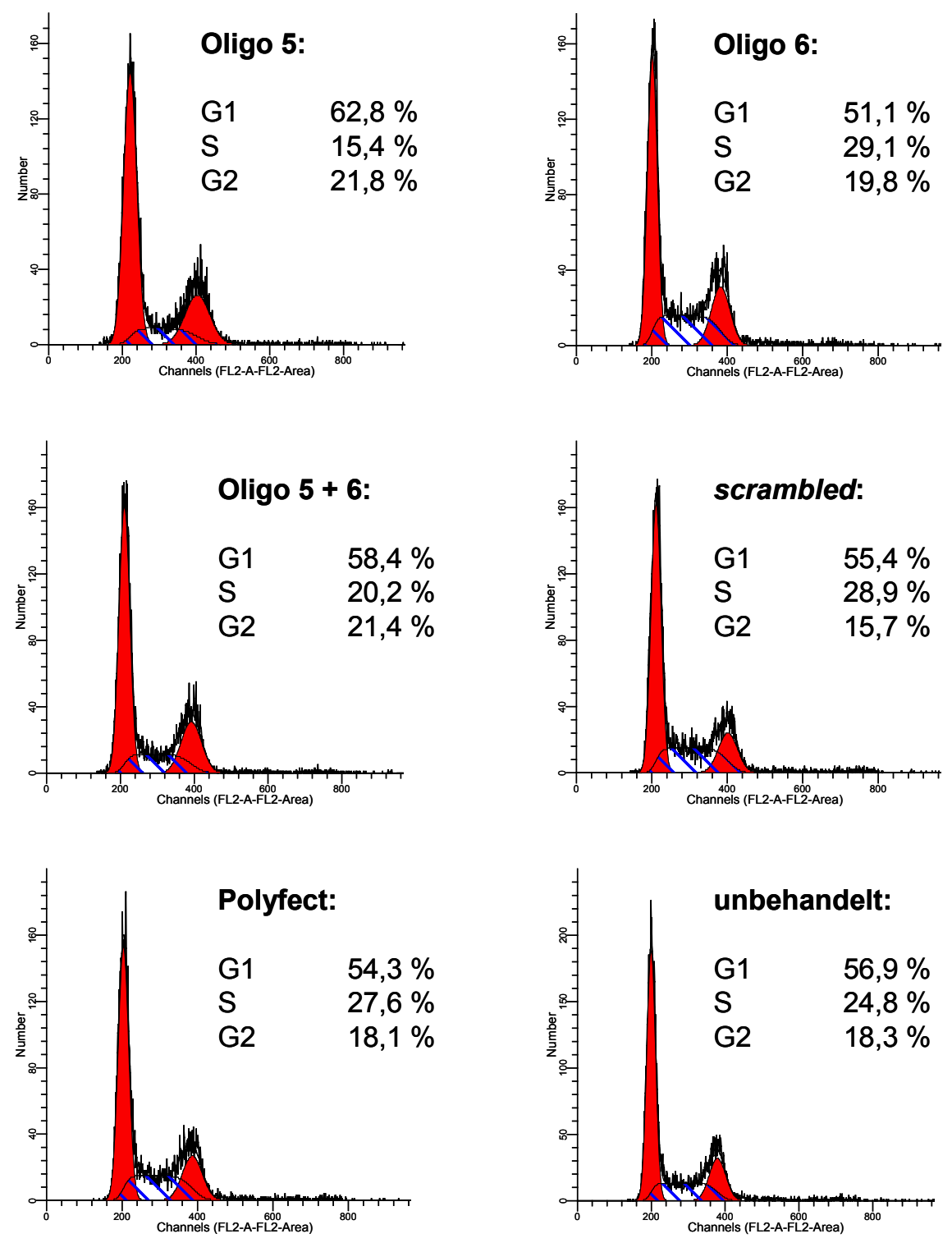

\section{Abbildung 29: Depletion von Eferin bewirkt Rückgang von S-Phase-Zellen}

Vor der Analyse mittels FACS-Gerät wurden HeLa-Zellen $24 \mathrm{~h}$ nach der Ersttransfektion mit den angegebenen Oligonukleotiden retransfiziert, nach insgesamt $48 \mathrm{~h}$ geerntet und in Formaldehyd fixiert. Nach Anfärbung mit Propidiumiodid erfolgte die Messung im FACS-Gerät. Dabei zeigte sich für Oligo 5 eine Auffälligkeit im DNA-Profil, welche sich als Abnahme der S-Phase-Population darstellte. Der Erfolg der Depletion ist in Abb. 27 dargestellt. 
Die Verteilung der Zellpopulationen (G0/G1, S, G2/M) zeigte für den knock down mit Oligo 5, dass die betreffenden Zellen in gewissem Umfang daran gehindert wurden, einen normalen Zellzyklus zu vollziehen (Abb. 29). Dies machte sich als Abreicherung der S-Phase-Population und Anstieg der Zellen in G0/G1 und G2/M bemerkbar (zusammengefasst in Abb. 30).

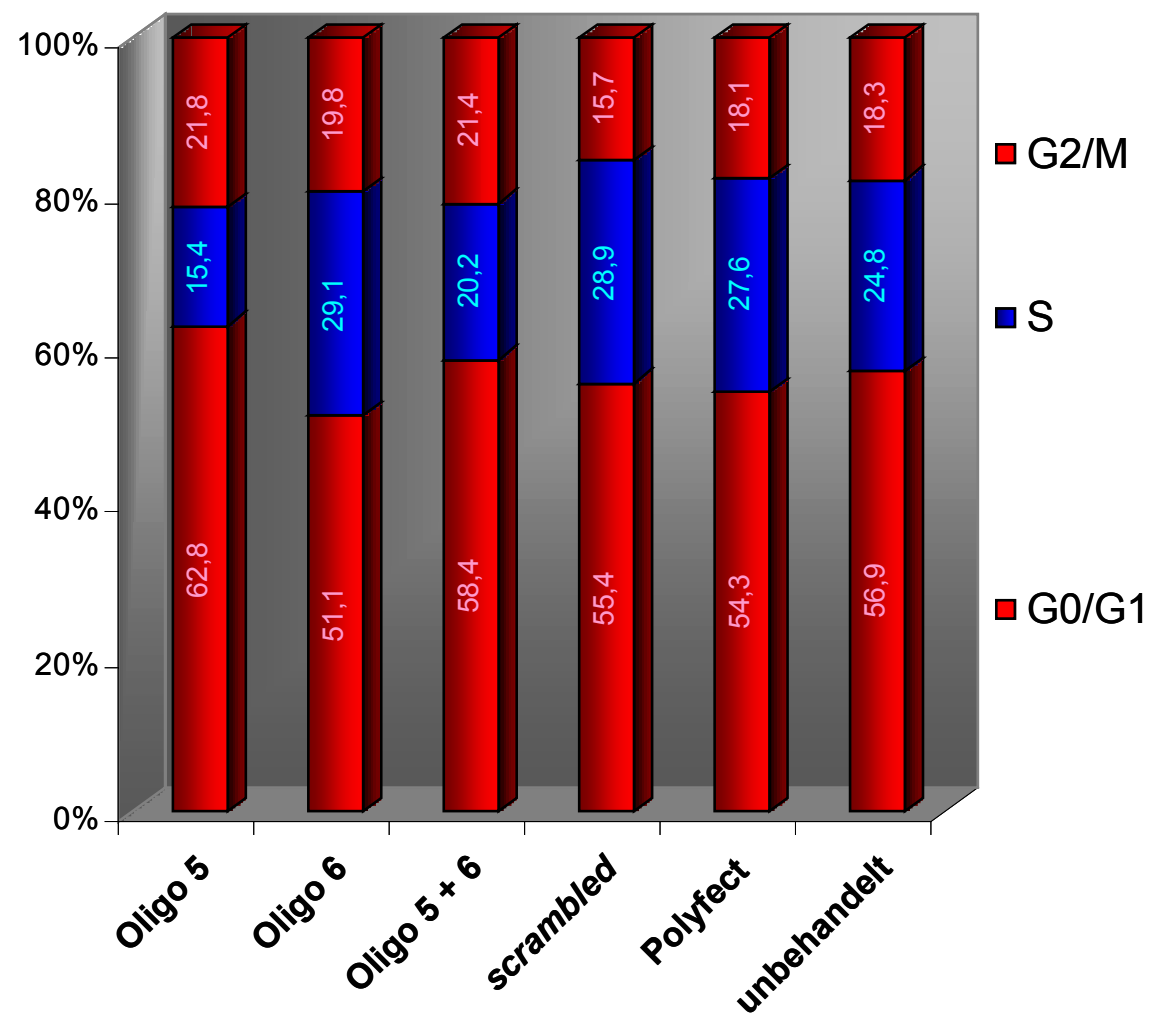

\section{Abbildung 30: Schematische Zusammenfassung der RNAi-Experimente}

Die in Abb. 29 ermittelten Populationsverteilungen sind zur Verdeutlichung graphisch zusammengefasst. Hierbei zeigt sich, dass der Einsatz des Oligonukleotids 5 stets zu einer deutliche Abnahme der S-Phase-Zellen führt.

\section{Mitotische RanGAP1-Lokalisation bleibt bei Eferin-knock down erhalten}

Da zwar eine Interaktion zwischen RanGAP1 und Eferin über Immunpräzipitation gezeigt, dieser Wechselwirkung jedoch keine Funktion zugeordnet werden konnte, wurde überlegt, zu welchem Anlass diese beiden Proteine miteinander interagieren könnten. Bisher war gezeigt worden, dass Eferin in bestimmten Phasen der Mitose an den Centrosomen anzutreffen ist, während RanGAP1*SUMO1 an der mitotischen 
Spindel und den Kinetochoren lokalisiert (Abb. 31). Da diese Kinetochor-Lokalisation die Integrität des mitotischen Mikrotubuli-Apparates benötigt, besagt ein Modell, dass RanGAP1*SUMO1 entlang der Spindel-Mikrotubuli auf die Kinetochore geladen werden könnte $\left[{ }^{121}\right]$. In diesem Zusammenhang könnte Eferin (an den Centrosomen sitzend) die Beladung der Spindel mit RanGAP1*SUMO1 durch eine transiente Interaktion mit diesem zu Beginn der Mitose übernehmen. 


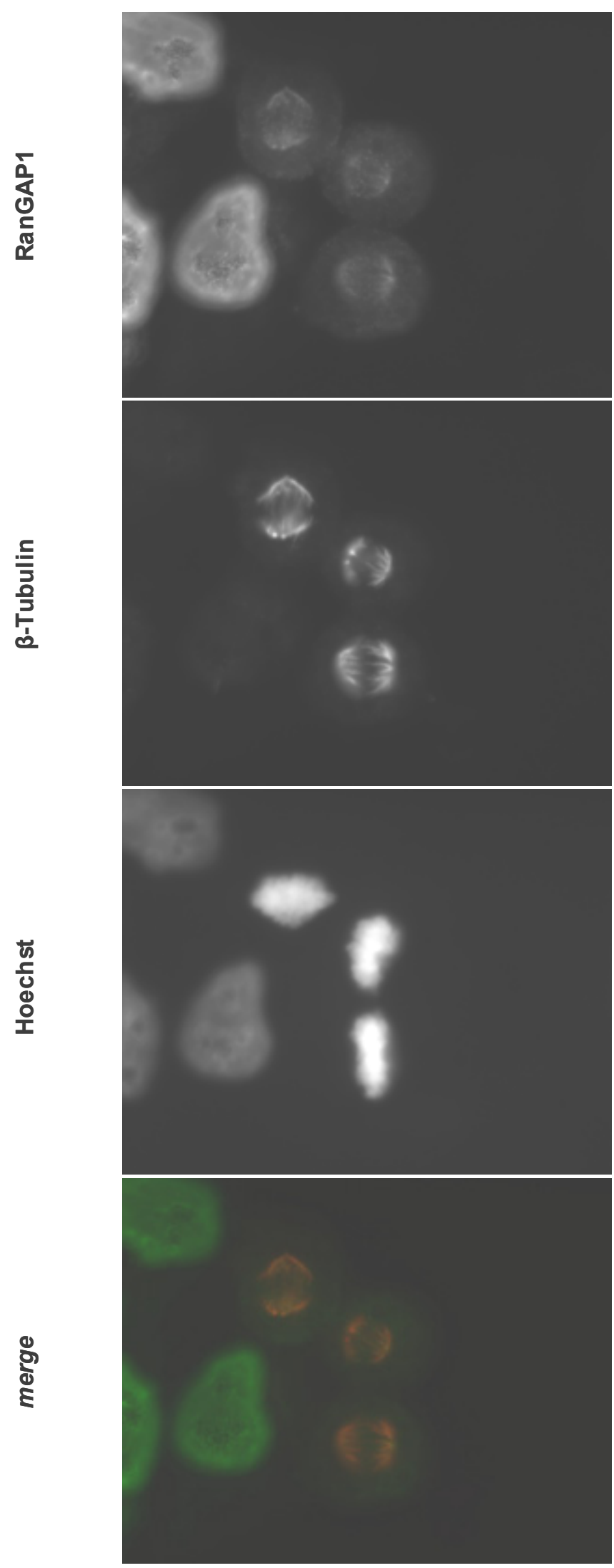

\section{Abbildung 31: Zelluläre RanGAP1-Lokalisation}

Auf Deckgläschen gewachsene HeLa-Zellen wurden zunächst für 5 min mit Digitonin in PBS-Puffer auf Eis präpermeabilisiert, danach mit Formaldehyd fixiert. Es folgte die Doppelanfärbung mit einem Ziegen-Antikörper gegen RanGAP1 und einem gegen $\beta$-Tubulin gerichteten Kaninchen-Antikörper. 
Nach einem Waschschritt folgte die Inkubation mit den Zweitantikörpern (anti-Ziege Alexa 488 und anti-Kaninchen Cy 3) sowie die Anfärbung der DNA mittels Hoechst. Wie in der Abbildung zu sehen, war RanGAP1 bei nichtmitotischen Zellen an der Kernhülle (genauer an Kernporenkomplexen) zu detektieren. In mitotischen Zellen befand sich RanGAP1 an der mitotischen Spindel und den Kinetochoren. Wegen der Präpermeabilisierung der Zellen war der Großteil von RanGAP1 (Iöslich / zytoplasmatisch) nicht mehr zu detektieren.

Um diese Hypothese zu überprüfen, wurden HeLa-Zellen 48 h nach Eferin-Depletion in einer Immunfluoreszenz-Analyse auf das Vorhandensein von RanGAP1 an Kinetochoren und der mitotischen Spindel hin untersucht (Abb. 32). Dabei stellte sich heraus, dass RanGAP1 trotz Eferin-Depletion (Abb. 33) weiterhin korrekt lokalisierte. 
Oligo 5
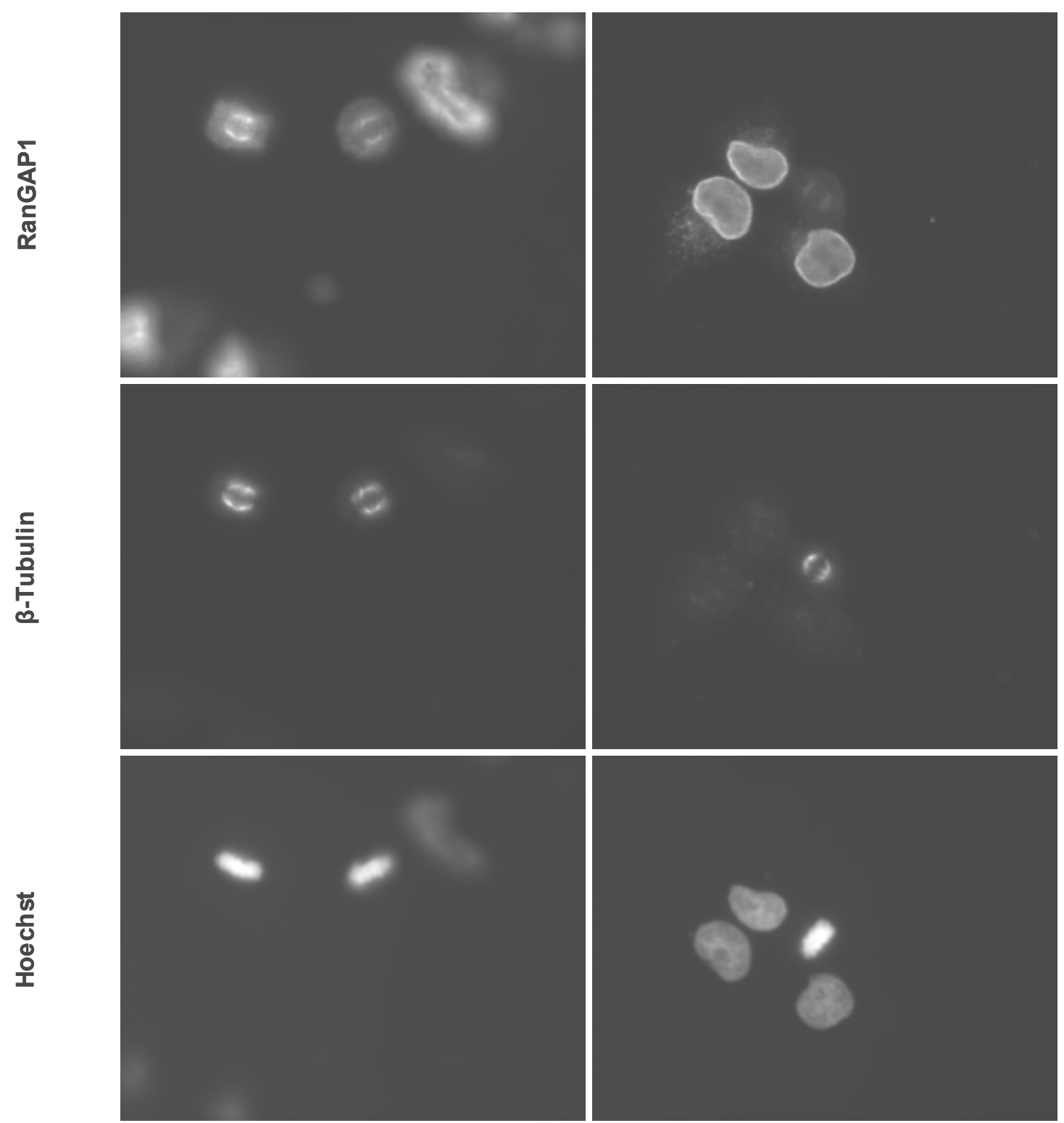

호
음
오

8
$\frac{\pi}{2}$
$\frac{5}{2}$

Abbildung 32: Eferin-Depletion nimmt keinen Einfluss auf mitotische RanGAP1-Lokalisation

Die Depletion von Eferin in HeLa-Zellen wurde mittels RNAi-Methode durchgeführt. $48 \mathrm{~h}$ nach

Transfektion wurden die behandelten Zellen zunächst auf Eis präpermeabilisiert, danach mit

Formaldehyd fixiert. Es folgte die Doppelanfärbung mit einem Ziegen-Antikörper gegen RanGAP1 und 
einem gegen $\beta$-Tubulin gerichteten Kaninchen-Antikörper. Nach einem Waschschritt folgte die Inkubation der Zweitantikörper (anti-Ziege Alexa 488 und anti-Kaninchen Cy 3) sowie die Anfärbung der DNA. Wie zu sehen ist, führte Eferin-Depletion zu keinerlei Veränderung der mitotischen RanGAP1-Lokalisation an den Kinetochoren und der mitotischen Spindel.

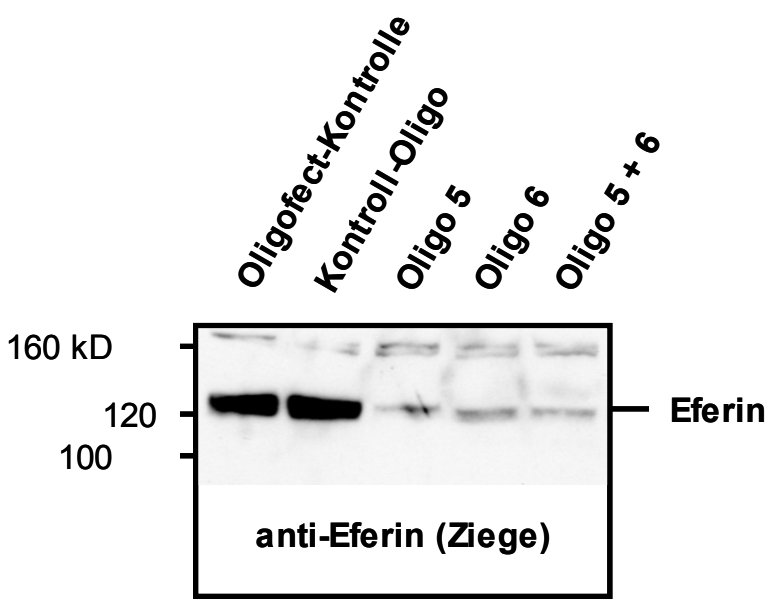

\section{Abbildung 33: Überprüfung des Erfolges der Eferin-Depletion}

Der Umfang der gewünschten Eferin-Depletion (mittels RNAi-Methode) sollte für HeLa-Zellen, die in der Immunfluoreszenz-Analyse (vorangegangene Abbildungen 32 und 4) verwendet wurden, untersucht werden. Dafür waren die HeLa-Zellen $24 \mathrm{~h}$ nach der Ersttransfektion nochmals mit den angegebenen Oligonukleotiden retransfiziert worden. Die Erfolgsrate für die Depletion von Eferin (nach 48 h) wurde auf mindestens $80 \%$ geschätzt. Dies schien für die Auswertung der Gesamtergebnisse ausreichend zu sein.

Dies weist darauf hin, dass die Funktion von Eferin an den Centrosomen für die RanGAP1-Lokalisation ohne Bedeutung ist. Es ist allerdings nicht auszuschließen, dass ein Eferin-knock down in gewissem Rahmen durch verwandte Proteine wie z.B. Arfophilin $2\left[{ }^{91}\right]$ in seiner Funktion kompensiert werden könnte.

\section{Eferin besitzt zwei SUMO-Bindedomänen}

Bei genauer Betrachtung der Aminosäuresequenz von Eferin wurde festgestellt, dass neben den bisher beschriebenen Domänen zwei putative SUMO-Bindungsstellen vorhanden sind (Abb. 34) $\left.{ }^{77-80}\right]$. Diese Bindemotive für SUMO entsprechen der Sequenz [V/I]-x-[V/I]-[V/I] und [V/I]-[V/I]-x-[V/I/L]. Vor diesem Hintergrund sollte ermittelt werden, ob Eferin an SUMO binden und ob es zwischen SUMO1 und SUMO2/3 unterscheiden kann. 
1

1

434 MASA.

\section{Abbildung 34: putative SUMO-Bindungsstellen in Eferin und Eferin $\Delta C$}

In der Aminosäureabfolge der Eferin-Sequenz sind zwei mögliche SUMO-Bindedomänen (gelb unterlegter Einbuchstabencode) enthalten, die den Motiven [V/I]-x-[V/I]-[V/I] und [V/I]-[V/I]-X-[V/I/L] entsprechen.

\section{Eferin bindet präferentiell an SUMO1}

Zur Feststellung, ob Eferin SUMO binden kann, wurde die mögliche Interaktion der rekombinanten Proteine analysiert. Zu diesem Zweck wurden jeweils rekombinantes SUMO1 und rekombinantes SUMO2 in gleichen Konzentrationen (0,1 mg / ml) kovalent an Cyanogenbromid-aktivierte Sepharose gebunden. Beide immobilisierten SUMO-Paraloge sowie eine Ovalbumin-Kontrolle wurden mit rekombinantem Eferin (His-Eferin und His-Eferin $\Delta \mathrm{C}$ ) versetzt und nach Inkubation und einem Waschschritt für SDS-PAGE eluiert. Dabei zeigte sich einerseits, dass Eferin generell in der Lage ist SUMO zu binden (Abb. 35). Andererseits konnte gezeigt werden, dass Eferin präferentiell an SUMO1 bindet, an SUMO2 dagegen nur schwach. Darüber hinaus wurde durch Verwendung einer c-terminal trunkierten Form von Eferin gezeigt, dass die n-terminale Bindedomäne allein nur eine geringe Neigung SUMO zu binden besitzt. 


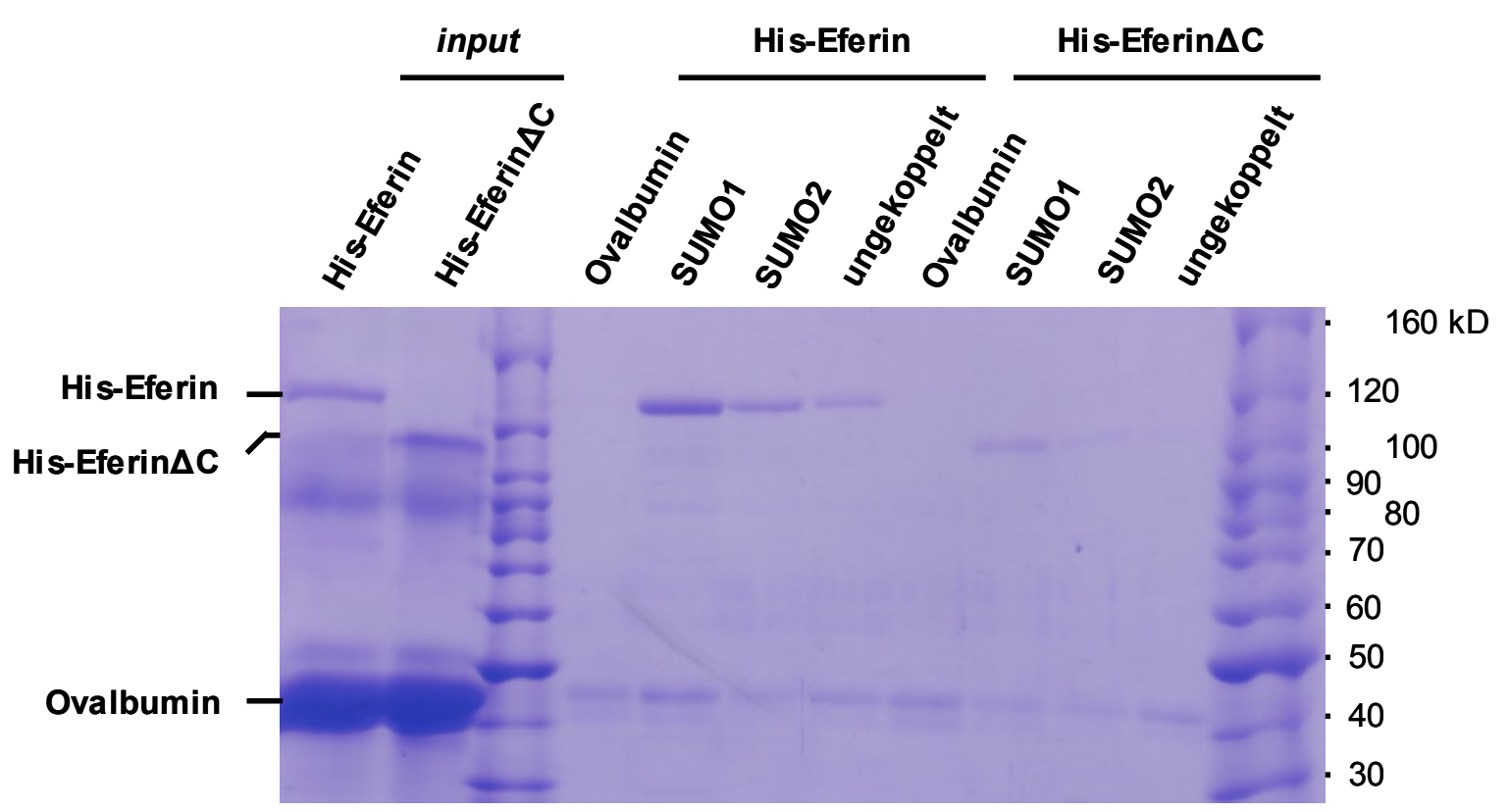

\section{Abbildung 35: Eferin bindet präferentiell SUMO1}

Jeweils mit SUMO1, SUMO2 oder Ovalbumin gekoppelte und ungekoppelte (inaktivierte)

Cyanogenbromid-aktivierte Sepharose wurde zur Absättigung unspezifischer Bindestellen für $1 \mathrm{~h}$ bei $4^{\circ} \mathrm{C}$ auf dem Drehrad in SUMO-Bindungspuffer vorinkubiert. Es folgte Zugabe von His-Eferin bzw. His-Eferin $\Delta \mathrm{C}$ und Inkubation für $4 \mathrm{~h}$ bei $4^{\circ} \mathrm{C}$ auf dem Drehrad. Dem Waschen der Matrices folgte Elution mit 1x SDS-Probenpuffer, bevor die Proben nach SDS-PAGE über Coomassie-Färbung ausgewertet wurden. Es zeigte sich, dass beide Eferin Konstrukte in der Lage waren SUMO zu binden. Dabei konnte His-Eferin mit zwei theoretischen SUMO-Bindemotiven eine stärkere Bindung zu SUMO aufbauen als His-Eferin $\Delta \mathrm{C}$ mit nur einer SUMO-Bindedomäne. Des Weiteren stellte sich heraus, dass beide Konstrukte eine Präferenz für SUMO1 aufwiesen, während sie SUMO2 schwächer banden.

\section{Trotz putativer Sumoylierungsstellen ( $\Psi$ KxE) wird Eferin auch in Anwesenheit bekannter E3-Ligasen in vitro nicht modifiziert}

Eine Reihe von Proteinen, die mit SUMO interagieren, sind selbst auch Substrate für die Modifikation mit SUMO. Deshalb sollte zunächst überprüft werden, ob Eferin potentielle Konsensus-Sumoylierungsstellen besitzt $\left[{ }^{59}\right]$, die eine kovalente Verknüpfung mit SUMO erlauben. In der Tat trifft das auf Eferin zu (Abb. 36). 


\section{Abbildung 36: Putative Sumoylierungsstellen in Eferin}

In der Aminosäureabfolge der Eferin-Sequenz sind zwei mögliche Sumoylierungsstellen (gelb unterlegter Einbuchstabencode) enthalten, die dem SUMO-Konsensusmotiv $\Psi$ KxE entsprechen.

Aufgrund dieser Tatsache galt es zu überprüfen, ob sich Eferin in vitro mit SUMO modifizieren ließe. Zunächst wurde mit dem in unserem Labor etablierten Verfahren (= SUMOylation assay) versucht, Eferin in Anwesenheit von E1- und E2-Enzym in ATP-abhängiger Manier mit SUMO1 zu modifizieren. Da keine Modifikation erfolgte, wurde der Versuch dahingehend verändert, dass der vollständige SUMOylation assay mit E1-, E2- und den in unserem Labor vorhandenen E3-Enzymen durchgeführt wurde. Als Kontrolle wurde das bekannte SUMO Zielprotein p53 (als GST-p53) eingesetzt. Dabei zeigte sich, dass His-Eferin in vitro auch unter diesen Bedingungen nicht zu modifizieren war, während GST-p53 das erwartete Modifikationsmuster zeigte (Abb. 37).

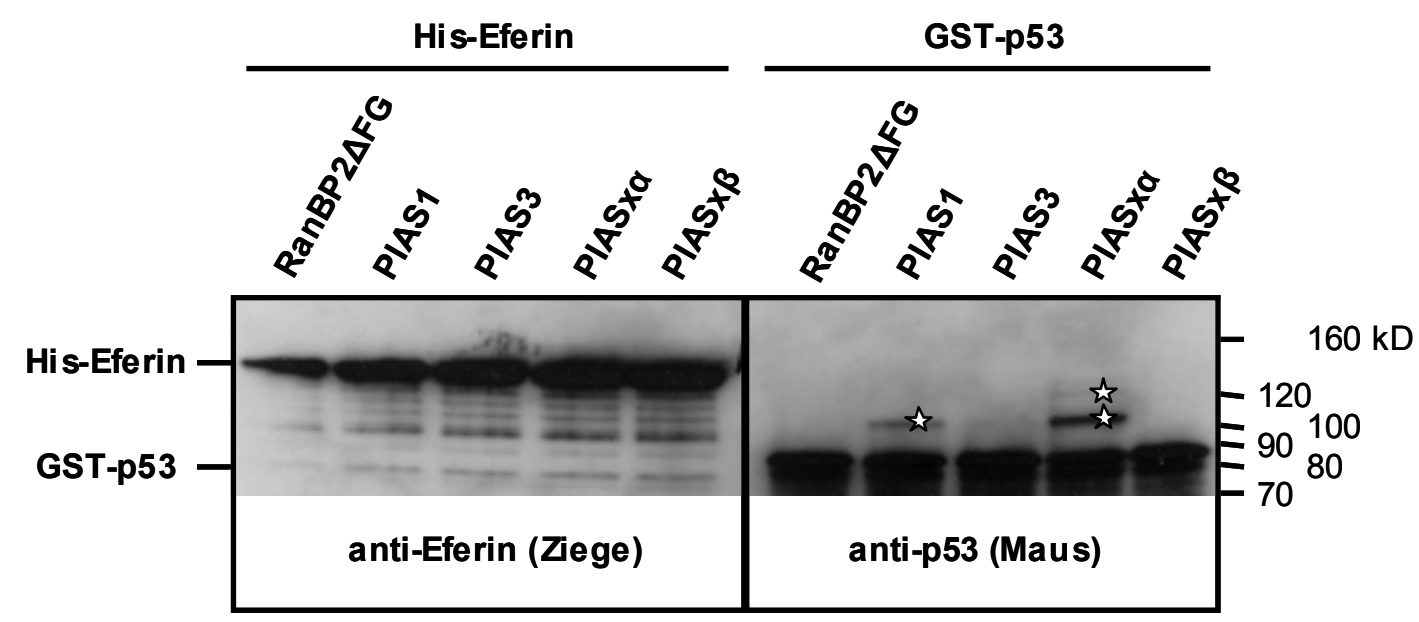

\section{Abbildung 37: in vitro Sumoylierungsansatz mit His-Eferin und GST-p53}

Je $100 \mathrm{ng}$ rekombinantes His-Eferin bzw. GST-p53 wurden in Anwesenheit der angegebenen E3Enzyme (je $10 \mathrm{ng}$ ) mit ATP, SUMO1 (500 ng), E1- (150 ng) und E2-Enzym (10 ng) für $1 \mathrm{~h} 30$ min bei $30^{\circ} \mathrm{C}$ inkubiert. Wie die Abbildung zeigt, ließ sich Eferin trotz Anwesenheit verschiedener E3-Ligasen nicht sumoylieren. GST-p53 konnte dagegen, wie erwartet, von PIAS1 und PIASxa (Sternchen), nicht aber mit dem katalytischen Fragment von RanBP2 (= RanBP2 $\triangle F G$ ) oder den übrigen PIAS-Proteinen modifiziert werden. 
Da allgemein die Überzeugung herrscht, dass neben den bisher bekannten E3Ligasen noch weitere, bislang unidentifizierte Ligasen existieren müssen, diese im in vitro Modifikationsansatz naturgemäß aber nicht zur Verfügung stehen, wurde der SUMOylation assay schließlich unter Einsatz von Zellextrakten durchgeführt. Die Idee dahinter war, dass damit möglicherweise eine fehlende, zur Modifikation von Eferin nötige E3-Ligase (in aktiver Form) zur Verfügung gestellt würde. Leider führte auch diese Herangehensweise nicht zum Erfolg. Statt der erhofften Modifikation mit SUMO stellte sich in den Nocodazol-Extrakten lediglich die bereits beschriebene Phosphorylierung von Eferin ein (Abb. 38).

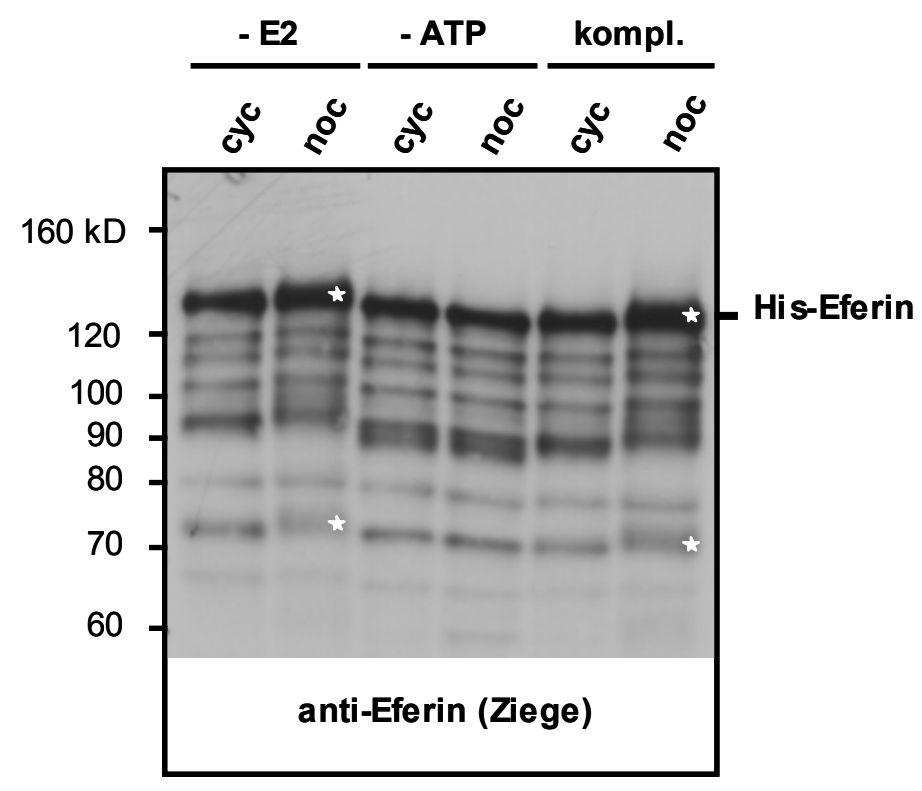

\section{Abbildung 38: Sumoylierung von Eferin ist in vitro nicht möglich}

Rekombinantes His-Eferin wurde in Anwesenheit der angegebenen Zellextrakte, ATP, E1- und E2Enzym (= kompl.) oder in Abwesenheit von ATP (= - ATP) oder E2-Enzym (= - E2) für $2 \mathrm{~h}$ bei $30^{\circ} \mathrm{C}$ zur in vitro Sumoylierung inkubiert. Wie die Abbildung zeigt, konnte Eferin in ATP-abhängiger Weise modifiziert werden. Diese Modifikation (sogar der Abbauprodukte; sichtbar zwischen den Sternchen einer Spur) von Eferin stellt jedoch aufgrund des Größenzuwachses (und wegen des fehlenden rekombinanten E2-Enzyms in den ersten beiden Spuren) keine Sumoylierung sondern vielmehr nur die bereits beschriebene Phosphorylierung dar. 


\section{Keine Hinweise auf eine in vivo Sumoylierung von Eferin}

Um zu überprüfen, ob Eferin in vivo mit SUMO1 modifiziert werden kann, wurde eine stabile His-SUMO1-Zelllinie dazu benutzt, Eferin als mögliches SUMO1-Zielprotein anzureichern. In dieser Zelllinie werden Proteine statt mit endogenem SUMO1 (wegen der Überexpression des stabil integrierten His-SUMO1-Konstruktes) vorwiegend mit His-SUMO1 modifiziert. Dadurch können mit His-SUMO1 kovalent verknüpfte Proteine über $\mathrm{Ni}^{2+}$-Affinitätschromatografie von den übrigen unmodifizierten Proteinen abgetrennt werden [ $\left.{ }^{111}\right]$. Da für Eferin weiterhin die Schwierigkeit eines niedrigen Expressionslevels bestand, wurde die entsprechende Zelllinie zudem mit ungetagtem Eferin transfiziert. Die transfizierten Zellen wurden nach einem etablierten Protokoll unter denaturierenden Bedingungen mit Guanidiniumhydrochlorid aufgeschlossen, um eine Demodifikation durch SUMO-Isopeptidasen zu verhindern. His-SUMO1-modifizierte Proteine wurden unter denaturierenden Bedingungen an eine $\mathrm{Ni}^{2+}$-Säule gebunden mit $8 \mathrm{M}$ Harnstoff gewaschen, mit SDSProbenpuffer eluiert und im SDS-PAGE analysiert. Während der Nachweis von sumoyliertem, endogenem RanGAP1 problemlos gelang, konnte für Eferin keine Modifikation nachgewiesen werden (Abb. 39). 


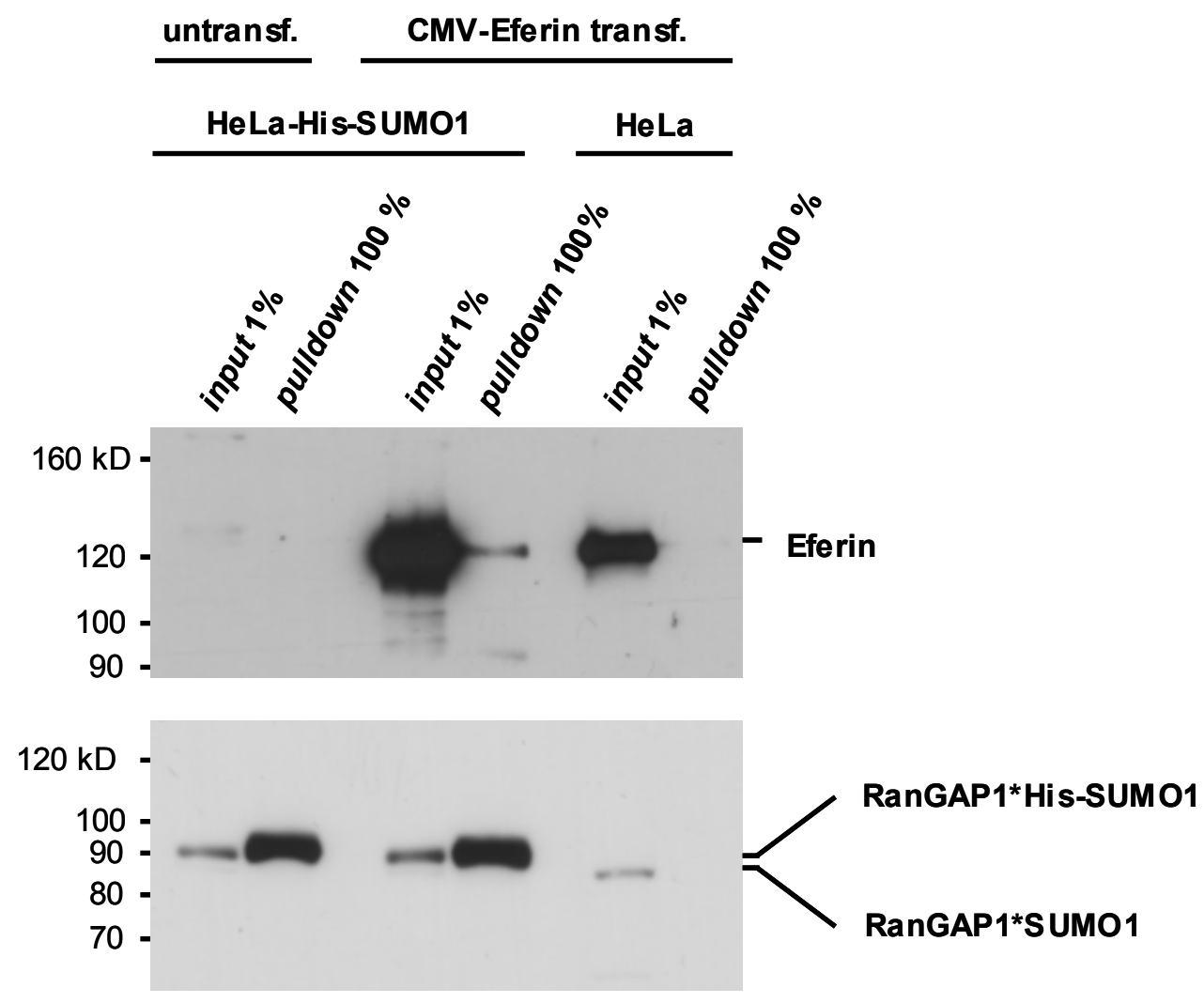

\section{Abbildung 39: in vivo Sumoylierungsversuch (nach Jaffray und Hay ) [ $\left.{ }^{111}\right]$}

$5 \times 10^{7}$ HeLa-Zellen bzw. His-SUMO1 stabil exprimierende HeLa-Zellen wurden nach der Calciumphosphat-Methode mit $\mathrm{CMV}_{\mathrm{P}}$-Eferin transfiziert oder untransfiziert eingesetzt. $48 \mathrm{~h}$ nach Transfektion wurden die Zellen geerntet und in Guanidiniumchlorid-Lösung aufgeschlossen. Die durch Zentrifugation gewonnenen Extrakte wurden mit $\mathrm{Ni}^{2+}$-IDA-Matrix versetzt und für $24 \mathrm{~h}$ inkubiert. Die an der Matrix immobilisierten Proteine wurden unter denaturierenden Bedingungen gewaschen und schließlich eluiert. Da im Ansatz mit den stabilen His-SUMO1-Zellen für RanGAP1 eine Anreicherung in Form von RanGAP1 ${ }^{*}$ His-SUMO1 erreicht wurde, bedeutet dies, dass sowohl in vivo Sumoylierung erfolgte als auch die Anreicherung über die Matrix (wenn auch in einer Ausbeute von nur 10\%) funktionierte. Zur Detektion der Proteine kamen Antikörper gegen Eferin (Ziege) und RanGAP1 (Ziege) zum Einsatz. Wie die obere Abbildung zeigt, konnte für Eferin jedoch in keinem Fall eine sumoylierte Form detektiert werden.

So muss angenommen werden, dass Eferin in vivo kein Zielprotein für eine Modifikation mit SUMO1 ist. 


\section{Rekonstitution der Wechselwirkung von RanGAP1(*SUMO1) und Eferin ist in vitro bisher nicht möglich}

Um die in vivo gezeigte Eferin-RanGAP1-Interaktion (Abb. 13 und 14) weiter zu untermauern, wurde ein Präzipitationsexperiment (= pulldown-Experiment) mit den rekombinanten Bindepartnern durchgeführt. Da eine direkte Interaktion der rekombinanten Proteine bisher nicht zu beobachten war, wurde Ubc9 aufgrund der beschriebenen RanGAP1-Eferin-Interaktion in Hefe als möglicher Überbrückungsfaktor in Betracht gezogen $\left[{ }^{83}\right]$. Es wurden deshalb rekombinantes, tagfreies RanGAP1, rekombinantes Eferin (His-Eferin und His-Eferin $\Delta C$ ) und als möglicher bridging factor His-getagtes Ubc9 in unterschiedlichen Kombinationen miteinander inkubiert. Der pulldown-Versuch wurde mittels Immunpräzipitation über EferinAntikörper und ProteinG-Agarose durchgeführt. In all diesen Ansätzen war jedoch keine direkte oder Ubc9-vermittelte Interaktion von Eferin mit RanGAP1 zu detektieren. Daher galt es auszuschließen, eine mögliche Modifikation von RanGAP1, in Form von Phosphorylierung und / oder Sumoylierung, sei für diese Interaktion nötig. Dazu wurden die für die Modifikation von RanGAP1 mit SUMO1 oder Phosphat notwendigen Enzyme, eine Energiequelle sowie Extrakte in unterschiedlichen Kombinationen bereitgestellt. Durch Zugabe von Zellextrakt wurde zudem versucht, einen anderen bridging factor als Ubc9 in der Reaktion zur Verfügung zu stellen. Da eine Modifikation von Eferin nebst Modifikation von RanGAP1 für die Interaktion von entscheidender Rolle sein könnte, erfolgte zudem eine quantitative in vitro Phosphorylierung von Eferin, auf welche bereits eingegangen wurde. All diese Bemühungen einer Rekonstitution der in vivo Situation blieben ohne Erfolg (Abb. 40), weshalb Ubc9 als Überbrückungsfaktor dieser Interaktion ausgeschlossen wurde. 


\begin{tabular}{|c|c|c|c|c|c|c|c|c|c|c|c|c|}
\hline His-Eferin & + & - & - & - & + & + & + & + & + & - & + & - \\
\hline His-Eferin $\Delta \mathrm{C}$ & - & + & - & - & - & - & - & - & - & + & - & + \\
\hline RanGAP1 & + & + & + & + & + & + & + & + & + & + & - & - \\
\hline His-Ubc9 & + & + & - & + & + & - & + & - & - & - & + & + \\
\hline Aos1 / Uba2 / SUMO1 & + & + & + & + & + & + & + & + & - & - & - & - \\
\hline ATP & + & + & + & + & - & - & + & + & - & - & - & - \\
\hline Nocodazol-Extr. & - & - & - & - & - & - & + & + & - & - & - & - \\
\hline
\end{tabular}

$\mathrm{kD}$
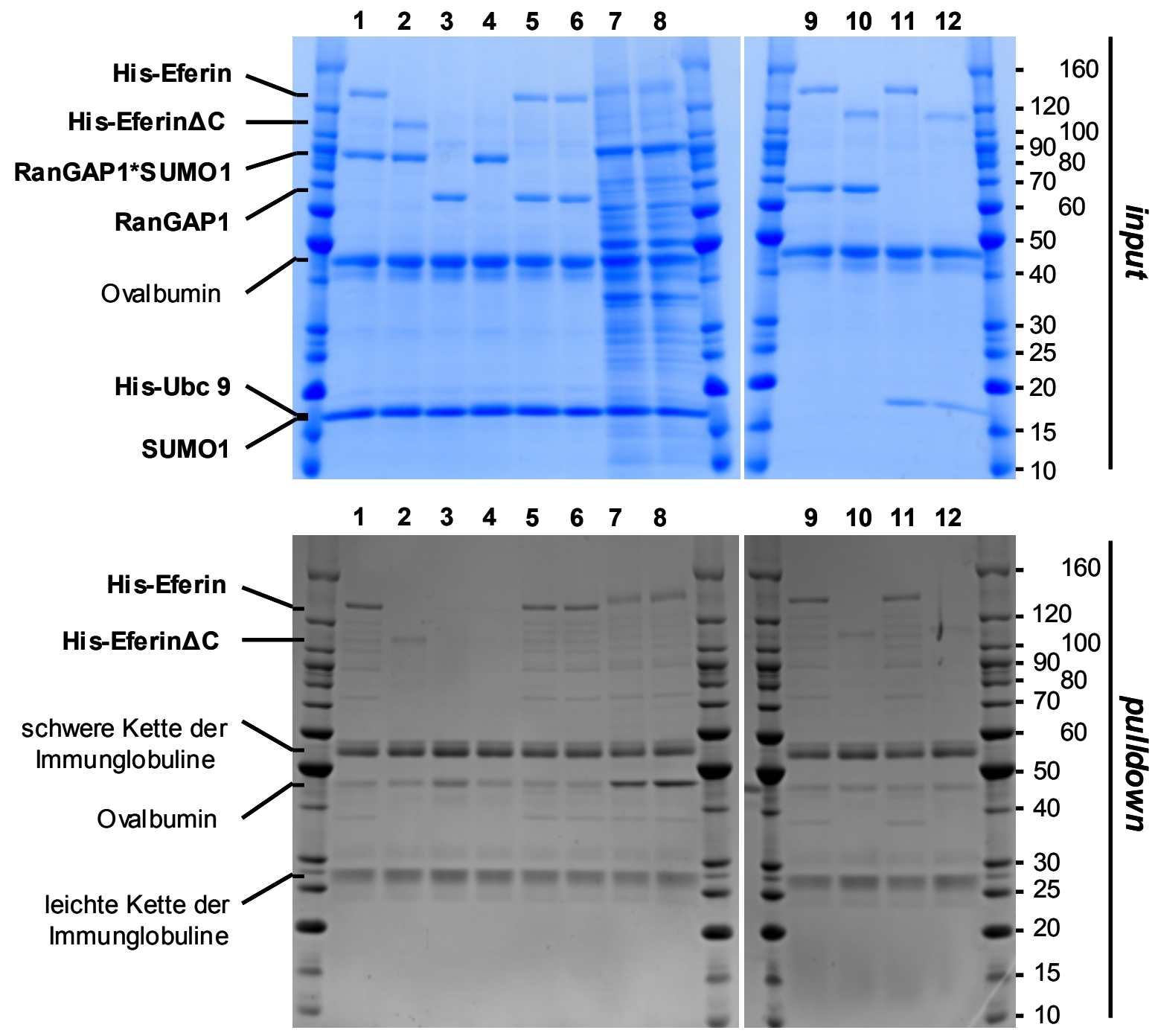

\section{Abbildung 40: Eferin-RanGAP1-Präzipitationsexperiment mit in vitro Modifikation}

Zur Rekonstitution der in vivo vorgefundenen Interaktion zwischen RanGAP1 und Eferin wurden alle Komponenten wie angegebenen ohne oder in Anwesenheit von ATP für $2 \mathrm{~h}$ bei $30^{\circ} \mathrm{C}$ inkubiert. Dabei wurde sichergestellt, dass die interagierenden Proteine Eferin und RanGAP1 sowie Ubc9 als möglicher Überbrückungsfaktor in nahezu äquimolarem Verhältnis zueinander eingesetzt wurden. Der Versuchsansatz sollte zudem Modifikationen wie Sumoylierung und Phosphorylierung zur möglichen Steigerung dieser Interaktion erlauben. Zur Präzipitation von Eferin und von Eferin-interagierenden Proteinen wurde jeder Ansatz mit Ziegen-Antikörpern gegen Eferin versetzt und $1 \mathrm{~h} 30$ min auf dem Drehrad inkubiert. Zur Immobilisierung der Immunkomplexe wurde jeder Ansatz mit ProteinG-Agarose versetzt, $2 \mathrm{~h}$ danach gewaschen und für die Analyse eluiert. Wie der input vor Präzipitation (blaue 
Abbildung) zeigt, wurde RanGAP1 in den Spuren 1, 2, 4, 7 und 8 vollständig sumoyliert und in den Spuren 7 und 8 zudem phosphoryliert (sichtbar am Größenzuwachs durch Vergleich mit der Markerspur). Eferin wurde in den Spuren 7 und 8 phosphoryliert. Es zeigte sich aus diesem Experiment, dass trotz Präzipitation von Eferin (graue Abbildung) weder eine bestimmte Modifikation noch die Anwesenheit von Ubc9 die Interaktion von Eferin und RanGAP1 in vitro nachzustellen vermag. Daher wurde Ubc9 als Überbrückungsfaktor für diese Interaktion ausgeschlossen und die Wechselwirkung von RanGAP1 mit Eferin als indirekt, also bridging factor-vermittelt, klassifiziert.

So muss angenommen werden, der die Interaktion zwischen RanGAP1 und Eferin vermittelnde, unbekannte bridging factor war gar nicht, nicht in ausreichender Menge oder nicht in der notwendigen Form (modifiziert / unmodifiziert) vorhanden. Daneben ist aber auch denkbar, dass Eferin und / oder RanGAP1 für eine (direkte / indirekte) Wechselwirkung eine Modifikation erfahren müssen, welche sich in diesem in vitro Experiment nicht bewerkstelligen ließ.

\section{RanGAP1 in Mitose}

Aufgrund des in dieser Arbeit erbrachten Nachweises von RanGAP1 als Bindepartner von Eferin, wurde mir auch die Bearbeitung eines Aspekts der RanGAP-Phosphorylierung in Mitose als Seitenprojekt dieser Arbeit angetragen. Aufgabe sollte sein, in Zusammenarbeit mit Dr. Sowmya Swaminathan, verschiedene RanGAP1-Mutanten auf ihre GTPase-aktivierenden Eigenschaften und ihre Bindungsfähigkeit gegenüber Ubc9 zu testen. Zudem sollte versucht werden RanBP2 durch Immunpräzipitation anzureichern und dabei copräzipitiertes RanGAP1*SUMO1 auf seine aktivierenden Eigenschaften gegenüber der GTPase Ran zu untersuchen. Diese Aufgabenstellung sollte der Klärung dienen, ob die Phosphorylierung von RanGAP1 funktionell in die RanGTPase-Aktivierung oder in die Assemblierung mit Ubc9 und RanBP2 eingreift (Abb. 41). 


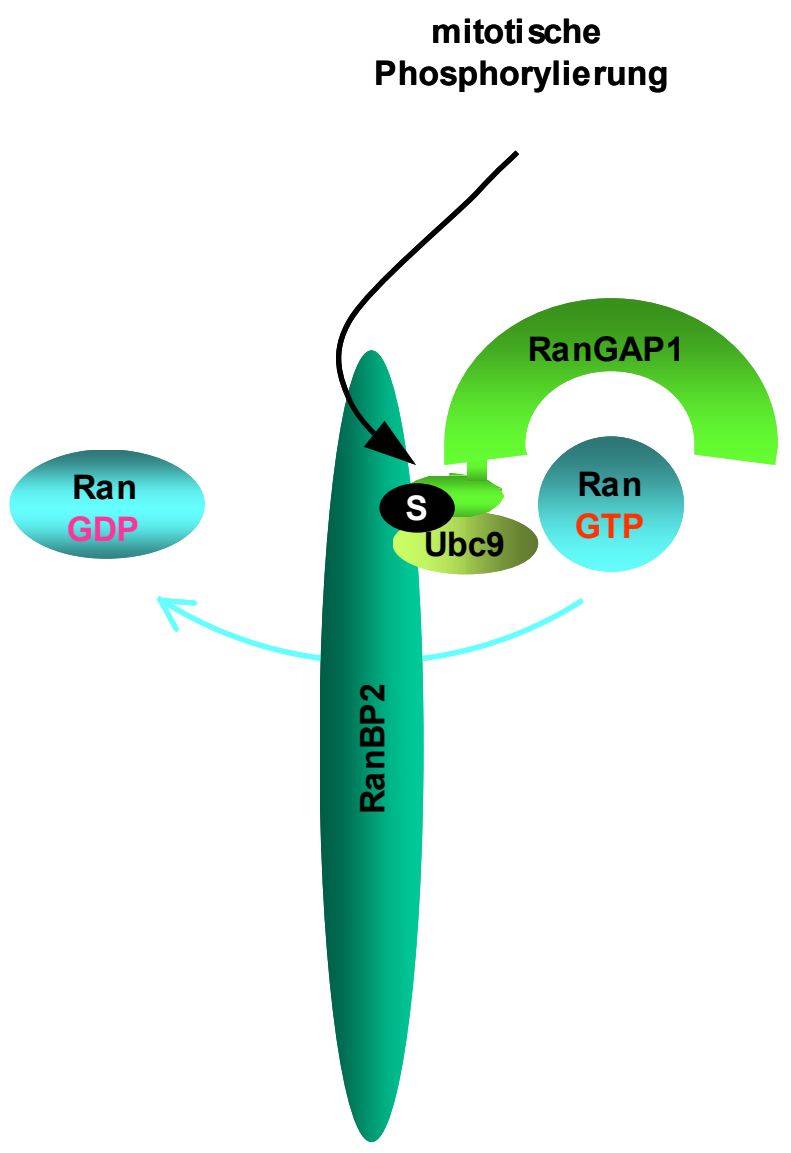

\section{Abbildung 41: Der RanBP2-RanGAP1*SUMO1-Ubc9-Komplex}

Schematische Darstellung des Komplexes, bestehend aus der Kernporenkomponente RanBP2, dem daran gebundenen, sumoylierten (mit S gekennzeichnet) RanGAP1*SUMO1 und Ubc9. Der schwarze Pfeil deutet die mitotischen Phosphorylierungsstellen im C-Terminus von RanGAP1 an. Die aktivierende Eigenschaft von RanGAP1 gegenüber der RanGTPase ist mit der Umsetzung von RanGTP zu RanGDP dargestellt.

\section{Aufgereinigte RanGAP1 Mutanten zeigen gegenüber Ubc9 gleiches Bindungsverhalten}

Bisherige Untersuchungen von Dr. Sowmya Swaminathan hatten gezeigt, dass humanes RanGAP1 in Mitose an den Positionen T409, S428 und S442 (entspricht Positionen T411 / S430 / S444 bei Mus musculus) Phosphorylierung erfährt $\left[{ }^{85}\right]$. Es galt daher zunächst zu überprüfen, ob diese Phosphorylierung die Wechselwirkung mit Ubc9 beeinflusst [122]. Da RanGAP1 in vitro nur an der Position T409 effizient phosphoryliert werden kann, wurden statt einer phosphorylierten Form eine phosphomimetische und eine phosphodefiziente Mutante eingesetzt. Bei der pseudophosphorylierten (= phosphomimetischen) Mutante von murinem RanGAP1 waren die 
Aminosäuren S411 / T420 / T444 jeweils durch die Aminosäure E (= Glutamat) und bei der phosphodefizienten Mutante dieselben Stellen jeweils durch A (= Alanin) ersetzt worden. In einem pulldown-Experiment wurde nun His-getagtes Ubc9 an eine $\mathrm{Ni}^{2+}$-Affinitätssäule gekoppelt. Das immobilisierte Ubc9 wurde in Anwesenheit der unterschiedlichen Mutanten und des Wildtyps inkubiert. Schließlich wurde die Bindungsstärke anhand der Menge des gebundenen Proteins über CoomassieAnfärbung nach SDS-PAGE bestimmt. Dabei zeigte sich, dass alle Varianten von RanGAP1 in etwa gleiche Affinität zu Ubc9 besaßen (Abb. 42).

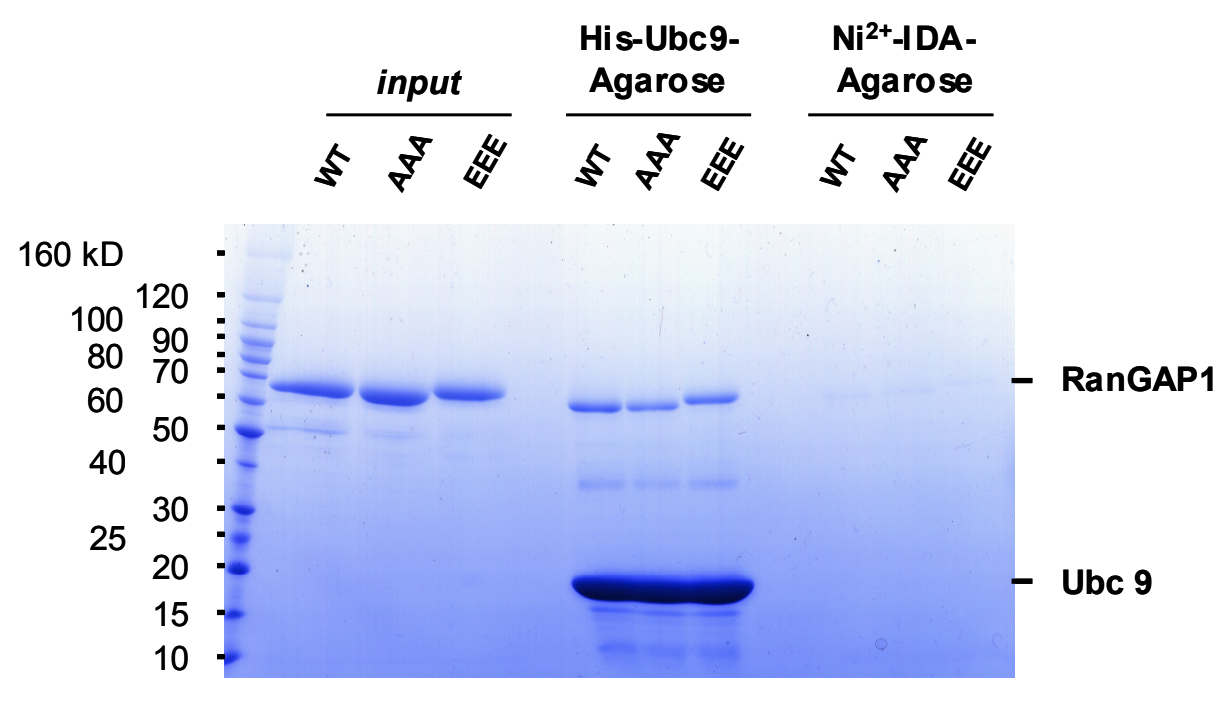

\section{Abbildung 42: Wildtyp und RanGAP1-Mutanten zeigen ähnliche Affinität zu Ubc9}

Rekombinantes His-Ubc9 wurde in einer Konzentration von $5 \mu \mathrm{g} / \mu \mathrm{l}$ an einer $\mathrm{Ni}^{2+}-$ IDA-Matrix immobilisiert. Zu 50 ug gekoppelter His-Ubc9-Matrix bzw. ungekoppelter $\mathrm{Ni}^{2+}$-IDA-Matrix wurden jeweils $2 \mu$ g rekombinantes RanGAP1 Wildtyp, unphosphorylierbare AAA- oder die pseudophosphorylierte EEE-RanGAP1 Mutante zugesetzt und für $1 \mathrm{~h}$ bei $4{ }^{\circ} \mathrm{C}$ auf dem Drehrad inkubiert. Ohne jegliches Waschen wurden die Matrices vom Reaktionsmix durch Zentrifugation über Filtersäulen getrennt. Das an die ungekoppelte $\mathrm{Ni}^{2+}$-Matrix und die His-Ubc9-Matrix gebundene RanGAP1 wurde mittels SDS-Probenpuffer eluiert und nach SDS-PAGE durch Coomassie-Färbung sichtbar gemacht. Dabei zeigte sich, dass RanGAP1 in allen Varianten ähnliche Affinitäten gegenüber Ubc9 aufwies. 
Dieses Ergebnis war insofern nicht weiter erstaunlich, als dass Phosphorylierungsstellen und die Ubc9-Bindungsstelle nicht miteinander überlappen (siehe Einleitung, Abb. N) $\left.{ }^{60,61}\right]$. Da jedoch die identifizierten Phosphorylierungsstellen von RanGAP1 *SUMO1 mit der Bindungstelle für die RanBP2-Interaktion überlappen [ ${ }^{41}$, ${ }^{122}$ ], galt es als nächstes zu klären, ob die mitotische Phosphorylierung von RanGAP1*SUMO1 darauf Einfluss nehmen könnte.

\section{RanBP2-RanGAP1*SUM01-Ubc9-Komplex bleibt nach mitotischer RanGAP1-Phosphorylierung stabil assoziiert}

Zur Überprüfung der Stabilität des RanBP2-RanGAP1*SUMO1-Ubc9-Komplexes in Mitose war zunächst ein Zellaufschluss unter Detergenz nötig, um das Nukleoporin RanBP2 aus dem Kernporenkomplex herauszulösen. Dazu wurden Nocodazolarretierte und unbehandelte HeLa Zellen in RIPA-Puffer aufgebrochen und durch Zentrifugation daraus jeweils ein Extrakt löslicher Komponenten gewonnen. Diese Extrakte wurden zur Immunpräzipitation mit RanGAP1-, RanBP2-spezifischen bzw. unspezifischen $(=\lg G)$ Antikörpern verwendet. Nach Inkubation wurden die immobilisierten Antikörper und die daran gebundenen Proteine gewaschen und für SDS-PAGE eluiert. Die Westernblot-Analyse ergab, dass der in Interphase stabile Komplex aus RanBP2, RanGAP1*SUMO1 und Ubc9 auch nach Auflösung der Kernhülle in Mitose stabil assoziiert bleibt (Abb. 43). 


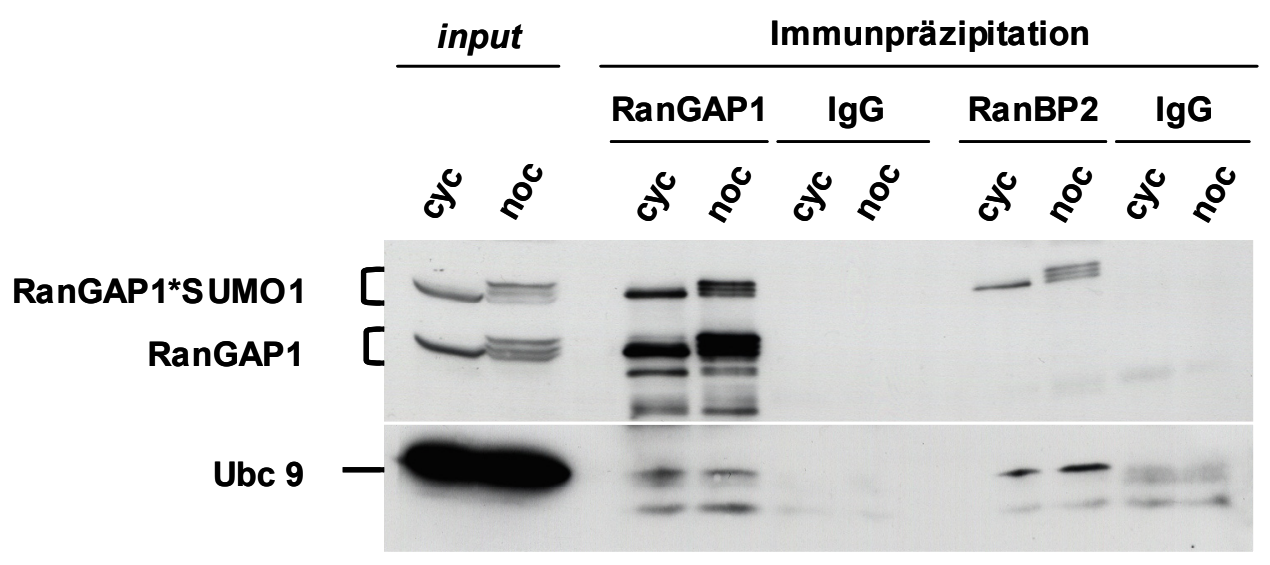

\begin{abstract}
Abbildung 43: RanBP2-RanGAP1*SUMO1-Ubc9-Komplex bleibt in Mitose stabil assoziiert $5 \times 10^{7}$ Nocodazol-arretierte (= noc) oder unarretierte HeLa-Zellen (= cyc) wurden jeweils in RIPAPuffer (150 mM NaCl, 1\% (v/v) NP40, 0,5\% (w/v) Natriumdeoxycholat, 0,1\% (w/v) SDS, $50 \mathrm{mM}$ Tris$\mathrm{HCl}, \mathrm{pH} 8,0$ ) aufgenommen und sonifiziert. Neben Phosphatase-Inhibitoren enthielt der RIPA-Puffer lodoacetamid. Zelltrümmer wurden durch Zentrifugation für $1 \mathrm{~h}$ bei $100.000 \mathrm{~g}$ und $4^{\circ} \mathrm{C}$ pelletiert, die Überstände zur Immunpräzipitation eingesetzt. Die eingesetzten Antikörper waren nach Angabe des Herstellers irreversibel in einer Konzentration von $2 \mu \mathrm{g} / \mu \mathrm{l}$ an Ultralink ProteinG-Agarose kreuzvernetzt, ungebundene Antikörper mit 100 mM Glycin pH 3,0 entfernt worden. Die Immunpräzipitation fand auf dem Drehrad bei $4^{\circ} \mathrm{C}$ für $1 \mathrm{~h}$ statt. Zur Detektion von RanGAP1 und Ubc9 wurden in beiden Fällen die entsprechenden Ziegen-Antikörper eingesetzt. Wie die Abbildung zeigt, war ein kleiner Anteil an Ubc9, unabhängig davon, ob die Zellen mitotisch arretiert oder unarretiert waren, an RanGAP1 gebunden. Wie die RanBP2-Immunpräzipitation verdeutlicht, störte eine mitotische Phosphorylierung von RanGAP1 weder die Interaktion zu Ubc9 noch führte sie zu einer Auflösung der RanBP2-RanGAP*SUMO1 Interaktion.
\end{abstract}

Eine mitotische Phosphorylierung von RanGAP1 führt also nicht zu Auflösung des aus RanBP2, Ubc9 und RanGAP1*SUMO1 bestehenden Komplexes.

\title{
Rekombinante RanGAP1-Varianten zeigen im GTPase Aktivitätstest gleiche Aktivität
}

Um zu testen, ob die mitotische Phosphorylierung von RanGAP1 direkt dessen enzymatische Aktivität beeinflusst, wurde im Folgenden ein GTPase Aktivitätstest (im Weiteren als GAP assay bezeichnet) durchgeführt $\left[{ }^{18}\right]$. In einem in vitro Experiment mit rekombinantem RanGAP1 wurde das Wildtyp-Protein mit den bereits beschriebenen phosphomimetischen und phosphodefizienten Mutanten verglichen. 
Um Aktivitätsunterschiede aufgrund unterschiedlicher Aufreinigungsbedingungen oder Proteinkonzentrationen auszuschließen, wurde eine exakte Angleichung der Konzentrationen der zu untersuchenden (parallel aufgereinigten) Proteine vorgenommen (Abb. 44) und schließlich die Reaktion durch Zugabe von radioaktiv markiertem $\alpha^{32} P$-RanGTP gestartet.

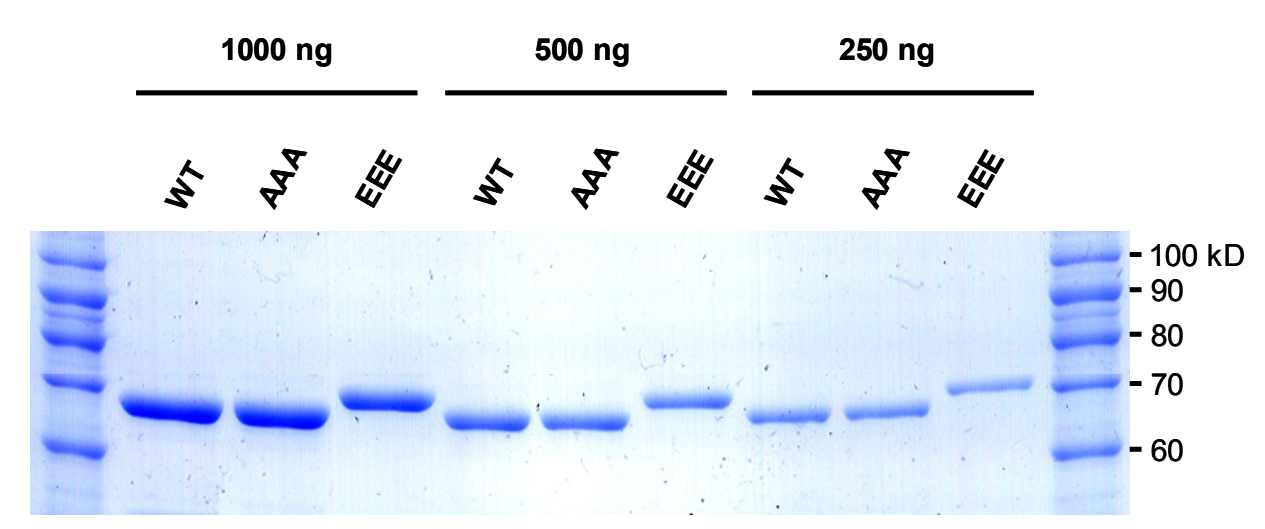

Abbildung 44: Konzentrationsangleichung der rekombinanten RanGAP1-Varianten

Die Proteinkonzentrationen von RanGAP1-Wildtyp und Phospho-Mutanten wurden für den GAP assay im Coomassie-gefärbten SDS-Polyacrylamidgel einander angeglichen.

Die Ermittlung der Umsetzungsrate von RanGTP zu RanGDP erfolgte unter Zuhilfenahme eines Phospholmagers nach chromatographischer Auftrennung von GTP und GDP auf einer Dünnschichtchromatografie-Platte (= TLC-Platte). Dabei macht man sich das unterschiedliche Laufverhalten von GTP und GDP auf der TLCPlatte zunutze und ermittelt für jeden Zeitpunkt das Verhältnis von GTP zu GDP. Dabei konnte gezeigte werden, dass sich Mutanten- und Wildtyp-RanGAP1 katalytisch nicht unterscheiden (Abb. 45). 


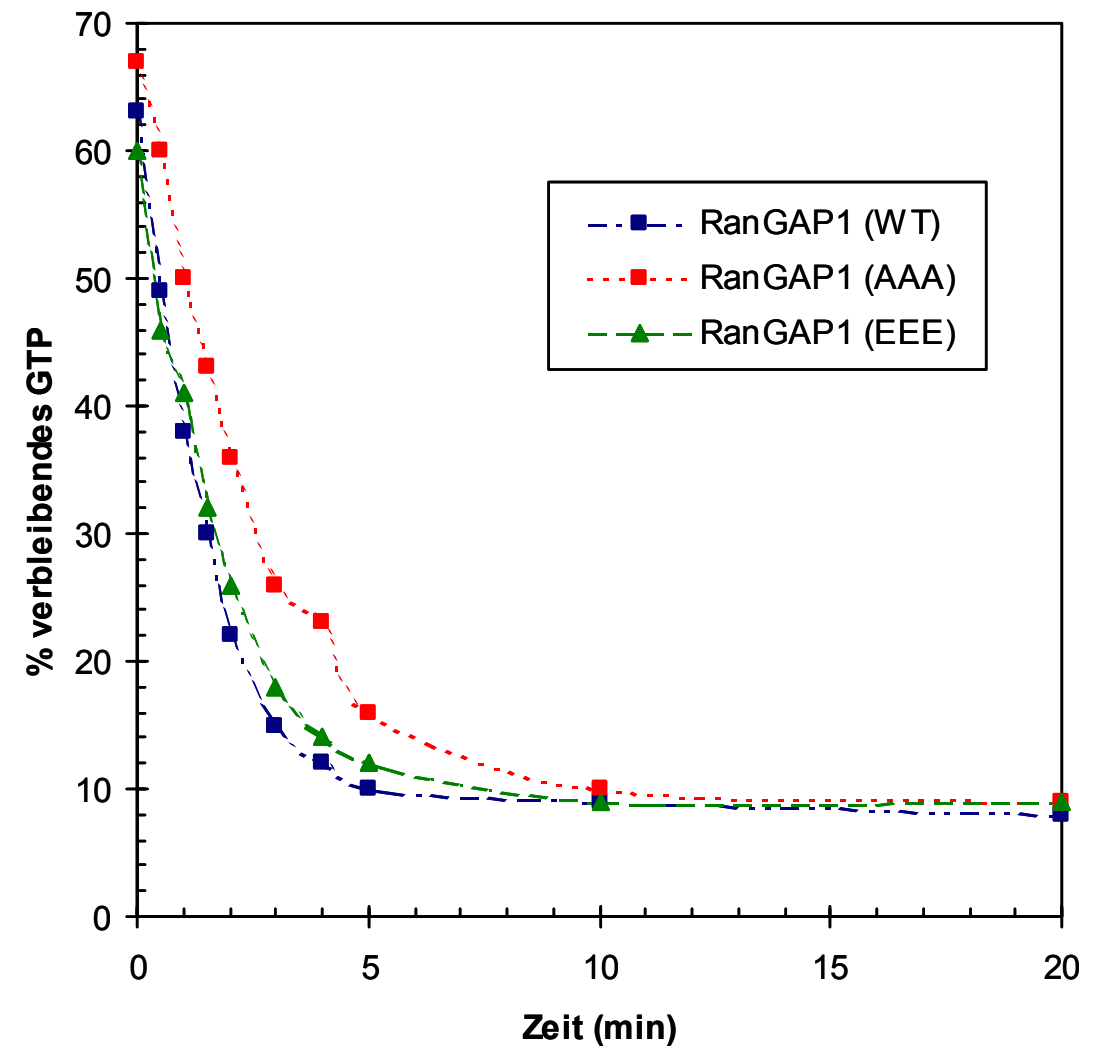

\section{Abbildung 45: Mutagenese der Phosphorylierungsstellen verändert die aktivierenden}

\section{Eigenschaften von RanGAP1 nicht}

Rekombinantes Wildtyp-RanGAP1 (WT), die Trippelmutante T411A/S430A/S444A (AAA) oder die Trippelmutante T411E/ S430E/ S444E (EEE) wurden in einer Konzentration von 25 ng / ml jeweils mit $133 \mu \mathrm{g} / \mathrm{ml}$ [a-32P] RanGTP bei $30^{\circ} \mathrm{C}$ inkubiert. Zu den angegebenen Zeitpunkten wurden Aliquote auf TLC-Platten zur Dünnschichtchromatografie aufgebracht und in TLC-Laufpuffer aufgetrennt. Mengen an [a-32P] GTP und [a-32P] GDP wurden mit Hilfe des Phospholmagers bestimmt und der Prozentsatz an verbleibendem GTP berechnet. Die Grafik verdeutlicht, dass gegenüber dem Wildtyp keine der Mutanten von RanGAP1 eine Aktivitätsänderung bewirkte.

\section{Aktivierende Eigenschaften bleiben bei mitotischer RanGAP1- Phosphorylierung unbeeinflusst}

Um zu testen, ob der RanBP2-RanGAP1*SUMO1-Ubc9-Komplex auch in Mitose als GTPase-aktivierender Komplex aktiv ist, mussten zunächst geeignete Voraussetzungen gefunden werden, die eine Solubilisierung und anschließende Immunpräzipitation der kernporengebundenen Komponenten unter aktivitätsschonenden Bedingungen (in Bezug auf RanGAP1) ermöglichten. 
Die Immunpräzipitation gegen RanBP2 wurde schließlich in einem Glucopyranosidpuffer (1\% (w/v) n-Octyl- $\beta$-D-glucopyranosid, 300 mM KCL, 20 mM HEPES pH 7,3) durchgeführt. Danach wurden die an der ProteinG-Sepharose immobilisierten Immunpräzipitate zunächst auf die Bedingungen des GAP assays umgepuffert und schließlich die Reaktion durch Zugabe von radioaktiv markiertem $\alpha^{32}$ P-RanGTP gestartet. Normalisiert wurde hierbei auf die Menge an RanBP2. Wie sich zeigte, war die Aktivität beider Komplexe vergleichbar (Abb. 46).

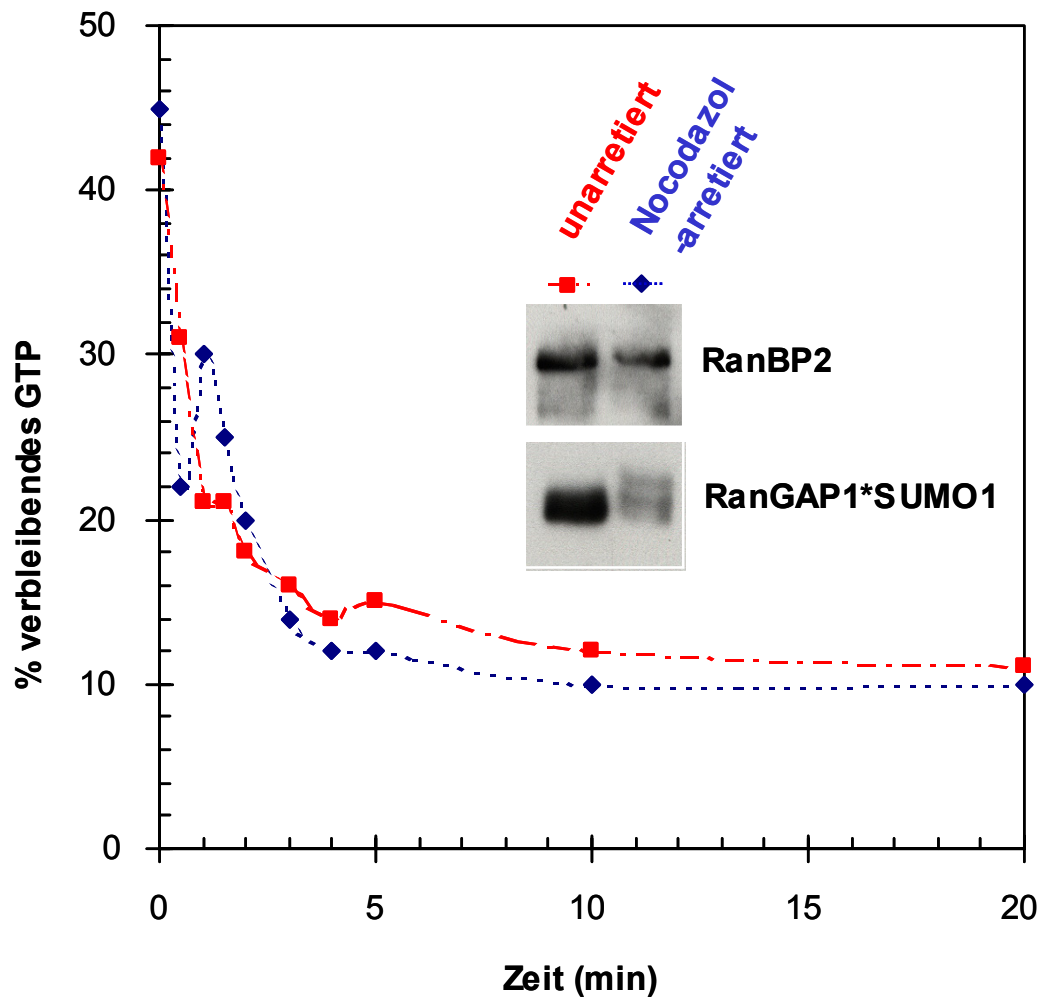

\section{Abbildung 46: Phosphorylierung bleibt ohne Einfluss auf die RanGAP1-Aktivität}

RanBP2-Immunpräzipitate von $5 \times 10^{7}$ HeLa-Zellen solubilisiert in Glucopyranosid-Aufschlusspuffer (mit Phosphatase-Inhibitoren) wurden in Transportpuffer gewaschen und auf ihre RanGAP1-Aktivität hin getestet. Die Westernblots der Präzipitate wurden mit Antikörpern gegen RanGAP1 bzw. RanBP2 detektiert, um annähernde Mengengleichheit zu verdeutlichen. Wie die Abbildung zeigt, waren RanBP2-RanGAP1*SUMO1-(Ubc9)-Komplexe aus unarretierten oder Nocodazol-arretierten HeLaZellen in ihrer RanGAP1-Aktivität vergleichbar.

Daraus kann man schließen, dass die Phosphorylierung von RanGAP1 keinen unmittelbaren Einfluss auf seine katalytische Aktivität hat. Da die Immunpräzipitation unter Detergenzbedingungen stattfand, lässt sich jedoch nicht ganz ausschließen, dass durch die Phosphorylierung rekrutierte, regulatorische Proteine verloren gingen. 
Zusammenfassend lässt sich sagen, dass die Phosphorylierung von RanGAP1 in Mitose weder seine Aktivität noch seine Assoziation mit RanBP2 und Ubc9 beeinflusst. Es bleibt abzuwarten, ob über Rekrutierung unbekannter Faktoren eine Funktionsänderung ausgelöst werden kann. 


\section{Diskussion}

\section{Die Funktion der mitotischen RanGAP1 Phosphorylierung}

Das RanGTPase-aktivierende Protein RanGAP1 wird in Interphase und Mitose für die Regulation des RanGTPase-Zyklus benötigt. Ein Teil von RanGAP1 ist durch Modifikation mit SUMO1 in der Lage stabil an die Kernporenkomponente RanBP2 zu binden $\left[{ }^{18,19}\right]$. Dadurch wird RanGAP1*SUMO1 in Interphase zum Bestandteil der Kernporenkomplexe, während in Mitose ein kleiner Teil von RanGAP1 mit RanBP2 an Kinetochoren und der Spindel lokalisiert (vergleiche Abb. 31). Aufgrund der Tatsache das RanGAP1 in Interphase und Mitose unterschiedliche Funktionen der GTPase Ran reguliert, stellte sich Frage, ob RanGAP1 dafür selbst reguliert wird. Wie die Arbeiten von Dr. Sowmya Swaminathan in unserem Labor zeigten, wird RanGAP1 mit Beginn der Mitose quantitativ an drei Resten mit Phosphatgruppen modifiziert und schrittweise bis zu Beginn der G1/G0-Phase wieder dephosphoryliert $\left[{ }^{85}\right]$. Diese Phosphorylierung könnte, so unsere Annahme, dazu genutzt werden, um die Aktivität von RanGAP1 zu regulieren oder wie für die mitotische Deassemblierung der Kernporenkomplexe vorgeschlagen $\left[{ }^{123,124}\right]$, dazu dienen den RanBP2-RanGAP*SUMO1-Komplex in Mitose aufzulösen.

Um Hinweise auf die möglichen Funktionen der Phosphorylierung zu erhalten, wurden in dieser Arbeit sowohl Bindungsstudien als auch GTPase-Aktivierungsversuche mit RanGAP1 durchgeführt. Dabei kamen phosphomimetische und phosphodefiziente Mutanten wie auch endogenes, mit RanBP2 und Ubc9 assoziiertes, phosphoryliertes bzw. unphosphoryliertes RanGAP1 zum Einsatz. Wie die Untersuchungen ergaben, konnte im Vergleich zum Wildtyp keine der rekombinanten Mutanten von RanGAP1 die Bindungsfähigkeit zu Ubc9 beeinflussen (Abb. 42). Dieses Ergebnis könnte damit erklärt werden, dass sich keine der Phosphorylierungsstellen in RanGAP1 mit dessen Ubc9-Bindedomäne überschneidet $\left[{ }^{60,61}\right]$. Dagegen ist eine Überschneidung von RanBP2-Bindedomäne und Phosphorylierungsstellen in RanGAP1 gegeben [ ${ }^{41,122}$. Da jedoch, wie in dieser Arbeit gezeigt, der aus Zellen immunpräzipitierte RanBP2-RanGAP1*SUMO1-Ubc9Komplex trotz eingesetzter Detergenz stets stabil assoziiert blieb (Abb. 43), wird angenommen, dass eine Phosphorylierung nicht dem Zweck dient diesen Komplex in Mitose zu destabilisieren. 
Als weitere Möglichkeit wurde die Regulation der GTPase-Aktivierung durch Phosphorylierung von RanGAP1 untersucht. Dabei konnten, im Vergleich zu WildtypRanGAP1, mit den eingesetzten phosphomimetischen und phosphodefizienten Mutanten keine Unterschiede in der GTPase-Aktivierung festgestellt werden (Abb. 45). Ein sehr ähnliches Bild ergab sich mit dem immunpräzipitierten RanBP2RanGAP1*SUMO1-Ubc9-Komplex aus Nocodazol-arretierten und unarretierten Zellen. Auch hier war kein deutlicher Unterschied bei der GTPase-Aktivierung zwischen phosphoryliertem und unphosphoryliertem RanGAP1*SUMO1 festzustellen (Abb. 46). In Anbetracht der Tatsache, dass in RanGAP1 die Phosphorylierungsstellen nicht in der katalytischen Domäne angesiedelt sind, wird die mitotische Phosphorylierung von RanGAP1 vermutlich auch nicht zur direkten Regulation der GTPase-Aktivierung genutzt. Insofern erscheint es auch nicht weiter von Belang zu sein, dass eine Mengengleichheit des eingesetzten RanGAP1 bei diesem Experiment nicht gänzlich sicherzustellen war. Die Resultate dieser Untersuchungen lassen insgesamt den Schluss zu, dass Phosphorylierung weder einen Zerfall des RanBP2RanGAP1*SUMO1-Ubc9-Komplexes bewirkt noch die Aktivität des RanGAP1Proteins direkt reguliert.

Für die beobachtete mitotische RanGAP1-Phosphorylierung sind daher weitere Erklärungen in Betracht zu ziehen.

Die Phosphorylierung von RanGAP1 zur Rekrutierung unbekannter Bindeproteine könnte eine Möglichkeit sein. Ein solches Bindeprotein könnten seinerseits RanGAP1 und damit die GTPase-Aktivierung regulieren. Der Umstand, dass bei den durchgeführten Immunpräzipitationen durch die stringenten Waschbedingungen derartige Bindepartner verloren gegangen sein könnten, würde erklären weshalb bisher keine Regulation der GTPase-Aktivierung durch Phosphorylierung zu beobachten war. Denkbar ist aber auch, dass durch die Phosphorylierung Bindeproteine rekrutiert werden, welche eine mitosespezifische Sumoylierung durch RanBP2 (und Ubc9) erfahren sollen. Bisher konnten für die E3-Ligase RanBP2 solche mitosespezifischen Substrate nicht identifiziert werden. Eine dritte Möglichkeit besteht darin, dass die Phosphorylierung in Mitose eine spezifische Lokalisation des RanBP2-RanGAP1*SUMO1-Ubc9-Komplexes bewirken könnte. Tatsächlich ist eine solche mitosespezifische Lokalisation des RanBP2-RanGAP1*SUMO1-Ubc9Komplexes an den Spindel-Mikrotubuli und den Kinetochoren beschrieben worden $\left[{ }^{19,125}\right]$. Dabei ist jedoch nicht geklärt, welche Proteine letztlich die veränderte 
Lokalisation bewirken. Das zukünftige Vorgehen wird daher auf die Identifikation phoshorylierungsabhängiger Bindepartner für RanGAP1 gerichtet sein.

\section{Eferin interagiert mit RanGAP1}

Bei dem Versuch der Identifikation RanGAP1-bindender Proteine, die als mögliche Regulatoren des RanGTPase-Zyklus oder als mögliche Substrate für Sumoylierung am RanBP2-RanGAP1*SUMO1-Ubc9-Komplex dienen könnten, wurde Eferin in einem yeast two hybrid Ansatz als neuer Bindepartner identifiziert. Darauf folgte zunächst die Kartierung der dafür nötigen Bindedomänen $\left[{ }^{83}\right]$. Dabei wurde gezeigt, dass für die Interaktion zwischen RanGAP1 und Eferin keine Sumoylierung von RanGAP1 nötig war. Erste in vitro Versuche mit rekombinantem RanGAP1 und Eferin konnten die in Hefe vorgefundene Situation nicht nachstellen. Aufgrund dessen wurde das hefeeigene Ubc9-Homolog als bridging factor dieser Interaktion vorgeschlagen.

In der Literatur war Eferin bis dahin als Bindepartner von Rab11 und der ARFGTPasen ARF4, 5 und 6 beschrieben [ ${ }^{86,87,89-93,101,114, ~ 115, ~ 126, ~} 127$ ].

In dieser Arbeit wurde nun in zwei verschiedenen Ansätzen erstmals gezeigt, dass die Interaktion von RanGAP1 mit Eferin auch in humanen Zellen ihre Gültigkeit besitzt. Wie in Abb. 13 zu sehen ist, konnte RanGAP1 auf der Basis von endogenem Eferin in geringem Maße copräzipitiert werden. Da sich diese RanGAP1-EferinInteraktion in vitro jedoch nicht nachstellen ließ, legt dies die Vermutung nahe, dass es sich um eine bridging factor-vermittelte oder modifikationsabhängige Interaktion handelt (Abb. 40). Die Annahme eines limitierenden bridging factors wird durch die Beobachtung gestützt, dass Überexpression von Eferin nicht zu einer vermehrten Copräzipitation von RanGAP1 führte (Abb. 14). Vermutlich begrenzt also mindestens eine limitierende Komponente (entweder Modifikation oder Überbrückungsfaktor) diese Interaktion.

Die Schlussfolgerung aus diesen drei Experimenten ist deshalb, dass die RanGAP1Eferin-Interaktion zwar in vivo existiert aber entweder nur transienter oder sehr schwacher, vermutlich jedoch nicht direkter Natur ist. 


\section{SUM01 als mögliches Bindeglied zwischen RanGAP1 und}

\section{Eferin}

Wie gezeigt wurde (Abb. 13), ist Eferin ein bona fide Bindepartner für RanGAP1. In vitro ließ sich diese Interaktion mit rekombinanten Proteinen bisher nicht nachstellen (Abb. 40). Da RanGAP1 in der in vivo Situation vornehmlich als sumoyliertes RanGAP1*SUMO1 vorliegt und in Eferin zwei SUMO-Bindemotive vorhanden sind (Abb. 34), wurde überprüft, ob die Eferin-RanGAP1-Interaktion auf einem von Reverter und Lima für RanBP2 und RanGAP*SUMO1 beschriebenen Wege zu Stande kommt $\left.{ }^{128}\right]$. Darin bindet RanBP2 RanGAP1*SUMO1 nur anhand des SUMO-Restes und die Interaktion zwischen RanBP2 und RanGAP1 wird zusätzlich von Ubc9 überbrückt. Auf die beobachtete Eferin-RanGAP1-Interaktion übertragen, würde Eferin RanGAP1*SUMO1 über dessen SUMO-Rest erkennen und ein noch zu identifizierender Überbrückungsfaktor könnte der Interaktion die nötige Stabilität verleihen. Gleichzeitig ist diese gedachte Wechselwirkung von Eferin mit RanGAP1*SUMO1 allein aber nicht stark genug, um in vitro nachweisbar zu sein (Abb. 40).

Es wurde dementsprechend überprüft, ob Eferin in der Lage ist SUMO zu binden. Wie sich zeigte, konnte freies Eferin in der Tat an immobilisiertem SUMO binden (Abb. 35). Dieses Ergebnis wurde auf die für Eferin vorhergesagten SUMOBindemotive zurückgeführt (Abb. 34) und im Weiteren mit einem Aviditätseffekt aufgrund der bereits gezeigten Homodimerisierung von Eferin erklärt [ ${ }^{89,114,126,127}$ ]. Es wurde also angenommen, dass sich eine Einzelaffinität von Eferin für SUMO bei Dimerisierung zu einer Gesamtavidität verstärkt. Denkbar ist ebenfalls, dass beide SUMO-Bindemotive zusammen diesen Aviditätseffekt auch ohne Dimerisierung erzielen können. Im Falle der Immobilisierung von Eferin sollten alle Aviditätseffekte wegfallen und daher keine starke SUMO-Bindung mehr zu Stande kommen. Tatsächlich konnte immobilisiertes Eferin keinerlei freies SUMO binden (ohne Abb.). Zudem zeigte sich, dass bei einem verkürzten Eferin das Vorhandensein eines einzelnen Bindemotivs (His-Eferin $\Delta C$; Abb. 35, rechte Hälfte) nur noch eine sehr schwache Bindung von SUMO zuließ.

Aufgrund dieser Ergebnisse wird angenommen, dass eine mögliche Funktion von Eferin als propagiertes Gerüstprotein [ $\left.{ }^{89,90,126}\right]$ darin besteht, seine SUMO- 
Bindemotive zur Rekrutierung bestimmter Effektorproteine zu nutzen, um dadurch zwischen sumoylierten und unmodifizierten Proteinen unterscheiden zu können. In Bezug auf Eferin und RanGAP1 wird davon ausgegangen, dass SUMO einen Beitrag zur Interaktion beisteuert ohne aber der allein entscheidende Faktor zu sein. In diesem Zusammenhang sei noch einmal auf die Ergebnisse der yeast two hybrid Analyse hingewiesen $\left[{ }^{83}\right]$. Hier hatte sich gezeigt, dass eine Sumoylierung von RanGAP1 für eine Wechselwirkung mit Eferin nicht erforderlich ist (siehe Abb. N). Es ist daher alternativ denkbar, dass Eferin einen sumoylierten bridging factor erkennt und über inn RanGAP1 bindet. Deshalb sollten alle beschriebenen Interagierer von Eferin auf eine mögliche Sumoylierung hin untersucht und als potentielle Überbrückungsfaktoren der RanGAP1 Interaktion in Betracht gezogen werden. Dies könnte Aufschluss darüber liefern, wozu die RanGAP1-Eferin-Interaktion eigentlich dient.

\section{Eferin ist an recyclisierenden Endosomen, den Centrosomen sowie an der Teilungsfurche zu finden}

Im Rahmen der Charakterisierung von Eferin sollte dessen Lokalisation in der Zelle analysiert werden. Da zu Beginn dieser Arbeit für endogenes Eferin eine Lokalisation an den recyclisierenden Endosomen beschrieben war $\left[{ }^{87,}{ }^{90}\right]$, sich bei Vorversuchen zur Lokalisation von Eferin eine centrosomale Anreicherung gezeigt hatte, wurde ein weiterer affinitätsgereinigter Antikörper gegen Eferin für Lokalisationsstudien erzeugt. Mit diesem wurde zunächst festgestellt, dass die endogene Menge an Eferin extrem niedrig ist (Abb. 5). Zudem konnte gezeigt werden, dass Eferin zum Teil löslich im Zytoplasma vorliegt und zum Teil mit Membranen assoziiert ist (Abb. 12). Bei Analyse der Lokalisation von Eferin wurde in Interphase die beschriebene Anreicherung an den recyclisierenden Endosomen bestätigt (Abb. 8). Darüber hinaus wurde in Pround Telophase eine Lokalisation an den Centrosomen und in der Zytokinese an der Teilungsfurche festgestellt (Abb. 7). Wegen des beobachteten niedrigen Expressionslevels wurde die Lokalisation von Eferin daraufhin mithilfe eines Überexpressionskonstruktes erneut beleuchtet. Hier zeigte sich in Mitose eine Anreicherung an den Centrosomen sowie in der Zytokinese an der Teilungsfurche (Abb. 9). Auffallend war jedoch, dass Eferin auch in Meta- und Anaphase weiter an den Centrosomen zu detektieren war. Diese Beobachtungen stehen im Einklang mit den während dieser 
Arbeit veröffentlichten Ergebnissen anderer Arbeitsgruppen, die Eferin in Interphase an den recyclisierenden Endosomen, in Mitose am Centrosom und in der Zytokinese am midbody und an der Teilungsfurche lokalisiert sehen [ $\left.{ }^{91,101,115,116}\right]$. Für diese Diskrepanz zwischen antikörper- und überexpressionskonstruktbestimmter Lokalisation kommen zwei Erklärungen in Frage. Wie in dieser Arbeit mit Hilfe von RNAiDepletion gezeigt wurde, können Antikörper gegen Eferin, die auch gegen dessen coiled coil Domäne (wie bei Fielding et al., Hickson et. al, Meyers und Prekeris, Wilson et al. [00, 91, 101, 115]) gerichtet sind, Kreuzreaktivität mit coiled coil Proteinen aufweisen (siehe Abb. 4, vergl. Abb. 6 und 7). Zudem ist davon auszugehen, dass aufgrund des extrem niedrigen Expressionslevels von endogenem Eferin dessen artifizielle Überexpression nicht immer eine korrekte Lokalisation wiedergeben muss. Diese Annahme wird auch durch die Aussage von Horgan et al. gestützt, wonach sich überexprimiertes und endogenes Eferin in ihren Lokalisationen unterscheiden $\left.{ }^{[129}\right]$. Diese Daten lassen den Schluss zu, dass sich Eferin für die Zytokinese an der Teilungsfurche, in Interphase an den recyclisierenden Endosomen und nur in Pround Telophase an den Centrosomen anreichert. Da für diese Lokalisationen bisher nur Rab11 und ARF6 verantwortlich gemacht wurden [ ${ }^{86,87,90-93,101,114-116}$ ], muss noch gezeigt werden, ob der selbst identifizierte Interaktionspartner RanGAP1 einzelne Lokalisationen von Eferin beeinflussen kann.

\section{RNAi-Depletion von Eferin führt zur Verlängerung der G1/G0 und G2/M-Phase}

Trotz der Identifikation von Eferin als Bindepartner von RanGAP1 konnte diesem bisher keine Funktion zugeschrieben werden. Es sollte deshalb untersucht werden, ob eine Depletion von Eferin für die betreffenden Zellen zu messbaren Konsequenzen führt. In der Immunfluoreszenz-Analyse waren bei Eferin-Depletion außer des Verlustes von Eferin (Abb. 4, untere Hälfte) keine phänotypischen Auswirkungen auszumachen. Wie die FACS-Analyse erbrachte, führte eine Eferin-Depletion dagegen zur Abreicherung von S-Phase-Zellen (Abb. 29 und 30). Diese Beobachtung könnte bedeuten, dass die S-Phase bei Eferin-Depletion deutlich verkürzt oder die G1/G0- bzw. die G2/M-Phase verlängert ist. In Anbetracht der Tatsache, dass Eferin für finale Schritte der Zytokinese verantwortlich gemacht wird $\left[{ }^{91,101,115,116}\right]$ und, wie von Shin et al. und Hickson et al. beschrieben, bei erhöhter 
Expression mit einer erhöhten Teilungsrate in Verbindung gebracht werden kann $\left[{ }^{91,92}\right]$, wird bei Eferin-Depletion von einer Verlängerung der G1/G0 und G2/M-Phase ausgegangen. In weiteren Experimenten sollte daher über eine Markierung mit Bromdesoxyuridin und Propidiumiodidfärbung dieser Versuch wiederholt werden. Desweiteren sollte die Teilungsrate bei Eferin-Depletion ermittelt und mit der unbehandelter Zellen verglichen werden. Darüber hinaus sollte der Vollständigkeit halber auch geklärt werden, ob eine Depletion in anderen Zelltypen schwerwiegendere Auswirkungen hat als in den äußerst robusten HeLa-Zellen. Schließlich könnte bei Zellen, denen eine angenommene Kompensation des knock downs (z.B. durch Arfophilin2) nicht möglich ist, ein auffälligerer Phänotyp zu Tage treten und damit eine Analyse der Funktion von Eferin erleichtern.

\section{Eferin hat keinen Einfluss auf die RanGAP1 Lokalisation} In Mitose lokalisiert Eferin an den Centrosomen (Abb. 7), während RanGAP1 an der mitotische Spindel und den Kinetochoren detektierbar ist (Abb. 31). Da die Wechselwirkung von RanGAP1 und Eferin in vivo gezeigt wurde (Abb. 13), stellte sich die Frage, ob die mitotische Lokalisation von RanGAP1 durch Eferin beeinflusst wird. Mittels RNAi gegen Eferin mit anschließender Immunfluoreszenz-Analyse konnte gezeigt werden, dass weder die Anreicherung von RanGAP1 an den Kinetochoren noch dessen Lokalisation an der mitotischer Spindel von diesem beeinflusst wird (Abb. 32). Deshalb sollte, da mitotisches RanGAP1 an den Kinetochoren und der mitotischen Spindel sichtbar gemacht werden konnte, noch einmal genauer geprüft werden, ob sich RanGAP1 in geringem Umfang nicht auch an den Centrosomen befindet. Sollte dies der Fall sein, wäre zumindest denkbar, dass centrosomales Eferin und RanGAP1 an diesem Ort in Wechselwirkung treten. In Anbetracht der Tatsache, dass RanGAP1 in der Zelle mehr als 25-mal häufiger vorkommt als Eferin sollte auch überprüft werden, ob ein knock down von RanGAP1 Einfluss auf die Lokalisation von Eferin nimmt.

\section{Spezifischer Verlust von Eferin in Meta- und Anaphase}

In der mit Antikörpern gegen endogenes Eferin durchgeführten ImmunfluoreszenzAnalyse war festgestellt worden, dass sich für Eferin zu Beginn der Metaphase ein 
deutlicher Signalrückgang an den Centrosomen einstellte (Abb. 7). Dies könnte mit Verlust des Proteins oder mit Umverteilung in weniger konzentrierte Strukturen erklärt werden. Durch Arretierungsversuche mit Nocodazol bzw. Taxol ließ sich dieser Rückgang in Prometa- und Metaphase in der Westernblot-Analyse nachahmen. Dabei konnte gezeigt werden, dass es sich um Proteindegradation handelt (Abb. 15, 16, 18 und 19). Zwei Mechanismen zur Steuerung dieses Abbaus erscheinen plausibel. Einerseits könnte permanente Degradation in Zusammenspiel mit einem Translationsstopp in Mitose zum vollständigen Rückgang von Eferin in Meta- und Anaphase führen. Andererseits könnte der Abbau als regulierte Degradation erfolgen. Es wurde mit Eferin deshalb eine Sequenzanalyse zur Auffindung bekannter Degradationsmotive durchgeführt. Dabei stellte sich heraus, dass Eferin vier D-Box-Motive (= destruction-box-Motive) besitzt, die mit proteasomalem Abbau (in Mitose) in Verbindung gebracht werden (Abb. D1).

\section{Abb. D1: D-Box Motive in Eferin}

In der Aminosäureabfolge der Eferin-Sequenz sind vier D-Box-Motive (gelb unterlegter Einbuchstabencode) enthalten, die dem Konsensusmotiv $[R]-x-x-[L]$ entsprechen. Eines davon entspricht dem klassischen D-Box-Motiv mit der Abfolge [R]-x-x-[L]-x-x-x-x-[D/N/E].

Hierbei ist das Motiv zwar direkte Erkennungs- jedoch nicht Ubiquitinierungsstelle. Die Markierung D-Box-tragender Proteine mit Ubiquitin erfolgt durch eine mitosespezifische E3-Ligase, dem anaphase promoting complex, an einem Lysin, das vornehmlich in unmittelbarer Nachbarschaft zum Erkennungsmotiv liegt [ $\left.{ }^{130,131}\right]$. Neben den identifizierten D-Box-Motiven findet sich im Aminoterminus zudem ein PEST-Motiv, das mit Calpain-abhängigem Abbau aber auch mit phosphorylierungsabhängiger Ubiquitinierung (durch den SCF-Komplex) in Verbindung gebracht wird [44, 94, 132]. PEST- und D-Box-Motive lassen einen raschen, zellzyklusabhängigen Abbau von Eferin über das Proteasom bzw. über bestimmte Proteasen (z.B. Calpain als mitoserelevante Protease) erwarten. 
Eine regulierte Degradation ist beispielsweise für das Eferin-verwandte Protein RCP (=R्ab coupling protein) gezeigt worden $\left[{ }^{133}\right]$. In zukünftigen Experimenten sollte deshalb zunächst geklärt werden, ob Eferin einer regulierten Degradation (in Abhängigkeit von $\mathrm{Ca}^{2+}$ und Calpain), analog zum Rab coupling protein oder einer Degradation durch gezielte Ubiquitinierung zum Opfer fällt, um im Anschluss den Zweck dieser spezifischen Degradation in Meta- und Anaphase zu klären.

\section{Phosphorylierung als möglicher Regulationsmechanismus für Eferin}

Die beobachtete zellzyklusabhängige Lokalisation und Stabilität von Eferin legt eine Regulation durch posttranslationale Modifikation nahe. Am wahrscheinlichsten ist dabei die Phosphorylierung durch zellzyklusabhängige Kinasen. In der Tat war es möglich, Eferin mit mitotischen Extrakten in vitro zu phosphorylieren (Abb. 20 und 22). Darauf folgte die Suche nach einer potenziellen Kinase. Unsere Wahl fiel auf die Aurora-A Kinase, da von ihr bekannt ist, dass sie in Mitose aktiv und wie Eferin an den Centrosomen zu finden ist $\left[{ }^{119,120}\right]$. Wie sich in Kollaboration mit Thomas Kufer (AG Nigg, MPI für Biochemie, Martinsried) zeigen ließ, ist Eferin ein in vitro target dieser mit Aurora-B eng verwandten Aurora-A Kinase (Abb. 23) und dies, obwohl in Eferin kein bekanntes Aurora-A Konsensusmotiv vorhanden ist [ $\left.{ }^{134,135}\right]$. Da zudem gezeigt wurde, dass Eferin in vitro rasch und quantitativ modifiziert wird (Abb. 21), ist denkbar, dass in vivo eine Phosphorylierung von Eferin tatsächlich erfolgt. Bestätigung fand meine Herangehensweise durch eine zwischenzeitlich erschienene Veröffentlichung von Wilson et al. $\left[{ }^{101}\right]$. Darin wurde Phosphorylierung als Regulationsmechanismus für die Lokalisation von Eferin vorgeschlagen und als mögliche Kinasen Aurora-B und Polo-like kinase genannt. Doch trotz dieser Versuche zur Phosphorylierung von Eferin verbleiben drei ungeklärte Fragen. Offen ist, ob AuroraA die in vivo Kinase für Eferin ist, welche Reste in Eferin modifiziert werden und welche Auswirkung(en) eine Phosphorylierung von Eferin tatsächlich hat.

Da Eferin vermutlich auch in vivo phosphoryliert wird, kann spekuliert werden, dass Phosphorylierung auch hier zur Regulation der Lokalisation genutzt wird. Unklar ist dabei jedoch, ob eine Phosphorylierung die Assoziation mit Membranbestandteilen oder mit Bindeproteinen steuert, denn Eferin besitzt keine bekannten Membranbindedomänen $\left[{ }^{136}\right]$. 
Die Beeinflussung der Degradation durch Phosphorylierung war bereits in Zusammenhang mit der in Eferin enthaltenen PEST-Sequenz angesprochen worden. Zur Klärung, ob Phosphorylierung von Eferin in Mitose Degradation auslöst, wurden bereits erste Degradationsexperimente durchgeführt. Mit diesen Ansätzen konnte aber bisher in vitro keine Degradation von Eferin nachgestellt werden (Abb. 24 und 25). Dies wird damit erklärt, dass in den Ansätzen zellzyklusrelevante Proteasen sowie Ubiquitin-E3-Ligasen oder das Proteasom nicht vorhanden oder nicht aktiv waren. Wegen des beobachteten Signalrückgangs von Eferin in Mitose (Abb. 7 und 15) und der in vitro Phosphorylierung mit mitotischen Extrakten (Abb. 22) wird jedoch davon ausgegangen, dass der beobachteten Degradation zunächst eine Phosphorylierung von Eferin vorausgeht.

Zu klären bleibt also, ob eine Phosphorylierung von Eferin die Rekrutierung bestimmter Faktoren erlaubt, membranbindende Eigenschaften verleiht oder für die Degradation von Eferin (zu einem definierten Zeitpunkt) sorgt und ob Phosphorylierung an unterschiedlichen Stellen eventuell unterschiedliche Auswirkungen hat. Dazu müssten dementsprechend auch alle in vivo Phosphorylierungsstellen identifiziert werden.

\section{Modell zur Funktionsweise von Eferin}

In der Absicht, aus den Ergebnissen dieser Arbeit und den bisherigen Veröffentlichungen zu Eferin ein allgemeines Modell zu formulieren, wird dafür eine Abwandlung des Modells aus Fielding et al. vorgeschlagen $\left[{ }^{115}\right]$. In einer Verfeinerung dieses Modells wird nun davon ausgegangen, dass der in Interphase stattfindende Reflux endocytierter Plasmamembran via recyclisierender Endosomen wegen des Bedarfs an Membranmaterial für die Zytokinese bereits in der frühen Mitose eingestellt werden muss. Diese Einstellung und spätere Umlenkung des gerichteten Vesikeltransports könnte ab der Metaphase durch den in dieser Arbeit festgestellten Abbau von Eferin geschehen. Diese Annahme wird auch durch die Beobachtung von Wilson et al. gestützt, wonach Rab11 bzw. die recyclisierenden Endosomen in Meta- und Anaphase im Zytoplasma zu detektieren sind $\left.{ }^{101}\right]$. Ab Telophase wird Eferin dann neu synthetisiert, anschließend mittels GTP-aktiviertem Rab11 an die recyclisierenden Endosomen rekrutiert, an den Centrosomen auf die Mikrotubuli geladen und mit Hilfe von Motorproteinen an der Teilungsfurche 
abgeliefert (Abb. D2). Dort sorgt das aktivierte ARF6 dafür, dass die ankommenden Vesikel gebunden werden und leitet deren Fusion mit der Plasmamembran ein. Hierfür wird auch dem dort befindlichen Exocyst-Komplex eine gewisse Beteiligung zugeschrieben [ $\left.{ }^{115,137}\right]$. Zudem steuert die Beobachtung, wonach ARF6 in Interphase an der Plasmamembran anzutreffen ist und für die Zytokinese zur Teilungsfurche relokalisiert, eine Unterstützung für diese Modellverfeinerung bei [115, 138, 139]. Wird ARF6, durch Abbau von Eferin und der damit angenommenen Einstellung des Vesikeltransports, die Zeit zur Konzentration an der Teilungsfurche eingeräumt, kann in der Zytokinese mittels Rab11 und Eferin eine gezielte Vesikelauslieferung erfolgen (ohne vorher wertvolles Membranmaterial ungezielt zu verbauen).

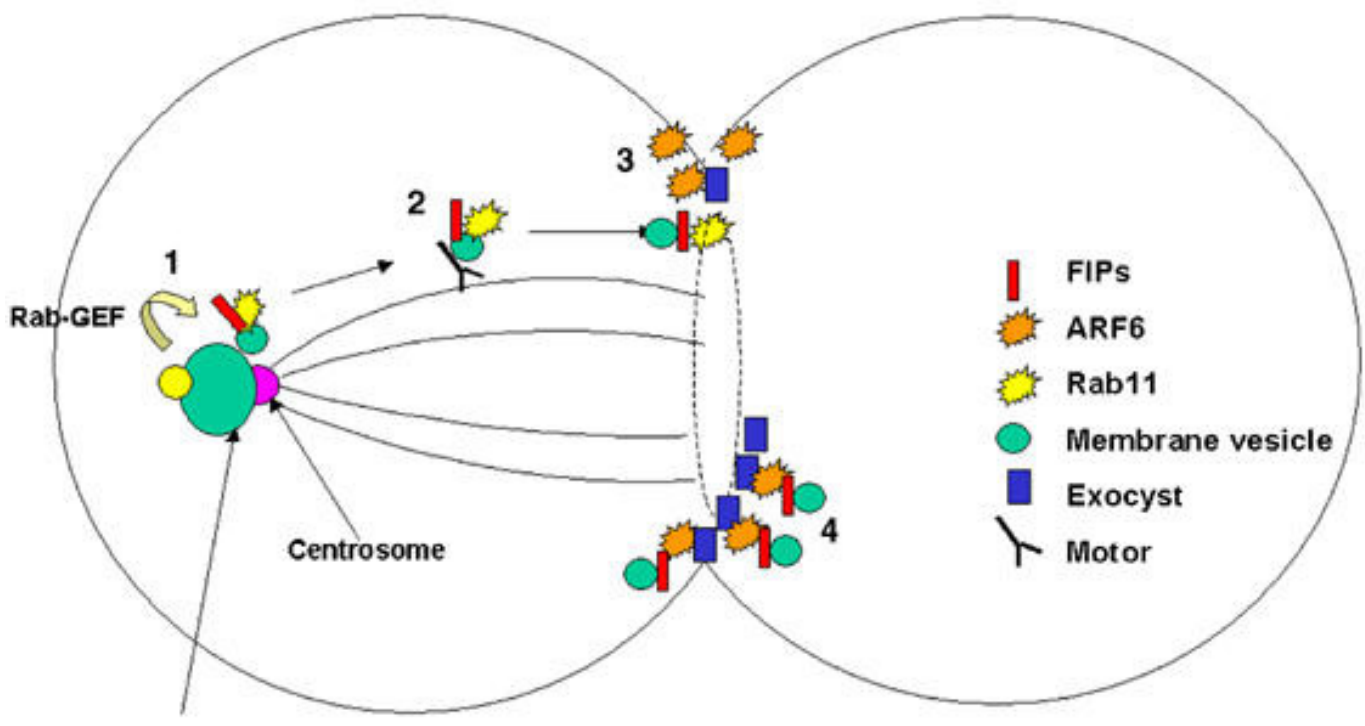

Recycling endosome

Abb. D2: Modell zur Vesikelrekrutierung für die Zytokinese

GTP-aktiviertes Rab11 rekrutiert Eferin an die recyclisierenden Endosomen; zu Beginn der Mitose werden diese Vesikel an den Centrosomen auf die mitotische Spindel geladen; durch Interaktion mit Motorproteinen werden die Vesikel an der Teilungsfurche abgeliefert; die Wechselwirkung mit ARF6 und dem Exocyst-Komplex führt zur Verankerung dieser Rab11-Eferin-Vesikel an der Teilungsfurche; ausgelieferte Vesikel bewirken durch Membranfusion die vollständige Ausbildung der Teilungsfurche und erlauben schließlich die Zytokinese; Abb. aus Fielding et al. $\left.{ }^{[15}\right]$.

Das Modell von Fielding et al. behält dementsprechend seine Gültigkeit nur ab Telophase bis zur Zytokinese und nicht über die gesamte Mitose hinweg. An diesem Modell ist besonders reizvoll, dass, wie von einem Gerüstprotein zu erwarten, sehr unterschiedliche Prozesse durch Eferin miteinander verknüpft werden. Damit hätte Eferin ähnliche Funktionen wie sein Drosophila-Homolog Nuf [ $\left.{ }^{96-99}\right]$. Wie 
kürzlich gezeigt wurde, konnten die Bindedomänen der bekannten Interagierer Rab11 und ARF6 weiter eingegrenzt werden[ $\left.{ }^{127}\right]$, so dass theoretisch ein simultanes Binden von RanGAP1, ARF6 und Rab11 möglich ist (vergleiche Abb. O) $\left[{ }^{83}\right]$. Allerdings bleibt unklar, welche Funktion RanGAP1 in diesem Zusammenhang übernimmt.

\section{Ausblick}

Es bedarf noch einiger Anstrengungen, um die Funktionsweise von Eferin in Mitose gänzlich zu verstehen. Dazu würde sicherlich die genauere Aufklärung bisher beschriebener Wechselwirkungen von Eferin zu Faktoren wie NSF $\left[{ }^{140}\right.$ ] oder RanGAP1 beitragen, zumal Eferin schon länger als Gerüstprotein zur Proteinrekrutierung angesehen wird [ $\left.{ }^{89,90,126}\right]$. Die Fähigkeit von Eferin, zudem SUMO1 bzw. sumoylierte Proteine zu erkennen und eventuell für bestimmte Prozesse zu rekrutieren, lässt spannende Entwicklungen erwarten. Möglicherweise spielt Sumoylierung als Regulationsmechanismus auch im Vesikeltransport eine Rolle. 


\section{Literatur}

1. Wennerberg, K., Rossman, K. L. \& Der, C. J. The Ras superfamily at a glance. J Cell Sci 118, 843-6 (2005).

2. Takai, Y., Sasaki, T. \& Matozaki, T. Small GTP-binding proteins. Physiol Rev 81, 153-208 (2001).

3. Vetter, I. R. \& Wittinghofer, A. The guanine nucleotide-binding switch in three dimensions. Science 294, 1299-304 (2001).

4. Bernards, A. \& Settleman, J. GAP control: regulating the regulators of small GTPases. Trends Cell Biol 14, 377-85 (2004).

5. Kahn, R. A. \& Gilman, A. G. Purification of a protein cofactor required for ADPribosylation of the stimulatory regulatory component of adenylate cyclase by cholera toxin. J Biol Chem 259, 6228-34 (1984).

6. Tsuchiya, M., Price, S. R., Tsai, S. C., Moss, J. \& Vaughan, M. Molecular identification of ADP-ribosylation factor mRNAs and their expression in mammalian cells. J. Biol. Chem. 266, 2772-2777 (1991).

7. D'Souza-Schorey, C. \& Chavrier, P. ARF proteins: roles in membrane traffic and beyond. Nat Rev Mol Cell Biol 7, 347-58 (2006).

8. Zerial, M. \& McBride, H. Rab proteins as membrane organizers. Nat Rev Mol Cell Biol 2, 107-17 (2001).

9. Novick, P. \& Zerial, M. The diversity of Rab proteins in vesicle transport. Curr Opin Cell Biol 9, 496-504 (1997).

10. Ali, B. R. \& Seabra, M. C. Targeting of Rab GTPases to cellular membranes. Biochem Soc Trans 33, 652-6 (2005).

11. Pfeffer, S. A model for Rab GTPase localization. Biochem Soc Trans 33, 62730 (2005).

12. Weis, K. Regulating access to the genome: nucleocytoplasmic transport throughout the cell cycle. Cell 112, 441-51 (2003).

13. Becker, J. et al. RNA1 encodes a GTPase-activating protein specific for Gsp1p, the Ran/TC4 homologue of Saccharomyces cerevisiae. Journal of Biological Chemistry 270, 11860-5 (1995).

14. Bischoff, F. R., Klebe, C., Kretschmer, J., Wittinghofer, A. \& Ponstingl, H. RanGAP1 induces GTPase activity of nuclear Ras-related Ran. Proc Natl Acad Sci U S A 91, 2587-91 (1994). 
15. Bischoff, F. R., Krebber, H., Kempf, T., Hermes, I. \& Ponstingl, H. Human RanGTPase-activating protein RanGAP1 is a homologue of yeast Rna1p involved in mRNA processing and transport. Proceedings of the National Academy of Sciences of the United States of America 92, 1749-53 (1995).

16. Nemergut, M. E., Mizzen, C. A., Stukenberg, T., Allis, C. D. \& Macara, I. G. Chromatin docking and exchange activity enhancement of RCC1 by histones H2A and H2B. Science 292, 1540-3 (2001).

17. Ohtsubo, M., Okazaki, H. \& Nishimoto, T. The RCC1 protein, a regulator for the onset of chromosome condensation locates in the nucleus and binds to DNA. J. Cell Biol. 109, 1389-1397 (1989).

18. Mahajan, R., Delphin, C., Guan, T., Gerace, L. \& Melchior, F. A small ubiquitin-related polypeptide involved in targeting RanGAP1 to nuclear pore complex protein RanBP2. Cell 88, 97-107 (1997).

19. Matunis, M. J., Coutavas, E. \& Blobel, G. A novel ubiquitin-like modification modulates the partitioning of the Ran-GTPase-activating protein RanGAP1 between the cytosol and the nuclear pore complex. J Cell Biol 135, 1457-70 (1996).

20. Kuersten, S., Ohno, M. \& Mattaj, I. W. Nucleocytoplasmic transport: Ran, beta and beyond. Trends Cell Biol 11, 497-503. (2001).

21. Ribbeck, K., Lipowsky, G., Kent, H. M., Stewart, M. \& Gorlich, D. NTF2 mediates nuclear import of Ran. Embo J 17, 6587-98 (1998).

22. Smith, A., Brownawell, A. \& Macara, I. G. Nuclear import of Ran is mediated by the transport factor NTF2. Curr Biol 8, 1403-6 (1998).

23. Strom, A. C. \& Weis, K. Importin-beta-like nuclear transport receptors. Genome Biol 2, REVIEWS3008 (2001).

24. Gorlich, D. \& Kutay, U. Transport between the cell nucleus and the cytoplasm. Annu Rev Cell Dev Biol 15, 607-60. (1999).

25. Mattaj, I. W. \& Englmeier, L. Nucleocytoplasmic transport: the soluble phase. Annu Rev Biochem 67, 265-306 (1998).

26. Chaillan-Huntington, C., Braslavsky, C. V., Kuhlmann, J. \& Stewart, M. Dissecting the interactions between NTF2, RanGDP, and the nucleoporin XFXFG repeats. J Biol Chem 275, 5874-9 (2000).

27. Ribbeck, K. \& Gorlich, D. Kinetic analysis of translocation through nuclear pore complexes. Embo J 20, 1320-30 (2001). 
28. Gruss, O. J. et al. Ran Induces Spindle Assembly by Reversing the Inhibitory Effect of Importin a on TPX2 Activity. Cell 104, 83-93 (2001).

29. Kalab, P., Pu, R. T. \& Dasso, M. The ran GTPase regulates mitotic spindle assembly. Curr Biol 9, 481-4. (1999).

30. Nachury, M. V. et al. Importin Is a Mitotic Target of the Small GTPase Ran in Spindle Assembly. Cell 104, 95-106 (2001).

31. Ohba, T., Nakamura, M., Nishitani, H. \& Nishimoto, T. Self-organization of microtubule asters induced in Xenopus egg extracts by GTP-bound Ran. Science 284, 1356-8. (1999).

32. Wiese, C. et al. Role of Importin-beta in Coupling Ran to Downstream Targets in Microtubule Assembly. Science 291, 653-656. (2001).

33. Wilde, A. \& Zheng, Y. Stimulation of microtubule aster formation and spindle assembly by the small GTPase Ran. Science 284, 1359-62. (1999).

34. Dasso, M. Running on Ran: nuclear transport and the mitotic spindle. Cell 104, 321-4. (2001).

35. Desai, A. \& Hyman, A. Microtubule cytoskeleton: No longer an also Ran. Curr Biol 9, R704-7. (1999).

36. Hetzer, M., Bilbao-Cortes, D., Walther, T. C., Gruss, O. J. \& Mattaj, I. W. GTP hydrolysis by Ran is required for nuclear envelope assembly. Mol Cell 5 , 1013-24 (2000).

37. Zhang, C. \& Clarke, P. R. Chromatin-independent nuclear envelope assembly induced by Ran GTPase in Xenopus egg extracts. Science 288, 1429-32 (2000).

38. Li, H. Y., Cao, K. \& Zheng, Y. Ran in the spindle checkpoint: a new function for a versatile GTPase. Trends Cell Biol 13, 553-7 (2003).

39. Rose, A. \& Meier, I. A domain unique to plant RanGAP is responsible for its targeting to the plant nuclear rim. Proc Natl Acad Sci U S A 98, 15377-82. (2001).

40. Saitoh, H., Pu, R., Cavenagh, M. \& Dasso, M. RanBP2 associates with Ubc9p and a modified form of RanGAP1. Proc Natl Acad Sci U S A 94, 3736-41 (1997).

41. Matunis, M. J., Wu, J. \& Blobel, G. SUMO-1 modification and its role in targeting the Ran GTPase-activating protein, RanGAP1, to the nuclear pore complex. J Cell Biol 140, 499-509 (1998). 
42. Bayer, P. et al. Structure Determination of the Small Ubiquitin-related Modifier SUMO-1. J Mol Biol 280, 275-86 (1998).

43. Vijay-Kumar, S., Bugg, C. E. \& Cook, W. J. Structure of ubiquitin refined at 1.8 A resolution. J Mol Biol 194, 531-44 (1987).

44. Hershko, A. \& Ciechanover, A. The ubiquitin system. Annu Rev Biochem 67, 425-79 (1998).

45. Melchior, F., Schergaut, M. \& Pichler, A. SUMO: ligases, isopeptidases and nuclear pores. Trends Biochem Sci 28, 612-8 (2003).

46. Desterro, J. M., Rodriguez, M. S., Kemp, G. D. \& Hay, R. T. Identification of the enzyme required for activation of the small ubiquitin-like protein SUMO-1. J Biol Chem 274, 10618-24 (1999).

47. Gong, L., Li, B., Millas, S. \& Yeh, E. T. Molecular cloning and characterization of human AOS1 and UBA2, components of the sentrin-activating enzyme complex. FEBS Lett 448, 185-9 (1999).

48. Johnson, E. S. \& Blobel, G. Ubc9p is the conjugating enzyme for the ubiquitinlike protein Smt3p. J Biol Chem 272, 26799-802 (1997).

49. Okuma, T., Honda, R., Ichikawa, G., Tsumagari, N. \& Yasuda, H. In vitro SUMO-1 modification requires two enzymatic steps, E1 and E2. Biochem Biophys Res Commun 254, 693-8 (1999).

50. Hay, R. T. SUMO: a history of modification. Mol Cell 18, 1-12 (2005).

51. Desterro, J. M., Thomson, J. \& Hay, R. T. Ubch9 conjugates SUMO but not ubiquitin. FEBS Lett 417, 297-300 (1997).

52. Kurepa, J. et al. The small ubiquitin-like modifier (SUMO) protein modification system in Arabidopsis. Accumulation of SUMO1 and -2 conjugates is increased by stress. J Biol Chem 278, 6862-72 (2003).

53. Bohren, K. M., Nadkarni, V., Song, J. H., Gabbay, K. H. \& Owerbach, D. A M55V polymorphism in a novel SUMO gene (SUMO-4) differentially activates heat shock transcription factors and is associated with susceptibility to type I diabetes mellitus. J Biol Chem 279, 27233-8 (2004).

54. Guo, D. et al. Proteomic analysis of SUMO4 substrates in HEK293 cells under serum starvation-induced stress. Biochem Biophys Res Commun 337, 130818 (2005).

55. Guo, D. et al. A functional variant of SUMO4, a new I kappa B alpha modifier, is associated with type 1 diabetes. Nat Genet 36, 837-41 (2004). 
56. Owerbach, D., McKay, E. M., Yeh, E. T., Gabbay, K. H. \& Bohren, K. M. A proline-90 residue unique to SUMO-4 prevents maturation and sumoylation. Biochem Biophys Res Commun 337, 517-20 (2005).

57. Tatham, M. H. et al. Polymeric chains of SUMO-2 and SUMO-3 are conjugated to protein substrates by SAE1/SAE2 and Ubc9. J Biol Chem 276, 35368-74 (2001).

58. Gill, G. SUMO and ubiquitin in the nucleus: different functions, similar mechanisms? Genes Dev 18, 2046-59 (2004).

59. Rodriguez, M. S., Dargemont, C. \& Hay, R. T. SUMO-1 conjugation in vivo requires both a consensus modification motif and nuclear targeting. J Biol Chem 276, 12654-9. (2001).

60. Sampson, D. A., Wang, M. \& Matunis, M. J. The small ubiquitin-like modifier-1 (SUMO-1) consensus sequence mediates Ubc9 binding and is essential for SUMO-1 modification. J Biol Chem 276, 21664-9. (2001).

61. Bernier-Villamor, V., Sampson, D. A., Matunis, M. J. \& Lima, C. D. Structural basis for E2-mediated SUMO conjugation revealed by a complex between ubiquitin-conjugating enzyme Ubc9 and RanGAP1. Cell 108, 345-56. (2002).

62. Hoege, C., Pfander, B., Moldovan, G. L., Pyrowolakis, G. \& Jentsch, S. RAD6dependent DNA repair is linked to modification of PCNA by ubiquitin and SUMO. Nature 419, 135-41 (2002).

63. Pichler, A. et al. SUMO modification of the ubiquitin-conjugating enzyme E225K. Nat Struct Mol Biol 12, 264-9 (2005).

64. Hochstrasser, M. Sp-ring for sumo. new functions bloom for a ubiquitin-like protein. Cell 107, 5-8. (2001).

65. Jackson, P. K. A new RING for SUMO: wrestling transcriptional responses into nuclear bodies with PIAS family E3 SUMO ligases. Genes Dev 15, 3053-8. (2001).

66. Kagey, M. H., Melhuish, T. A. \& Wotton, D. The polycomb protein Pc2 is a SUMO E3. Cell 113, 127-37 (2003).

67. Pichler, A., Gast, A., Seeler, J. S., Dejean, A. \& Melchior, F. The nucleoporin RanBP2 has SUMO1 E3 ligase activity. Cell 108, 109-20. (2002).

68. Steinacher, R. \& Schar, P. Functionality of human thymine DNA glycosylase requires SUMO-regulated changes in protein conformation. Curr Biol 15, 61623 (2005). 
69. Dohmen, R. J. SUMO protein modification. Biochim Biophys Acta 1695, 11331 (2004).

70. Johnson, E. S. Protein modification by SUMO. Annu Rev Biochem 73, 355-82 (2004).

71. Bossis, G. \& Melchior, F. Regulation of SUMOylation by reversible oxidation of SUMO conjugating enzymes. Mol Cell 21, 349-57 (2006).

72. Saitoh, H. \& Hinchey, J. Functional heterogeneity of small ubiquitin-related protein modifiers SUMO-1 versus SUMO-2/3. J Biol Chem 275, 6252-8 (2000).

73. Hietakangas, V. et al. PDSM, a motif for phosphorylation-dependent SUMO modification. Proc Natl Acad Sci U S A 103, 45-50 (2006).

74. Lin, J. Y., Ohshima, T. \& Shimotohno, K. Association of Ubc9, an E2 ligase for SUMO conjugation, with $p 53$ is regulated by phosphorylation of p53. FEBS Lett 573, 15-8 (2004).

75. Yang, S. H., Jaffray, E., Hay, R. T. \& Sharrocks, A. D. Dynamic interplay of the SUMO and ERK pathways in regulating Elk-1 transcriptional activity. Mol Cell 12, 63-74 (2003).

76. Minty, A., Dumont, X., Kaghad, M. \& Caput, D. Covalent modification of p73alpha by SUMO-1. Two-hybrid screening with p73 identifies novel SUMO1-interacting proteins and a SUMO-1 interaction motif. J Biol Chem 275, 36316-23. (2000).

77. Hannich, J. T. et al. Defining the SUMO-modified proteome by multiple approaches in Saccharomyces cerevisiae. J Biol Chem 280, 4102-10 (2005).

78. Hecker, C. M., Rabiller, M., Haglund, K., Bayer, P. \& Dikic, I. Specification of SUMO1- and SUMO2-interacting motifs. J Biol Chem 281, 16117-27 (2006).

79. Song, J., Durrin, L. K., Wilkinson, T. A., Krontiris, T. G. \& Chen, Y. Identification of a SUMO-binding motif that recognizes SUMO-modified proteins. Proc Natl Acad Sci U S A 101, 14373-8 (2004).

80. Song, J., Zhang, Z., Hu, W. \& Chen, Y. Small ubiquitin-like modifier (SUMO) recognition of a SUMO binding motif: a reversal of the bound orientation. $J$ Biol Chem 280, 40122-9 (2005).

81. Hillig, R. C. et al. The crystal structure of rna1p: a new fold for a GTPaseactivating protein. Mol Cell 3, 781-91. (1999). 
82. Ishikawa, K. et al. Prediction of the coding sequences of unidentified human genes. $X$. The complete sequences of 100 new cDNA clones from brain which can code for large proteins in vitro. DNA Res 5, 169-76. (1998).

83. Kiendl, F., Untersuchung eines neuen Bindungspartners von RanGAP1, Diplomarbeit, LMU München (2002).

84. Mahajan, R., Gerace, L. \& Melchior, F. Molecular characterization of the SUMO-1 modification of RanGAP1 and its role in nuclear envelope association. J Cell Biol 140, 259-70 (1998).

85. Swaminathan, S. et al. RanGAP1*SUMO1 is phosphorylated at the onset of mitosis and remains associated with RanBP2 upon NPC disassembly. J Cell Biol 164, 965-71 (2004).

86. Prekeris, R., Davies, J. M. \& Scheller, R. H. Identification of a novel Rab11/25 binding domain present in Eferin and Rip proteins. J Biol Chem 276, 3896670. (2001).

87. Hales, C. M. et al. Identification and characterization of a family of Rab11interacting proteins. J Biol Chem 276, 39067-75. (2001).

88. Lindsay, A. J. et al. Rab coupling protein (RCP), a novel Rab4 and Rab11 effector protein. J Biol Chem 277, 12190-9 (2002).

89. Wallace, D. M., Lindsay, A. J., Hendrick, A. G. \& McCaffrey, M. W. The novel Rab11-FIP/Rip/RCP family of proteins displays extensive homo- and heterointeracting abilities. Biochem Biophys Res Commun 292, 909-15. (2002).

90. Meyers, J. M. \& Prekeris, R. Formation of mutually exclusive Rab11 complexes with members of the family of Rab11-interacting proteins regulates Rab11 endocytic targeting and function. J Biol Chem 277, 49003-10 (2002).

91. Hickson, G. R. et al. Arfophilins are dual Arf/Rab 11 binding proteins that regulate recycling endosome distribution and are related to Drosophila nuclear fallout. Mol Biol Cell 14, 2908-20 (2003).

92. Shin, O. H., Couvillon, A. D. \& Exton, J. H. Arfophilin is a common target of both class II and class III ADP-ribosylation factors. Biochemistry 40, 10846-52 (2001).

93. Shin, O. H., Ross, A. H., Mihai, I. \& Exton, J. H. Identification of arfophilin, a target protein for GTP-bound class II ADP-ribosylation factors. J Biol Chem 274, 36609-15 (1999). 
94. Rechsteiner, M. \& Rogers, S. W. PEST sequences and regulation by proteolysis. Trends Biochem Sci 21, 267-71 (1996).

95. Sullivan, W., Fogarty, P. \& Theurkauf, W. Mutations affecting the cytoskeletal organization of syncytial Drosophila embryos. Development 118, 1245-54 (1993).

96. Riggs, B. et al. Actin cytoskeleton remodeling during early Drosophila furrow formation requires recycling endosomal components Nuclear-fallout and Rab11. J Cell Biol 163, 143-54 (2003).

97. Rothwell, W. F., Zhang, C. X., Zelano, C., Hsieh, T. S. \& Sullivan, W. The Drosophila centrosomal protein Nuf is required for recruiting Dah, a membrane associated protein, to furrows in the early embryo. J Cell Sci 112, 2885-93. (1999).

98. Zhang, C. X., Rothwell, W. F., Sullivan, W. \& Hsieh, T. S. Discontinuous actin hexagon, a protein essential for cortical furrow formation in Drosophila, is membrane associated and hyperphosphorylated. Mol Biol Cell 11, 1011-22. (2000).

99. Rothwell, W. F., Fogarty, P., Field, C. M. \& Sullivan, W. Nuclear-fallout, a Drosophila protein that cycles from the cytoplasm to the centrosomes, regulates cortical microfilament organization. Development 125, 1295-303. (1998).

100. Ullrich, O., Reinsch, S., Urbe, S., Zerial, M. \& Parton, R. G. Rab11 regulates recycling through the pericentriolar recycling endosome. J Cell Biol 135, 91324 (1996).

101. Wilson, G. M. et al. The FIP3-Rab11 protein complex regulates recycling endosome targeting to the cleavage furrow during late cytokinesis. Mol Biol Cell 16, 849-60 (2005).

102. Bossis, G. et al. A fluorescence resonance energy transfer-based assay to study SUMO modification in solution. Methods Enzymol 398, 20-32 (2005).

103. Melchior, F., Sweet, D. J. \& Gerace, L. Analysis of Ran/TC4 function in nuclear protein import. Methods in Enzymology 257, 279-91 (1995).

104. Birnboim, H. C. A rapid alkaline extraction method for the isolation of plasmid DNA. Methods Enzymol 100, 243-55 (1983).

105. Birnboim, H. C. \& Doly, J. A rapid alkaline extraction procedure for screening recombinant plasmid DNA. Nucleic Acids Res 7, 1513-23. (1979). 
106. Mullis, K. B. \& Faloona, F. A. Specific synthesis of DNA in vitro via a polymerase-catalyzed chain reaction. Methods Enzymol 155, 335-50 (1987).

107. Sanger, F., Nicklen, S. \& Coulson, A. R. DNA sequencing with chainterminating inhibitors. Proc Natl Acad Sci U S A 74, 5463-7 (1977).

108. Laemmli, U. K. Cleavage of structural proteins during the assembly of the head of bacteriophage T4. Nature 227, 680-5 (1970).

109. Chiang, E. T., Lim, M. J., Patton, W. F. \& Shepro, D. NFkappaB translocation in human microvessel endothelial cells using a four-compartment subcellular protein redistribution assay. J Biochem Biophys Methods 46, 53-68 (2000).

110. Melchior, F., Guan, T., Paschal, B. \& Gerace, L. Biochemical and structural analysis of nuclear protein import. Cold Spring Harb Symp Quant Biol 60, 70716 (1995).

111. Jaffray, E. G. \& Hay, R. T. Detection of modification by ubiquitin-like proteins. Methods 38, 35-8 (2006).

112. Rodriguez, M. S. et al. SUMO-1 modification activates the transcriptional response of p53. Embo J 18, 6455-6461 (1999).

113. Klotzbucher, A., Pascreau, G., Prigent, C. \& Arlot-Bonnemains, Y. A Method for Analyzing the Ubiquitination and Degradation of Aurora-A. Biol Proced Online 4, 62-69 (2002).

114. Eathiraj, S., Mishra, A., Prekeris, R. \& Lambright, D. G. Structural basis for Rab11-mediated recruitment of FIP3 to recycling endosomes. J Mol Biol 364, 121-35 (2006).

115. Fielding, A. B. et al. Rab11-FIP3 and FIP4 interact with Arf6 and the exocyst to control membrane traffic in cytokinesis. Embo J 24, 3389-99 (2005).

116. Horgan, C. P., Walsh, M., Zurawski, T. H. \& McCaffrey, M. W. Rab11-FIP3 localises to a Rab11-positive pericentrosomal compartment during interphase and to the cleavage furrow during cytokinesis. Biochem Biophys Res Commun 319, 83-94 (2004).

117. Ramsby, M. L. \& Makowski, G. S. Differential detergent fractionation of eukaryotic cells. Analysis by two-dimensional gel electrophoresis. Methods Mol Biol 112, 53-66 (1999).

118. Patton, W. F. Proteome analysis. II. Protein subcellular redistribution: linking physiology to genomics via the proteome and separation technologies involved. J Chromatogr B Biomed Sci Appl 722, 203-23 (1999). 
119. Bischoff, J. R. \& Plowman, G. D. The Aurora/lpl1p kinase family: regulators of chromosome segregation and cytokinesis. Trends Cell Biol 9, 454-9 (1999).

120. Giet, R. \& Prigent, C. Aurora/lpl1p-related kinases, a new oncogenic family of mitotic serine-threonine kinases. J Cell Sci 112 ( Pt 21), 3591-601 (1999).

121. Joseph, J., Liu, S. T., Jablonski, S. A., Yen, T. J. \& Dasso, M. The RanGAP1RanBP2 complex is essential for microtubule-kinetochore interactions in vivo. Curr Biol 14, 611-7 (2004).

122. Zhang, H., Saitoh, H. \& Matunis, M. J. Enzymes of the SUMO modification pathway localize to filaments of the nuclear pore complex. Mol Cell Biol 22, 6498-508 (2002).

123. Favreau, C., Worman, H. J., Wozniak, R. W., Frappier, T. \& Courvalin, J. C. Cell cycle-dependent phosphorylation of nucleoporins and nuclear pore membrane protein Gp210. Biochemistry 35, 8035-44 (1996).

124. Macaulay, C., Meier, E. \& Forbes, D. J. Differential mitotic phosphorylation of proteins of the nuclear pore complex. Journal of Biological Chemistry 270, 254-62 (1995).

125. Joseph, J., Tan, S. H., Karpova, T. S., McNally, J. G. \& Dasso, M. SUMO-1 targets RanGAP1 to kinetochores and mitotic spindles. J Cell Biol 156, 595602. (2002).

126. Junutula, J. R. et al. Molecular characterization of Rab11 interactions with members of the family of Rab11-interacting proteins. J Biol Chem 279, 334307 (2004).

127. Shiba, T. et al. Structural basis for Rab11-dependent membrane recruitment of a family of Rab11-interacting protein 3 (FIP3)/Arfophilin-1. Proc Natl Acad Sci U S A 103, 15416-21 (2006).

128. Reverter, D. \& Lima, C. D. Insights into E3 ligase activity revealed by a SUMO-RanGAP1-Ubc9-Nup358 complex. Nature 435, 687-92 (2005).

129. Horgan, C. P., Zurawski, T. H. \& McCaffrey, M. W. Purification and functional properties of Rab11-FIP3. Methods Enzymol 403, 499-512 (2005).

130. Glotzer, M., Murray, A. W. \& Kirschner, M. W. Cyclin is degraded by the ubiquitin pathway. Nature 349, 132-8 (1991).

131. Pfleger, C. M. \& Kirschner, M. W. The KEN box: an APC recognition signal distinct from the D box targeted by Cdh1. Genes Dev 14, 655-65 (2000). 
132. Rogers, S., Wells, R. \& Rechsteiner, M. Amino acid sequences common to rapidly degraded proteins: the PEST hypothesis. Science 234, 364-8 (1986).

133. Marie, N., Lindsay, A. J. \& McCaffrey, M. W. Rab coupling protein is selectively degraded by calpain in a Ca2+-dependent manner. Biochem J 389, 223-31 (2005).

134. Cheeseman, I. M. et al. Phospho-regulation of kinetochore-microtubule attachments by the Aurora kinase Ipl1p. Cell 111, 163-72 (2002).

135. Ferrari, S. et al. Aurora-A site specificity: a study with synthetic peptide substrates. Biochem J 390, 293-302 (2005).

136. Prekeris, R. Rabs, Rips, FIPs, and endocytic membrane traffic. ScientificWorldJournal 3, 870-80 (2003).

137. Chen, X. W., Inoue, M., Hsu, S. C. \& Saltiel, A. R. RalA-exocyst-dependent recycling endosome trafficking is required for the completion of cytokinesis. $J$ Biol Chem 281, 38609-16 (2006).

138. Schweitzer, J. K., Burke, E. E., Goodson, H. V. \& D'Souza-Schorey, C. Endocytosis resumes during late mitosis and is required for cytokinesis. J Biol Chem 280, 41628-35 (2005).

139. Schweitzer, J. K. \& D'Souza-Schorey, C. Localization and activation of the ARF6 GTPase during cleavage furrow ingression and cytokinesis. J Biol Chem 277, 27210-6 (2002).

140. Martin, H. G., Henley, J. M. \& Meyer, G. Novel putative targets of Nethylmaleimide sensitive fusion protein (NSF) and alpha/beta soluble NSF attachment proteins (SNAPs) include the Pak-binding nucleotide exchange factor betaPIX. J Cell Biochem 99, 1203-15 (2006). 


\section{Anhang}

\section{Danksagung}

Mein Dank geht an Frau Prof. Dr. Frauke Melchior für das mir entgegen gebrachte Vertrauen bei der Erstellung dieser Arbeit. Bedanken möchte ich mich auch für stete Diskussionsbereitschaft und nicht enden wollende Anregungen, für das angenehme Arbeitsumfeld und die Bereitstellung eines interessanten Arbeitsthemas.

Bei Herrn Prof. Dr. R. Ficner möchte ich mich für die Übernahme des Korreferats, bei Herrn Prof. Dr. R. Hardeland und PD Dr. M. Hoppert für die Begutachtung meiner Arbeit bedanken.

An dieser Stelle möchte ich mich bei allen der Arbeitsgruppe Melchior bedanken, die durch ihrer Hilfe und Unterstützung zum Gelingen dieser Arbeit beigetragen haben. Namentlich nennen möchte ich Katja Curth, für ihren unermüdlichen Einsatz beim Kampf um Klone und Mutanten sowie Frank Rhode für seine ungebrochene Hilfsbereitschaft und Kompetenz in Fragen der Organisation. Ein ausdrücklicher Dank geht an Ruth Geiss-Friedlander für den entscheidenden Hinweis zum SIM und Erik Meulmeester für gestellte Reagenzien und ein funktionierendes Protokoll. Nicole (Abteilung Prof. Doenecke) möchte ich danken für die Einführung und Erklärungen am FACS-Gerät und Jörg für die Einweisung in das Äkta purifier System.

Zu danken ist auch den ehemaligen Kolleginnen am MPI in Martinsried, die stets für ein gutes Arbeitsklima sorgten: Tanja, Marion, Jenny und Andrea. Hervorheben möchte ich Sowmya Swaminathan, die durch ihre angenehme Art zu einer kollegialen Arbeitsatmosphäre beigetragen hat und die mir mit geduldiger Anleitung viel beigebracht hat.

Meinen mitreisenden Leidensgenossen Guillaume, Katarzyna und Andrea sei gedankt für die Bahncomfort-Punkte und die Kurzweil bei der Reise. Ein besonderes Dankeschön an Andrea für die kulinarischen Untermalungen. 
Mein besonderer Dank gilt Annette Flotho. Dafür, dass Du stets ein offenes Ohr für wissenschaftliche und halbwissenschaftliche Fragestellungen hattest. Für Dein Interesse am Fortgang der Arbeit und für zahlreiche kritische Anmerkungen. Danke für die freundschaftliche Begleitung dieser Arbeit. Danke, dass ich Dein Kotzbrocken sein durfte. Danke, dass Du uns auch weiterhin besuchen kommst.

Guido, Tanja und Felix, vor Euch ziehe ich meinen Hut. Ich durfte geschlagene sechseinhalb Monate bei Euch wohnen, ohne dass Ihr mir jemals das Gefühl gegeben habt unerwünscht zu sein. Ihr habt mir nicht nur den freundlichsten Weckservice zur Seite gestellt, sondern auch Eure Kornspeicher für mich geöffnet. Ihr seid unübertroffen, dafür meinen ganzen Dank.

Danken möchte ich den Freunden, die mir trotz Vernachlässigung der Freundschaft während dieser Arbeit die Treue gehalten haben: Robert, Olivier, Michi, Patrick, Yvi, Lea.

Frau Margot Steichele möchte ich dafür danken, dass in ihrer Badehütte neue Ideen für diese Arbeit entstehen konnten. Dank auch an Ulrike Garrelt. Danke, dass man zur Erholung in Dein Reich einfallen durfte und dass Du einem Barbaren immer wieder Kultur vermittelt hast. Frau Dr. Petra Kerin möchte ich dafür danken, dass der Zustand „Denk ich an Eferin bei der Nacht, bin ich um den Schlaf gebracht" nicht Fuß fassen konnte.

Ganz herzlich danken möchte ich meiner Familie, besonders meiner Mutter, für das Interesse an meiner Arbeit, die stete Sorge und Unterstützung.

In liebevoller Dankbarkeit verneige ich mich vor Dir, Christina. Sina, ohne dich würde es diese Arbeit so nicht geben. Du hast mit Kopf, Herz und Hand zum Gelingen mit beigetragen. Du hast es verstanden mich aufzubauen wo sich Frustration auszubreiten drohte, Du hast mich abgelenkt damit neue Ideen entstehen konnten, Du hast mir den Rücken freigehalten sobald sich ein Problem andeutete. Du hast mich zum Lachen gebracht und mich immer wieder überrascht. Und Du hast über meine schlechten Witze gelacht. Für das alles danke ich Dir von ganzem Herzen und ich hoffe, dass wir in Zukunft noch oft einen caffee al imperatore im Caffé Florian schlürfen. 


\section{Curriculum Vitae}

\begin{tabular}{|c|c|}
\hline Name: & Kiendl \\
\hline Vorname: & Florian \\
\hline Geburtsdatum: & 25.10 .1971 \\
\hline Geburtsort: & München \\
\hline Staatsangehörigkeit: & deutsch \\
\hline $1978-1982$ & C.E.S International in Fontainebleau (Frankreich) \\
\hline $1982-1991$ & Käthe-Kollwitz-Gymnasium in München \\
\hline 07/1991 & Abitur \\
\hline $1991-1992$ & $\begin{array}{l}\text { Studium der Elektrotechnik an der Technischen Universität } \\
\text { München }\end{array}$ \\
\hline $1995-2002$ & $\begin{array}{l}\text { Studium im Fach Biologie an der Ludwig-Maximilians- } \\
\text { Universität München }\end{array}$ \\
\hline $4 / 1999$ & $\begin{array}{l}\text { Vordiplom in den Fächern: Anorganische und Organische } \\
\text { Chemie, Physik für Biologen und Allgemeine Biologie }\end{array}$ \\
\hline 06/2002 & $\begin{array}{l}\text { Studienabschluss als Diplom-Biologe an der Ludwig- } \\
\text { Maximilians-Universität München } \\
\text { Fächerschwerpunkt: Anthropologie und Humangenetik, } \\
\text { Genetik, Biochemie und Immunologie } \\
\text { Thema der Diplomarbeit:,Untersuchung eines neuen } \\
\text { Bindepartners von RanGAP1“ }\end{array}$ \\
\hline $7 / 2002-11 / 2006$ & $\begin{array}{l}\text { Doktorarbeit am Max-Planck-Institut für Biochemie in } \\
\text { Martinsried und am Institut für Biochemie und Molekulare } \\
\text { Zellbiologie der Georg-August-Universität Göttingen in der } \\
\text { Abteilung Biochemie I, bei Prof. Dr. Frauke Melchior } \\
\text { Thema: "Untersuchungen zur Funktion des RanGAP1 } \\
\text { Proteins“ }\end{array}$ \\
\hline
\end{tabular}

